Special

Collect.

QH45

S32 


\section{THE D. H. HILL LIBRARY}

NORTH CAOLINA STATE COLLEGE

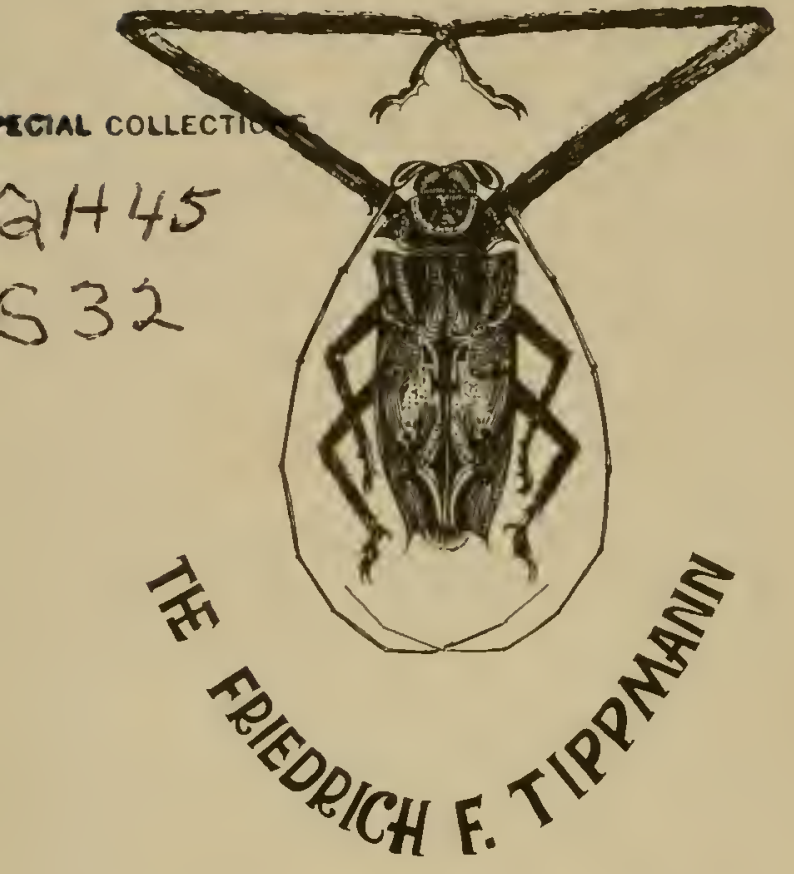

ENTOMOLOGICAL COLLECTION 


\section{5}

This book must not be taken from the Library building. 


D

$x \operatorname{sen} 14$ 


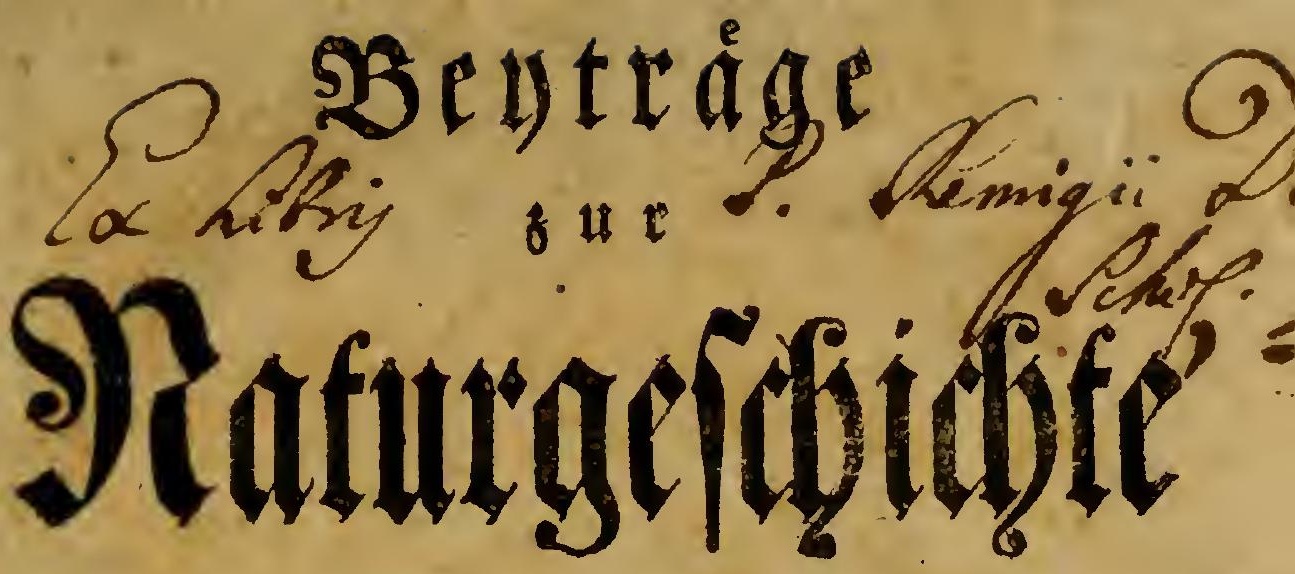

on

Eranj von Paula Sđrank.

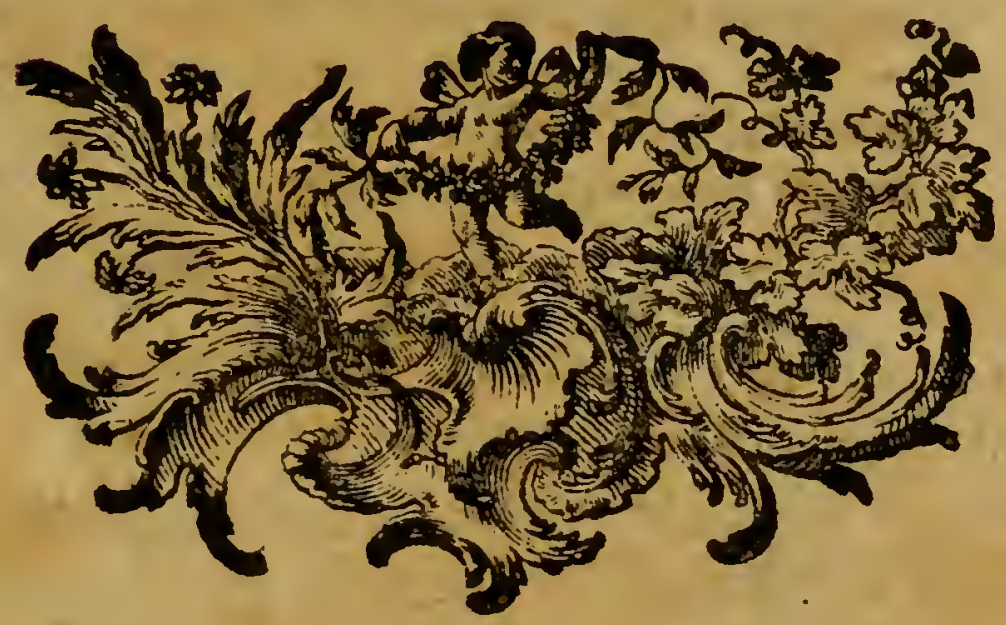

Shit fiebent oon bem izerfaffer felbit gezeichinten, wib is Supfer gefodienen Tabellen.

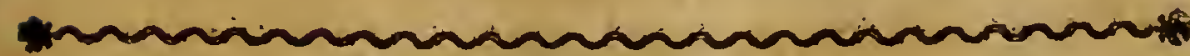

$$
\text { seipgig, }
$$

beg Cafpar 


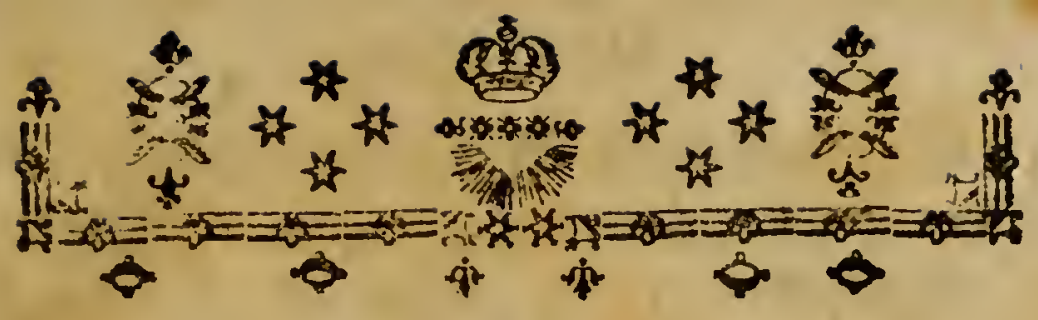

$\mathfrak{B} \mathfrak{D} \mathfrak{l} \mathfrak{l} \mathfrak{C} \mathfrak{D} \mathfrak{E}$

() 2.

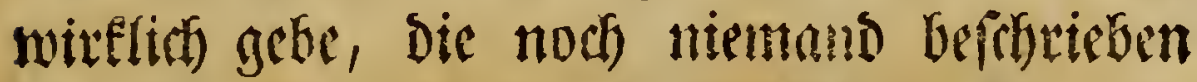

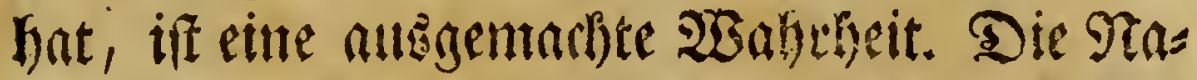

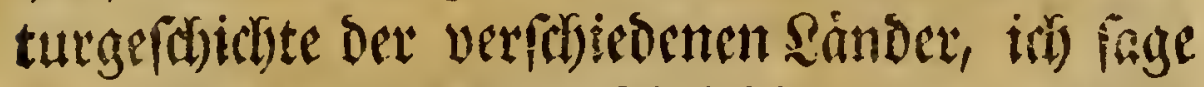

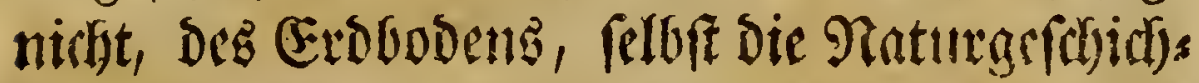

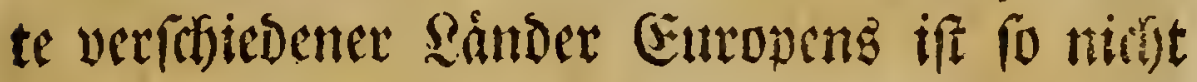

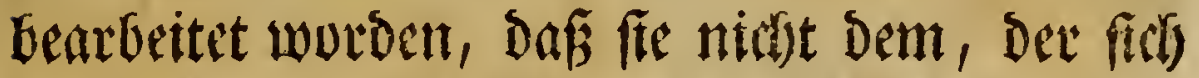

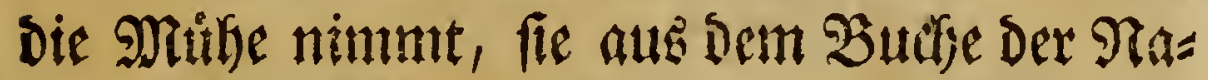
tur pelbfi zu ftubieren, zu einer reidfen grad)= Iefe Stoffez gemutg Darbitsten follte.

Seit meiner erffen Iugend begierig, Die

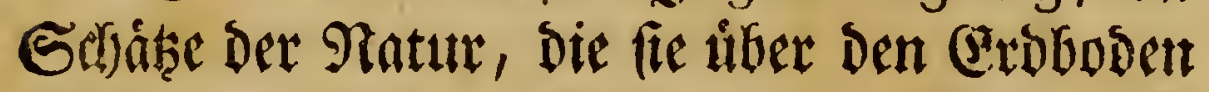

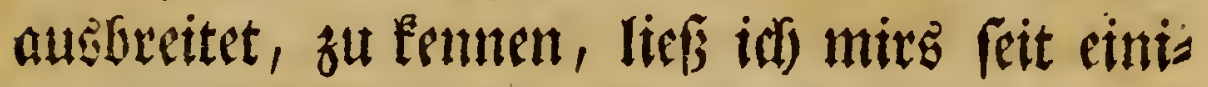
gen Gabren vorzúglicic) angelegen fenn, bie auff= frofenenden Taturalien Der Derter, in Denen idf midh auf fielt, zu fammeln, und mide mit Der Begend, Die im Strifie Gerumlag, befantmt

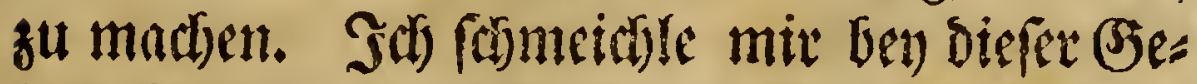

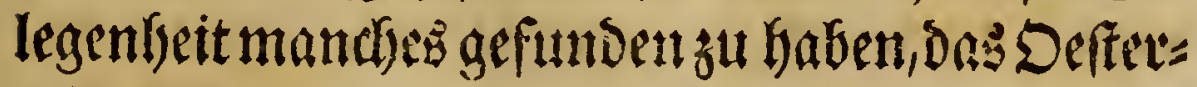

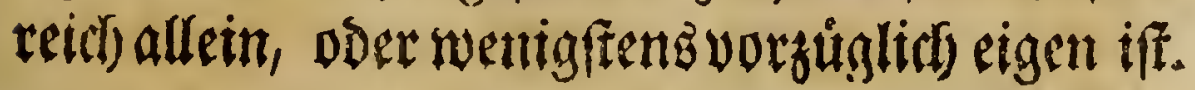




\section{Dorrede.}

Woil wir noth leine éfterteidsifats Fauma

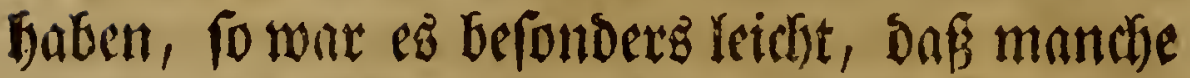

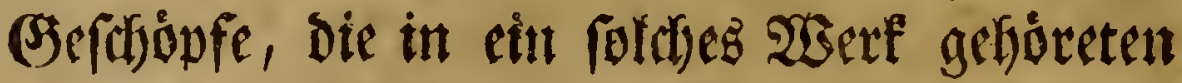
(bemn Das $\mathfrak{B}$ fautzen $=$ und Mineralreta) buben

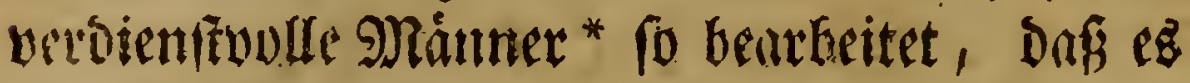
fojmer fallen follte, einen $\mathfrak{T a d}$ )trag zu machen)

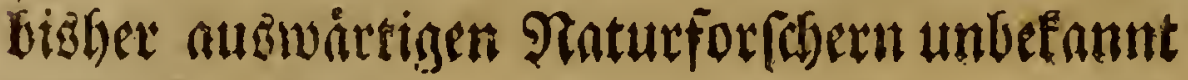
bleiben musten.

Sch glaute alfo nicht fu viel gemaget fut

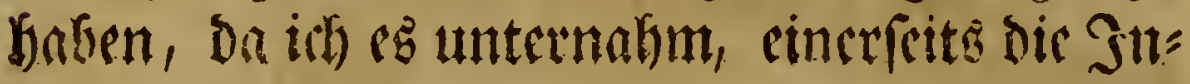

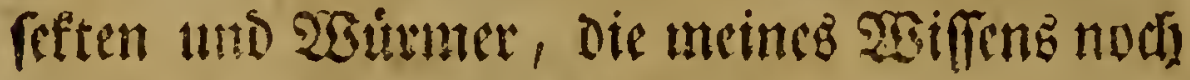
niemand befforieben Gat, anzuzeigen, und zu

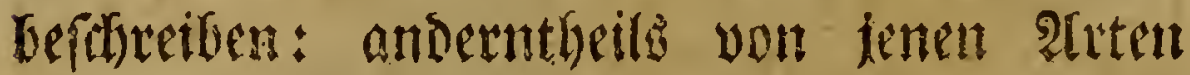

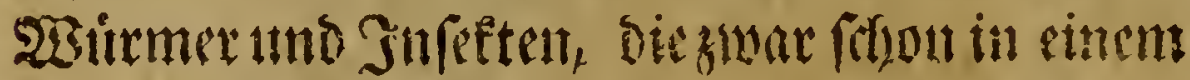
voer Dem antern Zerzeichniffe frethen, aber bey

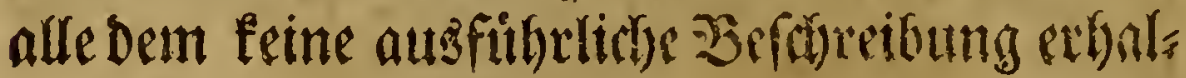
ten haben, eine Narblefe su marisus.

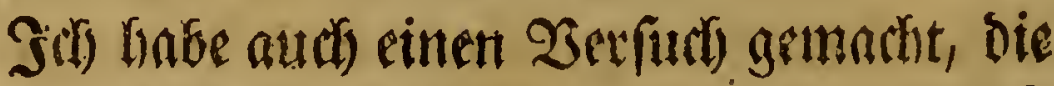

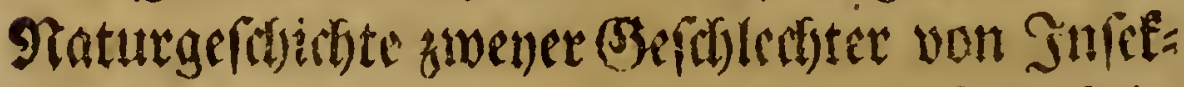

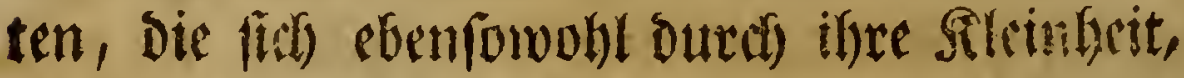

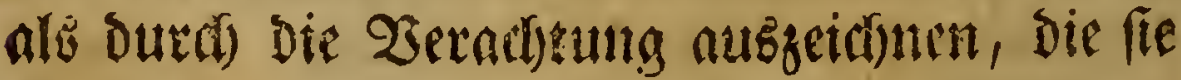

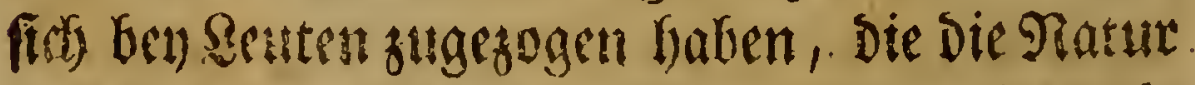

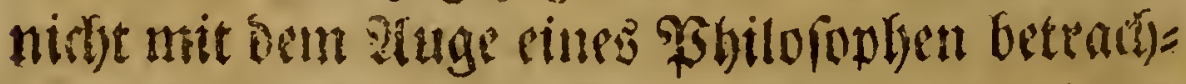
ten, fritulusife zu licfern. Woir find biobser innmer zu lanige bey ben bunten farben ber

Scilmeta

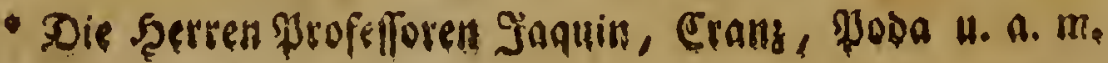




\section{Dortede.}

\section{Sthmetterlinge fiehen geflicten, und bothen}

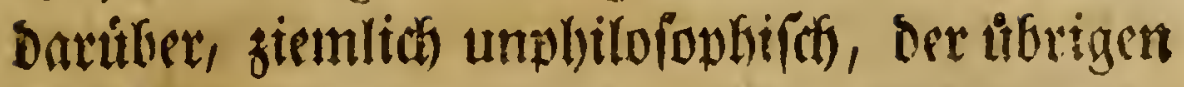

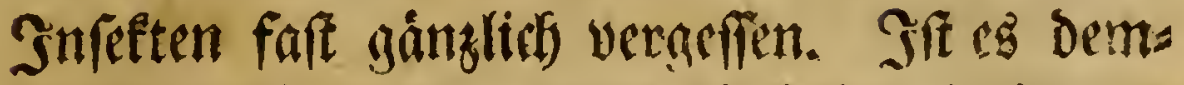
nach ein 2 sumber, wenn bie britte Droment Der Jnfetten, bie bic Sefmetterlinge enthält,

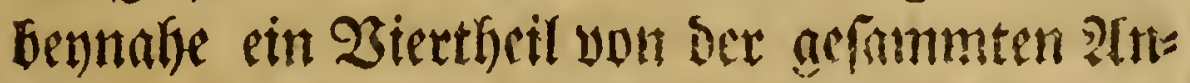

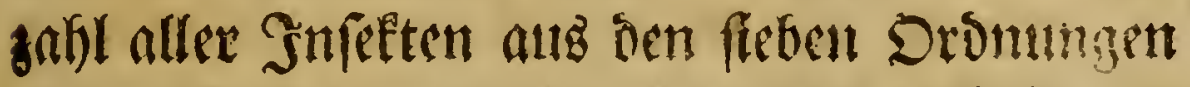

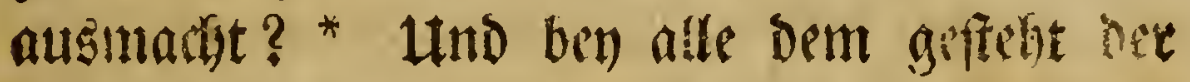
Sitter von Sinmee fehr offentscrsig, es miren if)m noch rect)e wiele Sdinetterlinge powath in

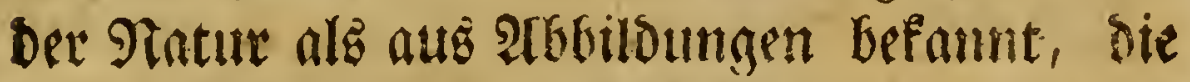

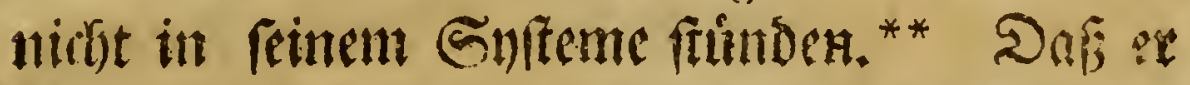
Siectit Gaben milfe, begentigen alle diferretidis fechen Gammlungen diefer Satung.

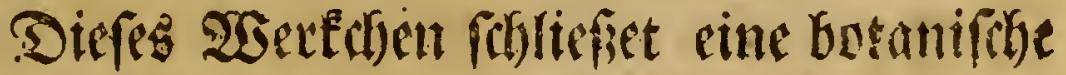

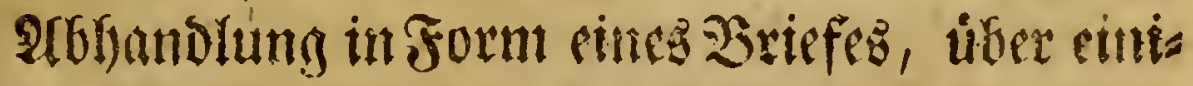

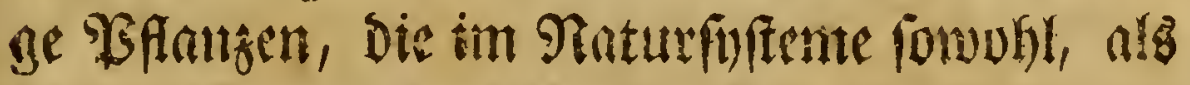
in den Speciebus Plantarum des gederiften ver:

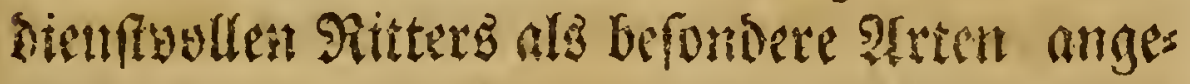
getien werden, und gleidyungl bloffe Epirlars ten zat fent forsinet.

$$
x_{3}
$$

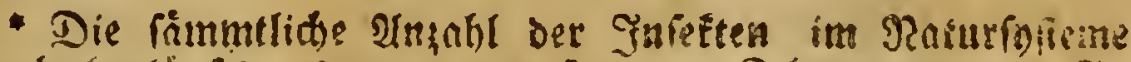
mad)t bevlanfsig 2888 , Dayon fino 780 Stimesterlinge. In Der Fanna mathen fie faft Den oritten Thail alls; Dean Da Die

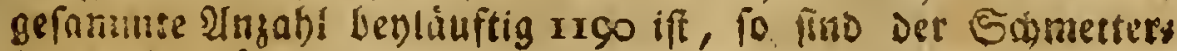
linge nflein ribet 420.

** Cmittere coactus plurimas fpecies paganarum (Phalznarum), nee non minutifimarum. facie, etiam auctorum picluris, notas, fed mihi sptis verbis non diftuguendas.

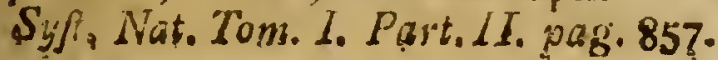




\section{Dorrede.}

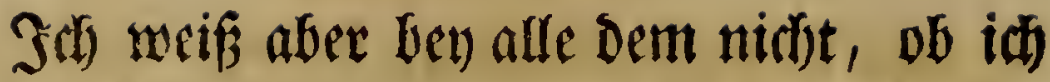

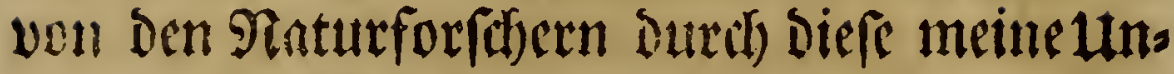
ternehmutng Dane veriture. Se mun! Der Evfritt if einmal geutad)t. Sollte iifi bas Unglict zu misifallen baben, io mag wohl dies

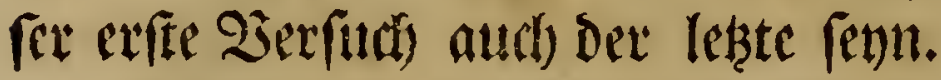

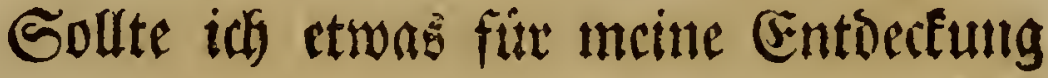
nușaegeben haben, bas forton anderwirtig be:

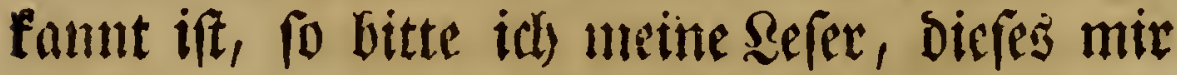

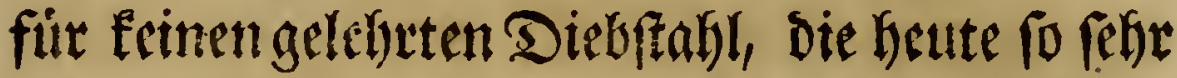
Gitte find, ouszurectsuen. Sab habe die mir

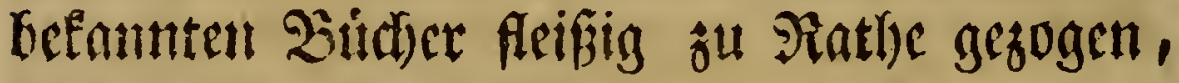
fo viel idf ifrer habhaft werden fomte; war aber allerdings unmóglidf), fowohl alle

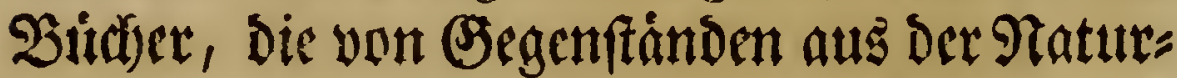

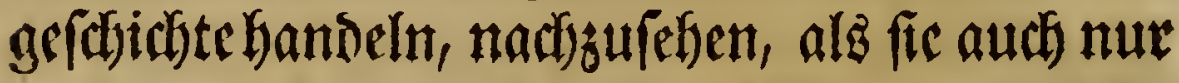

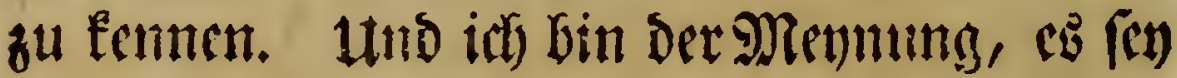
bie Beit aflental beffer natgemendes, wenn man Die Satur befraget, wie fie es ljaben will, als

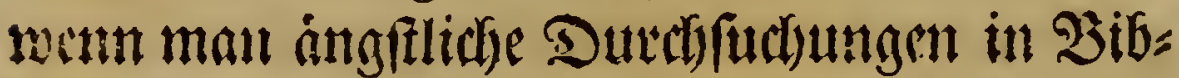
linthefen anfellet, ob Das (Set)eimnifis, Das inir

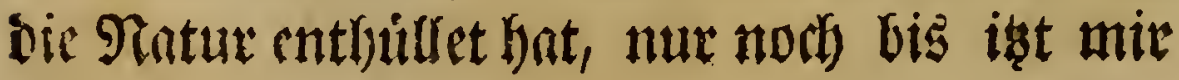
alfein entefuillet fey.

Sestlids woulen mids meine Sefer ber aufs frofientoen Druteferler lyalben entfouldoigen. Dic Entfernung bez Druttortes liefis entid)t zu,

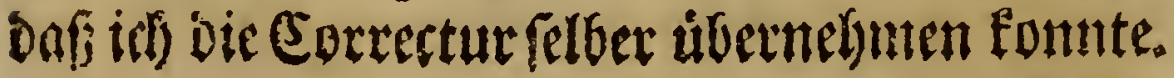




\section{Betjeidniß̊ \\ der Sifriftiteller,}

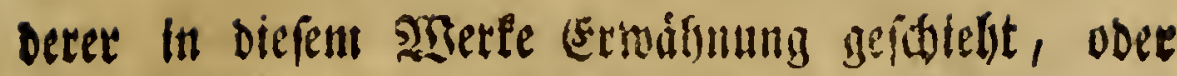
beter unan fich foula babev bedienet bat.

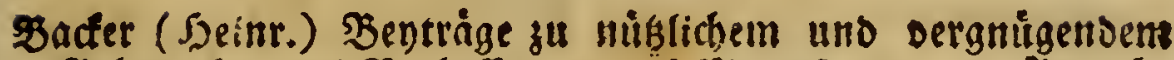
(Sebraudbe, uno Berbellerung oes Micrefcopii. 8. Zugsb. I754.

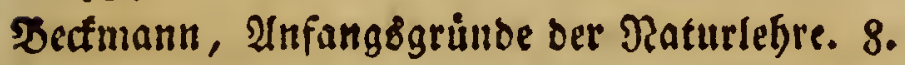
Bonnet, Confiderations fur les corps organifés. 8. Amfterd. Clufii (Car.) Hiftoria rariorum Plantarum per Pannoniam, Auftriam \&c. obfervatarum. Antw. 1583. $\mathrm{I}$

Dieterid, Pflanjenteid) nach Dem Snftem Des J̧errn won Eins nee. Br. 8. Fianlf. 1770.

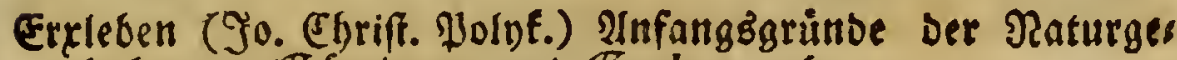
(4)idte. 8. Gostringen und Gotba. 1768.

frifd (Io. Reonf).) Beffireitumg von -afletley Infeften in Deuticilant. 4. Serlin. 1766.

Geer (Ch. de) Memoires pour fervir à l'Hiftoire des Infeetes. gr. 4. Stockholm. 1752.

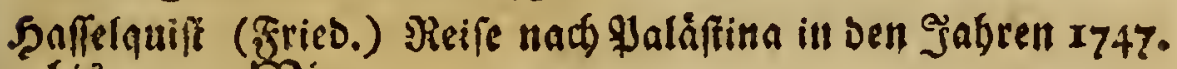
bis 1752. Wien.

Şandfuch Der Natur. 4. Theile. gr. 8. Kegensb. Linnæi (Car.) Fauna Suecica. Edit. I. 8. Stockholm.

-- -- -- Fauna Suecica. Edit. II. 8. Stockholm.

-- -- - Species Plantarum. Edit. III. 8. Vindoban.

-- -- -- Syftema Naturze. Edit. XIII. 8. Vindobon.

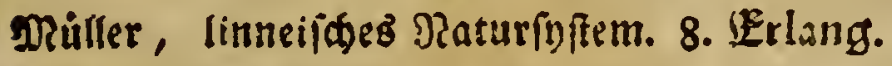

Pallas (P.S.) Spicilegia zoologica. Berol. Fafcic. I - X. 4. maj.

-.- -- Elenehus Zoophytorum. 8. Hagœ Comitum.

Poda (Nic.) e S. J. Infecta Mufæi Græcenfis. 8. Grac. Redi, Opurcula phyfiologica. 12. Amftel. I

Nienger, die un Danzig wilowacblende Pflnmen mad ifren Sefolectbtätheilen befitrieben. 8. Danjig. 1768 .

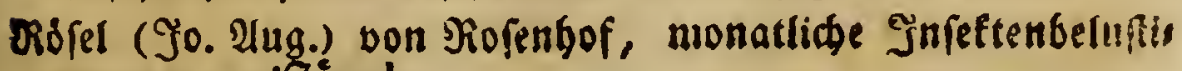
gungen. 4. hiurnb. 


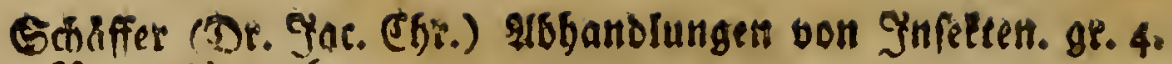

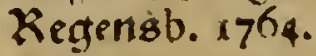

Schæffer (Dr. Jar. Chr.) Irones Infectorum circa Ratisbonam indigenorum. 4. maj. Ratisb. i

Ediffermiller, Berfuch pineś Farfeninfermb. gr. 4. Dien.

Scopnli (Jo. Ant.) Flora Carniolica, exhibens Plantas Carniole indigenas. 8. Vienna. 1760.

Tabernåmentani (J゙ac. Ţgeod.) Aråuterbuc. fol.

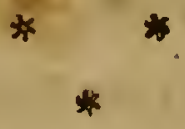

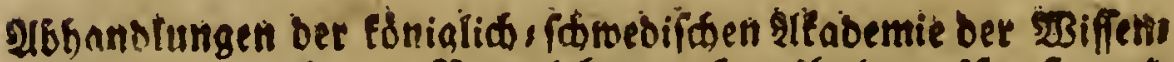

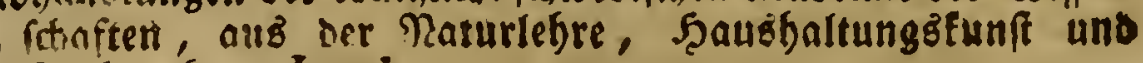
Nechanif. 8. Sarmb.

Hittoire de l' Academie royale des Sciences, avec les Moo moires. 12. Amft.

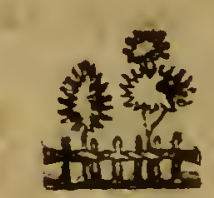




\section{*) 距}

แส

\section{Abbandlunty. \\ Bertareibung ciner Donite.}

Tipula alis fufcis, maculis tribus, fafciisque duabus albis.

Tab. I. Fig. I. 2. IIIt A.

C-in Raturlunoiger, Der nur Schmetterlinge betradss tet, glaubet ganz getwif́, Der puppemftano, da cas Thiet die Earvenbant wegnirft, utto in feiner fünfs

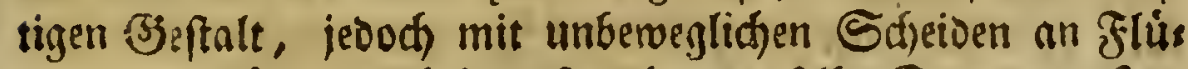
geln und Friffen erfaceint, fen eben berferte Stand des Jins feftes, wo es in einer vollfonmenen Ulutbatigeteit fith ers

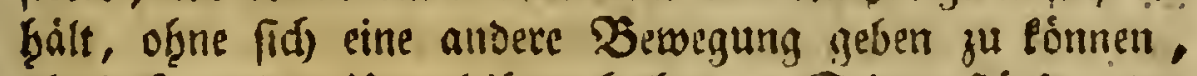
als bus es ben Unterleib nach beyden Seiten ftáreer odee

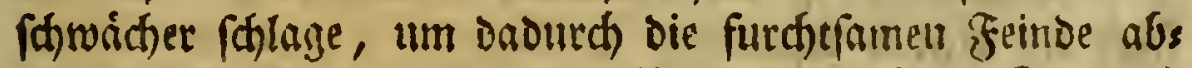
zutreiben, gerabe fo, roie die Pferbe mit ihrem Sd,weife nach benden Seiten fallagen, ofne Daben, einn Tritt zu

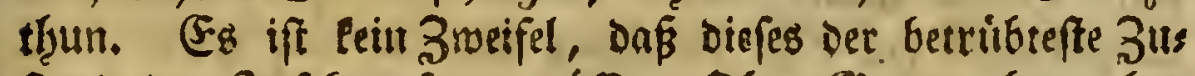

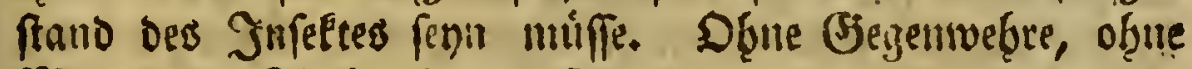
Mittel zur fludbt liegert fie oa, um von dem elenditen Sáfer ungeftraft aufgefteffen zu merden. Aber fornen wir

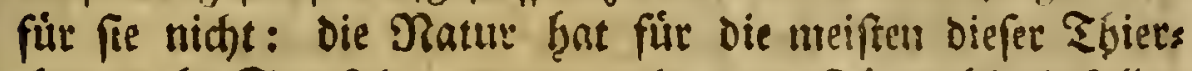
den melgr Sorgfalt getragen, als man fid mohl einfaúlen lást. Sie bat ein jebes eigente Sunftgriffe gelef̧ret, Das

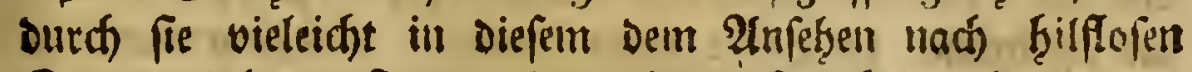
Stande fidherer find, als nadbern fie ibere volfeonmente

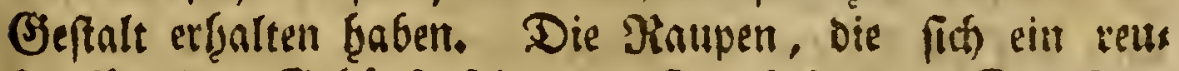

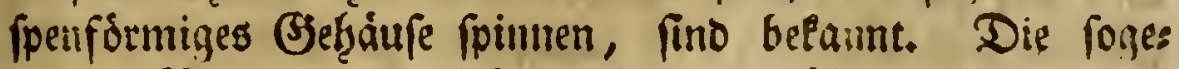

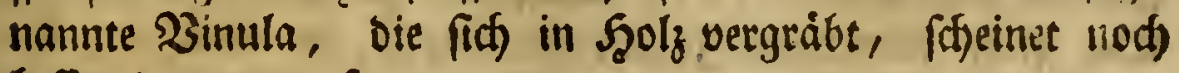
beffer baran zu fenu.

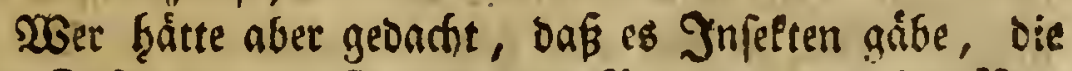
diefem Suftande, Da fie eben eine puppe im engften $\mathfrak{B e w}$ ม

ftande 
ftande find, ifren Feinden ourch die Fludte entgeben esons nen? Had doch ift diefes gerade der Jall, ben id hier erzáḩlen will.

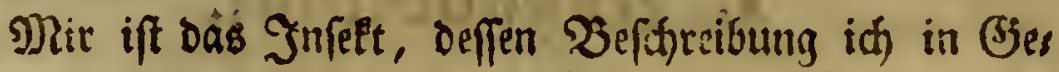
genwart liefere, in feiner Earbenf̧nut nicht betaunt; vies leidyt ift es jeme Made, bie in vietten Theile bes Szunts

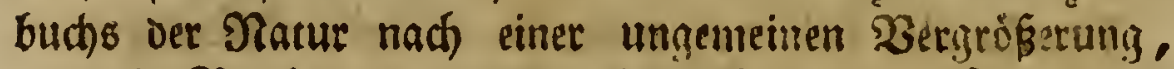

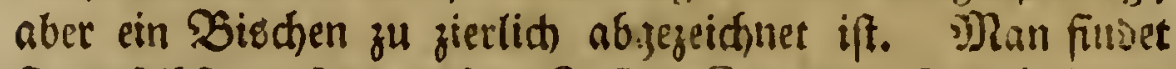

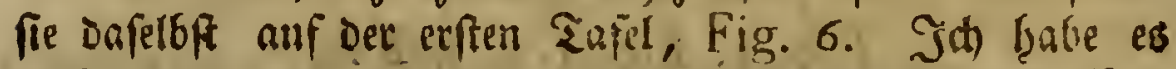

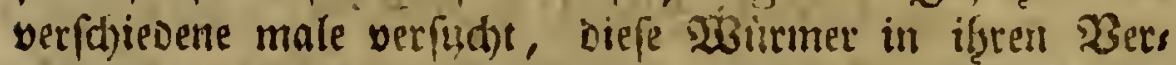
soandlungen zu belaufhen; aber nadjoem fie ein gervifies 2liter erreidset batten, farben, fie mir alle meg.

Die Yuspe ift auf Der erften Tafel Fig. r. abgebils Det, aber namtiaft vergrésert... In iḅtem naturtiden Zults ftande ift fie etroa yon Der (S)rópe einer Blattimottenpuppe. a, a find bie Füblficontreerfheiben, die beroeglich fino, aber von Dem Smpelte nicht leidht beroeget werber.

Sefonders ift der Sdwang inerfwuirdig. $\mathfrak{B}$ el b firzet ein Elemes erhabenes Drischen, Dus in Der Mitte

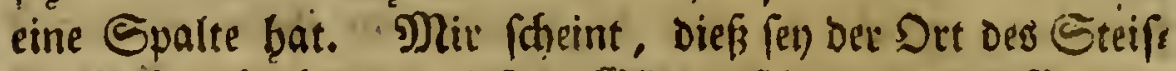

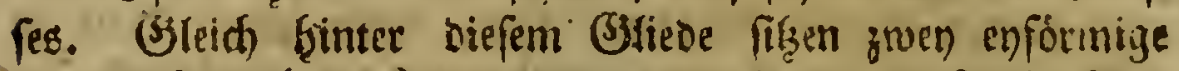
Eanjetblátter (c, c.), Die etwas Dumfeler von jarbe fino.

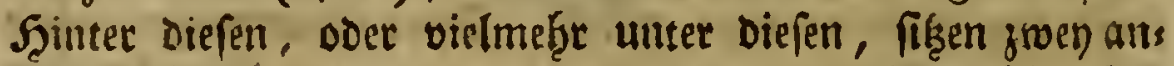
Dere Blätter von eben ber (Seftalt, aber viel gró̉ier, (de, de)

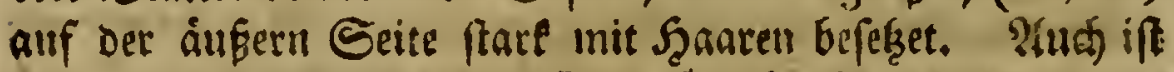
bie ganke Stelle um Das Stlied b Fef̧r baarig.

Diefe Blítter find maf̧re Floffen, Derer fíd die Puppe bebienet, eben fo fondll im waffer bermm zu fohwimmen, als es immer bie Earve thun fonnte. Sie gebr damit fo

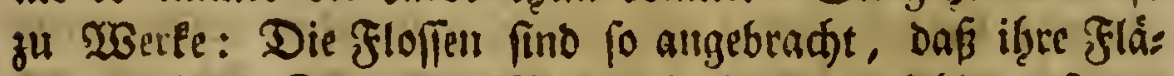
dhen auf oie Seiten oer Pouppe fentred)t, mitb̧in auf Dent Ruiden uno Baud) (ff) waagreddt zu ftehen Poinmen.

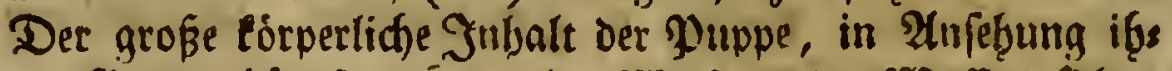

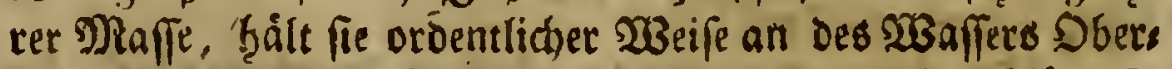

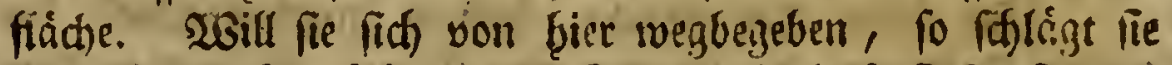
Die Sloffen (de, de) auf Die 2 ruft; fogleidf fintet fie, ins 
Deffer Dab fie fidh mit Dem Dbatcibe eint Ridfung giebt, die fie will. Diefes Sd)lagen ift fefre fandll, uno muś von dem Junefte beftándig nieberfiolet werden. Will es aber unten am Soden mustnfen, fo bat ps roeiter nia)t mefre zu thun, als fich in oer Stellutin zu erbalten, in

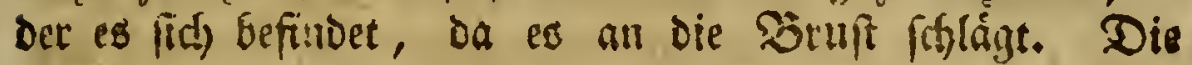
Beid)mumy, Die den Dberleib etwas geranmiger als den Syins terleif vorftellet, niebt fhon fur fich zll et?enten, Dafim Echwimmen der \$orderleib obell, und der Şinterleib uns ten feiyn mủffe.

Dis isatbe Der Duppe ift grau. Die Floffen fino ein

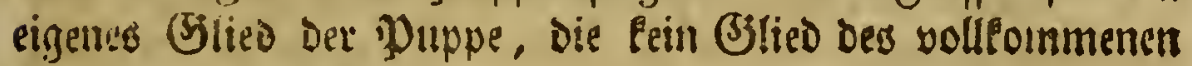
Snjętes cinfitiefent.

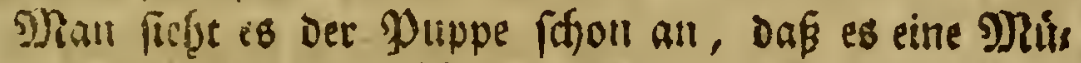

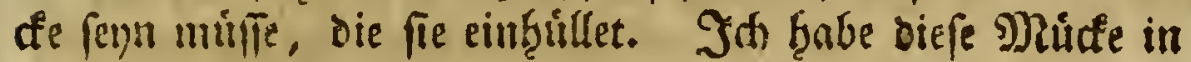

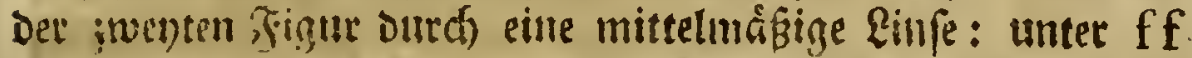
aber einen filtigel Durch eine ftirlere Riufe vergróbert abge: zeichnet. c c C fino meiffe flecten; ee, ee, find zroeen weiffe Streifen, von benen Der untere bunfeler ift; $d$ ift sin granter Flecf. Zwoijden aa, aa, und auf ber ganjen Serie, die mit fff begcidunct ift, fino die Frangen weif;

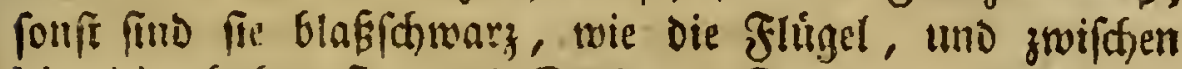

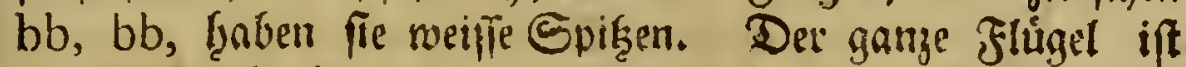
Durchants fefs: Gaarig, befonders aber an den 2loern. Die eigentlid)e Bróbe biefer Juturfe ift wie ben oer gemeinen (Selie (Culex pipiens L.); Der Baud) untenber, uno Die Frife fino weis, wie unyearbeitet Warho; Die Psuft, und Die obere Seite des Sauthes find forwary.

\section{Ifbrandlung.}

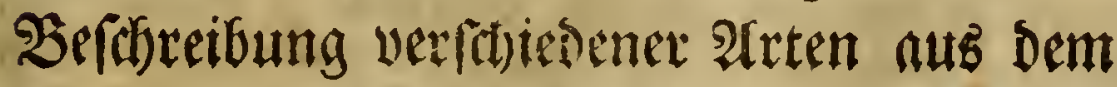
Millbenge(t)lectite.

Se Eleiner die Tbiere fino, Defto grókere Aufinerffameit

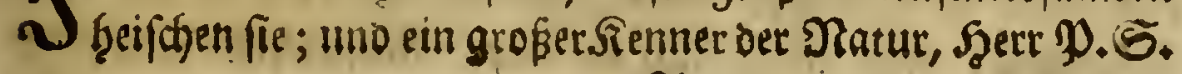




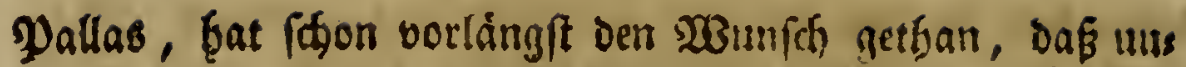
fere Dinturaliften, bie fo gerne mit bunten Stimetterlins gen fpielen, ibren flei auf Die lleinfren Thiere, ale on find bie Milben, Poouren, Eåuje u. D. gl. verwenoen wolltent.

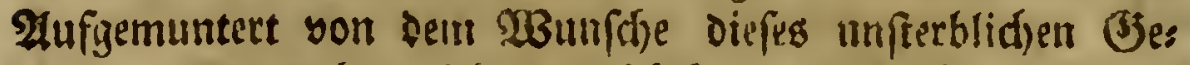

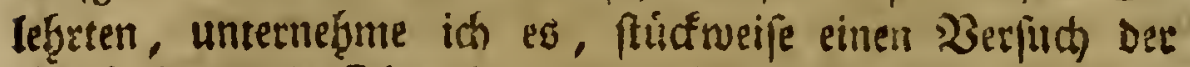

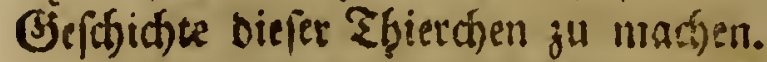

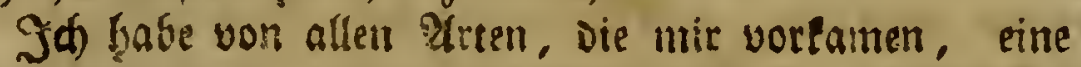
Zeidgnung gennacht; nidje, als went yon manảen no. Peine ba máre, fonverti um meme syjer in ben Stano zu

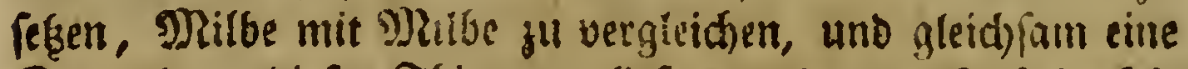
Sammlung biefer Thiere ju licfern, bie man fonft in leis

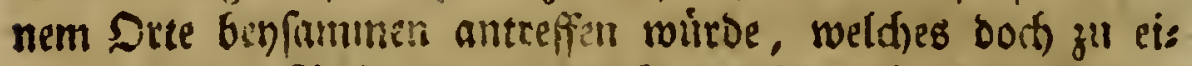
ner ridstigen Seftimmung ver Hrten fo notbmendig ift.

Sch weifs nicht, of bie אiennzeichen, bie id, vo:n Dr. Wallas geborget bafe, und bier angebe, Giiureichend genug fino, alle $\mathscr{A}$ rten, bie noch belaunt werden ivirften, zu daracterifiren. Sisher Ģaben fie bey allen $\mathfrak{2}$ trten ridstig eingetroffen.

Reungetiden Des Milbengefdlect)ter.

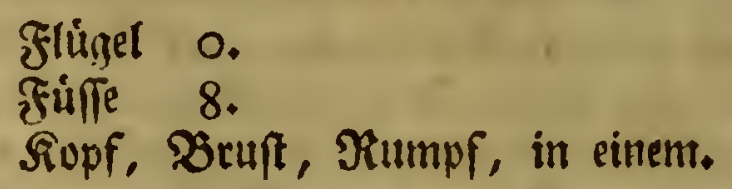

İ) etrodbne ber צugen gefliffentlich nidt, , bie boch ber Ritter von \&innee gany zuberfids:lich mit unter bie Sienn:

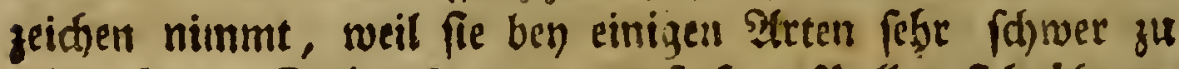

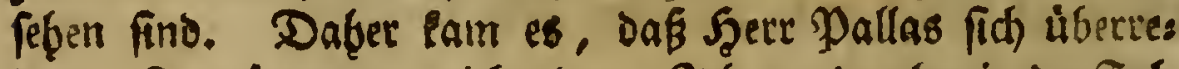
Dete, fie waden gar nidjt ba. Tah werde aber in Der Fols

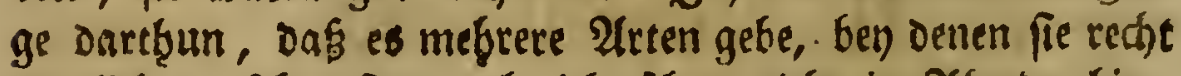

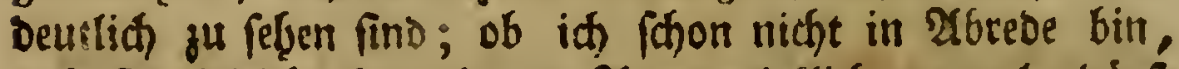

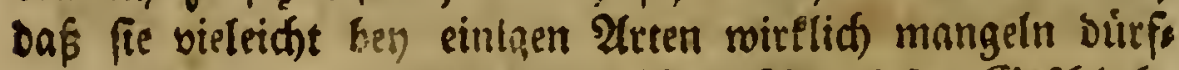

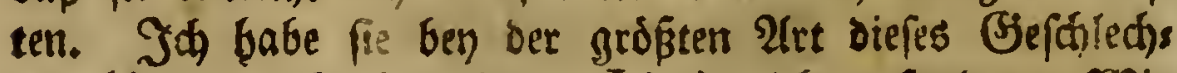
tes (Acarus elephantinus. Lin.) niift gefunben. WBie Dem aber inmer fann mag, fo bin íf boch iminer ber

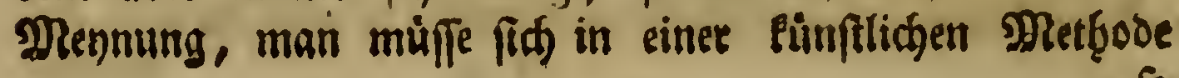




\section{3ivete 2lbbandlung.}

fo viel, als moglid, von gar zul Iteinen Sennzeidjert ents Galten, of fie fobon fonft rid)tig fenn undgen.

\section{(E) $\mathfrak{t} \mathfrak{t} \mathfrak{e} \mathfrak{i} \mathbf{t}$.}

Acarus corpore poftice attentato, elongato.

$$
\text { Tab. 1. Fig. 3. } 4 .
$$

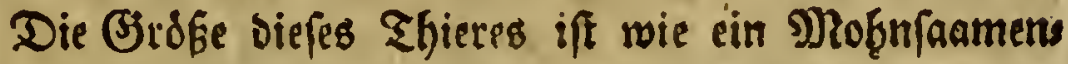

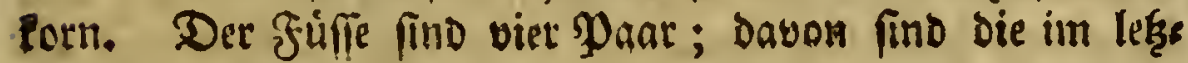

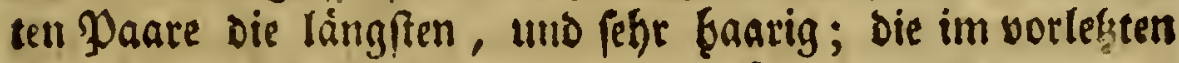
fino elirzer, uno reniget ḩaarig. $2 \mathfrak{n}$ ben vier vorbern nimmt man bie Szanre Eaum wab̧r. Fig. 4. ift einer von

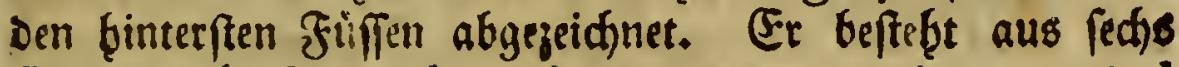
Gtiedern $(a, b, c, d, e, f$.$) von denen nur b, c, und d$ Buifhel von Szaaren nadh ber innern Seite, und einige wentige nad) Der ánsern geteffret baben. Wrir roerden uns

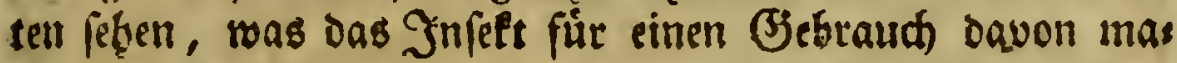

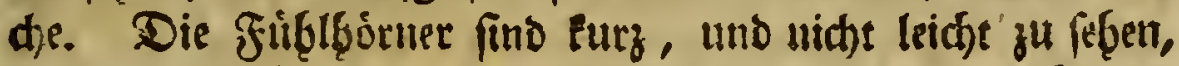
weil fie bie Milbe nach unten beuget. Die zwen $\mathfrak{2}$ (ugen fiub fatwar, unto nidft fonderlid) berborftebeno, $(a, a)$. Der Reib ift enfórmig; um Die Mitte aber fángt er an

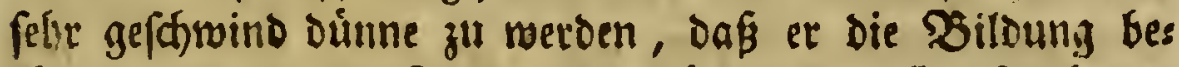

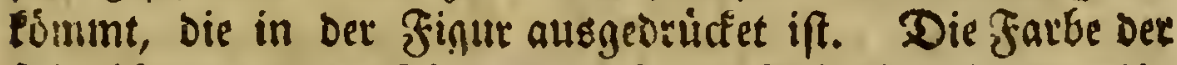

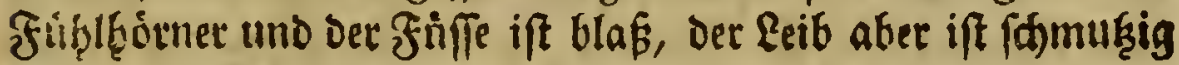

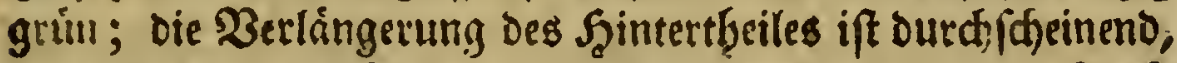

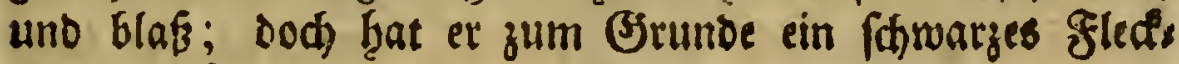
den. (b fig. 3.)

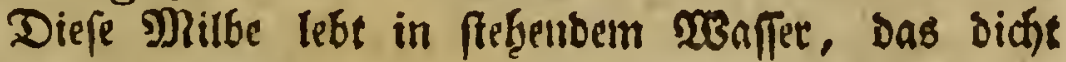
mit $\mathfrak{X a f f e r l i n f e n ~ b e f a e t ~ i f t . ~ Z u e r f t ~ b a b e ~ i d ~ f i e ~ i n ~ b e n ~ \& a s ~}$ den auf Dem fogenannten Sapuzinerfelde ber; Eing gefun:

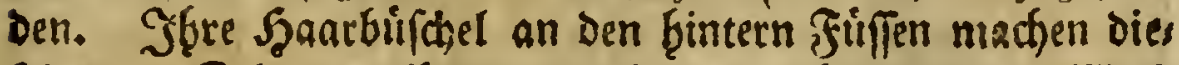

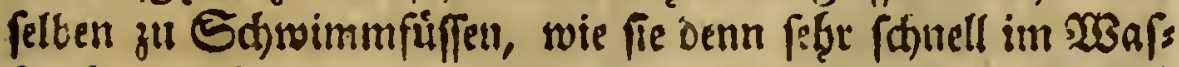
fer berumfoninmet; auser Demfelben aber fann fie fid nidjt bie geringfte Serwegung geben, und wenn unan bas Waffer verounften läft, fo ftirbt fie gar. Shre Bebes cung, oder bie Şaut, ift bartfóanlig. 


\section{Swe $\mathfrak{d} \mathfrak{t} \mathfrak{e} \mathfrak{A} \mathfrak{t}$.}

Acarus globofus corneus, pedibus pofticis natatoriis.

Tab. 1. Fig. 5. 6. 7. 10.

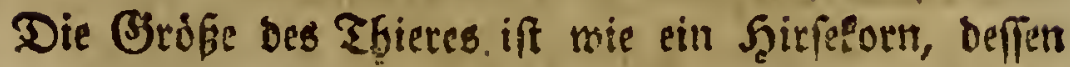

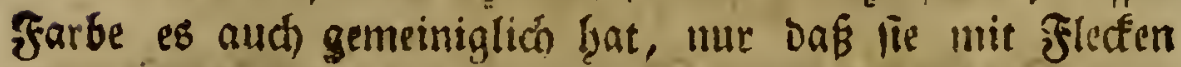

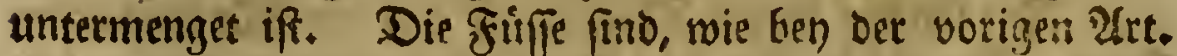
Bon bem binterften Paare ift einer Fig. 7. Gefontiers abs gezeidynet, Daran fino bie Bjlicber $c$, d, e lyaarig, uno

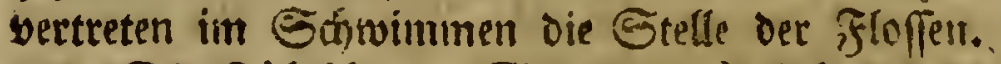

Die Fúflgórner (Fig. 5. a a) fiefht man yon oben nidft leicht, weil fit unten an esinem Segmente bes lugets formigen Thieres befindlich find, uno von bem Gufefte

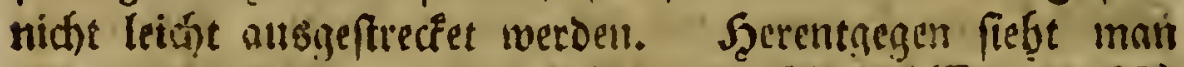
fie yon unten defto leichter. Die zwen) Augen (Fig. 6. ff.)

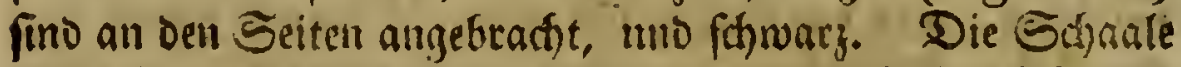

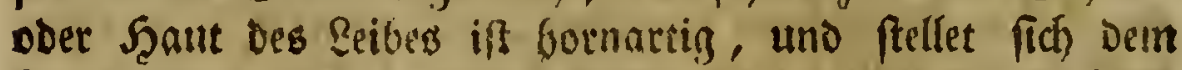
Iluge butch bas Bergreffermingr!as vor, wie die Shallt

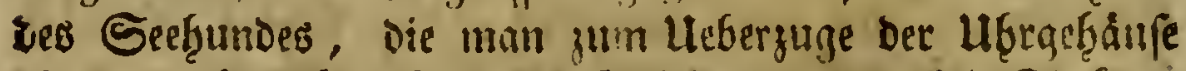
nimmt. Doenfier hat Das Snfeft bren Dumpele Fleefen; einen zwitchen den $\mathfrak{A}$ ugen (g. Fig. 6.), tuto cinen kuf benden Seiten des Reibes $(\mathrm{h} h)$, welche lefsteren ans mefrs rern zufammerigefeget fheinen, uno nicht inmer eben dite ferbe Stelle gennu einnebunen. 2 Benn man Die Mlitbe nuf Den Ritfen legt, und Diefe Steflumg nimmit fie febe leid)t an, fhwimut aud) int Derfitben ebent fo bequem, als in

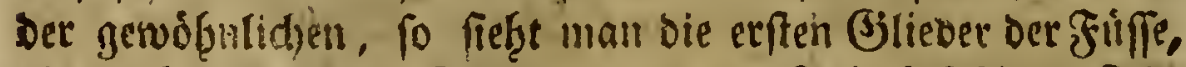
bie nach allen iţeen Durámefern am Reibe befeptiyet find,

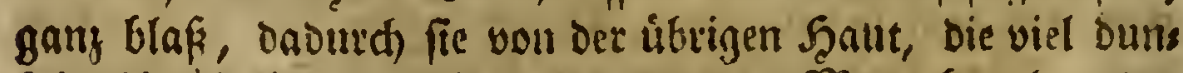
feler iff, leicht unterichicden merden. Man hat sen ber

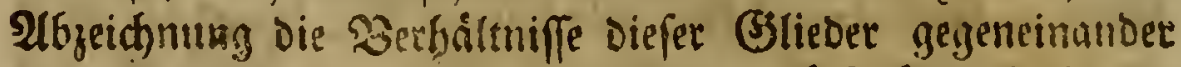
genaul beobachtet. (Fig. ร.) WBeiter rúcfwairts ift ein ans Deres blaffes fretisfomiges Élied (d), Das der \&dnge-Nach gefpalten fheint; gleich unter biefen ifte eine braune Mlas

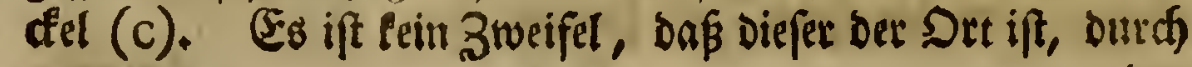
$\rightarrow$ :. 
ben das Jnfet ben Unflat ausfiberet, melden biefe Graune

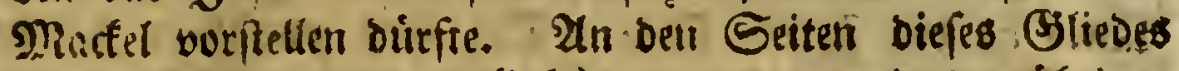
fino zwo Eittelformen ( $b$ b), Die ganz mit Der úbrigen Şaut úberétitsfommen, beret Beftimmung mit aber unbe: fannt-ift.

(Fine Dille biefer $\mathfrak{A}$ tegte (Ener an Die Seite Des

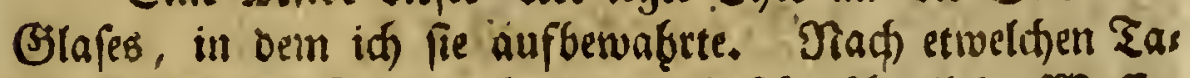

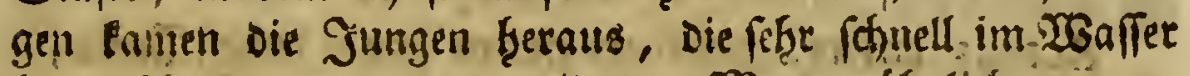
berumidrwammen, uno alle Der Mutter d́fultid) roaren.

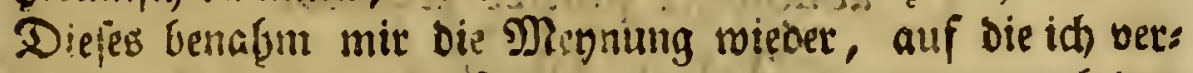
fil, Daßi biefe jwente $\mathfrak{A}$ rt won ber vorigen nur Durdh bas

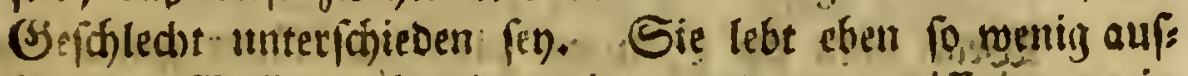
fer bem Woffer, als Die vorige, uno man triff immer in cinerlen (Sewáfer bende, Urten an.

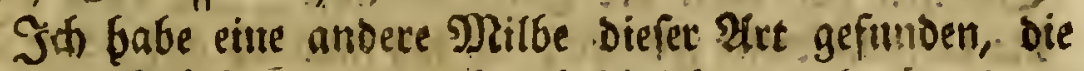
in einisen Studfen bon Der eben befthriebenen abgrbet: Denn

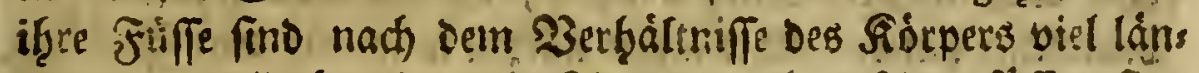
ger, und alle Gandig; Die fimmen an ben șinterfingen fino nidjt to fare, als oie 7. Fig. nusweijet; Die farbe iff gleidformiger; Die flecten h h (Fig. 6.) Aliefien zuams

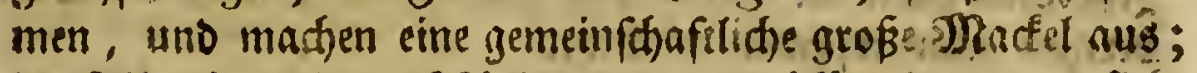
ber \&eib ift viel burchidheinender, gleidformainger, uno fiebt Peiner. Szayenbaut gleidh. (58 ift auch oiefe Spielart viel Hleiner, als die eben bejahripbene. Sollte bies Der Unter: fthied bes (Befdlectes fenn? Ben biefer. Spielart nab̨m

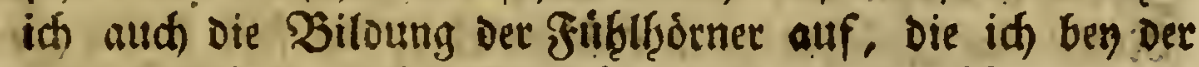
vocigen nicht beutliaj genug fab, ob fie fdjon gróber waren. Jch Gabe fre in bee 10. Ffigur abgezeidgnet. Sie beftebent aus brenen Glicbern, Dabon bas åuperfte - in eine fafarfe Spif̧e find endiget.

\section{Dritte $\mathfrak{A r t}$.}

Acarus, pedibus tertii paris craffifimis.

Acarus pedibus tertii paris mole monftrofis. De Geer ad: holm. I 740 .

Acarus pafferinus. Lin. fn. fu. n. 1970. S. N. p. 1023 . fp. 10. 


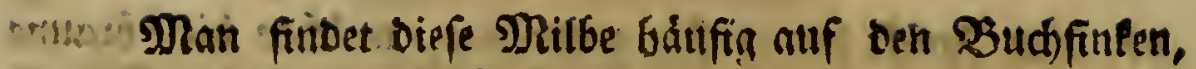
unten an Den Febern figen. Der Szert von (J)eer hat in

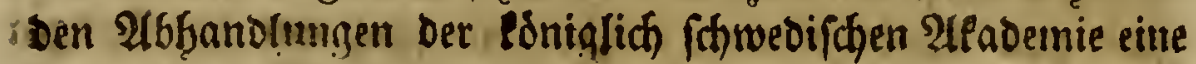

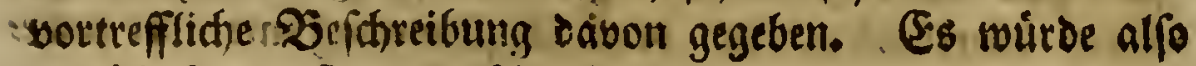

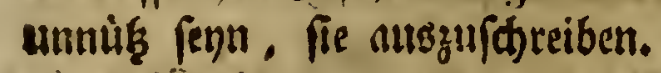

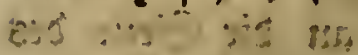

\section{$\mathscr{D}$ ierte $\mathfrak{A} \mathfrak{r}$}

Acarus rufus, pedibus primi paris longiffimis, abdomine poftice crenato.

\section{Tab. 1. Fig. 8.9.}

Wenn man im Soummer bie Grasblåtter genau bos

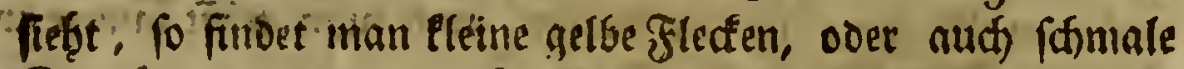
Streifen von eben ber Farbe darauf. Sal fand gar balo

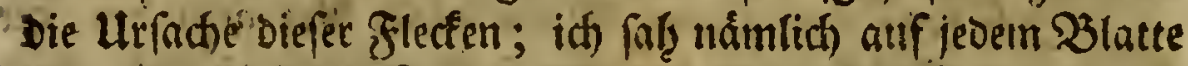

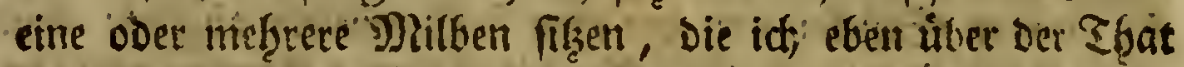
belaufhet batte. Sie faffen aliejeit unten an Demi Flectiden, bas fie veruifadiet hatten; fie freffen alfo yon oben berab.

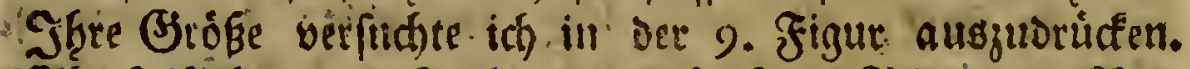

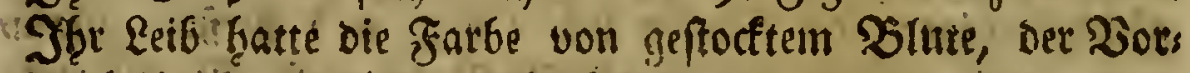
bertbeil aber erfogient getwridst:

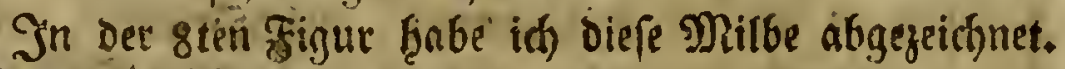
a a fino oie fitghisdrner, bie navelformin altsfegen, und

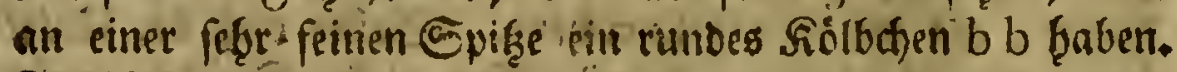
3wifden biefen find gerade Siber Der Punne, ooer dem

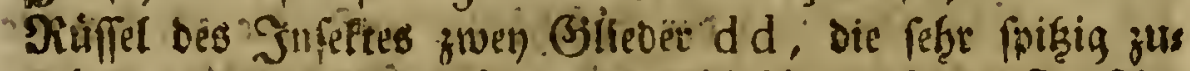

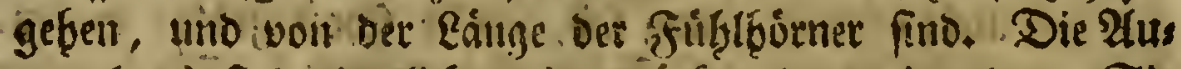
gen (cc) futb giemlidf tweit gurüe uno auseinander. Sic fino fotwary. Der Reib ift ryformig, aber risfwarte wie

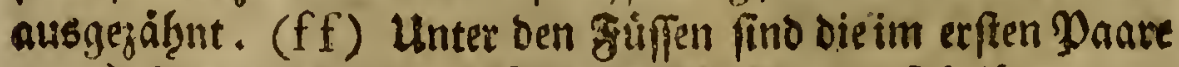
(g g) beforiders lang. Das Infelt bedienet fich ibrer zmar

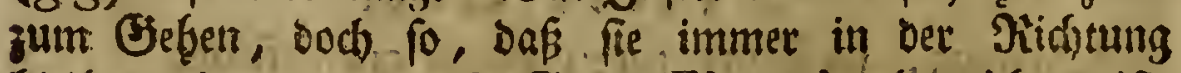
bleiben, in Der Das erfte Estied (Fig. 8.) abgegeiduet iff.

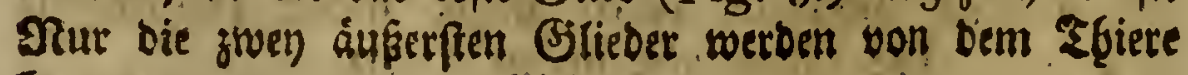
beweget. 


\section{Ŝmetste abbandluttg.}

Die Farbe miro ourch Das ßergrdfferungsglas etwas

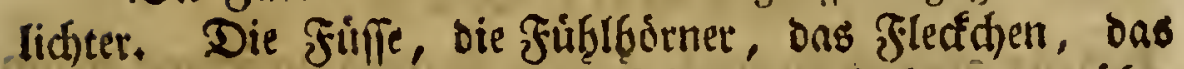
mit e bezeidnnet ift, uno ber Sheil des \&eibs, ber úber Dent Itngen ift $(h)$, fino blaß̧, uno Glicten ins Belbe.

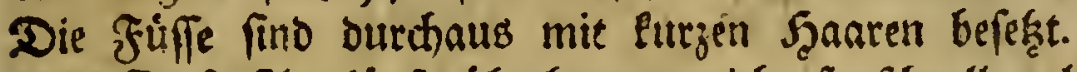

Diefe 2at láuft liberbaupts nidst fo fónell, als die úbrigen, und man cann oft fogar einen Grastalim ab: pflucfen, obgne daḱ es berowegen feinen Drt vetlaffe.

\section{$\mathfrak{F} \mathfrak{u} \mathfrak{n} \mathfrak{t} \mathfrak{e} \mathfrak{A} \mathfrak{t}$.}

Acarus antennis longis, apice bifetis.

Tab. I. Fig. I I. 12.

Acarus longicornis. Lin. S. N. p. 1026. fp. 29. Acarus rupeftris. Lin. fn. fu: n. 1985.

Die Milbe, die ith bier bejareitie, fand Rinnee nuf Jelfen: id aber hiabe fie unter Solumentopfen gefunden. Eie ift febr eleill, uno wáce fie nicht meiftentbeils fobon jinnoberfärbig, fo wurbe man fre laum feben. Dar אapf (a) láuft fugeipifgt biuaus, uno bat, wie es mir fatien, eill oder jwey Belente. Ein Elein werig yor Dem Drte Der

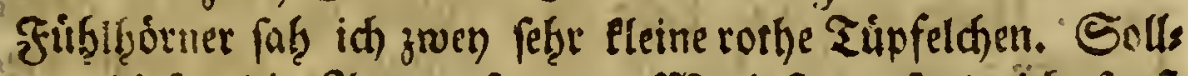

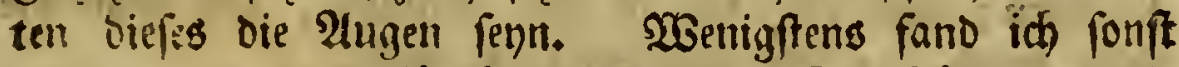
nichts, Das ich onfur Galten fonnte. Die Fuffe uno oet enformige Fórper if ourchaus mit furgen Sgaren beferet; bernours fino aber bey diefer $\mathcal{A}$ te bie Fublborner (c c) mertwuroig. Sie find jiemlich lang, uno ragen auk weit über den Rúffel Ginaus; fie beftefenen aus oren Belems fen, Dayon Das itittlere das furgefte ift. Das áuferfte (Jilente ift an oer Spife wie abgeftumpft, unto bat groo lange Sorften (d e, d e). Sonft bat biefe J) Milbe nidhts fonterlides. Der Seert von Rinnee fagt, wenn fie auf ben

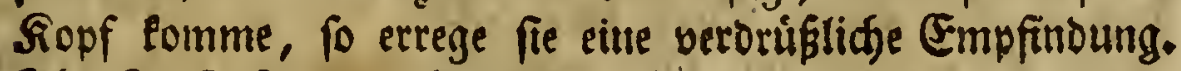
Jor Eauf ift ziemlid id)uell.

Die Farbe diefes Snfettes ift verånderlich, man findet caftanienbraune, blaf́braune, uno fabon carmefins ober jino: berrotge. 


\section{Sedif ite $\mathfrak{A} \mathfrak{r}$.}

Acarus ano pallidiore, tharfis pedum intermediorum veficulofis.

Tab. I. Fig. I3. I4.

Acarus coleoptratorum. Lin. fn. fu. n. 120 . S. N. p. 1026. fp. $2 \%$.

Ween bie Shumutel alt werden, fo findet man zwis

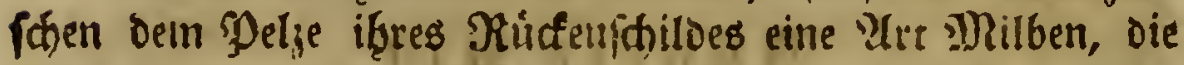

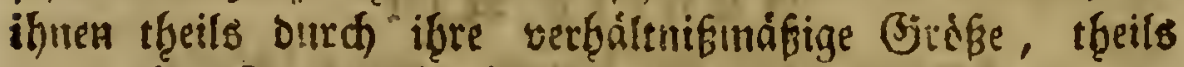

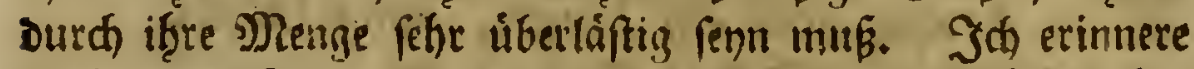
mid, eine Frliege, (Denn auch oiêe und bie Miúcten ba:

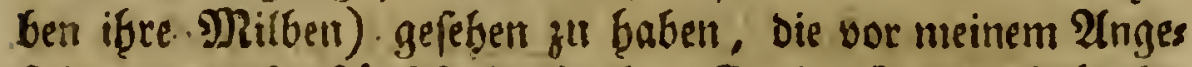

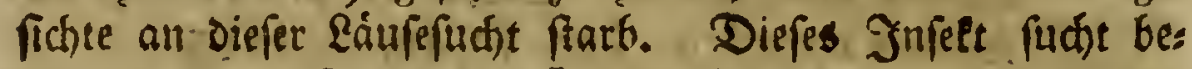
fonders in ois formen der SFlieder fich einzudringen, wo es Durch anb̧attendes Sarigen und Strhent Der frliege erftlid Derbe Edfinerzen, Dann eine förmlide Rian?heit, uno mos rid Den Tos felber verurfachen mus. So lange die biene lebt, fino fie feger bart von ibe wergubringen, aber nad)

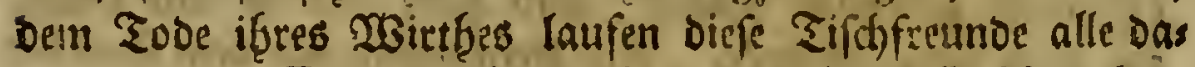

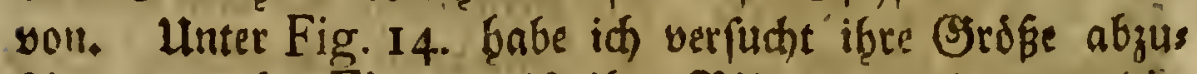
fothilbern; aber Fig. 13. ift ithe Bildung, wie man bies

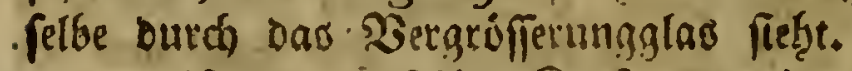

a ift Der gugepingęte Kopf, Der eine Spalt? bat, die

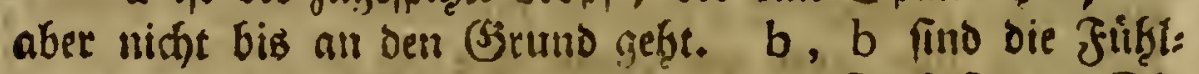
bơrner, Die ein biaden långer als ber finf find. Die

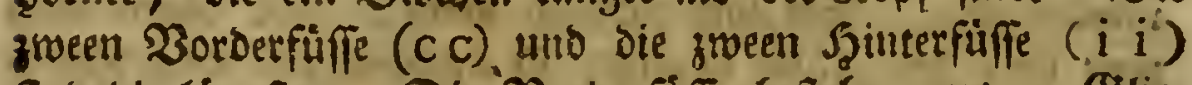

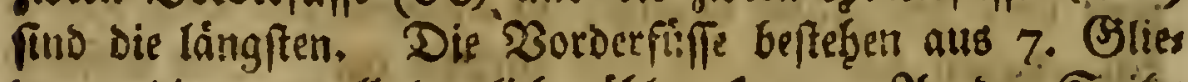
bern, die man alle beutlid) żóblen tann. $\mathfrak{Y} \mathfrak{n}$ ber Spire ift etraas, mis eime eleine Slafe baran befeftiget (d, d).

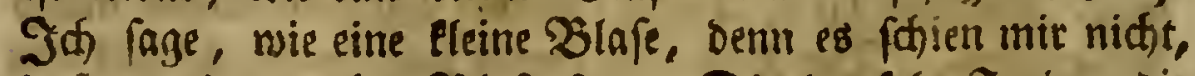
Da

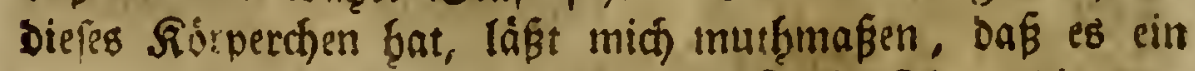
Doppelter Soafen fen, mir Dem die Mitbe fich an die vors

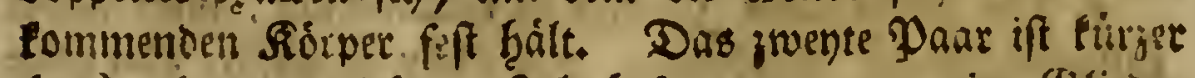
(ee) aber viel bider. J'd b̧abe daran nuc vier (Sticier gegifos 


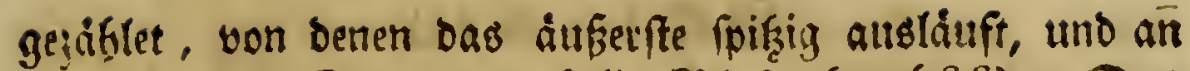
Der auberften Spilze cine belle Blaje frat $(f f)$. Das britte Yaar (g g) ift beyláuftị von efen ber Lange, aber

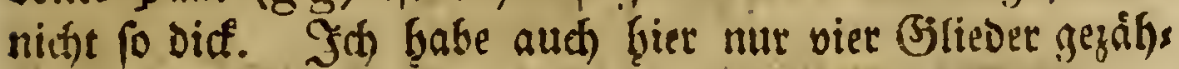
let, von Denem Das britte febr elury, Das vierte aber ziems lich lang ift, unto an einer feimen Spitge gleidfalls eine

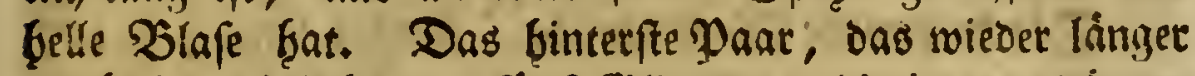
ift (i i), befteft aus fünf Stiebern, bie inmer bunner

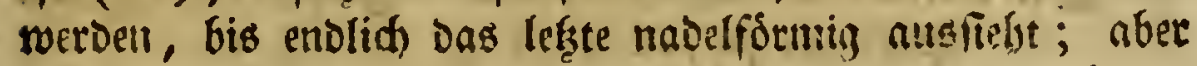

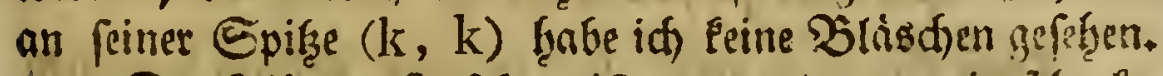

Der \&eib Des Jnfeltes ift un uno unt mit febr lurs

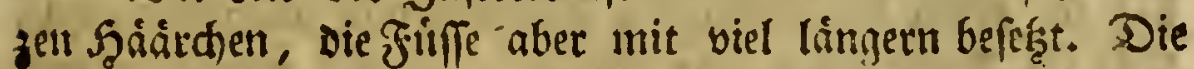
Farbe ift wie Die Farbe des Mandelbalges, Dod) etwas bluffer. Enolich ift sin Dueerfteifen (1), uno ber ganje

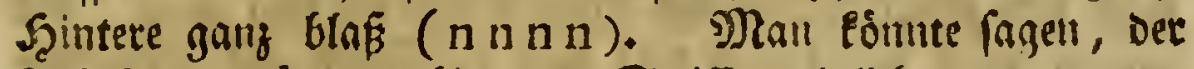
Rib fen yon 1 an, bis zum Striffe weislid)t, ausgentoms mèt bas ountelere Drenact $m$, das die Farbe des úbrigen Reibes ந̧at.

\section{Siebente Frt. Acarus ano poftice emarginato. \\ Tab. 1. Fig. 15. 16.}

Die 15. Fig. ftellet eitre Jilbe vor, Derer id zmo auf einer Felderdic fano. In Det 16. Fig. Fabe ith fie sergrofert abgegeidfnet. Die Farbe ift wie gebrannter Caffee; aber oben ain Siopfe, und biuten ain Steiffe bat fie zween unregelmáfige Flecfen $(b, c)$, Die bem Jirfefte. ein rumbers

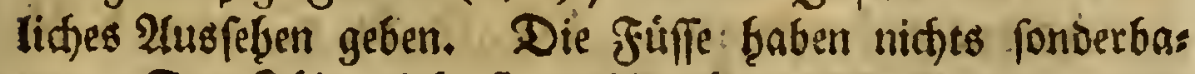

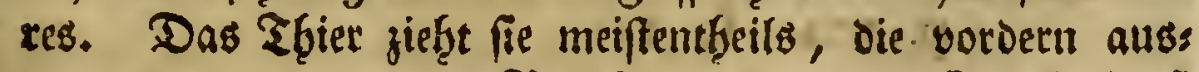
Benominen, unter ben Baud zufanmen. Der $\mathfrak{L e i b}$ if: ricfwáts (d) fachte vertieft, welajes aufer ber Farbe, Das

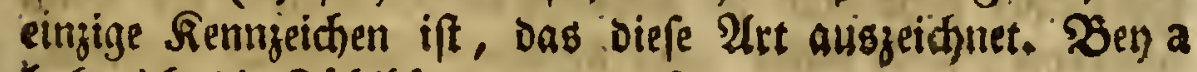
babe id bie Füblf̧orner entworfen. 


\section{$\mathfrak{A}$ ch) $\mathfrak{t e} \mathfrak{A} \mathfrak{r}$.}

Acarus holofericeus, fubglobofus, aquaticus.

$$
\text { Tab. 1. Fig. } 17 .
$$

Acarus aquaticus. Lin. fn. fu. n. 1978. S. N. p. I02s. fp. 2 r. Pod. græc. p. 121. fp. I.

Die bod)rotbe $\mathfrak{B a f f e r m i l b e . ~ R e f e l ~ I n p . ~ 3 . ~ p . 1 ~} 5 \%$.

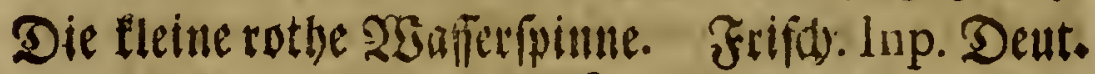
part. 8. p. 5.t. 1. f. 3 .

Diefe 2 art ift fo grof, unb in allen ₹eiden fo gemein,

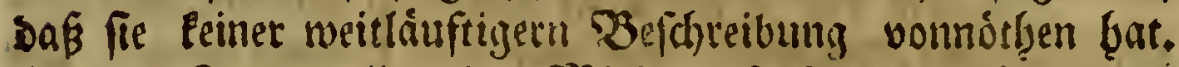

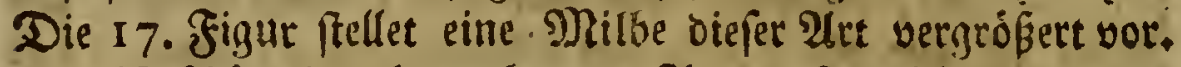

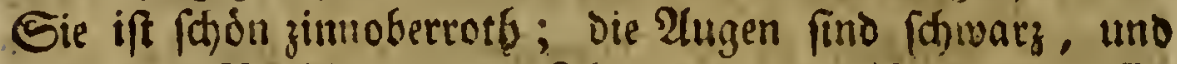

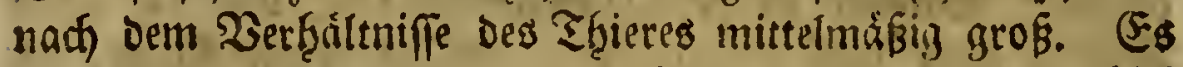

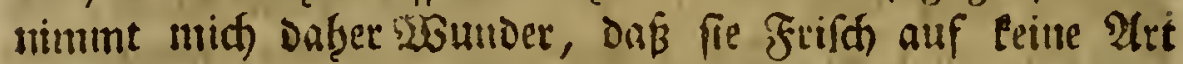
ferten founte. Die zwen) mittleren Pare, yon Den Finfen fino zottig, oas erfte und lekste Waar aber nur eill roenig fraarig. Das lef̧te Paar ift audh etras dúnher als die ưbrigen.

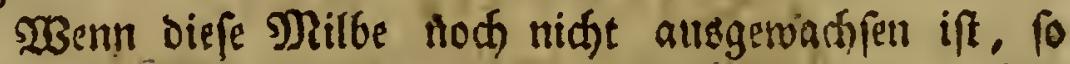

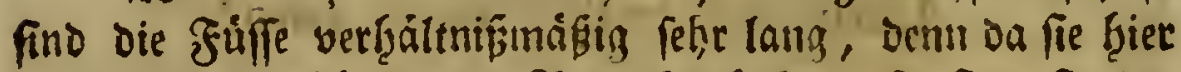
beuláuftig Die Ránge des SRumpfes bqaben, fo finto fie Das mals woht zrouminal to lange.

\section{Reunte $\mathfrak{A} \mathfrak{r t}$.}

Acarus integumento coleoptrato, angulofo.

$$
\text { Tab. I. Fig. 19. } 18 .
$$

Acarus coleoptratus. Lin. fn. fu. n. 1973. S. N.

$$
\text { p. 1023. fp. } 13 .
$$

Diefe 2 rt bălt fich gerne in der naffen Erbe allf. Sim

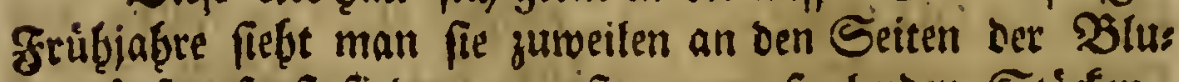
mentspfe; fonft finbet man fie unter faulenden Stodfen,

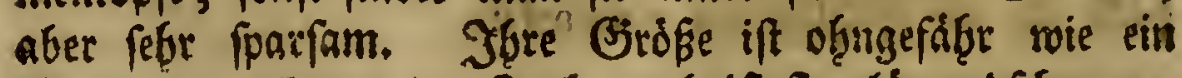
Mogbnfaamentoen; ber farbe nad ift fie glánzenofdrwarz; 
et eine wortteidhe (J)efdichte Des ŢGieres benfüget, Die fo viel ragen will.

I. Trifft man diefe Milbe autf allen Sthneffen, befons Ders auf Der groken (Startenfd;nede all; Dod) Diefes nidft zu

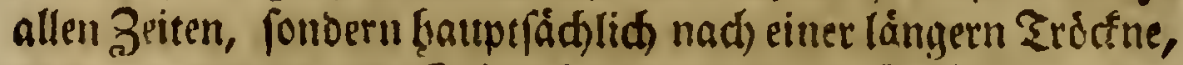
oder menn man bie Sajnedfe in trocfinen Befáfen aufbes rahbet.

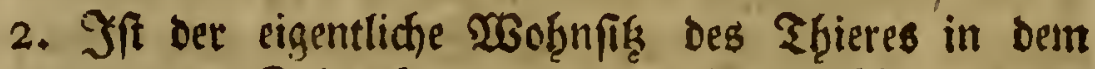

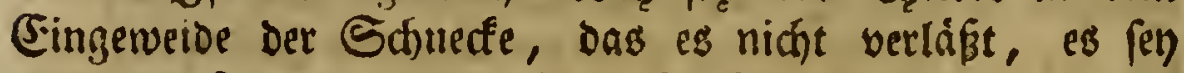
bann, Daḱ es mit Dem llnratbe herausgertieben werbe. 26at and Domals berfud)t es wieder Gineinzulommen, und id) Gabe gefeben, Dấ es ifrm meiftentbeils gelinge.

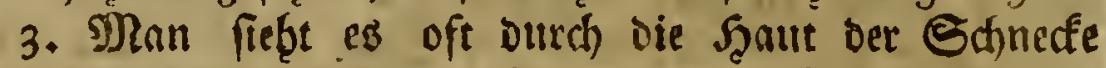
zafiltreid); sfters fommen fie wentiger zaffireid herans, und laufen auf Dem Şalsfragen Der Sdunecfe fonnell bers um. Es ift waḩr, was ber Şerr von Reaumúr fagt, fie woiren niemals auf Der' Sdhaale zul fegen; ager man mus

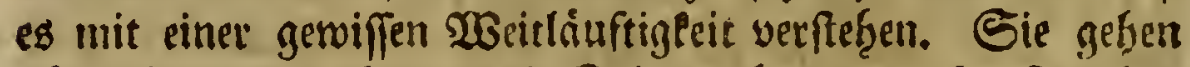
námlid zwar wobl auf bie Schaale berants; aber fie gehien Dod) Peine meite Streffe von dem Reite Der Shuneffe werg.

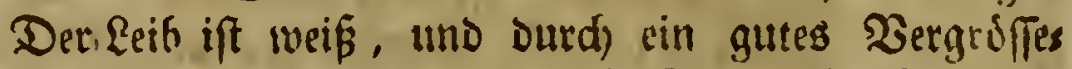
rungsglas frefht man, Daf er in fed) Stinge abgetfeilet ift. Err ţat nur f̧ier und Dort cinige bervorftebende Şaare. Defto ḩanriger fino bie frübe, bie alle you gleinger Lánge fint.

WEeil bie zwey) leģten Paare von den zwey vordern mer?lich entfernet fino, fo posmte man es vieleid)t nemren Acarus pedibus fecundis tertiisque diftantibus. \ah weís aber nid)t, ob Diefer Differentialnamen es gentry thas racterifire.

Diefe Mitbe låuft in $\mathfrak{x}$ affer, wenn es auth mit Burummi vermifhet ift, eben fo geid)wino als auf dem Sorors per ber Sdnecfe; ia, wemn man fir in einem Tropfen eins fahließen mill, fo láuft fie úter Denferten beraus, uno geḅt nach Belieben wieder binein. 
Reaumuir bebauptet, Das Tgier Fonne feine Sgdrner eingief̧en, nie es Die Sdynedfen pönnen, auf Denen es

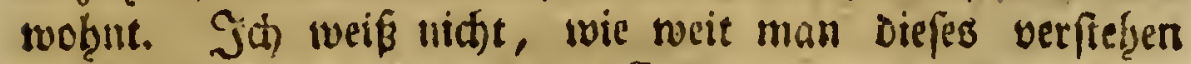
Durfe, Nitd) Dunlt, alle bie (Erfacinnngen, die man bey diefen Şórnern mafernimunt, laffen fid ourd cin bloffes Aboúrtgbiegen berfélben erflåren, eine Erflírung, bie bie (5rfabrung an vielen, grókern Urten biejes (Jejechlech)ts ers birct.

Diefe Ießzte Prt fand id auch jiemlich fiåufig anf oer untern Eeite eines Dogelfirjabenblnttes (Padus), mit allen Den (Figenfajaften, Die id) eben ergablet babe. Sie if Diefem Slatte cigen; Denn won Sdyucefen (anto id) (o wes

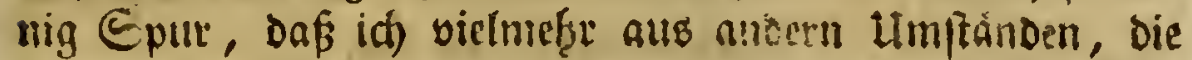

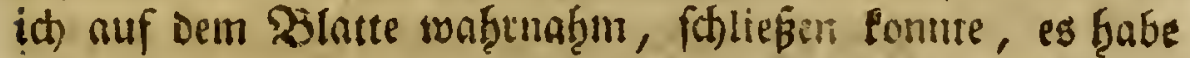
wenigftens pit einigen 200 den keine Sdhnede biejes Silatt betrodjen.

\section{Poblonorung.}

Wouthetelnungen mit den Snfufions:

thiereten.

\section{S. I.}

Pflangen, "1nd ibre Sbeile in $\mathfrak{B a f f e r}$ geweidt brins

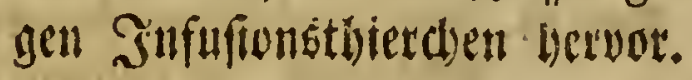

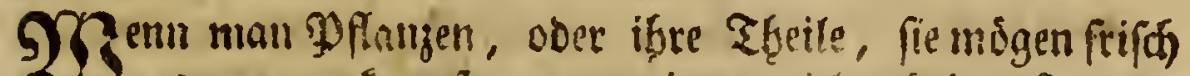

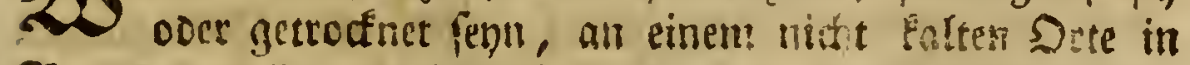
Stunnenmaffer weidjen lápt, fo fiebt man bimnen ciner

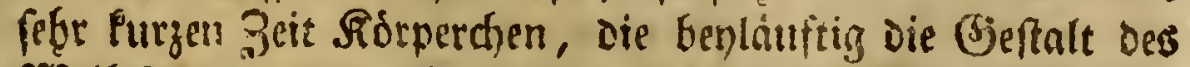

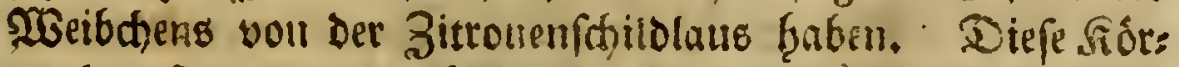

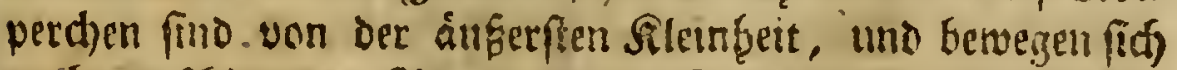

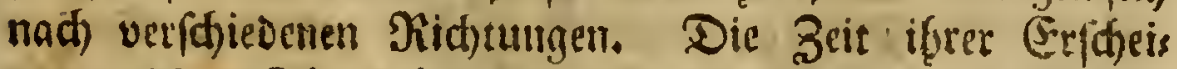

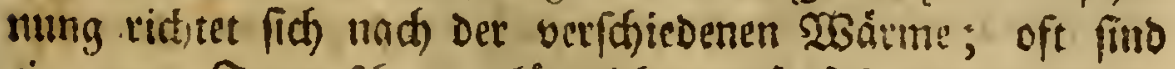
ciul paat Tage fofon zulánglich, Daß fich einige jeigut. Sie find aber anfangs feber roenige, nełmen aber an iţrer 


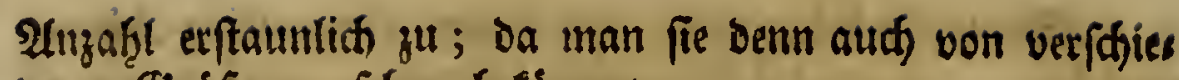

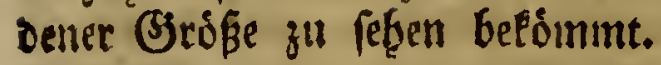

\section{Senveire.}

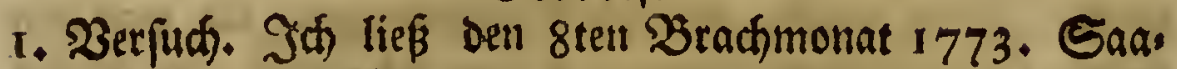

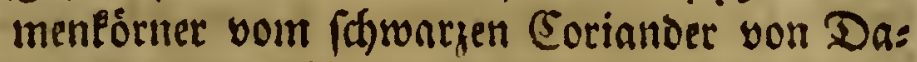
mastus (nigella damafcena) in gemeinem Brunnenwaffer weidjen. Şier finto bie Exs fheirungen.

Den I I, brad)te id einen Tropfert unter bas Эergróferungsglas, uno fand ifn bicht mit gan' unbe\{chreiblid) elteinem Staube angefúllet, ber aber taub und unberweglinf ba lag.

Den I2. nabim ich an biefen Staubldrpetchen eine belvegung waḩr, bie bod) nidjet felgr fanell war.

Den I3. wiefen fid einige grófere FĢierden. fonft war alles, wie geftern.

Den 19. Gatte Die großke Szikge, bie bamals war alles ausgetrocitret.

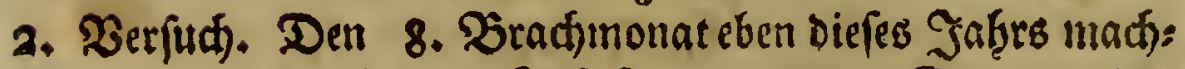
te id) eine Sinfurion von ben Snamen Des भdferbahnenfuffes (Ranunculus arvenfis). Man febe Gier Den Erfolg Davon. Den 1 I. Brachte id einen Fropfen unter bas DRifrofcop, oa erfđien er ganz didjt mit ungemein fleinen Staubtbeildsen angefúliet, Die alle Bemenungen madten, weldye aber nid)t befonters fifnell waretr.

Den I 2. 佸ien unir ifre 2 mafl vermintert. Den I 3, waren fie fefte zaf̧itreing.

Den 19. waren fie wentiger zablreid. (Es fans ben fid) auch einige grósere, aber feb̨e roenig.

Den 25. waren fle in einer febr gropen 2 angafl. 3. Bers 
3. Мerfuch. Den 22, פray infunditte idy den Srand bes Socfsbartes, ocr mid folgendes (ei)en liä. Den 24. liefen fir einige wenige Infuftond thicucticn fefen.

Den 28. naren ibrer mełurete. Es Eleften if. nen ant Eteiffe Somstugelden an, uno es gewann bas ?inferen, als

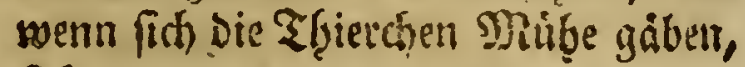
(id) Davon gll entlediger.

Den 29. nutuds Die \&nzabl. Mian faf bie Tfiertion mit frenem Huge mie Staubtheildhen, die fids an Der Some verfolgetr.

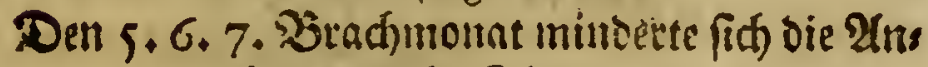

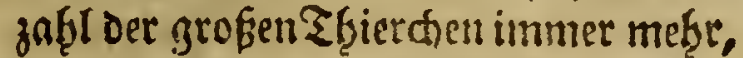

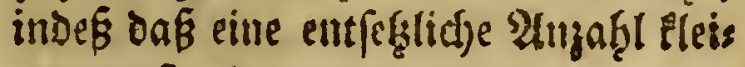
net entifand.

Den I I, saar Die 2lizaf̨l der leinen Thiterd)en nod) immer umgemein fare. (5inige wenige fanden fict ein, die von mitts lerer Girdse, uno mir feb̨e menige, die von ber volleommenen Sirofe was ren.

Die 21. Jigutr bee exften Tafel ift nad eitnent Diefer Sbierchen gimacht. Die (3)es ftalt Diefer Ifierchen ift zwar in ver: (a)jevenen Jinfufonen verfajieden, boch ift biejenige Biloung, die diefe Figur vorftellet, Die allergem!einfte. Die Durhfintigen Finge, Die id its nerbalb Des Reibes diefer Sbicrdyan entworfen babe, fino in Der 2tngabl uno Inreif̧ung bey verfhieberent Ibierden eben Decfelcen Snfufion verfficieden. 


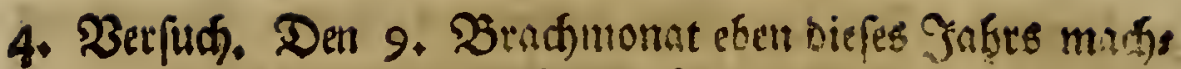

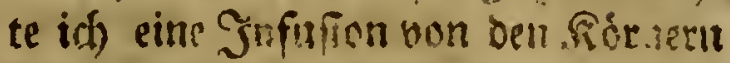
Des Becherfftimammd)en (Beziza lentifera), Dis now mitbt zeitig oa: ren, uno nor dav gallertige Mifer bes Sdywimmonens all fich hatt?n. Diefe Sallevte for unterm Sicrigrifges rungoglafe, wie eitle Conferle aus; es waren nåmlit Inuter verfás:edelits lich untereinancer gewumbene fóndur. Jyier fino bie (Er fdjeinungen, Die nit Diejer $\mathfrak{B e r f u d h}$ gab.

Den I $r$, war ein Tropfen, ben id unter sas

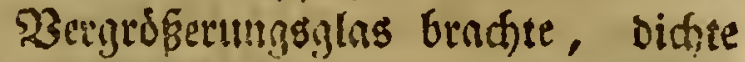

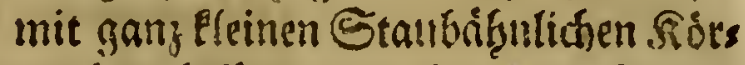
perdien befäet, bie aber feine Berves nutig frasten.

Den 1 2. Gatten fie Betwegung; id befam auth

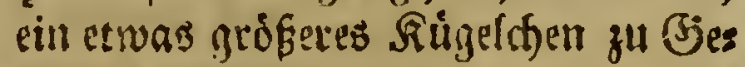
fichte. Die Sorvegumgen aber was ren nicht fithell.

Den I3. waren Die ganj fleinen TGGiercien uns

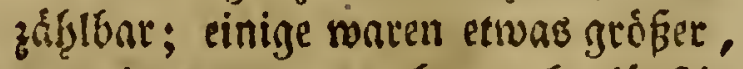
und eines oder zwey) fyatten Uenlåuftig zmen) Drittbeile von ber gerwisţnlid en Grdfe eines Эufurfonsthieudjens ex: reichet.

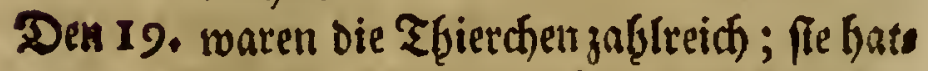
ten etroas an 2 Buchfe zugentommen, unb fielten fid meiftens in Şaulfen auf. (5i fanden fid) einige barunter, Die ben úbrigen an Ģróşe úberlegen

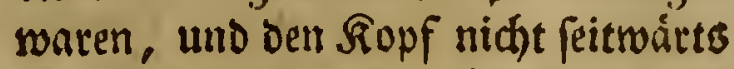
gebogen Gatten, wie ifgn fonft bieje

- FGgierthen thaben, fortdern if̧n getabe vor fid) bielten, Das if̧nen ein lángs lidetes $\mathfrak{A n f e g e n ~ g a b . ~}$ 


\section{Dritte 2(6houbdung.}

\section{S. 2 .}

2(116) Die Thiete unt ilyte Theile feltgen

Sufulionutbictden.

Was fid bey Infufionen alls dem פplangenteidie ers

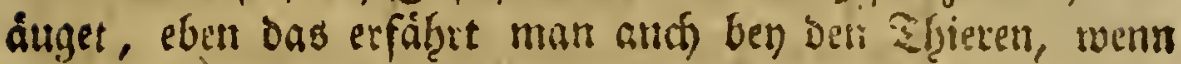

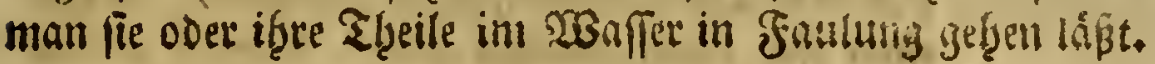

\section{3 eweile.}

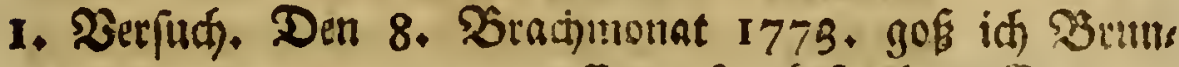
nennaiffer auf unbefruchrete (Ever Des Fichtenfpininers (Phal. Bomb. Pini), und erfielt forgendes.

Den I1. bewenten fich unzåglige munberlleine Ståubchen mit einar mittelmápigen (E)efdrmindigleit.

Den 12. Danterte eben diefe Erff feinung. Den 13. mard ihre 2 tnzaht vermindert. Den 19. war wegen der grópen Soitze alles vets trocent.

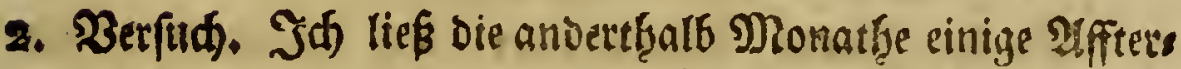
raupen, aus weldhen bie Frifilingsfliegen (Phryganeæ) entftegen, fammt if̧ren Sazaufers chen in ebendemferben unverintberten $\mathfrak{B}$ affer faulen. Sben auf bem 20 nferr. zog fid eine Shaut zufammen, welche ith mit ber Sprize siner Stectualsel megnabint, uno in frifores

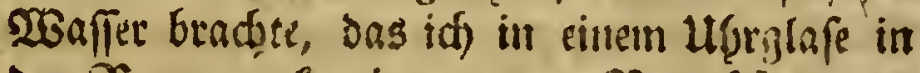

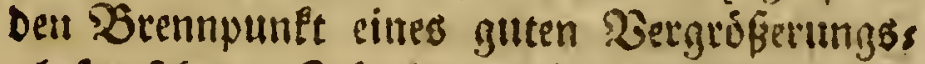

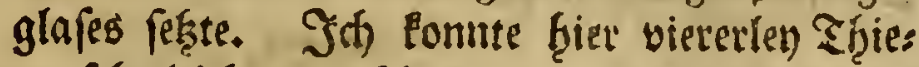
re febre leidft unterifheiden. Das erfer marents ganz Eleine Witumer, Die Den Ebaralter Der Sputlwitrmer in volfemmenfen Brabe bes fafen. Diefe SBirmer fatten Máfie fid von Der Sfaut lesjumtadben; fobalo fie fich aber int

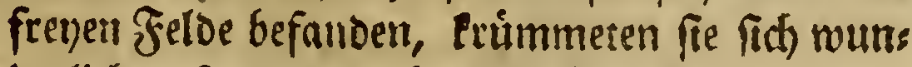
Derlici) jufaumen, ofgne den Det ju verándern, es fer) Denn, dap fie beunrubiget tourden. Die 


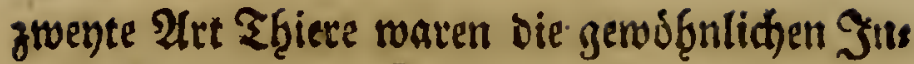
furfonstbierchen. Die britte waren fẹtre Fleis

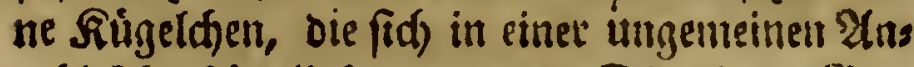
zafll febe fojnell bemegten. Die vierte (3)at:

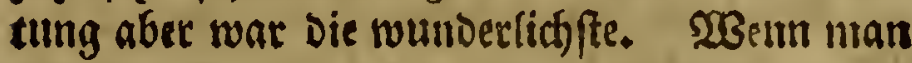
fid eine Stgampagnierfanfhe vorftellet, fo beat man fich einer jiemlich gutein SEegriff Daven gemadt. Fig. 22. Der 1, ₹af. Sie waren grófer, als die gemeinten Sunfurionsthierôn, uno Gatten an ber engern Seite Den אopf. Jịte Rórper ift ragerecht gufaummengedritaf. Sie fateinen find nach Belieben diefe Beftalt gebers. zu fónnent Detun als idh bes folgenben ₹ages

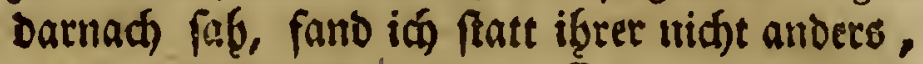
als lebendige und an benden Enden jugerundete 20alzen. Fig. 23. ebenderf. Fáf.

\section{Q. 3 .}

\section{Det Struls thut Desgleidhen.}

Da ber Staub, forwogl jener, Der fin unter frenem Scimmel befindet, als auch jener, welder in verifflofenen aber berwoghnten 3imunern erreget wirb, aus vegetabiliffser

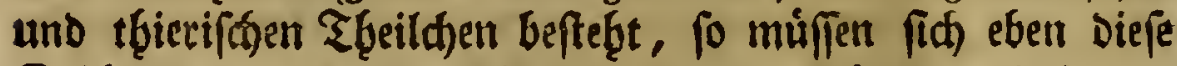
Erfcheinumgen in einem $\mathfrak{x a f f e r , ~ D a s ~ m a n ~ o b n e ~ e s ~ m i t ~ f r e m b s ~}$

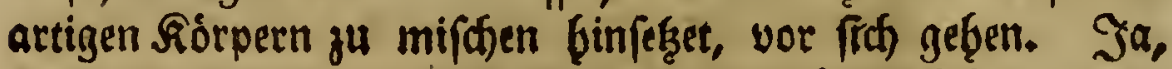
weil bas $\mathfrak{w a f f e r}_{\text {niemal }}$ rein ift, to misfen fid in einem

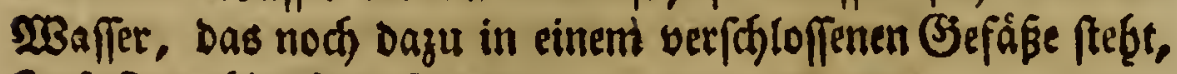
Infufionstbierden findelt.

3eweis.

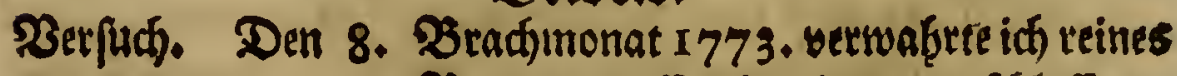
Brunmentwaffer in einem verfdoloffenen Brafe.

Den 19. naf̧m idf eituen Tropfen beraus, uno

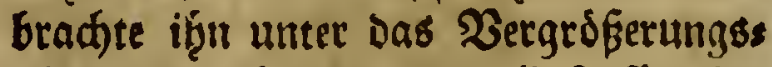
glas; oa id dant zwen limfenformige Zfoiete fanb, bie benláuftig ein Drittbeil 
5. 5.

Die Faulung tright gu ifter Entffekung ben, uno obne Derfelben entfethen fie gat nicht.

Diefe Tf̧ierchen entfteḩen nicht eber, als nadbem

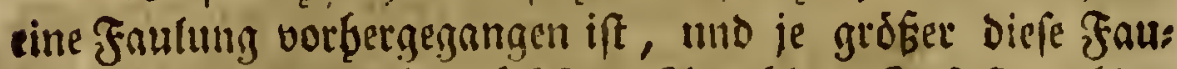

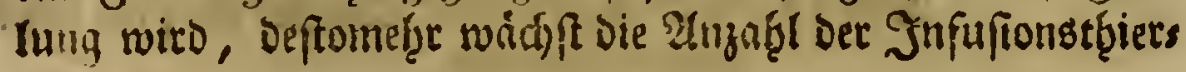
(f)en ain.

\section{Berweife.}

Frifd)es, elares Dutlwaffer, ober audh reines Bruths nentoaffer enthålt niemals ein einziges Srifutions: ţ̧ierd)en. Es mus erft citige Tage aufteroaḅret werben, Das ift, es mus anfangan faul ful roerden, che iman etwas gu (Jefidide beesdinmt, und autd Dann

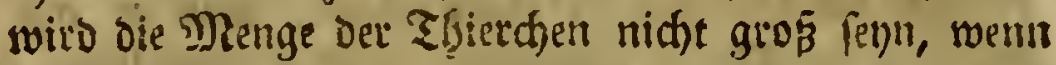
Das Gefáf́c rein ift, Intro wider Den Stanb beivafiret wiro. (\$. 3. 1. 20er.)

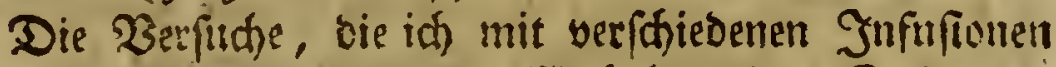

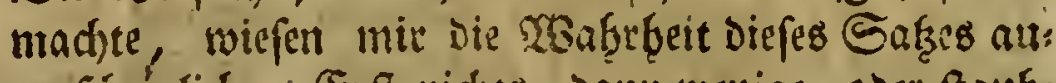
genfónentich. (Errf nidts, Dann wenige, oder faub:

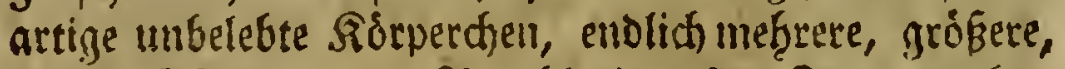

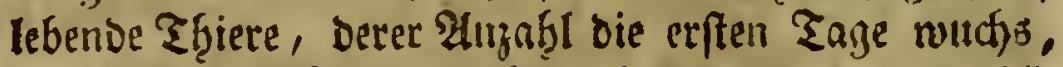

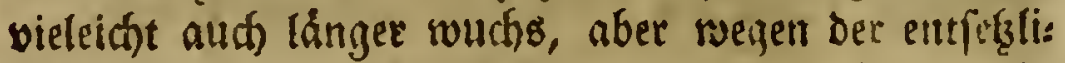

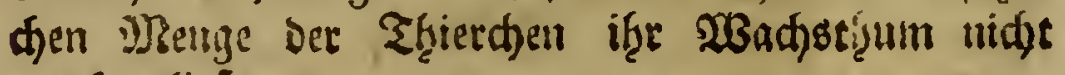
merten liȩ́.

\section{S. 6 .}

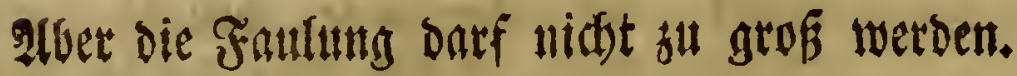

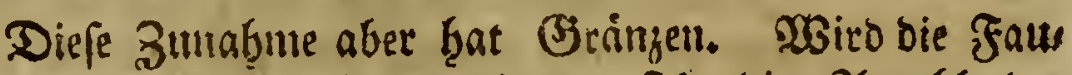

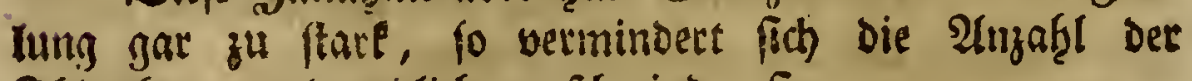

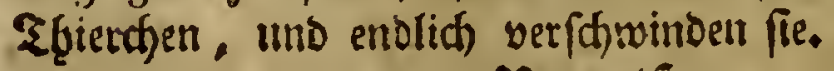

\section{כ̇etosife.}

Man Eann bies in aillen benen $3 e r f u c j e n$ finden, weld)e ith oben angefrifyet thabe, uno in taupeno ans

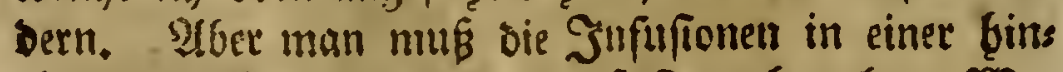

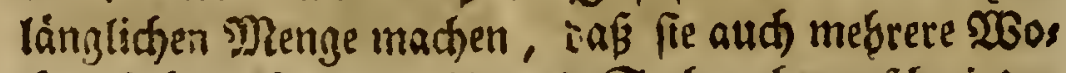

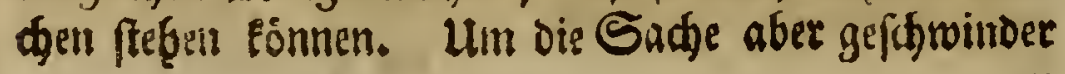


gu fehen, Darfunan nut ben $\mathfrak{B e r f u c h}$ mit Hrin miebers Golen, ben ids șll biefen Siele madte.

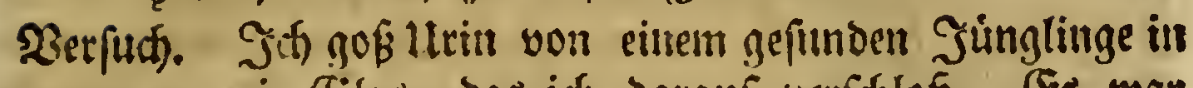
ein (jilas, bas in darauf verfalob́. Es war Det 8. Srachmonat 1773 . Da ith Diefes that. Den I I, Gratjte id Davon eimen Tropfen unter Das :3ergrópertungrglas, melder you

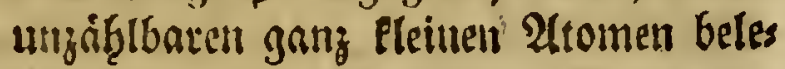
bet war.

Dan I 2. (âb id) tidfts mefil ; die Maffe aber firng an you ₹ay zu Tag unertrags: lidjer zu finten.

Den 13. 19.25. Unb 5. Des 2(erntemonathes fâ id) wieber batnad, aber niemals fonns te ich) ein Infutronatbier exblicten, ob, fajon bie Faultung bie ztwey lefitenmale fajon gropentbeils woruber war, indem bie Mlaffe nicht meb̧e fo ribel roch.

\section{\$. 7 .}

Sie fillo van werfhidenct alrten.

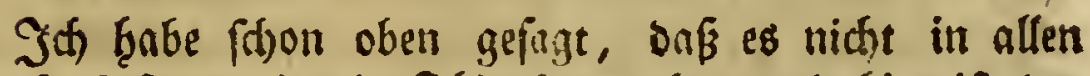

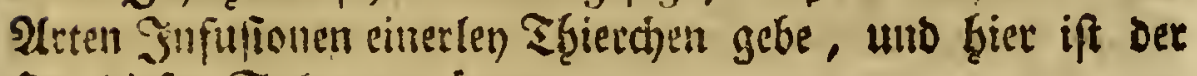
Dat biefen Sakz ju erórtern.

Die gemeinfte Art ift Die, Die man in ber Jnfufion Des Grandigen Borfsbartes entoecfet, welche alif Der 1. Fa: fel in ber 2 r. Figur abgebildet iff.

Fine von biefer gang verfíhiedenen 2 (rt ift bie, bie id

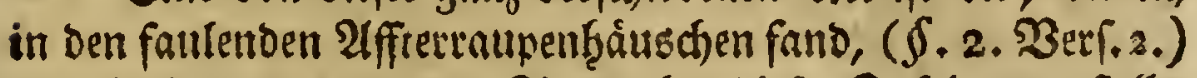
uno in ber 22. uno 23. Figur eben biefer Tafel sorgeftellet Gabe. Slun folgen nod) ein paar 2urten, bie ettoas gan: befonderes Gaben.-

Sक) nafim (S) Segieffen bereiten, Gradte es in einem Ubtglafe lunter Das 23eigróberungsglas, uno fano Darinnen eine Alt Thierden

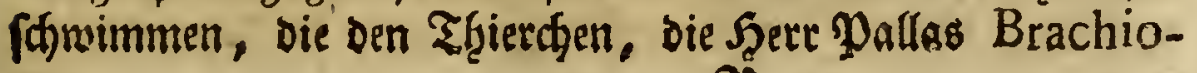

$$
\Re_{4} \text { nus }
$$


nus campanulatus nemuet, ganz åthntid, aber viel fleiner waien. Sie keftanben nämlich aus einem glocfenfótungen

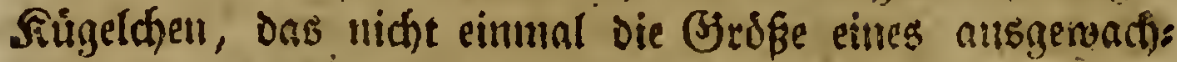

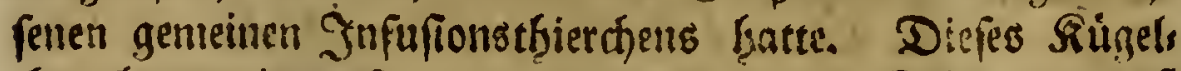

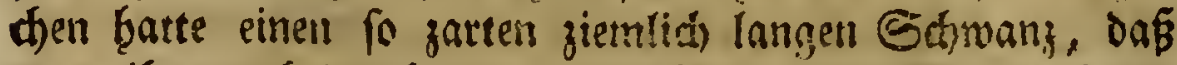

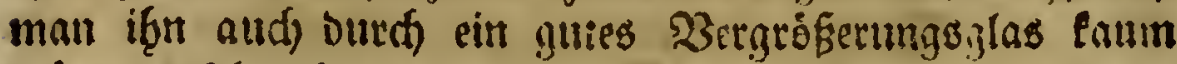
sourde zepenen baben, menn niche meiffentbeils an feitre

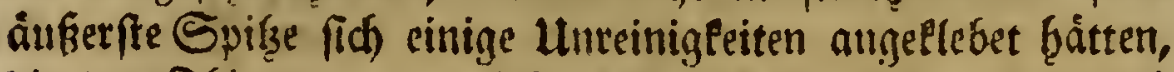

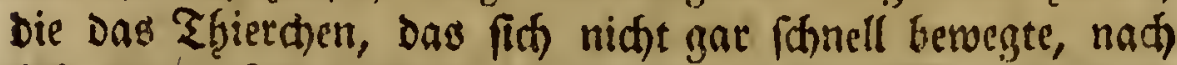
fich 30g. Seine abbildoung Gabe id anf ber: :. Tafel in Der 24. Figut verfud)t.

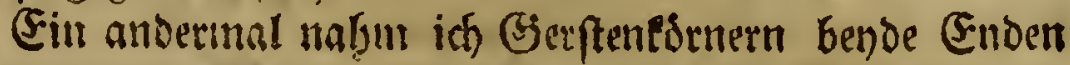
finney, legte fie barauf in 5 stunnennoafer, und lief fie einige Tage weiden, bis id mit blopent 2 unge einell weits

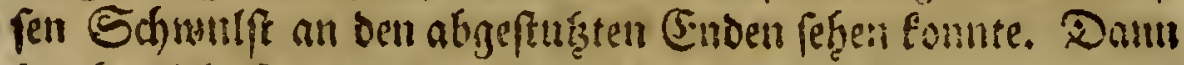

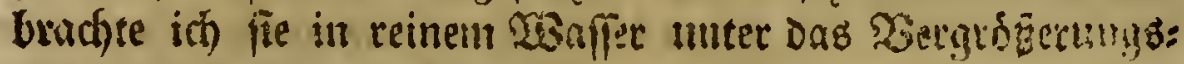
glas, ons midh alfogieich been verfofievente Dinge lighn

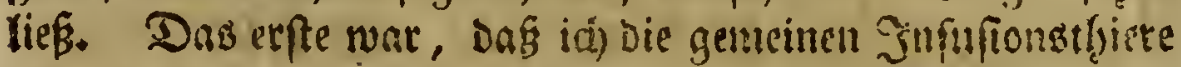

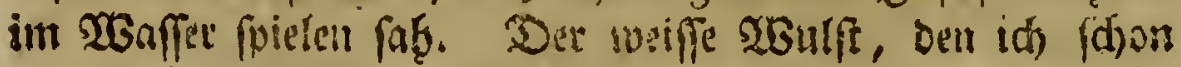

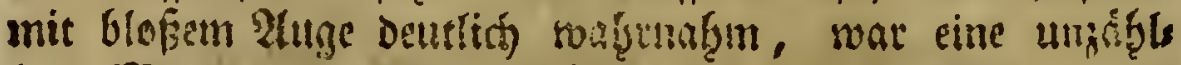
bare Mlenge gang fleiner Sirigeldan, bie butroh ein galler:

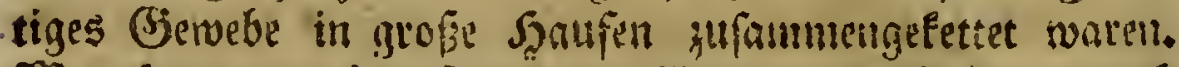

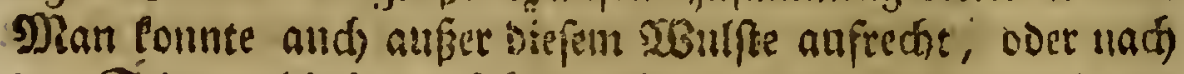

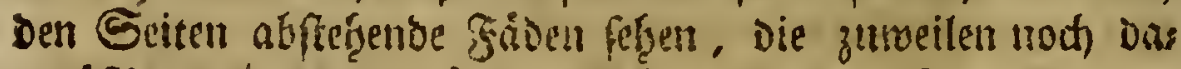

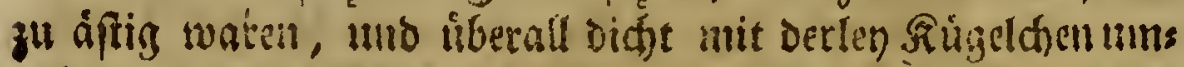

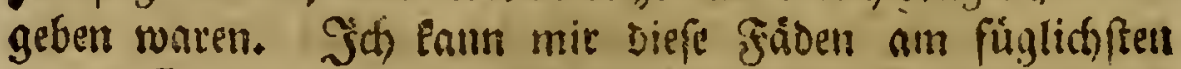

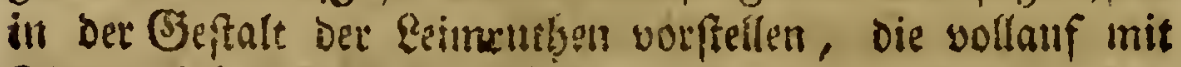
Fliegen beţangen find. Nian nafem Daran firt fid Pein

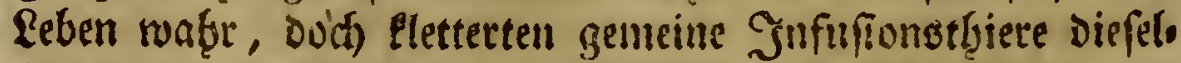

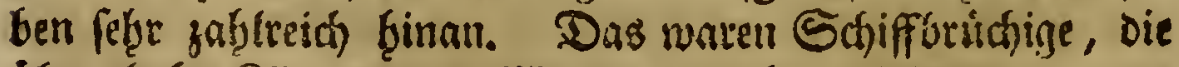

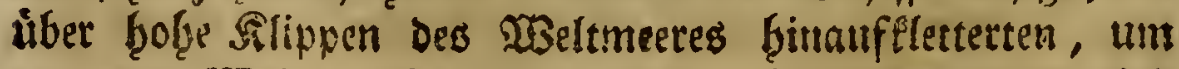
von ben şsellen gefichert zu fenis. Soer es raaren viels

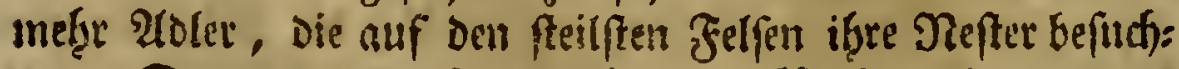

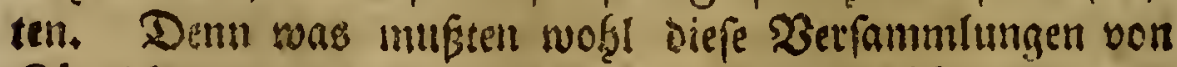

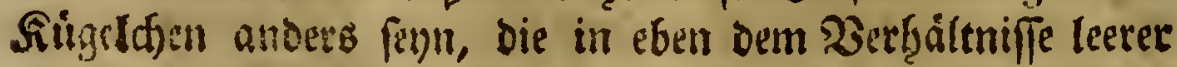
renroen, als die Jufurfonsthierchen, ober bie frecinen lebens 


\section{Dritte 26bandrung.}

Den Rigelden, bie erft zu Snfufionstf̧ietchen auswachfen

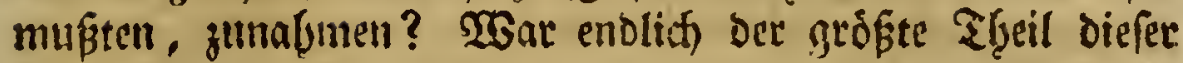

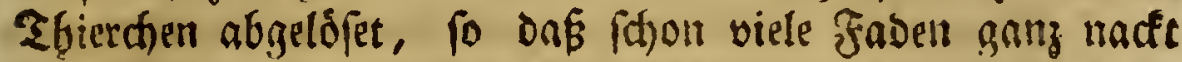
Da fanden, To war bie Amaf̧ der lebenden Sírperchet

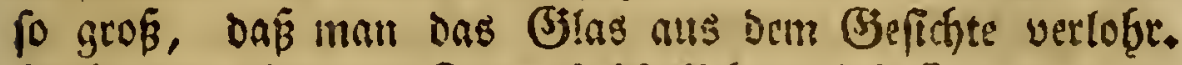
Ditht nur aber am Forne felbgt fleben diefe Eammlungen son werdenden Jufuftondtfierchen, fondern fie firigen auta

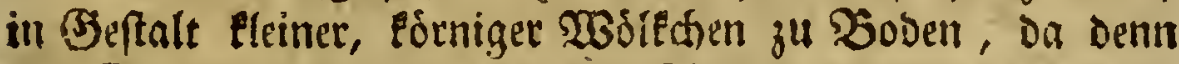
Das (Silas bicht un fie feer mit Firmern bedect ift, Die bas von ab́giengen.

Das fonberbarfte Jnfufronstfiter aber war eine Irt 2firserpolypen. Bleich Alnfangs, Da ich Davon Didsung thue, bitte id), man wolle mich fice feiner Unvorfirhtigs

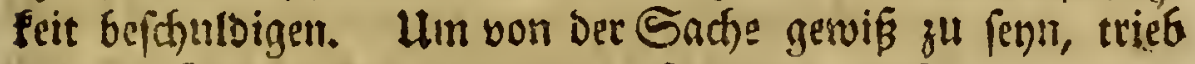

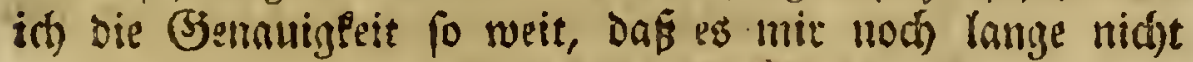
gemug war, ben ganzen Şerfudh in alnem woblgereinigten

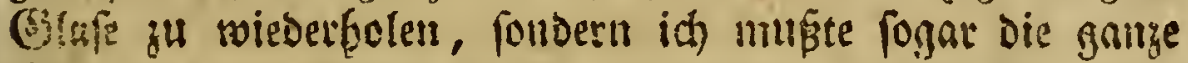

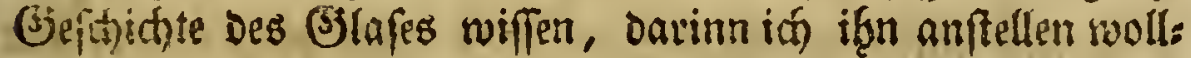
te. Da ich emrlish verfichert war, Dafs in biefem sslafe niemal detlensbaffer gewejen fen, das glolypen beroobuen, Damala eaft alaubie idos, oấ fie bey Gielegenteit Der Jins fufion entftanden jenn. Diefe afficerpolnpen figen eingeln any mistelmáfigen Stielen an dem Sorne. Sie find 0 Flein, Daßi man fie mit einer gemeinen Linje gat nicht, und

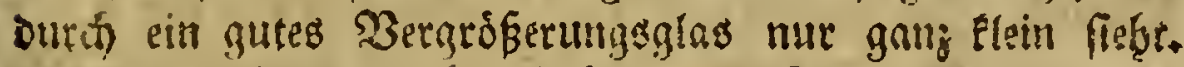
Loenu der polnpe rulst, fo flat ex die Figur einer Rimonie;

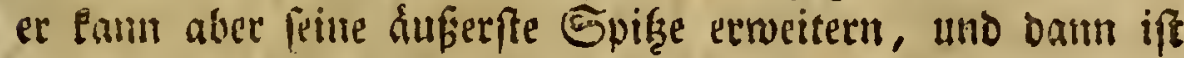

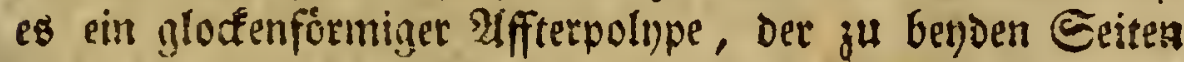
Der Deffmuny eurge Shorner Gervorftrecfet. Es ift vibrigens

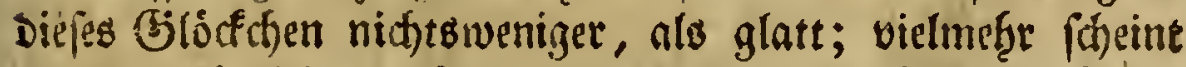

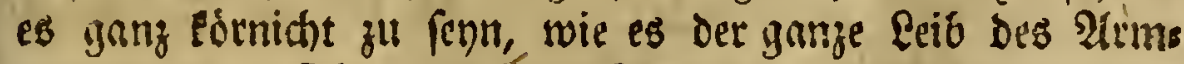
polypen ift. Jlye gemeinfte Bebregung beftergt barinnen,

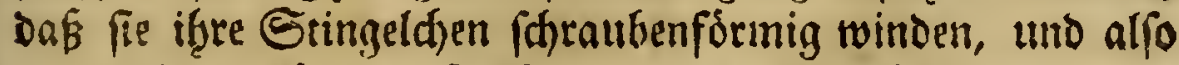
ungencin verlárzetr; fie then aber diefes feber fónnell, uno

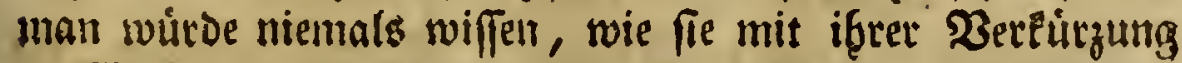

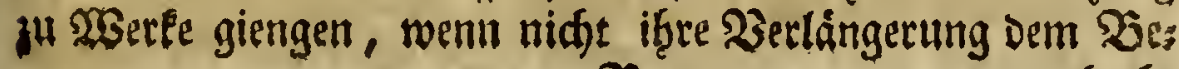


Dbadjter mebr Beit liefle. Denu damals fieb̨t man bie Sdjraubengánge fegre deutlid).

Eben viefe Erifheintungen gab mir die Snfution von

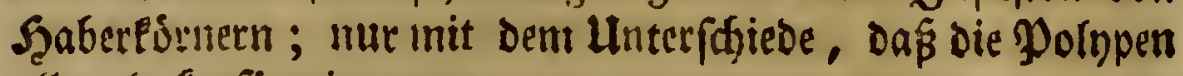
alle glodfenforming waren.

$$
\text { 5. } 8 .
$$

Die gemeine Sibe fit)abet ifmen nidt.

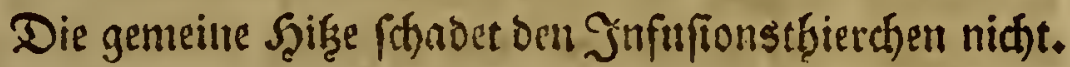

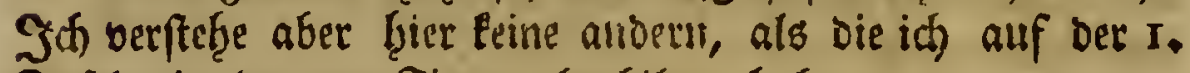
₹afel, in Der 2r. Figntr abogebiloet ţabe.

\section{3 eweis.}

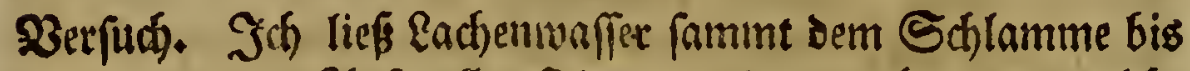
zum Alufwallen fieden, uno verwafirte es etweldhe

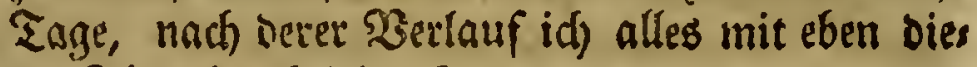
fen Thierden beleget fand.

\section{§. 9 .}

Sie fint nidbt in allen thierifoten and pfantenartigen Misefen jugegen.

Die Regel, Dali die thieriffen Sidrper, und die aus

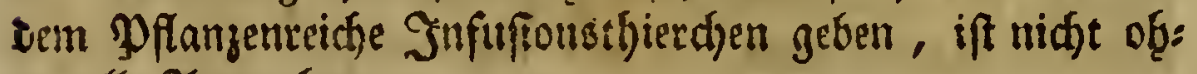

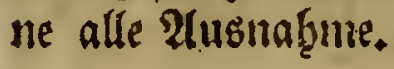

\section{$23 e \mathfrak{s e i s .}$}

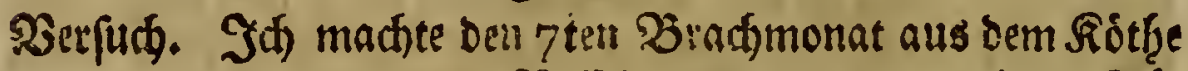
Der Dornigten Dieffeltraupe mit Den weiffen Rius den, Daraus Dat weiffe ce esmmt, cinte Infits fion yerḩưllte bas (J)las wiber den Staub, und fab bent $8,9,10,11,12,13,12,25$, fleifs fig darnad,, befam aber niemals nur das mins Defte zu Eefithte, Das id für ein Snfufionss thierden Gáatte Ģalten fónnen.

$$
\text { S. } 10 .
$$

Anmetungen und Folgetungen.

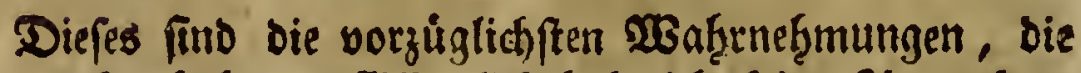
id) gemaḑet ḩabe; geflifentlich babe id teine 2(mmertuns 


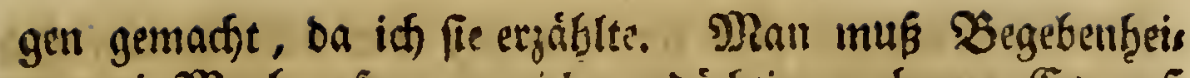
ten unit Mutbua aber aud) erlaubet fenn tiber eine lange Dieife von richtigen

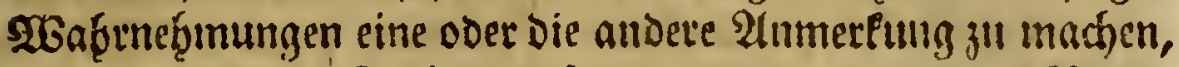
die entweder die Sadjen exláutern, oder zu weitern ßerfiu deen und Beobad)tungen Rular geben fómute.

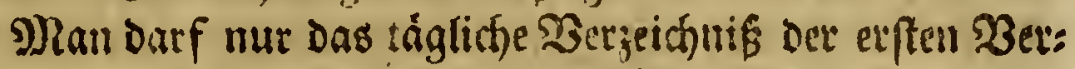

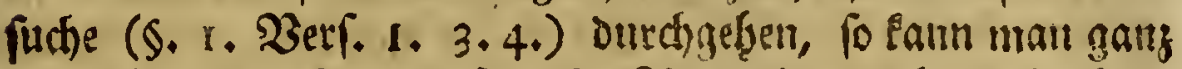

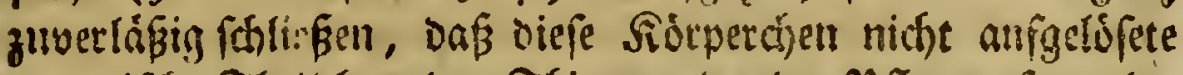

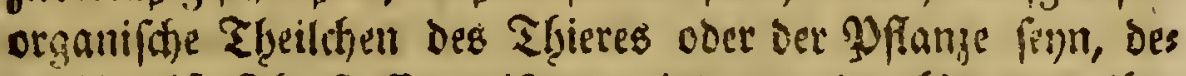

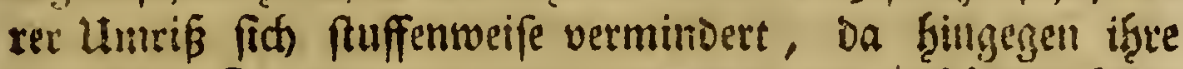

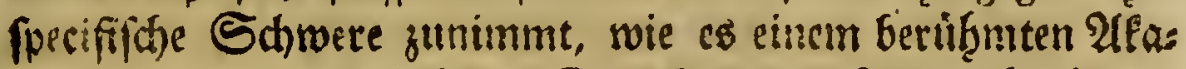

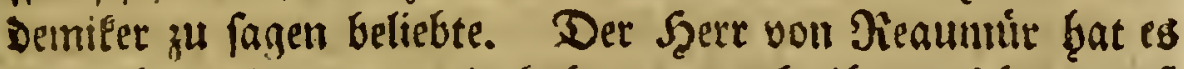

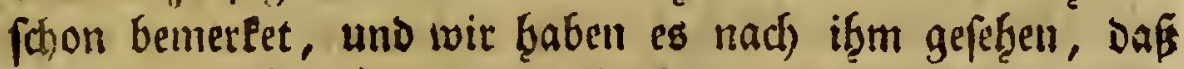
alles fo zugebe, wie fonft; die fleiten werden gróz, wenn

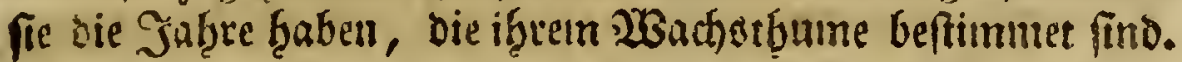

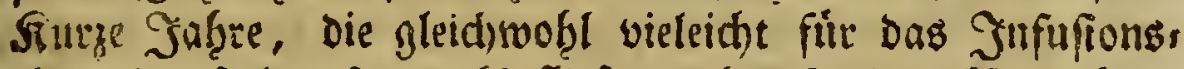

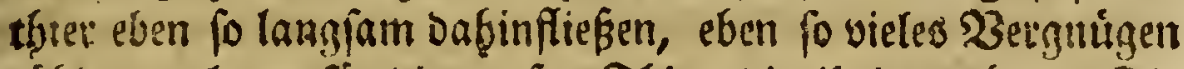
záblen, als es für Die grofsen Thiere bie ifrigent thun! Sie soachen alfo, Diefe Snfuigonsthietchen, uno fich bavon zu úbergeugen Darf man une petbit Sufufionen machen, und

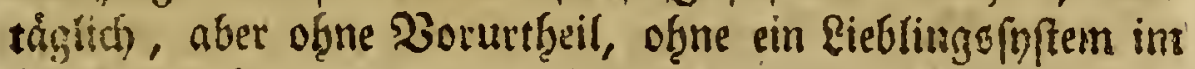
SБแ

(Es toad)per aber nicht aller Sufufionen Ffiere gleid

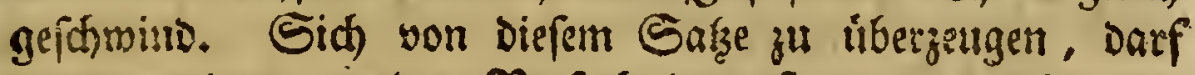
man mur den 1, uno 2, Derfind Des erften $\$$. gegeneinander Walten. In einerlen $23 a f f e r$, bey vollfonmen einerley $2 B$ ita terung find bie einen noch leblos, da bie andern fachon muns ter ill igrem Elemente fpielell. Sino es verfobiedene $\mathcal{A}$ ts ten? Zwar fheint ifgre Bildung fowohl als if̧e D?atuse einerlen zu fenn: aber fann man diefes ficher bef̧anteten. Daßs fie aluh in ber That einerlen fenn? Soer fino vielmef̧r

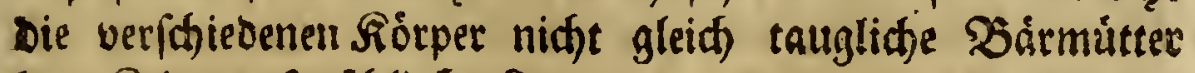
Den Sieim aufzulchliépen?

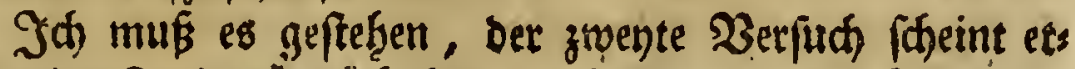

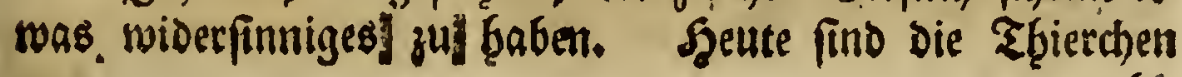


zaflreina, morgen find fie es nint, uno balo barauf finb

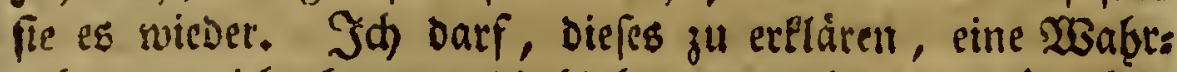

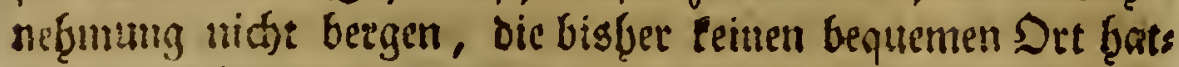
te, cingegda!tet zu rerben. The einem jeden warfer, in

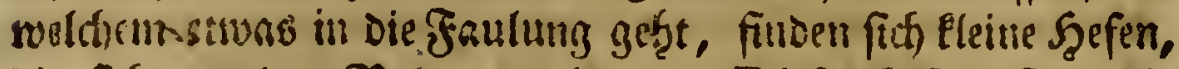
bie fir an den Boben antegen. Diefe Şefen funo die

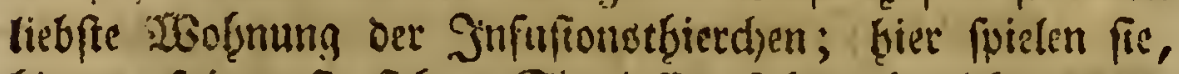
bier verforgen fis fids). Sie laffen fid antion nicht anbers Davon yettreiben, als wenn mant isten ife:e lieben Syefen neeguimmt. Uno diefes ift aud bie Utract)e, warum man

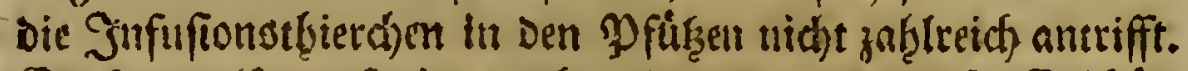
Es eaut alfo auf eine mefer ober meniger grefse Erfohits

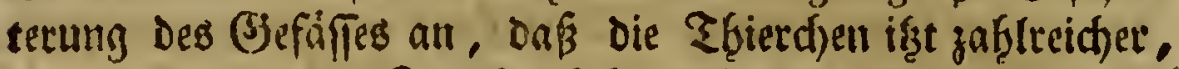
ilst feltener in bent Tropfen fich einfanden, Den ich in ben

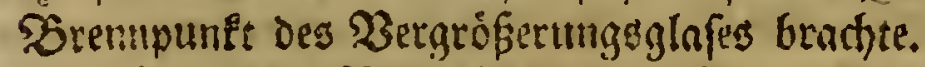

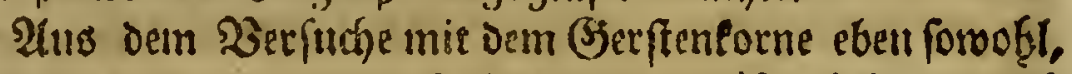

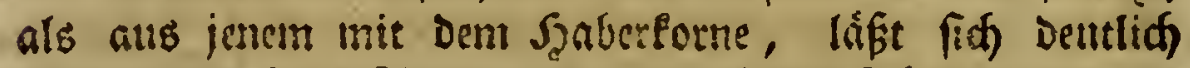

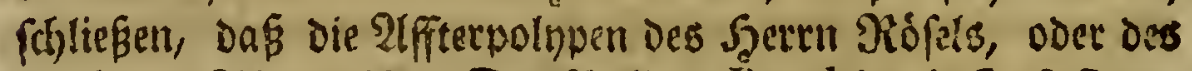

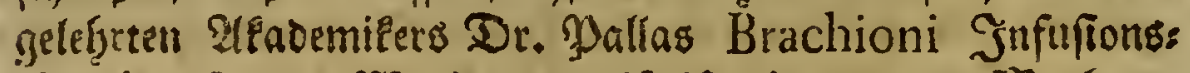

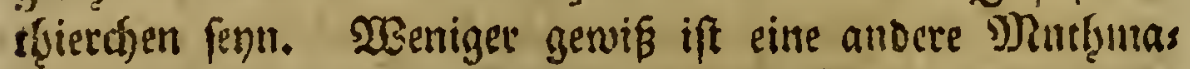
Bung, of bie gemeinen Snfufronetbiere Sifferpsinpen fetn. Mit Der Hydra ftentorea Des Ritters vou Rinuee fonmen fie ziemlid) libereitns; eine Eercheinung, die die Snfurion mit (Sterften: ober Şaberforne gieft, (theint Die Sadje

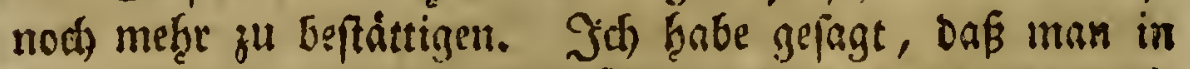
Diefen Sulfufionen auser Den 2 ffeerpolnpert uno Den gemeis nen Snfutronstbierchen, now eitre פlenge lofer, gang Eleinee

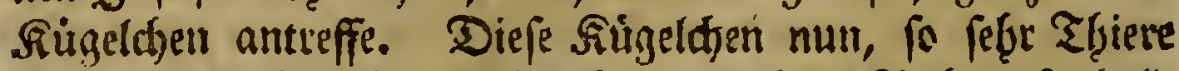

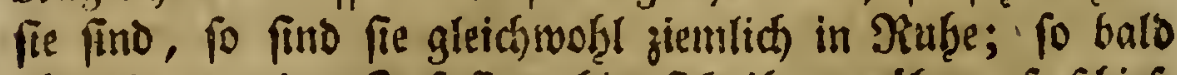

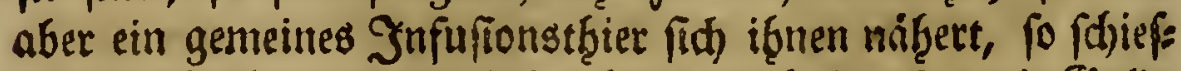

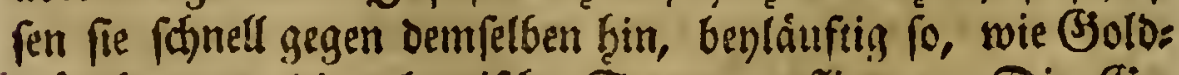
brättchen an oie electrifhe Stange anfliegen. Die Bjefotwinsigleit aber, und gar oft die ganze Betwegung, bos

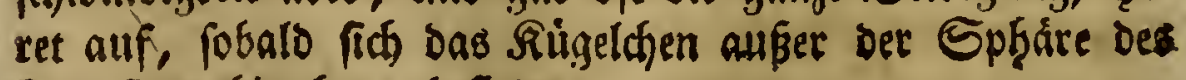
Infufiensţ̨ierdens befinbet. 


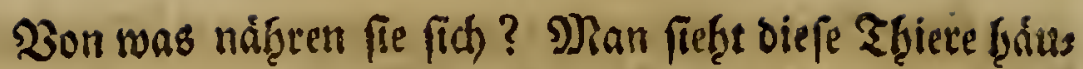

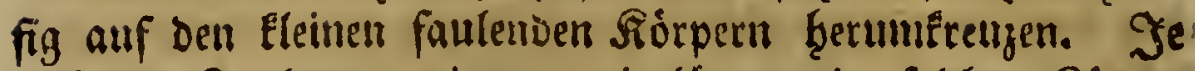

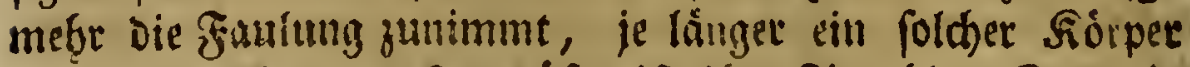

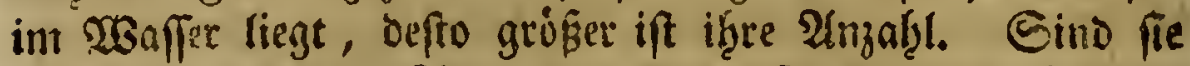

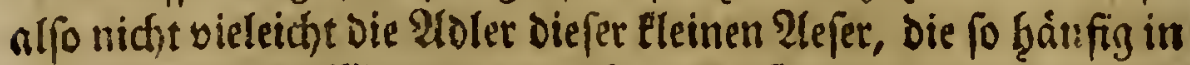
jeden fetenenden 2 affer fenn múfen? Simo fie es, fo fahrint

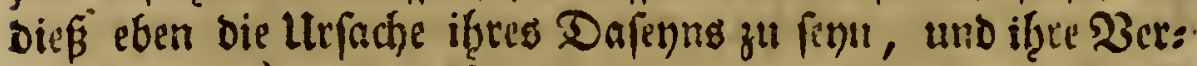
riç)tung if gerwiffermaken fo widtstig, indem fie uns diefe fleinen Ecionnalime weglánaffen, als es jener ber Raubsojgel ift, dás fie bie to libet ried)enden Sheujale bingefallener

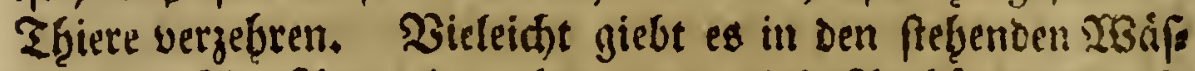
fern eine 2lrt Kegyptier, bey Denen biefe Rodgámen eten fo beilin fint als es die walgren ben ben Alesyptiern unter Den Menftgen waren.

Woie fterben fie? Man båtte noch eţer fragen posnnen: wie vermeb̨ren fie fich? 2(ber fowobl bie cine, als bie andes re Srage tann man mit Peiner erweisfichen $\mathcal{A}$ ntwort erwies Dern. B̧ebábren fie lebendige Junnge uno Ener zunleich), mie Die Yolnpen? oder zerplafen fie mie die Staubjatroimme (a)?

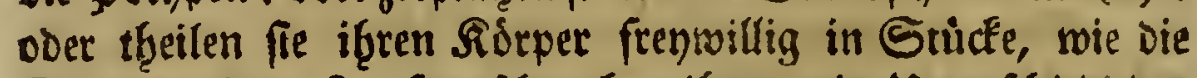

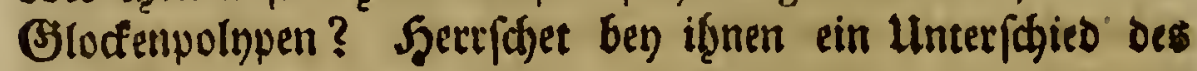
(Gerdidechtes?

\section{S. II. \\ Med)anif Des Sd)wimment.}

Nod) iff die Medfanie des Sdimimmens ůbrig. Man fief̧t an biefen Tftieren Durdh Dic beften $\mathfrak{B}$ ergróberungsglås fer nid)ts, beffen fie fich in Sthwimmen bedienten Pönnten, und bennod verricten fie diefes mit fo vieler Rebbuftigleeit

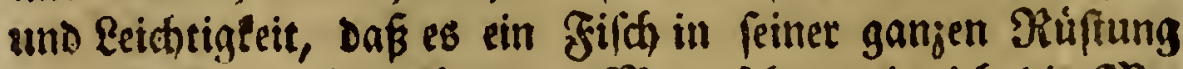
nidft beffer madjen fónte. Man feg̨e, rwie id bie פhe: d)anil biefer Thiere Dabery begreife.

Sie

(a) Eine Sheobadtung, Dic einer Der erfen Naturfenner

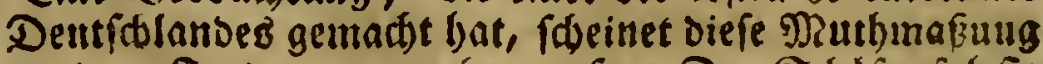

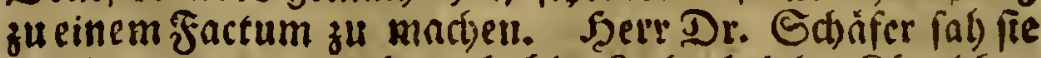
zerplaben, uno aus ibrem boblen \&eibe belebre Rügelder berbortomunen. 
Sis futs linfenformin flach, bas ift, fie furo obet

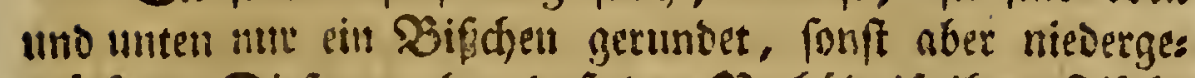

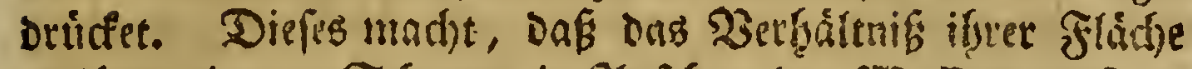

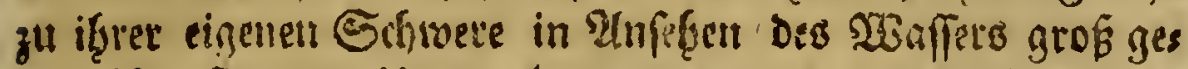
nuly ift, fie voun lintergeben all errettell, Das aber gleid erfolgen ming, folialo fie bie flád,e in geringften vermints

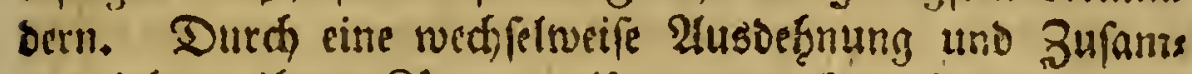
mentiek̨un ifores Sơrpers alfo werden fle auf uno nebee fteigen. Eckst man nut, baf fie verfhicbene Theile if̧ris

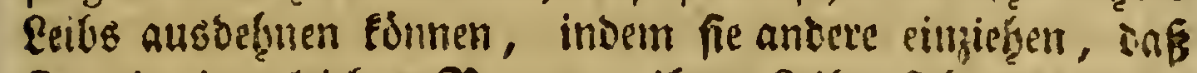

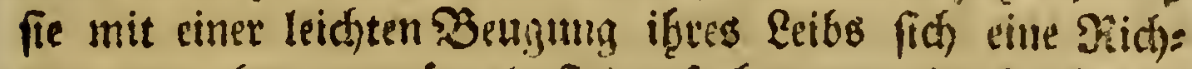
tung zu geben bermogueno fino, fo fiat man eine frudgtware Dotelle nod) fo zufainmengefézte Berwegungen zu erfláren.

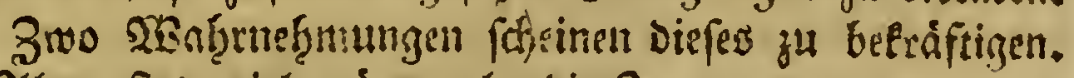
Die R̂tten fino viel träget als bie Sungen, uno bleiben meiftens auf rem Boben; bas ift, ifre Motuseln, ifre गerven find unbieglamer gerworden; der gange Sidper hat eine Fefitigeit erlangt, Dis ju fo feinen Bemegungen gaub untauglich ift.

S'wentens, soenn man in ein reines STlos, bas unen

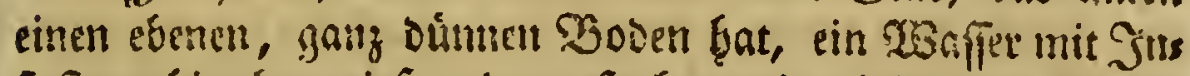

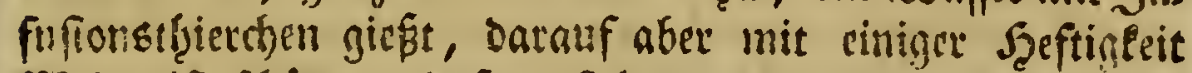

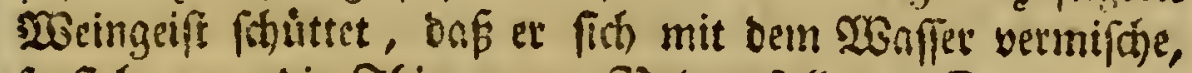

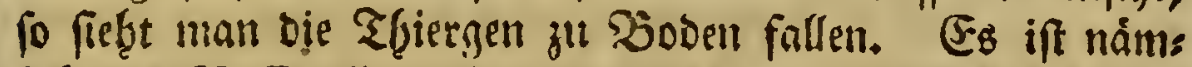
lid Das Naffe allzugering geworden, alo es if̨re fpecififhe Sdywere ettragen eann.

\section{IEbondling. \\ Beffosteibung eines Slafenfuffer. \\ Thrips flava, alis albidis, genannt. Tab. I. Fig. 25 . 411026.}

3 ie Rarbe bailt fich auf ber untern Seite ber $\mathfrak{B l a t t e r ~ b e r ~}$ Taubneffel, bes Rebenftocto, oes నogelfirfonentaums, Der Şafelftaude, befonders aber auf den Blättetu ber Bren: neferl, 
ueffel, Diefer furchitbaren Sheimath fo vieler mingiger SHIfets ten, auf, nicht hampenseife, fondern ganz einzeln. Sie ift imeiftens rufigi, und reemu mran fie bertibtet, fo láuft

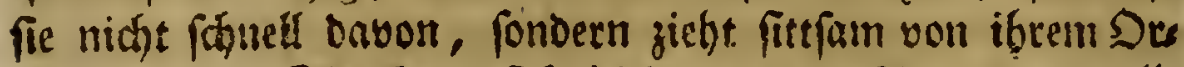
te hinweg. Sie faun fich leidht und geidhrind an alle

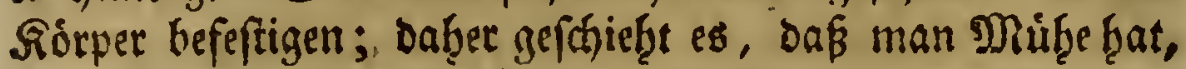
fie auf einen fáwarzen fideper afyufretifen, um fie unter

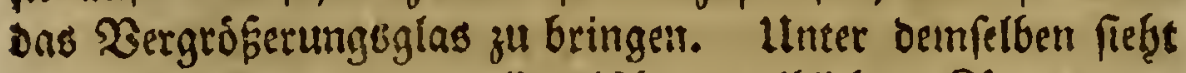

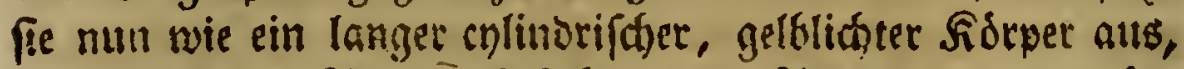

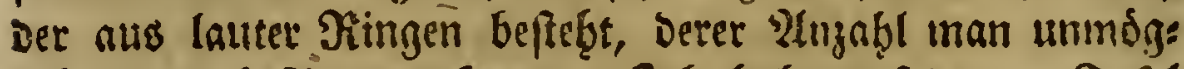
lich) genau beftimmen Eann. Sob Gabe nuf Der I. Safel Der 25 . Fingur verfuct) biefe \&arbe abjubilden. $a$ ift Die

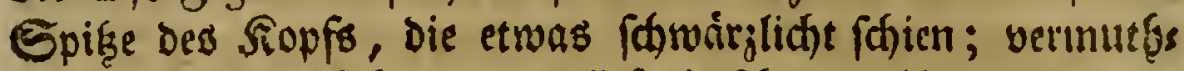
lid) ift fie butedsfichtig, und liés bie fahmarze Unterlage, die

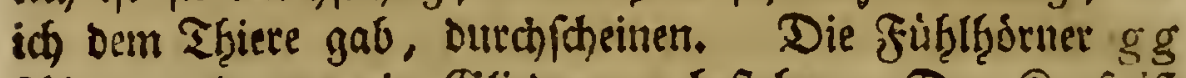

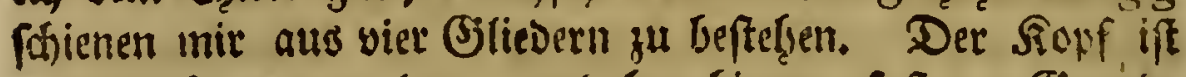
(n)(indrifh, etroas lantg, unb bat binten, faft am Grunoe zroen Angen $b b$, cintes auf jeber Seite, bie in ber Sonne ein fifón lafúrtes Earmefinroth vorftellen. Dann folgt Der Sheil, Der ben Dem Jufette die Sorberbruft ausmin: den follte, mit feinen zwoen Friffen, nach bicfem die Sins terbeuft mit if̧ren vieren. Der ganje Fidrper ift voll Pii:ss ge, aud) biefe Theile; aber man merlet es ibunen gleichs

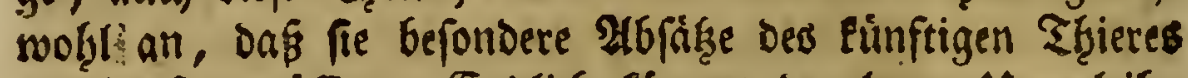

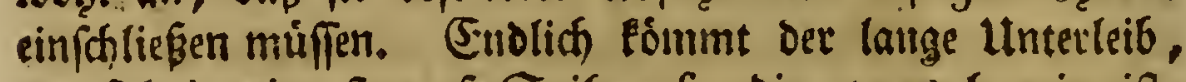
Der fid in eine ftumpfe Spige of, bie etwas baarig ift, endet. Die frúfe beftefyen aus bren Stliebern, und haben am Enbe eime fharfe Spifge.

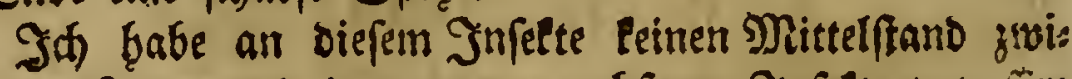

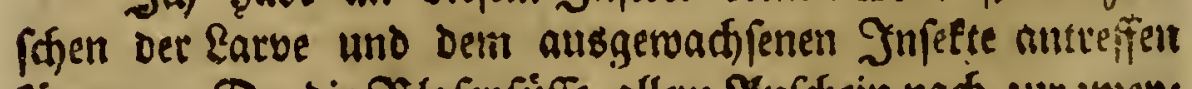

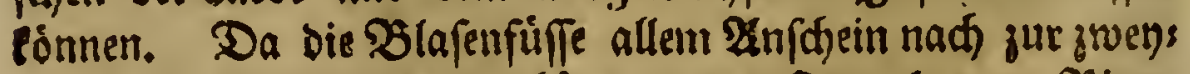

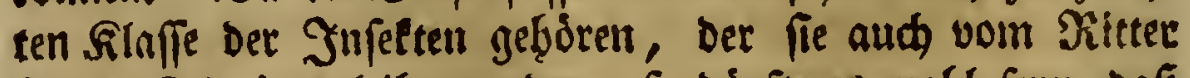
Einnee fimb einverleibt worden, fo durfte es wobl fenn, Daß fie (id) nad) uno nad) in Das vollfommente Infelt verwans

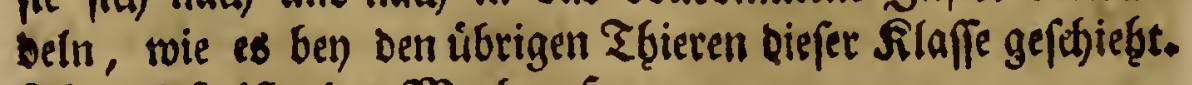

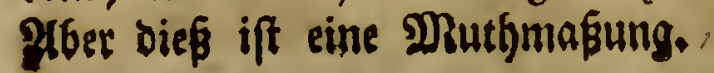




\section{Finfte erbandiung.}

Das altogemadtene Jufeft ift blapgelb: feine Fibbls

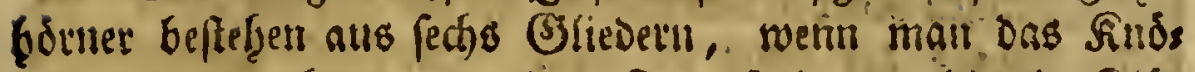
pfden baju reduet, aus beur fie entpringen; bie vier flus

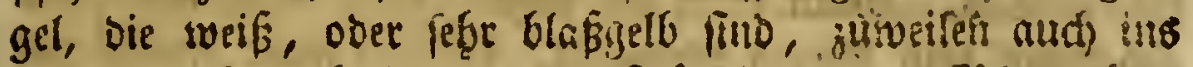

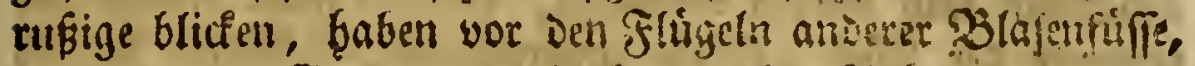

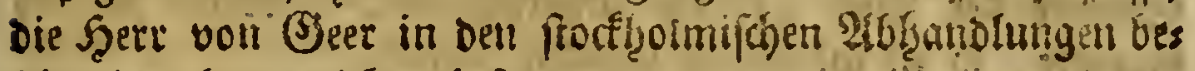
furrieben bat, nió)ts befonders.

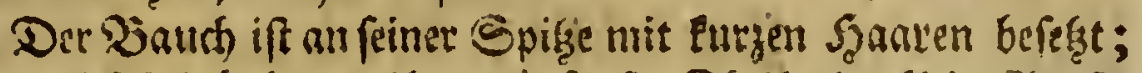

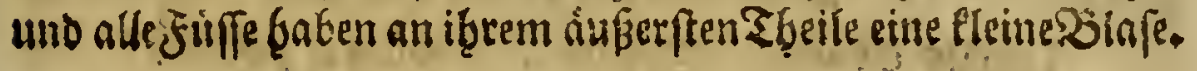

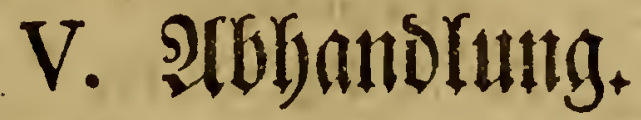

fortfetzuting

Der Seftereibung Der Miflben.

Eilfte $\mathfrak{A} \mathfrak{x}$.

Acarus ovatus hyalinus, nudus, pedibus omnibus æqualibus.

Tab. 1. Fig. 27.

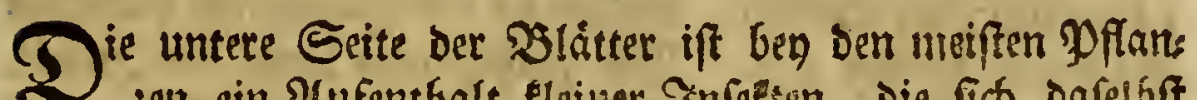
jen ein Iufenthalt Eleiner Snfetten, Die fich dafelbft lieber Derowegen anffialten, meil fie von Den Sommenftras

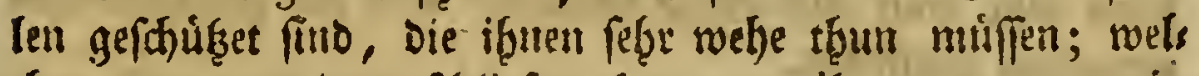
des man aus bem fhliesen eam, weil, went man cill Slatt auf der untern Geite von Der Soume befoseinen läpt, fie fich balo gu berwegen anfangen, oa fie fouft ganj fitle ficen. Dabey Eann nod) cine Urfache mit fenn, baf bie Slatter an oiefer Seite cauber, uno barun ungefdidter find, Daf Dieie Tbierchen fid) Daran feft halten Eanusten.

Die 9) lilbe, die wir in Gegentwart beff,reiben, ges 6ort unter "Diefe $\mathfrak{A}$ rt Jufelten, uno wit werden beffer unten

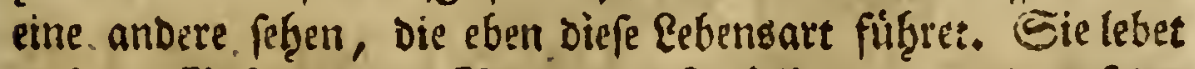
auf Den Sláttern Des Birn: und 2 pfelbaums, und auf bes nen vom: Jobannsberenftraudge. Sie bat einen blafien 


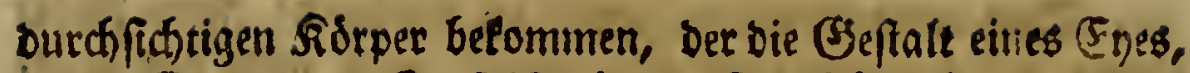

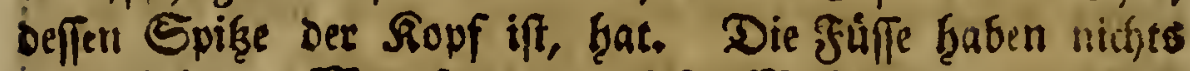
jonderlidies. Man fann an diefer Milbe nid)t unt teine Shdärchen und $\mathscr{Y}$ ungen entbecfen, fondern nicht eimmat die

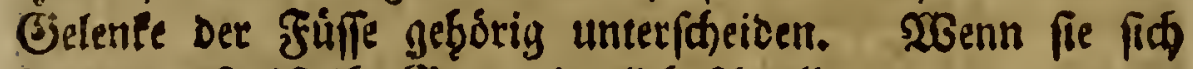

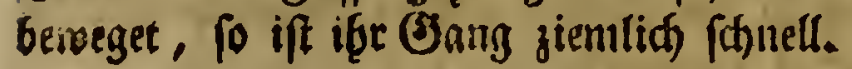

\section{Swif $\mathfrak{d}$ te $\mathfrak{A} \mathfrak{i}$ t.}

Acarus ovatus hyalinus, fetofus, pedibus fubæqualibus.

$$
\text { Tab. 1. Fig. 28. } 29 .
$$

In ber Gartenerde, befonders in SBlumentofpen findet

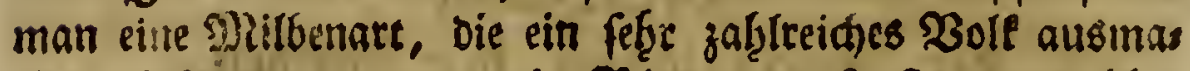
chet, befsneers, wenn ein BSlatt oder fonft etwas víer ober unter Der Eroe faulet. Sie ift etwas gróser, als bie yorige 2 int, jcood ebenfalls feb̧r tlein; der geib ift enförmig blä́, uno ourdyfid)tig. Bon aller Seiten fergen in einer faniefen Kiditung lange Szaare empor. Die zwen yordern Paare der friffe find etrons bider als die andern, uno frat jeder Fú funf Slieber, weld)e an Den Fugen mit einzelnen

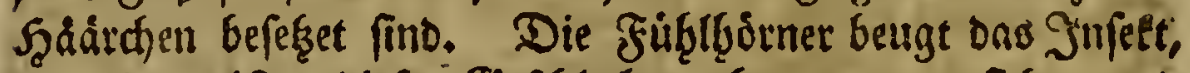

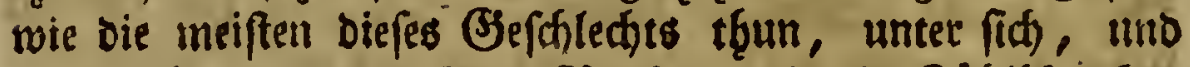
bann fief̧t man eine lurge Borfte, wie ein Futhlfgórndjen vorwátes Gimfegen.

Die 28. Figur bild et ein foldjes Jnjelt ab, wie es ausgemachfen ausfieft; ba berentgegen bie 29. Figur ein Junges vorftellet.

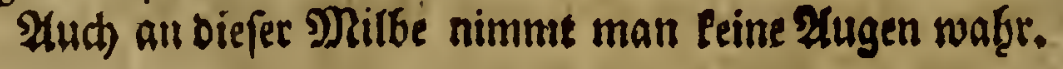

$$
\text { Srengehte } \text { Art: }
$$

Acarus ovatus ruber fetofus, pedibus æqualibus undique fetofis.

Acarus Baccarum. Lin. Sys. Nat. pag. 1025. Lin. fn. fu. n. 1280.

$$
\text { Tab. 1. Fig. } 30 .
$$




\section{grünfte Ablyanding.}

Die gegenwántige rothe Milbe ift viermal grofer uno fichtbarer als die zwo vorbergehenden 21rten. Gie Gat vieles mit ber $\mathfrak{W a}$ ffermilbe (Acarus aquaticus. Lin.) Ino mit oer fammetartigen (Acarus holofericeus Lin.) gemein. allein fie ift ob̧ue Bergleidy Eleiner als Diefe, nich)t fams metartig, fondern gans glatt, und bat auffethende lange Sorften. Sefoniers haben die füfe ein romberlides 2ursfeben, wenn man bas Jinfeft burd ein Bergrófferungss glas anfiegt; Denn ibere faft geraominílicht an jeoen (Ses lenfe abftehenden Stadjeln bezeichnen Das Tojier fo febr.

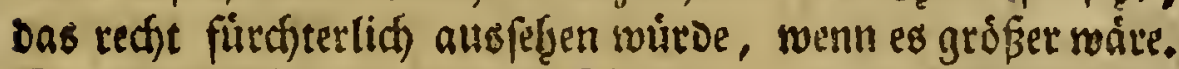
Sic llebet ferge feft an bell horpern, auf die fie fich feget; fie ift aber um Defto fóneller, wenn inan fie eimmal von itrem Drte vertrieben bat. Sie ift febr gemein, uno bält (id) an alten Stammen, in Stauben, bejonbers auf bem Sohanngberftraudje gerne auf. Diefe Art bat poieder fidts bare fdroarze 2lugent.

\section{$\mathfrak{B} \mathfrak{i} \mathfrak{e} \mathfrak{z} \mathfrak{e} \mathfrak{h} \mathfrak{n} \mathfrak{t} \mathfrak{A} \mathfrak{r} t$}

Acarus elliptoideus, pedibus fecundis tertiisque diftantibus.

Acarus telarius. Lin. fn. fu. n. 1974.

$$
\text { Tab. 1. Fig. } 31.32 \text {. }
$$

Die $\mathfrak{A}$ rt, bie wir f̧ier befhreiben, ift alls benen,

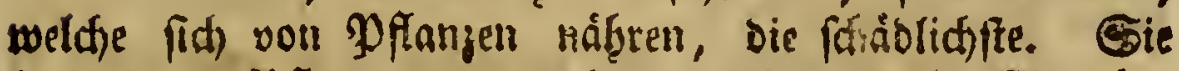

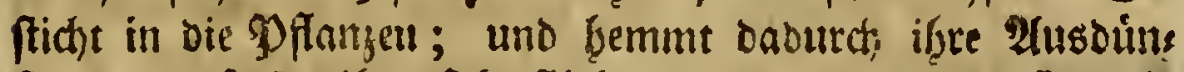

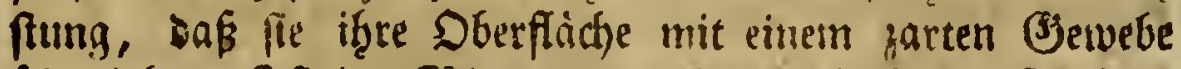
ubbergiefet. Sft bas Blatt einmal Erane, fo finden fich balb andere fleine Snjeften babey cin, bie Dann die pflamge ge:

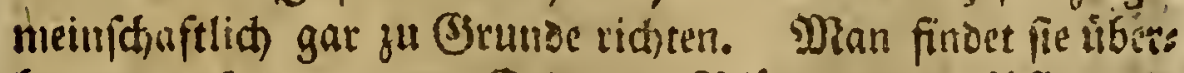
Gaupts auf ber untern Eeite der Slåtter jener Pflanzen, Die nicht gentig frene \&uft fraben.

Die 32. Figur ber 1. Tafel ftellet eine fold)e Milbe vor. Die Fathe if blaf́. Doch mag die Farbe, weil Der Sĭbrper, fo viel es die wenigen turzen $\mathfrak{g}$ åård)en, mit oes 


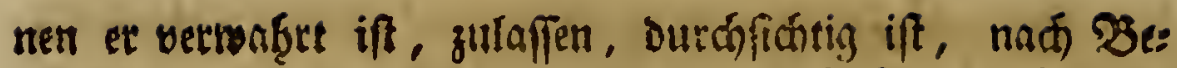

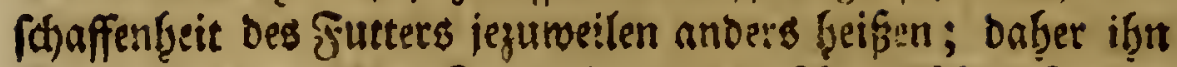

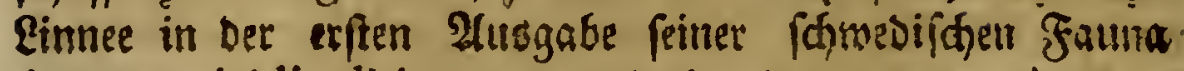
Acarus viridi albicans, uno in ber zimenten Acarus hyalino fulvus nennet. a a fint bie sleinen fowwargen Singen; b b frino zween braume glectert, bie ben einigen nad) Dem Ritter von Eintee rofffarben fint; c ifteine bims lele Macfel; fie mag vieleidgt bas burdfifheinende Şerz, coer Der Magen finn.

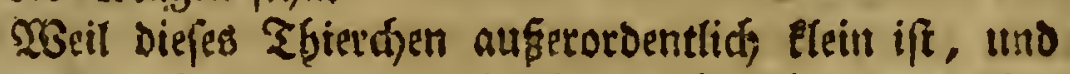
fich nui langfain berveget, fo iftes ferge fohiver befferber

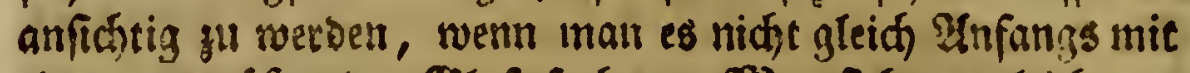
einem vergrósernden BTafe fudjet. DRan fieget es gleid) aus Der Yibsilbung, wie nahe biefes Jnfelt mit Heaumúrs Sdinectenmilbe vermanot fen; Dod) findet inan an eben des neir Drten, an weldjer ntan diefes antrifft, ein anderes,

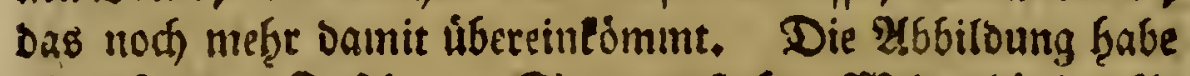

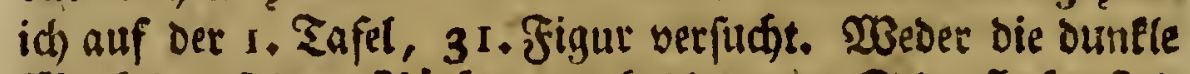

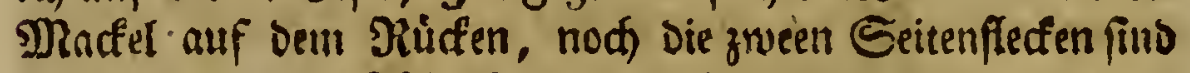
Gier zugegen, Die fruffe find, wie ben ber vorigen, und der

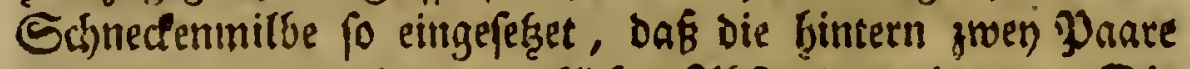
voll bels yorbern einen merflichen $\mathfrak{A} 6$ ffand gervinnell. Die Farbe ift balb blaßs, balo roth; Der \&eib uno die friffe mit

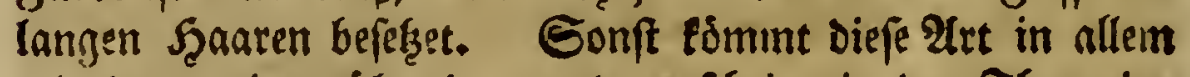
mit Der vorigen úberein, uno es fateint in bet Tf̧at eine blobe Spielart zu penn.

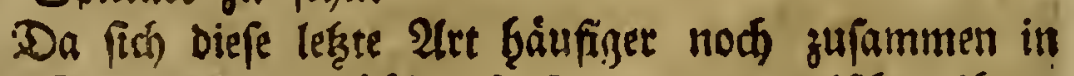

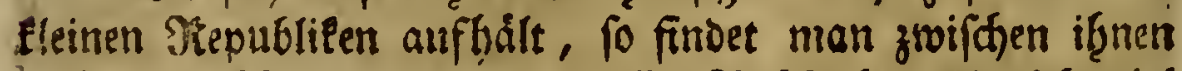
enformige Sidrper von einer blaffen Rofffarbe, bie nidft vid plemet als das Jnfelt feller: funb. Sinb fie vieleidt gat Suppen? Es faxeinet aber biefes tum fo meniger wahts

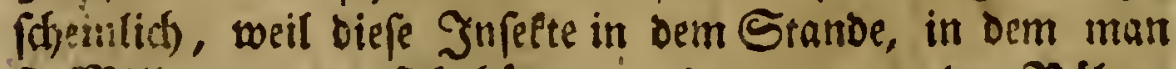

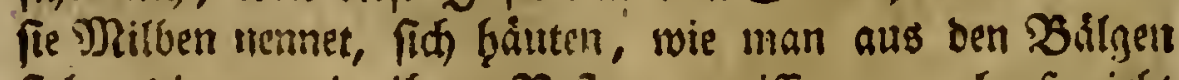
frethe, Die man in ibren Neperts antriffe; nutr aber fo giebut

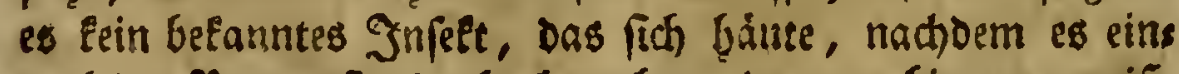
mal Den Yutppenftand ab́geleget b̧at; ba man ţingegen roeißs, 


\section{Sinfte 2lbbattoluttg.}

baf jene fegre oft ifire Şant verándern, bie ifrez yollfommes ne SBildung fdjon in beml Ene erbalten baben.

\section{$\mathfrak{F} \mathfrak{u} \mathfrak{n} \mathfrak{f} \mathfrak{e} \mathfrak{l} \mathfrak{n} \mathfrak{t} \mathfrak{e} \mathfrak{P} \mathfrak{x} \mathfrak{t}$.}

Acarus Saltatorius ano bicaudato.

Acarus aphidioides. Lin. S. N. Lin. fn. fu. n. 1972.

Tab. I. Fig. 33. 34 .

Einnee fagt, auf Den fidbtenftámmen tteffe man eine

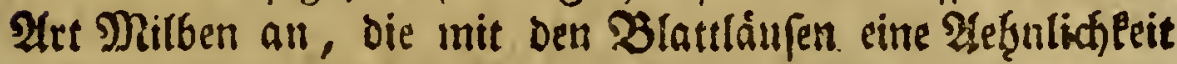

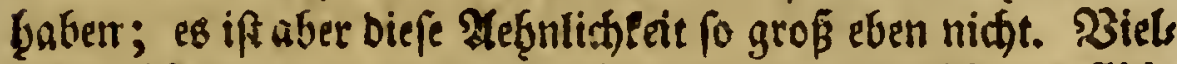
mege Gaatte man fratt ber Blattláufe die Pofanzenflóbe

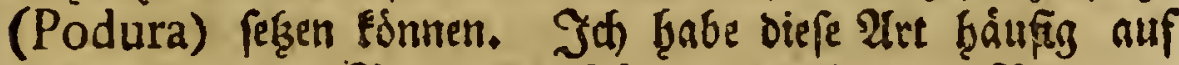
einem faulenden Blatte ber Fúnfrumbenblume (filene 5 . vulnera Lin.) angetroffen.

Der Reib ift lánglid)t walzenformig; gegen ben Steiß ju wird er etwas fhimáler. Die Farbe ift ein fo bumpeles roth, daf es faft ing Sdywarge blidt. 2tm Steiffe fits

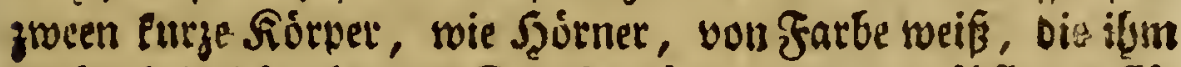

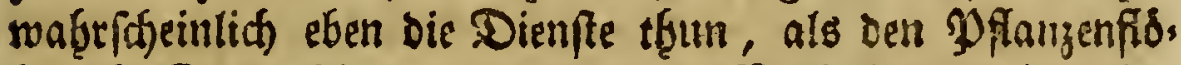
ben ifre Springfhroanj; Denn unfere Milbe pringt ebenfalls,

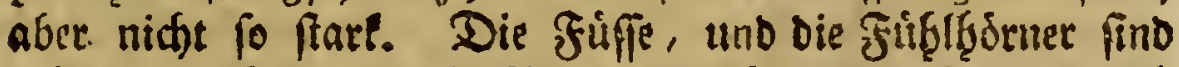

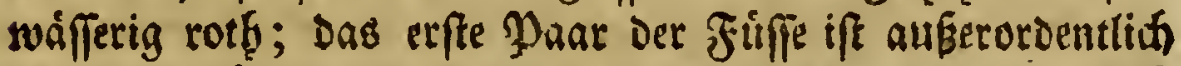
Iang; fie láuft zroar baunit, ftrefit es aber allezeit, alds

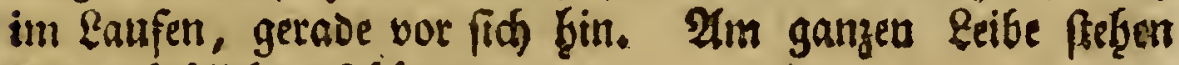

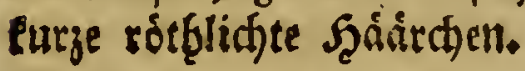

\section{Errflátung Det Figutent.}

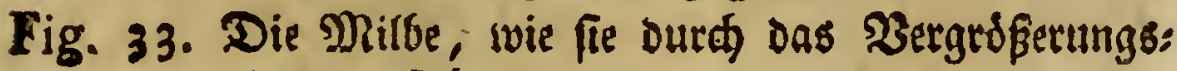
glas ansfieglyt.

a. Die Fứliticitner.

bb. Das erfte Waar ber firffe. Sie beftef̧en aus vier SJliedern, Davon Das erfte bas lángfte ift.

cc. Das zwente Yaar. Sie beftefen aus vier Gliebern, von denen bas erfte etroas lánger, Das juente etwas dider iff. 
dd. Das britte Paar. Die Filffe bes zwenten uno oritten parares, fino nicfte nur fúryer als Die erffen, fondern auch als die im vietten, jesodh nicht befonder's mertlict).

ee. Das vierte Paar. Die Schentel finb dife; Die tibrigen (Stelenfe einander gleid).

f. Die Sórperdien an: Steiffe.

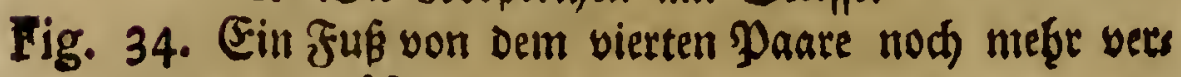
grépert.

\section{Sedfofinte $\mathfrak{A} \mathfrak{x}$.}

Acarus ovatus fubhyalinus, nigricans, nudus, pedibus fubæqualibus omnibus phyfapodibus.

$$
\text { Tab. 1. Fig. } 35 .
$$

2luf Den Stieglif̧en finbet man eine $\mathscr{A} \mathfrak{n t}$ Milfen in

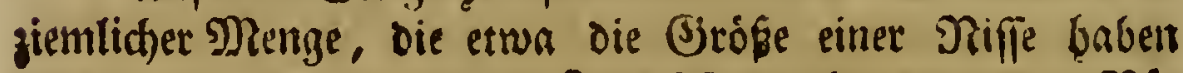

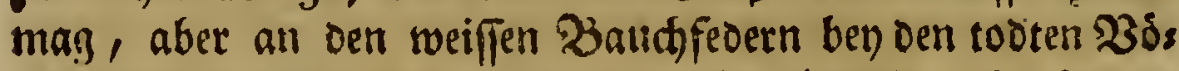

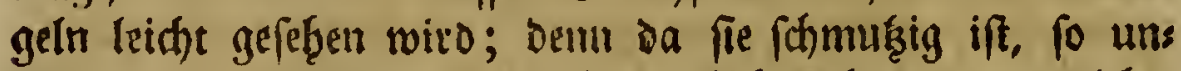

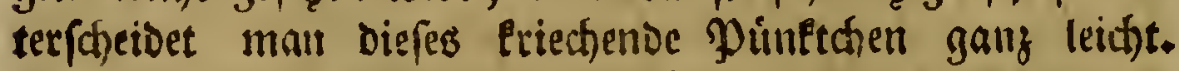

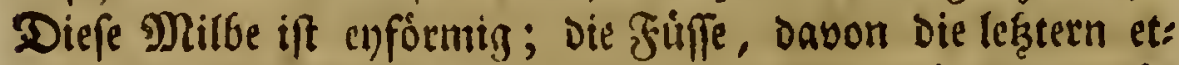
sas búnner uno oḅne Shaare fmo, haben benläuftig gleidge

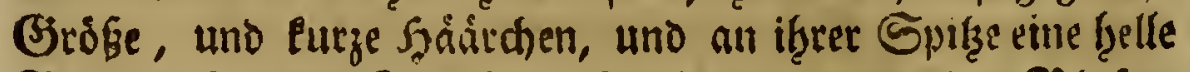

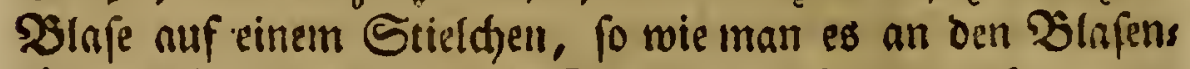

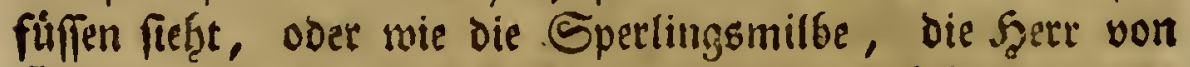

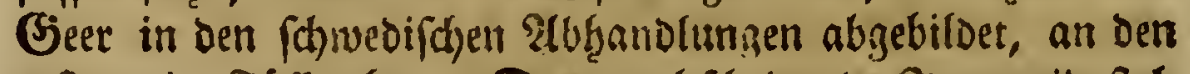

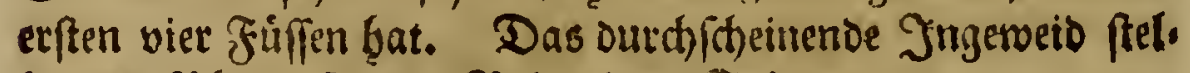
let Der Y̧Gantafie das Bild einer Spinme vor.

\section{Siebenzefite $\mathfrak{A} \mathfrak{x t}$.}

Acarus ovatus pallidus, ano pilis (4) corporis longitudine, pedibus anticis quatuor craffioribus, omnibus phyfopodibus.

Tab. I. Fig. 36.

Pediculus Pari. Lin. S. N. gen. 264. [p. 37. 


\section{Finfte $26 b$ andimtg.}

\section{A (d) $\mathrm{t} z \mathfrak{e h n t e} \mathfrak{A} \mathfrak{r}$.}

Acarus corneus pilofus, niger.

Tab. 2. Fig. 2.

Diefe" Sirt findet nan unter dem Moofe. Sie ift grd ber und feltuer als fintrees Acarus coleoptratus, Gart, nuo pedfforwar. Sie unterf(t)eidet fich von ver erftgenanns

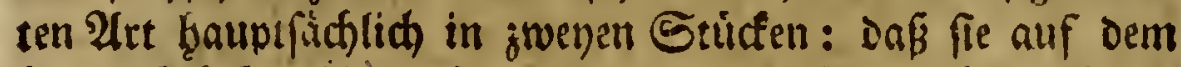

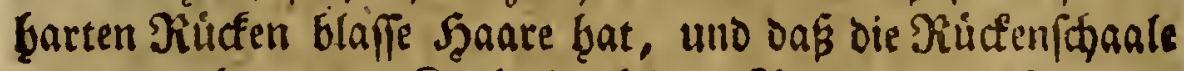
vornen neben dem אopfe in teinen Sand nuslaufe.

\section{Neungebnte $\mathfrak{x} \mathfrak{x t}$.}

Acarus ruber, ovato oblongus, pedibus :fubæqualibus.

$$
\text { Tab. 2. Fig. } 3 .
$$

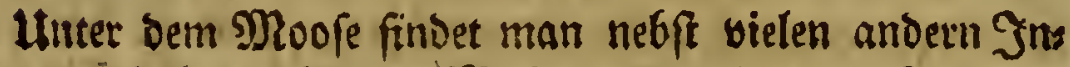

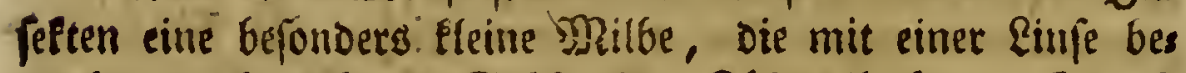

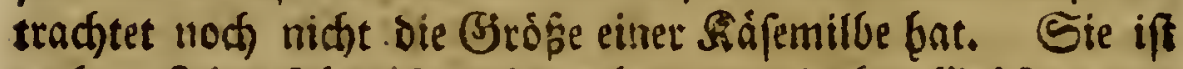
rotb. Shree frúfe ñmo beynab̧e von gleicher Şróse, uno von Eeiner befondern Sieftalt, Die einen Sharalter veraus laffen lobnte, wie mant es bey diefem (sefhled)te gerwobnt

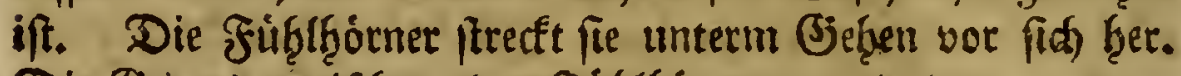

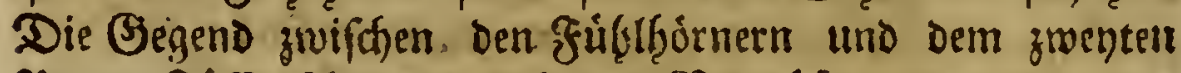
פaare Friffe fcheinet ourch das SBergrónecturgsg̣las etwas

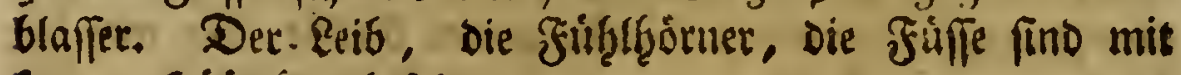

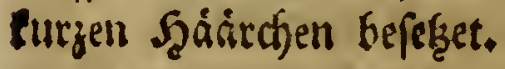

\section{A. . $3 \mathfrak{m} \mathfrak{a} \mathfrak{n} \mathfrak{z} \mathfrak{i g}$ fite $\mathfrak{A} \mathfrak{t}$.}

Acarus primi quartique paris longioribus, fecundi craffiufculis.

$$
\text { Tab. 2. Fig. } 4 .
$$

भuf Der untern Seite bes Şunbsmoofes (Lichen ca-

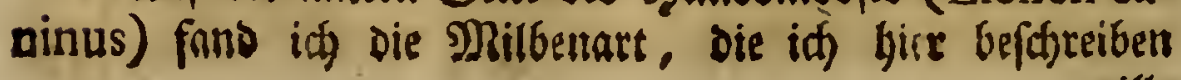
will. 
mill. Sie ift Elein, etwa von Der Brodße einer Niffe, glám zeno caftanienfarben, uno láuft fefe idjuell. Went man fie ourd bas Bergrópertungoglas beftebt, fo nummt man Dieje Gonberlichleiten mak̨r.

Der Friglbóner find zwen Paare, die einantber niffet ábnlich finb. Das innere Waar (a a) liuft jpif̧ig ju.

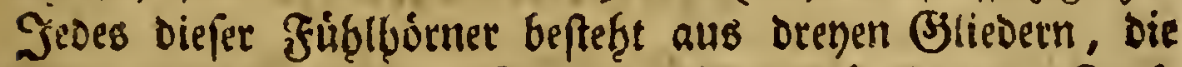
faft gleid) lang fino. Davon ift Das nád,fte am Sopfe Dunfel, Das jwente Dutchfidtig, und Das oritte rufig fdymary, uno inacht bie Epize aus. Diejes Paar iftuidst

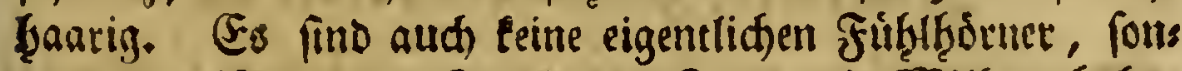
Dern Das J) Jaul Des Injeltes. Denn Die Mirken Gaben weder einen eigent(id)en Siopf, nod) э) Raul; fondern faugen Durch Derley Pumpen den Saft von Sp flanzen ooer Tfieren in fid, wie es fojon ebemals Szerc Poupart ben einem ans Derit Infelte, Der Earve Des Ulineifenlónens, bemerfet bat. Woir baben fie bier ausfübrlidjer beforrieben, als ben ans Deren $\mathfrak{Z}$ rten geicheben ift, weil fie bey leiner $\mathcal{A}$ rt fo fidtbar uno fo grof fito. Das Jnfeft frectefe fie, mentgftens zwis ftyen ben zwoen Sláttchen von ruffifhem Frauenglafe, ztwis (h)en bie id Daffelbe verfidolob, allezeit gerabe vor fid).

Die eigentlid)en Füblborner fino von gleidger Ránge mit diefen frefefpizzell, fabenformig uno baarig. Sie bes fteber gleichfalls aus brenen (stiedern, Davon jenes, bas bein Raibe das nád)fte ift, bas lángfte ift.

2uren babe ich nicht beobachtet.

Der Fúfe find, wie ben bein gangen Gefaslechte, vier Daate, bayon das exfe paar fehr lang und fadenformig; (s hat ein jeder Fus diejes paares fectso (3)lieber. Die

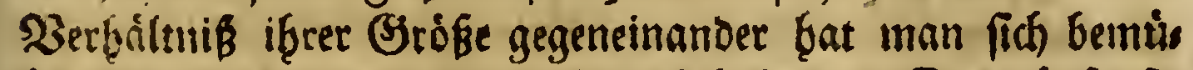
Get im sbjeidunen gennu bezzubebalten. Das áserfte (S)lieb ift oas lángfte: Das zroente Paar ift um ein gutes

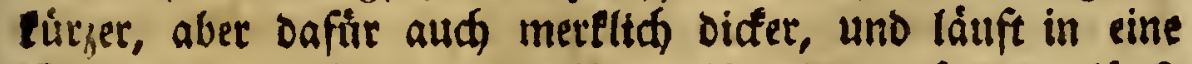
Spise auts. Das britte Paar ift wieder bưnne; låuft ebenfalls in eine foharfe Spifze aus, und if benlåuftig bon Der Ránge Des zmenten Paares. Das vierte Paar ends 
Iith, weld)es ebenfalls dúnne ift, und immner fpişiger witt, Gat vier bis finf Bjlieder, und ift von der \&ánge bes erften Paares. Hlle Füffe fino ftare baarig, aber Der Rumpf Der Milbe felbft bat leine Şaare.

\section{VI. श्bbandlung.}

Abbildung einiger Gureften, yon benen meis nes פrsiffents nodi feine, ober feine gute 3cichnung gemad)t worben ifi.

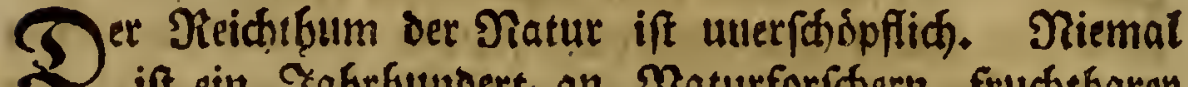

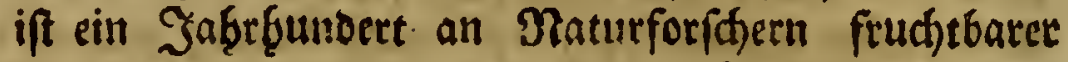
gerwefen, als das unfere, uns gleidjwoḩ Darf man eben

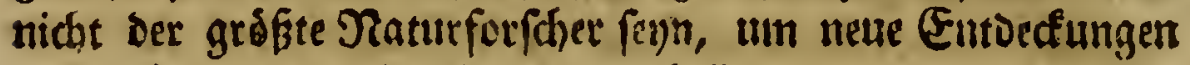
zu maden, oder die alten zu verteffern.

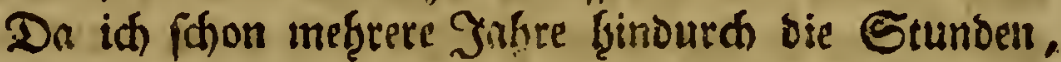

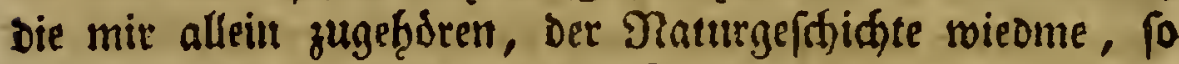
babe id Die wabatheit diefes Safecs oft genug erfafiren.

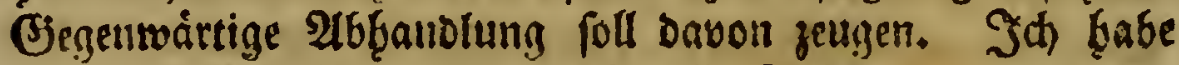
zwar Darinnen Gen meitem nidft alle Snfeften verzeirhnet, bie id) nirgenis, als im großzen Sittd)e Der Natur gefuns Dent babe; nut einige, uno sorghiglid fleine ţabs id ges wåhlet.

\section{S. I.}

Sliege aus bet Sienfptofifrntotte.

$$
\text { Tab. 2. Fig. i. H. D. folg. }
$$

פRan finbet in Frrifijab̧re an vielen 3 weigen ber Stienbdume einen barzigen Sthwulft. Diefen hiat eine Diaupe verurfadtet, oa fie in den saum bofrte, um fid zwifesen bem verdecten Safte, bet burd) bie şounde hers ausflest, eine 230 benung zu finden, Die fie niber bie bars ten $\mathfrak{Z}$ nfálle bes 2 winters, uno roiber bie mannigfaltigen $\mathfrak{A}$ rs

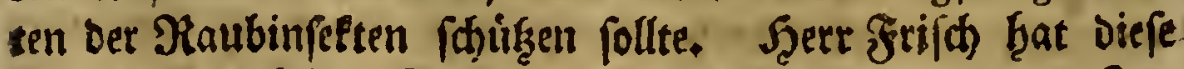

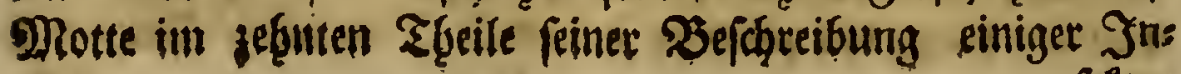


felten Deutichlandes geliefert, uno bat fie Rienfuroffenmotte

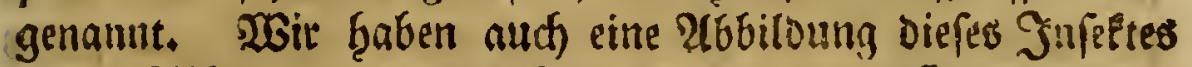
in Den आ6handlungen bes Rammerberen von Bjeer, und in riofels Snfeltenbeluftigungen.

Эd) roage es lidht, nach foid)en 230 igangern eine

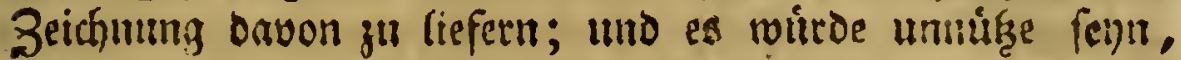
fie weitláuftig zu bef̧̧reiben. Senin Mitter von Rinnee Geiffet diefe Dotte Tinea refinella.

Es gewinnet das Geinuís aefunden Den Sirtfolgungen Der Silupfroepen uno Soflupfliegen ju entigefen. Dem, oa fie vour Ene an um uno un mit einem Elebridłten Şarge ungeben ift, wie follte ib̆r ein feinofelig Ynjęt uaben fómen?

Indeffen bat ez bod einem Surefte gegludet, auds son diefer Motte fid náf̨ren zu lónuren. Fo fóneinet uns glaublid); aber wie vieles b̨at uns oie SBeobacbtung glau: ben gemact), bas wir zlwor fogar für unmóglich gefols

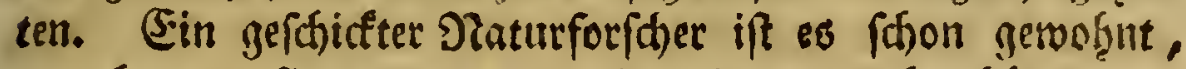
mandies gu firden, Das er niemals vermutbet batte.

Seffnet in Dárzen, fobald die ftárlern Winterfiofte

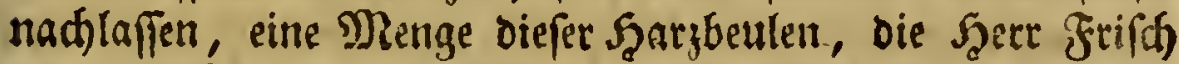

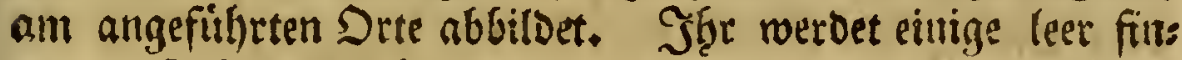

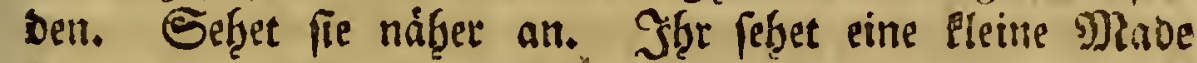
Darimen, die Faum eine Rinie lang ift. Td) Gabe fie auf Der jrooten Tafel Fig. 5. in if̧rer naturlidjen Girofis: abjzes biloet, wenn fie nods nidht galiz alsgyewady fen ift. Sie iff ourafichtig, uno fareinet in Der Ditte etroas buntes zu

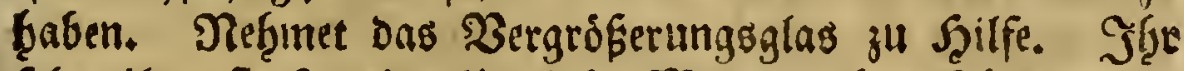

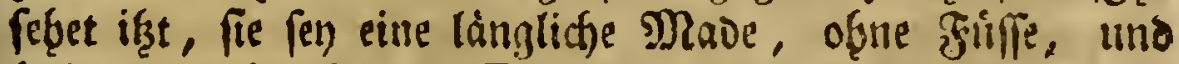
babe brengeben ßinge (Fig. 6.); gegen ben Ropf zu (A), Der aber eben nidjts bejonderes bat, nefime fie alt ber Dis

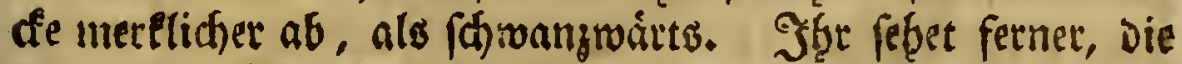
exfen oren (Sielente, ben Siopf mitgerechut, fenn Durchfobeis nend weís (Fig. 6. a a a.), fo wie es.auch die Dien lefenten fino $(\mathrm{b} b \mathrm{~b})$. Die úbrigen aber Gaben eine lichtbraune

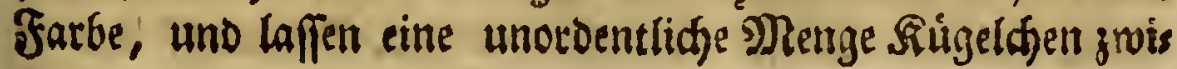




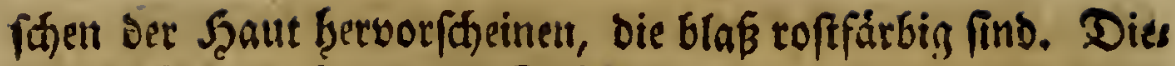
fes madit bas bunte des Jufeltes alts, weenn man felbes mit blopen stugen betrachtet.

Da Diefes Infeêt mitten in biefem Şarz?lumpen allein fin auffiált, fo fonnte man glauben, es babe if̣n fervors gebradt, auf eine $\mathfrak{A r t}$, Die Der Sinft Der Sienfproffenmotte

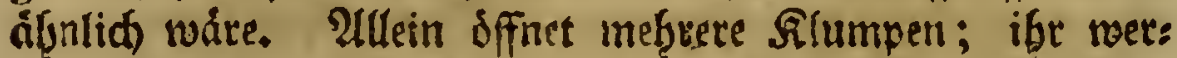

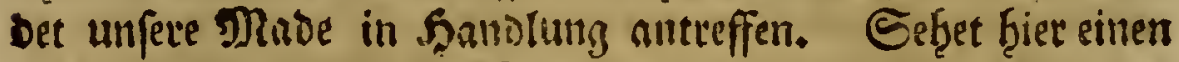
todten Eeidnnam einer Rimintoffentnotte, Die an unferer Mabe einen undarefaren Midider gefunden batte. Diefes

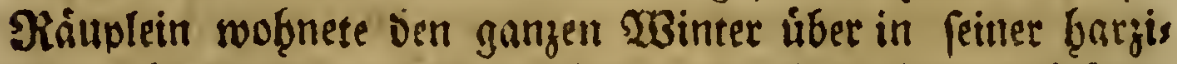

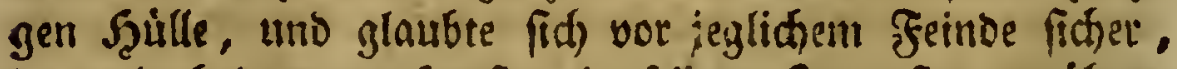
ba es bod) Den graufamften in feỉnem Innerfent etnágette.

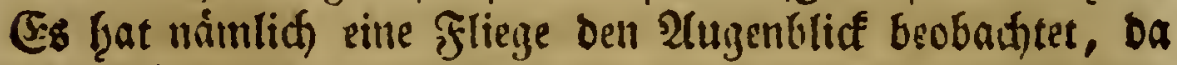

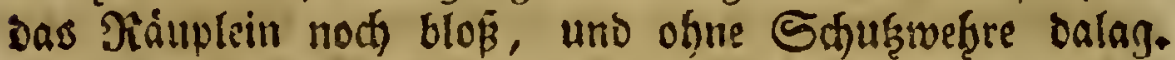
Schnell legt fie eines iffret Ener darauf. Das Räuplein "laget firf in oie Sienfproffe cin, Saft quilt Geraus, unto

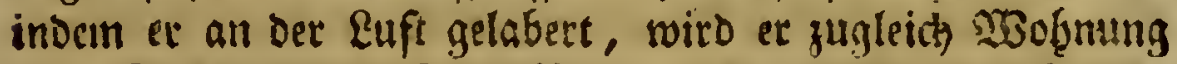
und Epeife peines Sinwohiners. Linterbeffen fotliest bas

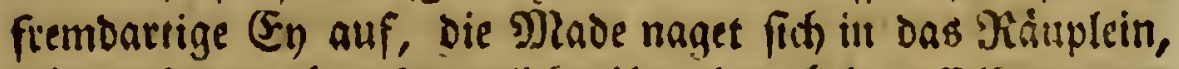
lebet anfangs obgne fonderlid)e Lungetegenteeit Deffelben, von Dem Snfte, Den es ants dem Zwweige gezogen, und in Feir eigenes 2 Befen verswandelt batte; aber thalo sorauf nimmt

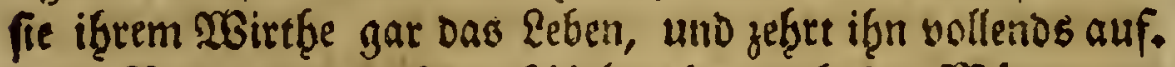
Nun, uno biefes geftiefrit eben nod, in Mairzmonas the, ober anfangs 2fprils, mun bat fie ifreen (J)uttbăter ver:

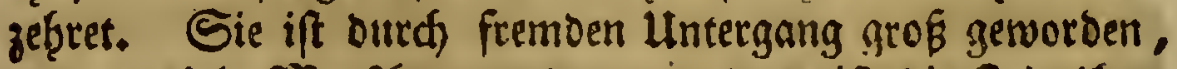
wie es viele Menffnen werden, uno es ift Die Zeit ib̧rer

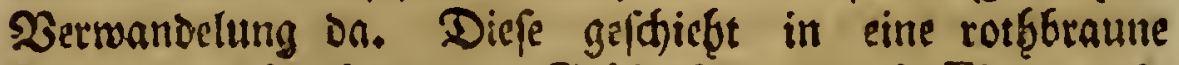
Duppe, Dic benlåuftig die Ģróbe bat, wie fie Fig. 7. ab: gezeidinet ift. Man nimmt Daran an einem Enbe zrwo gang fulze Spifen (b b) wafir; am andern aber enbiget fid Die Yuppe in einen enlinbrifđen Dimnen Rorper (a).

Das Jufelt, wenn es fid in biefe Bieftalt verwams

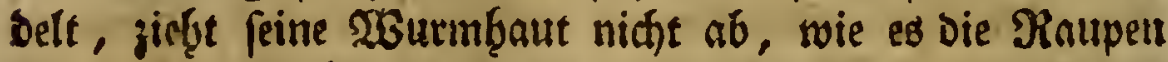
toum, fonbern låpt fie in einer getwiffen Stellung, bie es 
fich) girft, vertodfnen, Da bann biefe Bjeftalt Getauseldmut, bie id Fig. 8. vergrofert vorftelle. Mian nimmt anf Dicfer vergrofferten Yuppe vorme bey den Evifgen zroo ges Etrinmte Bertiefungen (c c) wabr. Die Stellen, roelç)e Die కgeitung Der Singe an Der Mabe bemerfen, futb an Der

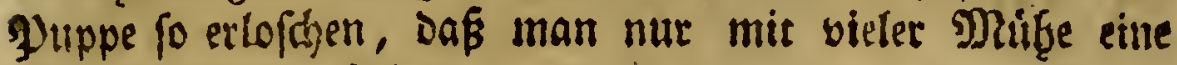
ober bie anbere findet.

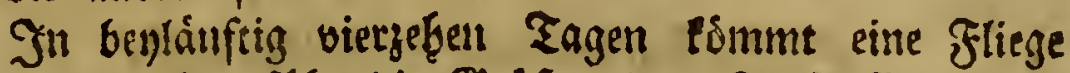

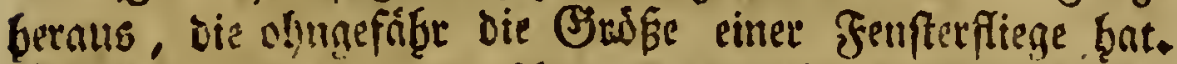

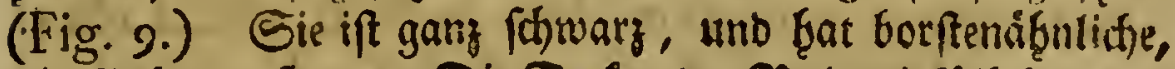

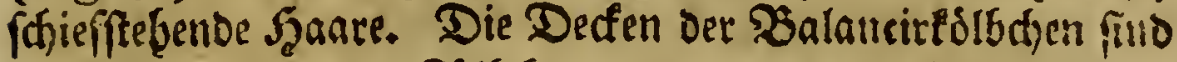

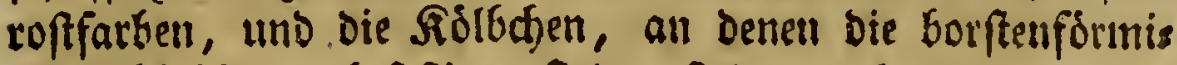

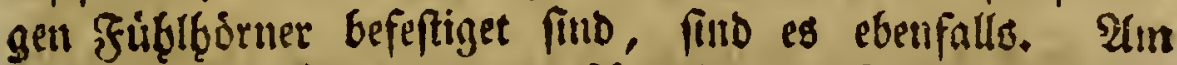
Saudje bemertet man zwo fómale, weisliffe Binben,

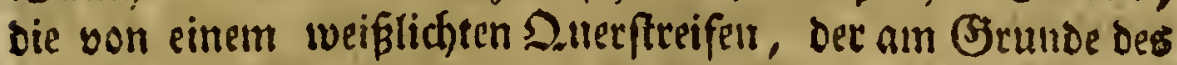

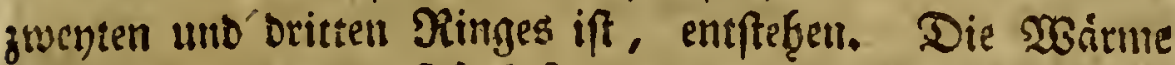
Der \&uft, in ber fie fich befand, als fie bie Đuppe verlié,

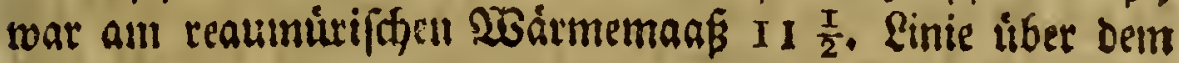
Eispuntt.

\section{Ertllitung bet Finuten.}

Fig. 5. Fine nod, nid)t ausgerwacb) fene Mabe in natuiv liçer Griófe.

Fig. 6. EGendiefelbe fart vergroseret.

A. Der Siopf.

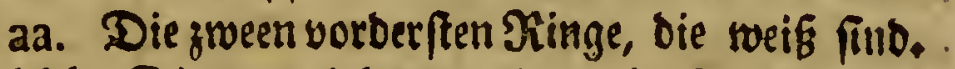
bbb. Die bren leştern, die es ebenfalls find.

Fig. 7. Die Yuppe.

a. Die Seite bes Sdmanzes.

bb. Die Stheiben Der Şdrner, ober vieleidft bet Borderfúfile.

Fig. 8. Ebendiefelbe ftare vergroserert.

a. bb. Sebeuten ében bie Theile, wie in bet vorigen frigur.

cc. Ztwo truinme $\mathfrak{B}$ ertiefungen.

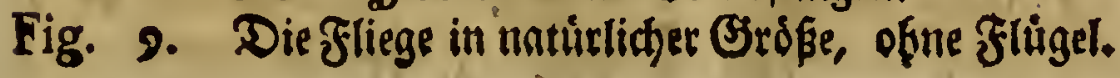

Fig. 10. 
Fig. 10. Fin Flügel, Hach Der Natur.

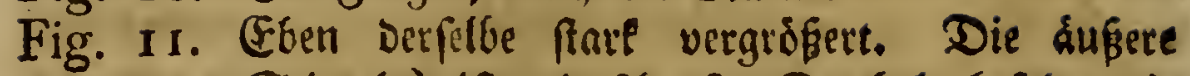
Erite (a) ift mit fharfert Stadeln befeset, Die itmere aber fein gefranzet.

Fig. 12. Der אâpf vergrókert.

$$
\text { S. } 2 .
$$

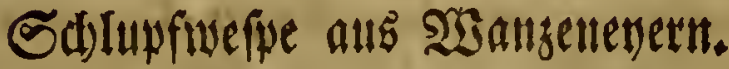

Ichneumon ovulorum. Lin. fn. fu. II. edit. n.I644: Defcript. (non nomen.)

$$
\text { : Tab. 2. Fig. 13. IInt A. }
$$

Эat) fand im Nayen I773. auf cinem Birlenblatte einige Evyer yon Baummanzent. Normifigi, was es fút eine 2 trt wáre, vertuafrete ich biefes $\mathfrak{B l a t t}$ bis die Jungen ausfróthen, um Die Art Davon zu erfaften, und vieleidit, Da idh fie your Ene an Eannte, einige Erláuterungen in Der

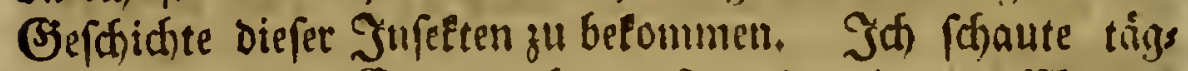
lich nad) Ineinen Enert:; aber anftatt Der jungeut waanger fament endich Eleine Schlupfimefipen (Ichneumon) beraus. Sie find nicht gróser als oer Eleinfte Flob; ganz und gar

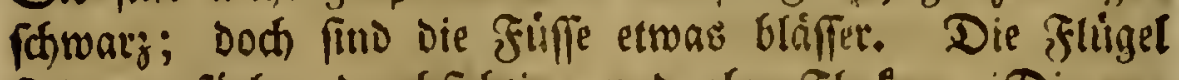

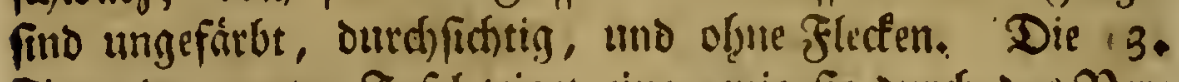
Figur ber zwoten Safel zeiget eine, wie fie Durch Das $\mathfrak{B} e r s$

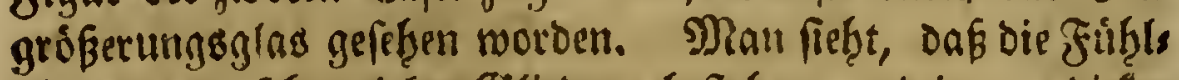

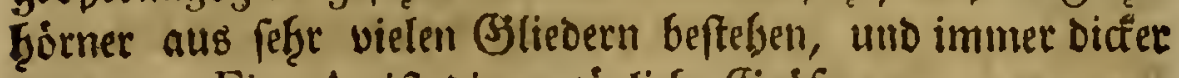
werben. Fig. A. ift die natúrliche Jirósée.

Diefe 2̂rt war Dem Sitter von Rinnee nidht unbelannt,

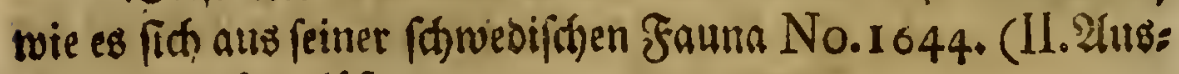
gabe) 低liépen lápt.

\section{S. 3. \\ Bottigter Eroflow.}

Podura villofa." Lin. S. N. Gen. 262. fp. 9. Tab. 2. Fig. 14. 15 . 


\section{Sechfte 24biandiutg.}

Unter bem Mroofe, bem $2 B$ obnorte fo vieler Sufelten, bavon wir fetber fajon einige befádieben baben, roofuet

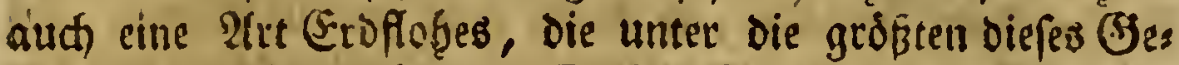

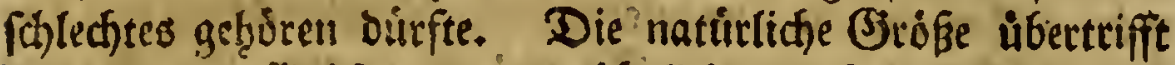

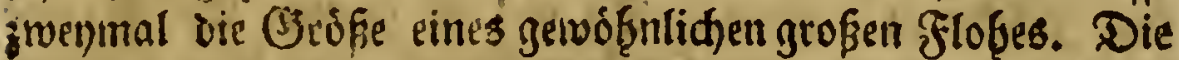
Farbe bes Surfeftes ift sie Staubfarbe, Dabien blift fie gleid)swobl cit wenig in bas blenfárbigte; mitbin bat bicfe

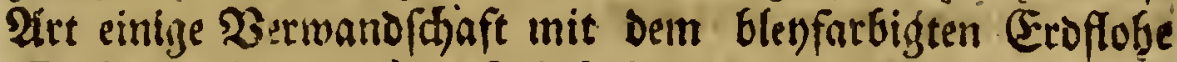
(Podura plumbea). Эd) Gabe diefes Jufelt auf oer green: ten Tafel in Der. 14. Figur vergrópert vorgeftellet. Fo uns terfaheibet fid von Den úbrigen $\mathscr{A}$ rten in verifjiedenen Stưcen.

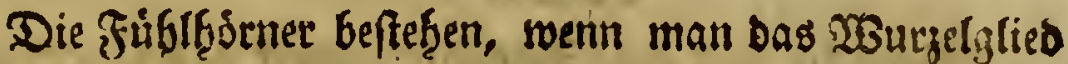
$(b, b$.) nid)t baju rechnet, ans breven (Stiebern (bc; cd, de. bc, cd, de.); Droon bav uriterfte ( $b c, b c$. ) uno bdiffite (de, de) faft uon gleicher Bróbefino, bas mittlete (cd, cd) aber vorzúglich lang iff. Die अlugen fino fothwarz, aber if̧re 2 nzabl ift nidjt leicht ju b:ftimmen. Der Rumpf

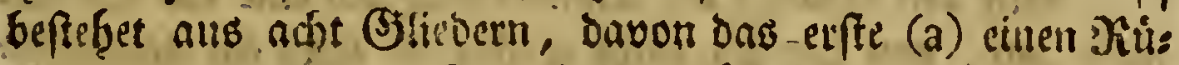
cenjdilo vorftellei. Das fiebente $(f, f$.$) uno arbite (j)tied$

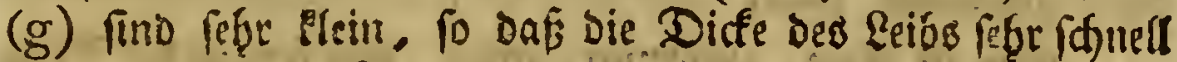
in einen fpitzigen Segel abnumbt." Das gange Śbier ift mit furzen Scaaren beivadjien; Das erfte (J)lied aber Des Sums pfes, Das, tvie gefayt, einein Ricfenffoilo gleichet, if unit

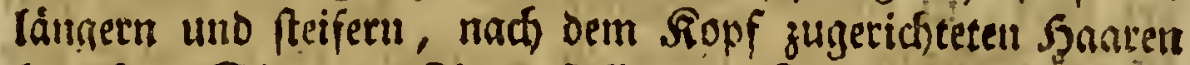

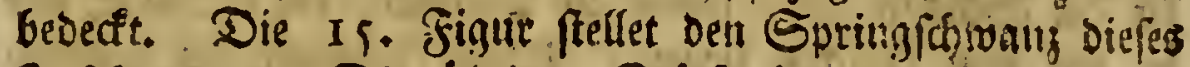
Jnfeftes vor. Die ibrigen Stúde bat es mit den úbri: gen Jnjeften peines (Sefd)lechtes gemein.

\section{4. \\ Ungefowånjtet (5tofiof).}

Podura fimetaria.: Lin. S. N. Gen.262i fp. r3. Lin. fn. fu. n. 1935.

$$
\text { Tab. 2. Fig. I. }
$$

Dichts ift gemeiner als Das gegentwärtige Jnjett, umb bennod bat fich nod) Niemand die Dúb̨e genoinmen, es. 
abzuzeidunet. Man barf nur bie Bartenerde ein wentg wegfrafser, man darf nur die Blumenfidefe, die man aum Jenfter bat, Gegiefen, fo findet man ifen in Menge. Es

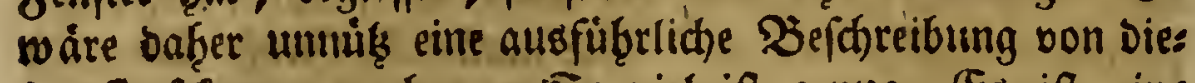
fen Grifefte zu machen. Eo viel ift genug: (Es ift eine

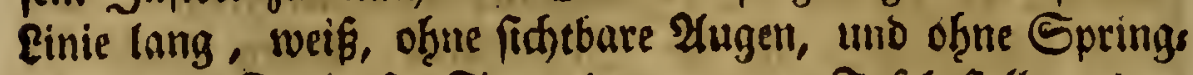
fhrwanl. Die erfe Jigur ber zwenten Tafel feellet eines biefer Jnjefte vergrósert vor.

\section{S. 5.

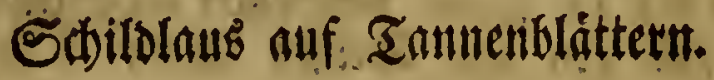

Coccus abietis.

SBieleidt nut eine Berfoiedentheit de Coccus Hepperidum. Lin. S. N. Gen. 229. fp. I. Lin. fn. fu. n. Iors.

Tab. 2. Fig. 16. unto bie folgg.

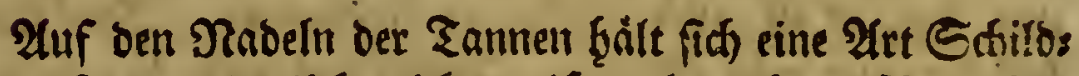

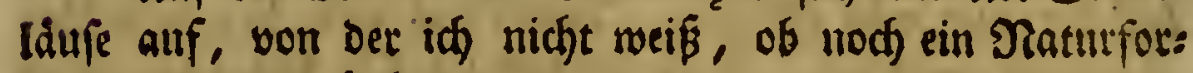
Ther gebandelt babe.

Sie ift tlein, enformig, grau, uno bat in ber Mitte eimen Punlt. Die 16. Figur ftellet fie in ifgrer naturtliden Eróse vor; Die 17. Fizur aber, twie fie auf einer Faris

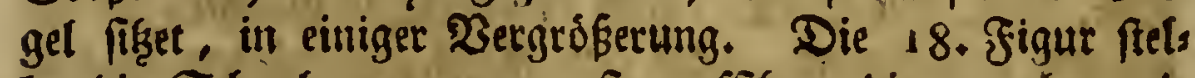
let bie Shaale ver, soenn fie allfifţet, bie 19. aber, twie fie auf bem Ruicfen lieget. Ollzeit bebeutet ber weísges laffene Mittelpunft, ben gelben $\mathfrak{P u n t t .}$

Nimmt man in Frnifjabere mit einer Stecfnader bie Shaale fadte von ber Tangel Ginmeg, fo erideinet unter

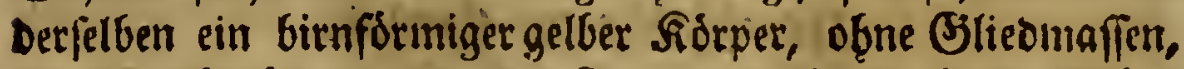
fo wie id if̧n in Der 20. Figur abgebirbet babe, ofgne

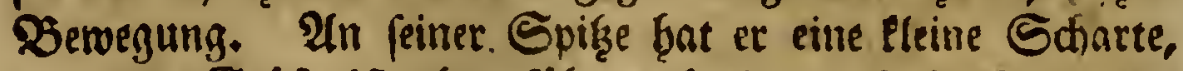

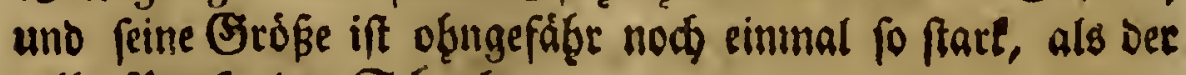
gelbe Pountt der Sajaale. 
S. 6 ,

Fetteffet an bent bunten Rodjetfowantm.

Dermeftes tholace marginato.

Tab. 2. Fig. 2. 1. H. D. folg. Tab. 3. Figi I, U. D.f.

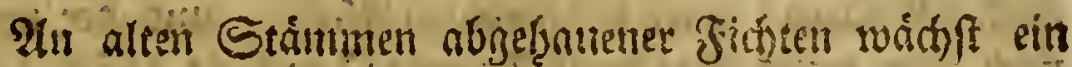

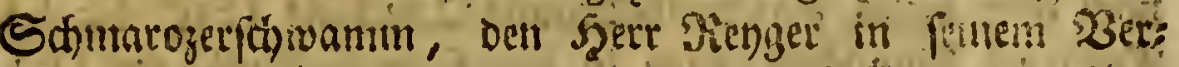

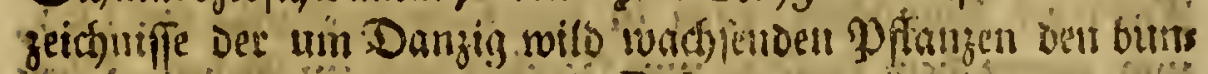
ten Eod)erifinamm; Rinnee Boletus verlicolor mentét.

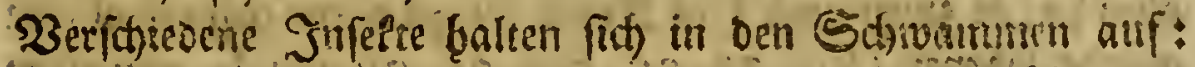

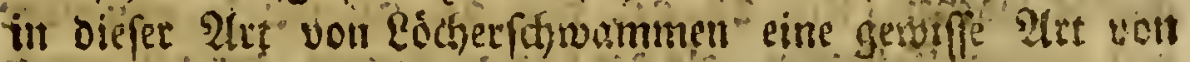
Fetteafer (Dermeftes) die ids in Segenwaribejdicriber mill.

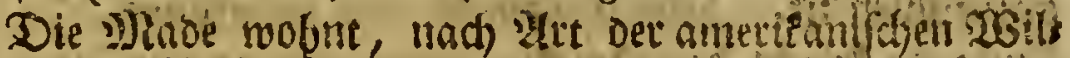
Den, in eleinan Sabanen, die fie fids feloft grabi. Sitfito nichts anders als feble, walyenformige sodjer, oie gennil

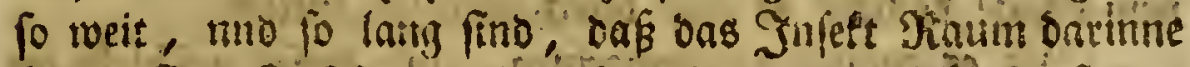

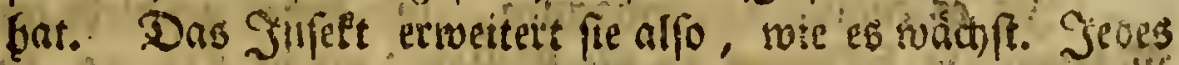
wofint in einer eingigein Shoble, aber in cithin cinjigen

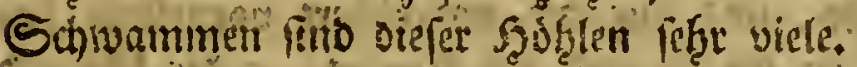

Die Made feloft int bren bis viertebats Einien lang, uno eine Galbe diaf. Die 21 . Figur ftillet eine yor, die

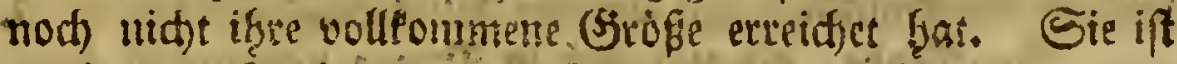

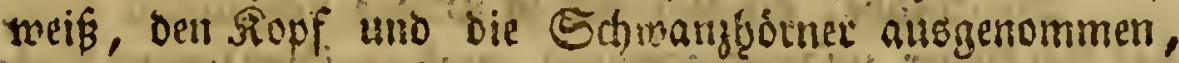
bon Dener wir gleich reben nerben.

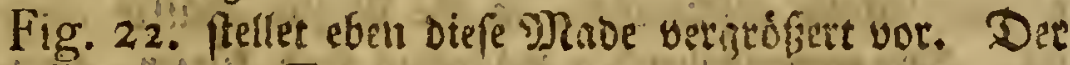
Sopf (Fig. 22. a. Fig. 23. ffbg b f) ift blationfátuig, glángend, nib hat ein lid)teg Drined ( $\mathrm{g} f$ ), weld)es feint Sdjeitel nicht erreidfet. Die funthourter (ff. Fig. 23.) uno oas Sangengebif mit oeti Fresiptlien find Eaftantenfais

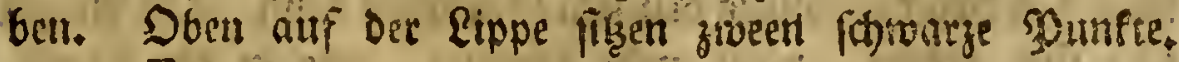
(n.n. Fig. 23:)

Der Leib; meldher ans eilf Ringen beftefget, ift weib́,

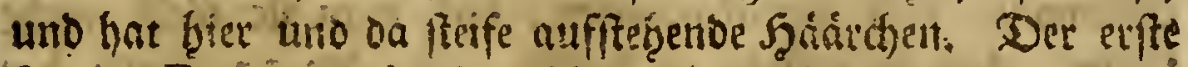

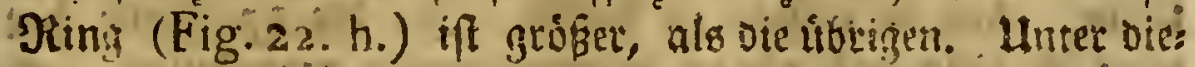

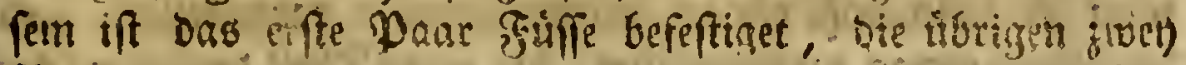
Pacre furo an oen folgenden zueenen feftgemact. . Die 
(Seftalt biefer fruffe ift, mie Fig: 24. Sie tefthţen aus brenen Gelenten, Die ineinander gefhoben Theinen. 24 der Spis Ge baben fie jno Slauen (D,d), Davon bie eine (D)

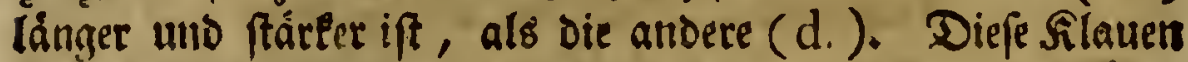
bliden ins rofttårbige. Die leşten Drel) Ninge Gaben oben na nok) úber diefes eine Dunfelbraune Suertinie (Fig. 22. 1.). Der leģte ßiting läuft unten in eine ftumpfe Spige aus (k),

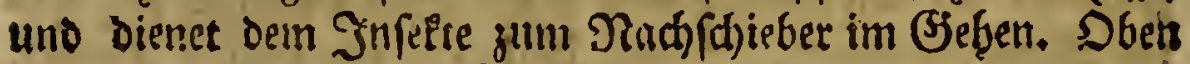

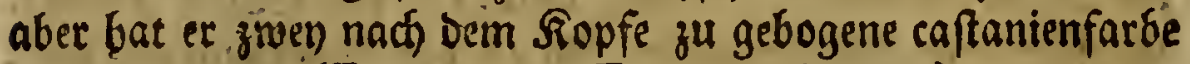
glänte J̧derner (Fig.22. cc. Fig. 25. 28. c c.), von einer

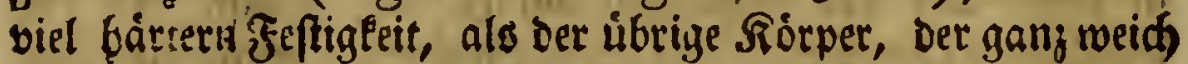

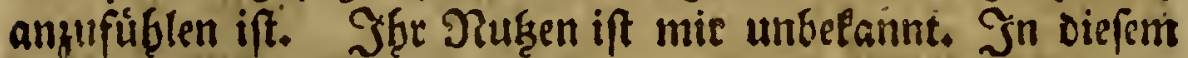

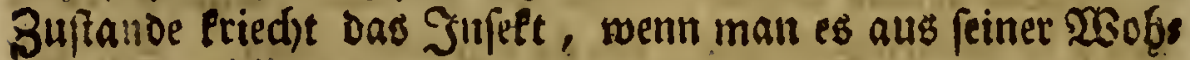
nung herausnimmt, auf Şolz und Bain fort, aber auf eis nem Blafe fómmt es nur ourd Woálgen soeiter.

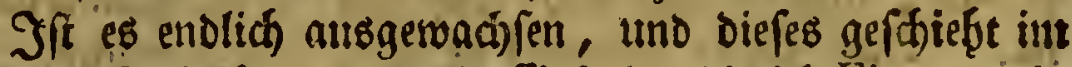

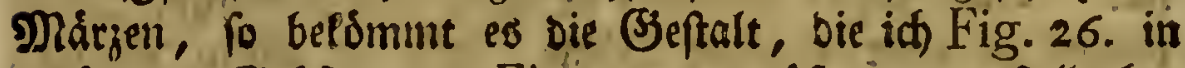

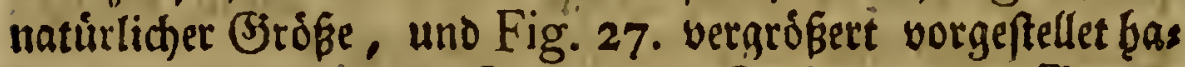
be, wo allemal $m$ bie Segeno bes Sioppes, $n$ bie Eegent Des Sdywanges ift. Jin diefem Zuftanie Gat es feine bes

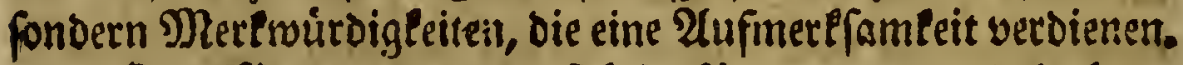

Die Made, Die nun fid in Duppe verwandeft bat. bat fid lúrzer zufaimmengezogen, uno an ifrer untern Seis

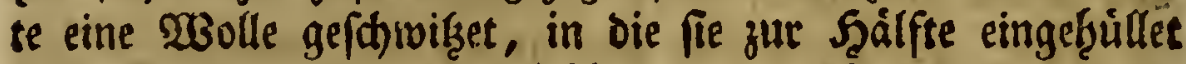

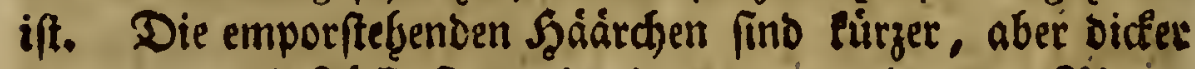
geworden; Die fruffe find wie eingezogen; Die zroeen ßinge,

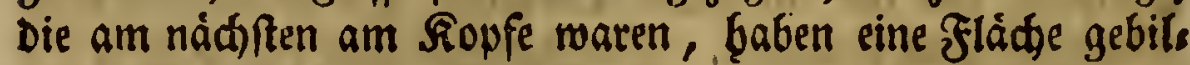
Det, um weldfe der Nand herum erţoben ift, Dás man bie

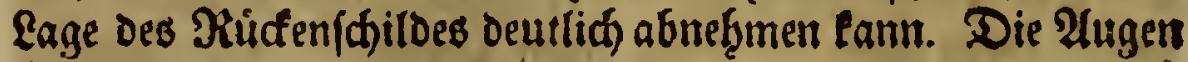

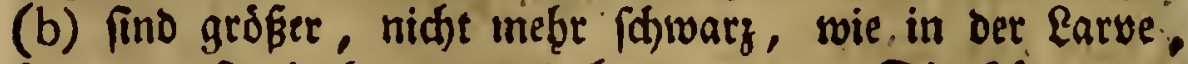
rondern caftanienbraun, und bervortageno. Die Şzrner an Sthroange. fint zurúdgetretten, daß man fie nicht leidht fárbe, oḅne fie gefucht gu baben. San ber 27. Figur bat man fie gleid)wobl etrwas bervorragender vorgeftellet, und

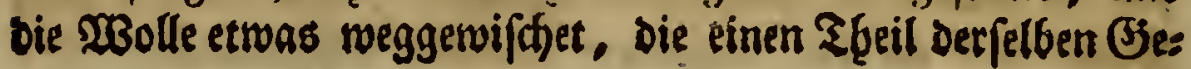




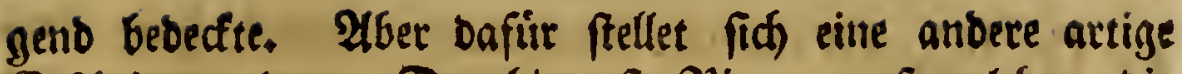
Eridseimung Dar. Der binterfte Pring, auf reeldtem bie Szơrner firgen, fat fíd verlängett, und etroas flad) gemad)t;

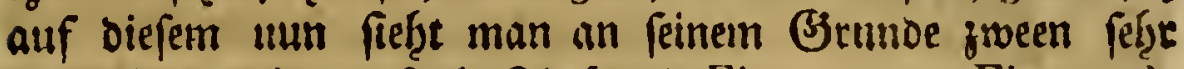
fonberbare caftanienfarbe Flecten (a Fig. 27. a, a Fig. 28.),

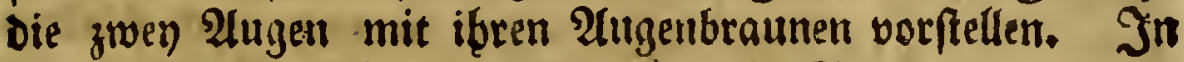
diefem Zuftande 'bat Das Smfeet feine Berwegung.

Nod) in biejem Mlonate, ober meninftens gleich) $2(n s$

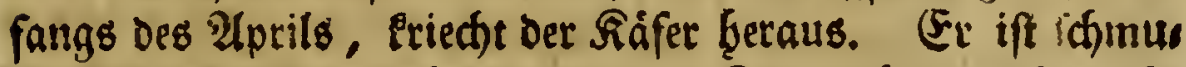

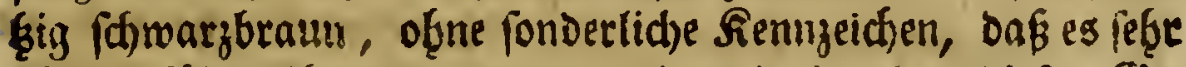

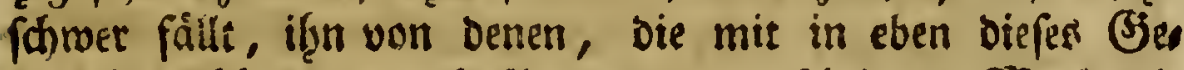

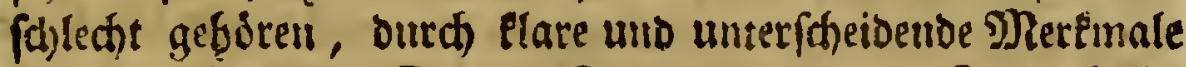
zu untericheiden. Die 29. Figur ber zmenten Eafel ftellet

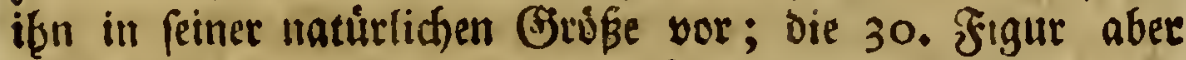
vergróbert, uno wie er auf Dem Bauche liegt. Эah) habe eitre Stellung firr ifgn gewáblet, Die er Feffre oft annimmt.

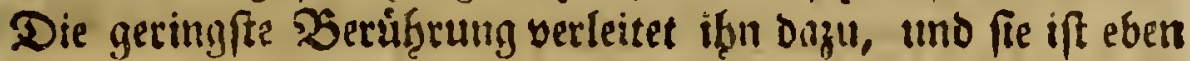

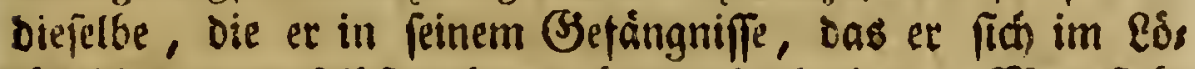

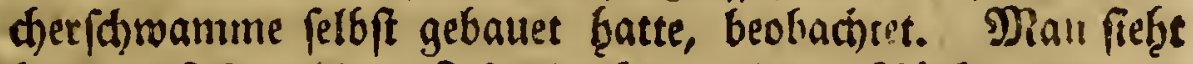

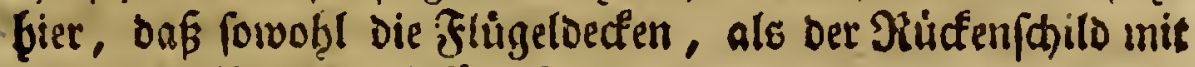
vertieften punkten befáet fernn.

Die erfte Figur Der Dritten Fafel ftellet ifn auf bem

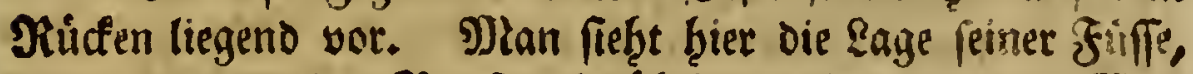
Derer zween an ber Bruft, die tibrigen viere an Dem $20 r s$ berbauch befeptiget find. Evinen bavon babe ith in Der 34. Fignur Der 2. Fafer nod nueber vergróbert vorge|zeflet. Die Şúfte (a) ift biffe, alámzend caftanienbraun; Der Schens Pel (b) ift meḅr als üm die Şálfte bưmer, faft von gleidher

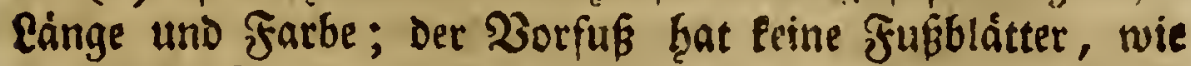
fie andere Infelte baben, forbern aefot in einem Slücfe fort. Seine Farbe ift ein suneelaelb, das ins caftaniens

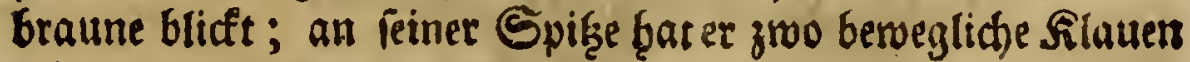
(d) von gleidher frarte.

Sein Sopf (Fig. 33. Tab. 2.) ift fifwarzbraum, bie $\mathfrak{A}$ ugen (c, c) aber ganz fibrarz. Linter Den 2Augen,

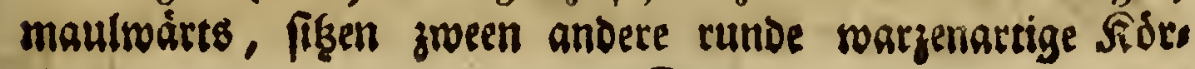

D 2 peE 


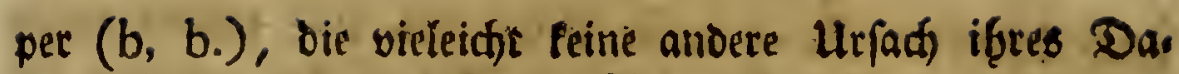

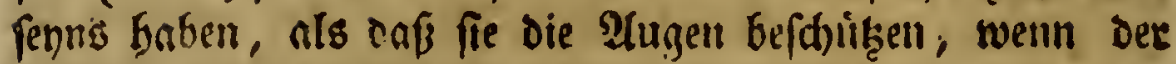
Fåfer Durd) Den bart gewordenten \&ódferf(hwamm fid) einen

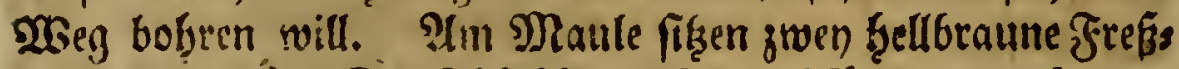

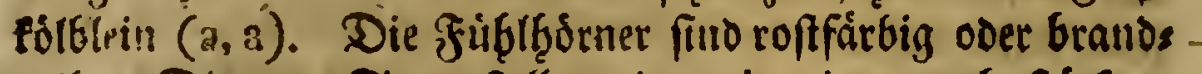
gei6. Die 31. Figur- Ptellet eines in einer nod) ftúrfern

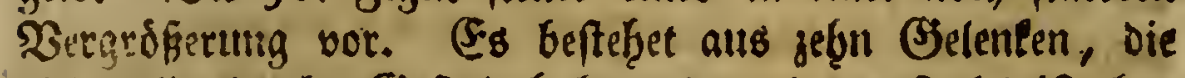
nicht alfe einerlen Seffalt ţaben: Berm bas erfte (a) ift obeur

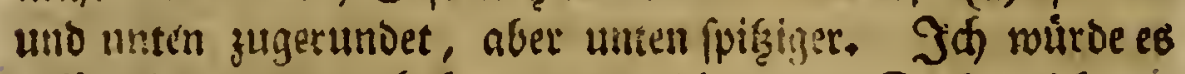
enfós:mig genennet baben, nenn bie untere Spişe nidht ju pebe abgettumpfet ware. Diefes Bstied ift Das färefte. Die bren folgenden fitto lainglide) (b, $c, d$ ) uno fegre ouns me; Barautf folgen bren Engelförmige (Stlieschen (e, f. g.),

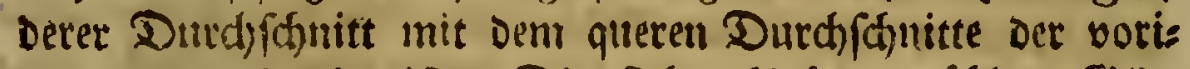

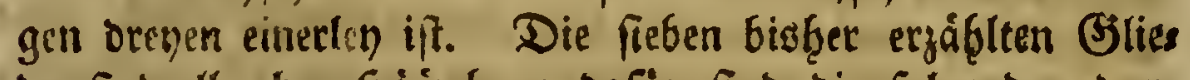

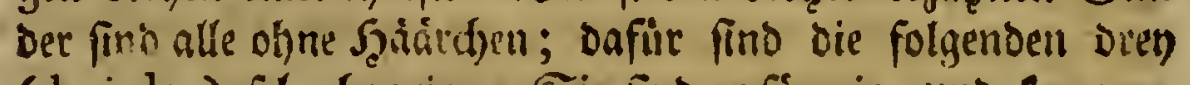
$(h, i, k$. ) fohe baarig. Sie find enforrnig, und fommen Dem erften (a) ant (Jióse faft gleid.

Noch fiaben sie ffitugel etwas befonderes. Sic fiub ungemein sinrd)fidtin, obne farbe, obue ein fid)tbarcs

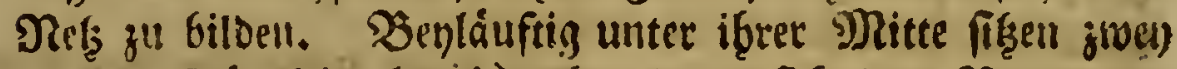

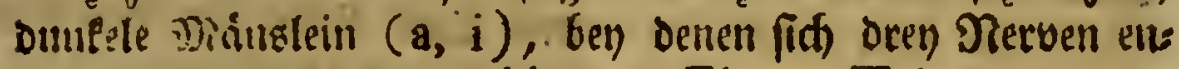
digen, navon zmeen (dh, e c. Fig. 3. Tab. 3.) voin $\mathfrak{u}$ rfuru:nge des, Flügets berfommen, Der Nerve (f b) aber, roe!cher liad Dem innern Rand låuft, entfpringt aus einem Der vorigen (ec), ober lief vielmeder, enge an ifun geffiloffen, bon ber warzel aus.

Diefe Muskeln und Nerden muifert bem Snfelte das

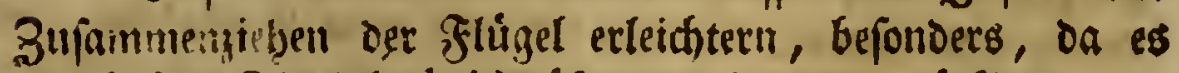
Den áußern Fbeil (a k i) ůber Den imuern zurúffleget.

Eerflitung Der Siguten.

\section{Tab. 2. .}

Fig. 2I. Die Made, nod) nicht vodllig ausgewacijpen. Fig. 22. EFbent oiefelbe vergrókert.

\section{a. Der $\mathfrak{N o p f}$.}


h. Der erfte ßing, ber grófer ift, als bie úbriget.

cc. Die St)manjbornet.

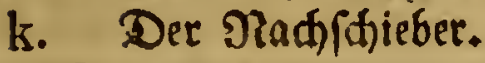

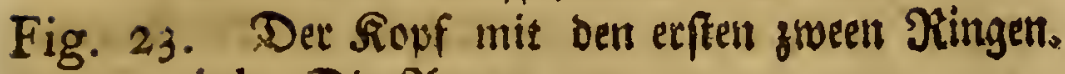

b,b. Die Atugerr.

f, f. Die f̧íblf̧orner.

g. Das betlle Drenect.

nn. Die zrueen Flecten auf ber Rippe.

Fig. 24. Fin F+16.

D. Die taingere Silante.

d. Die elúrzere.

Fig. 25. Die givcen lefeten Ringe.

cc. Die Edwwanffidrmer.

k. Der Siachifhieber.

1. Die fámárzlid)te Diterlinie.

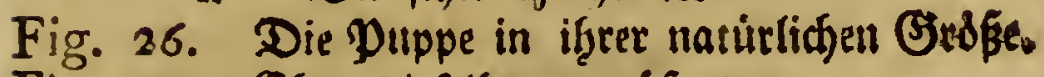

Fig, 27. EfGen diefelbe vergrófert.

m. Die Seite bes Roppes.

n. Die Seite bes Sdmanzes.

b. Das Aug.

a. Der augformige fled.

cc. Die St)manjfigrner.

Fig. 28. Das lef̧te (S)lied Der Yuppe nođ mef̧r vergrd peett.

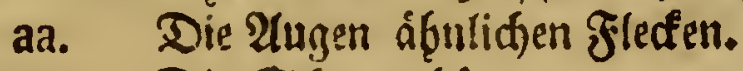

cc. Dis Shwanghorner.

Fig. 29. Der אáfer in feiner uacủrtidgen Grof́ce.

Fig. 30. EGben derfelbe vergrófert, suenn er fich wie tobt anfteilet.

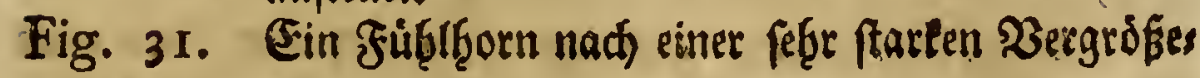
zung.

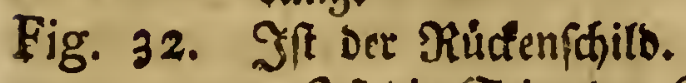

a. 乌/t die Geite Des $\Re$ sppes.

b. Die Seite bes Sdmanzes.

Man bemerlet bier beutlid ben $\Re$ and an betsoen

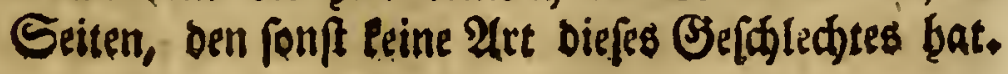

Fig. 


\section{Eedfte 26handlung.}

Fig. 33. Det siopf vergrófert.

d. Die ber;fórmige ßertiefung auf der Sdjeitel. cc. Die $\mathfrak{A}$ ugetr.

bb. Die warzerfơrmigen Sugeln vor ben \&ugen.

aa. Die Fref́ledtrtcin.

Fig. 34. Ein F̌ß

$$
\text { Tab. } 3 \text {. }
$$

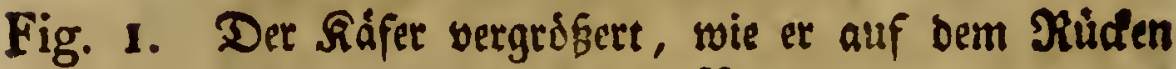
liegt, mit einer tleinen $\mathfrak{B e r t w e n b u n g . ~}$

Fig. 2. Eine fflúgeldecte, die auf Der ertyobenen Seite liegt.

a. Sos Der Drt, wo lie an ber Sdutter angefeftet ift.

b. Sili die Spize.

c. Ŝt bie innere Seite.

d. Die ánkete.

Fig. 3. Ein Flügel.

a. Das ćufere Mdustein.

dh. Eime Senne, die unch biefen Mäustein tåuft.

ec. Fiute andere Senne, die eben ong̨in gcb̧t.

i. Das innere Miáustein.

fb. Die Senne, Die nad) Dem innern MRăuslein ju lauft.

8. Eine tưzere Senne, bie fich am innern Ranoe endiget.

\section{7. \\ Siothe Sdildnus. \\ Tab. 3. Fig. 4. 5.}

Inter bent Moofe b̧ålt fid ein Jnfelt auf, bas man

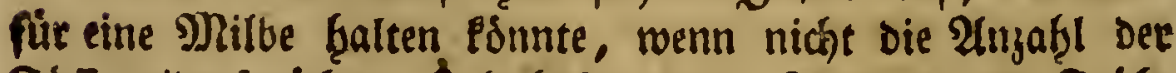

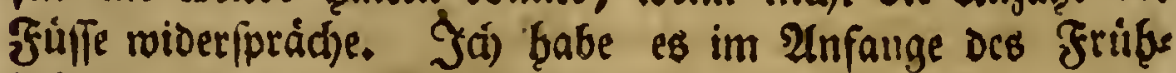
iađ̧res gefangen. Ess ift åußereft tråge, und mant mỏchte es wohl für ein Faultşier unter den Jnfeeten bुalten. Es

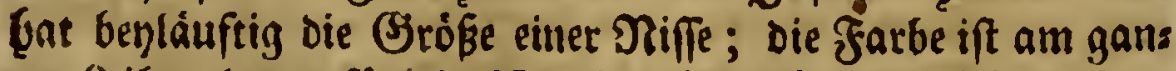
zen Seibe, ber enformig ift, zinnoberrotb; oie Jüufe aber,

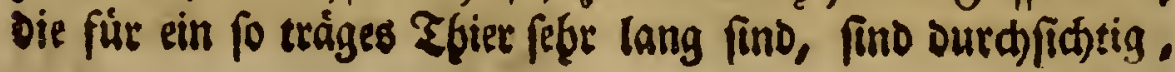




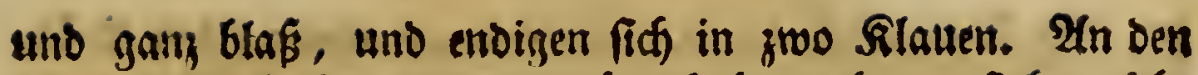

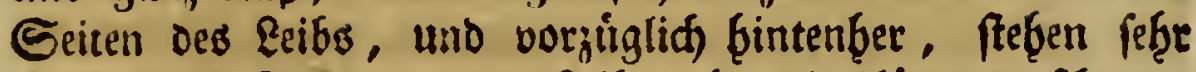
lurge fteife borften voun \&eibe ab, Die glánzeno fidnuarz fino. Bornen freben zwo folde) Borften, Derer jede aus

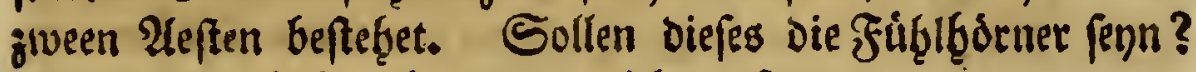
Westigftens babe id andere nidft gefunden.

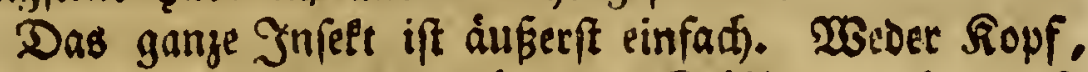

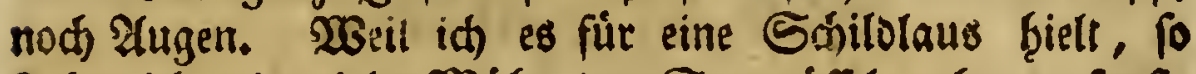

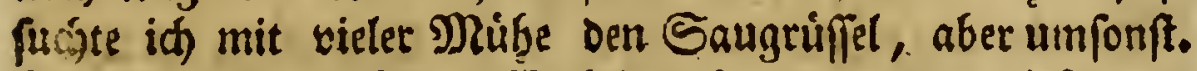

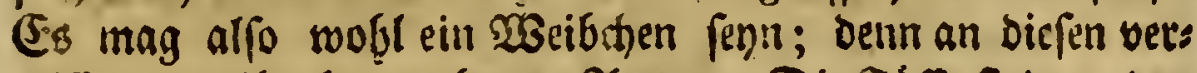

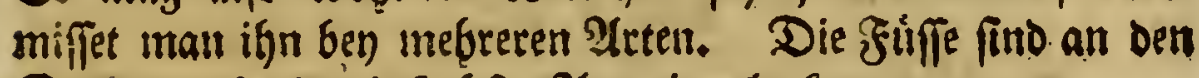
Seiterl auf oie eirffadfife 2 Att eingelentet.

Die viette Sigur Der britten Fafel fellet ein foldees

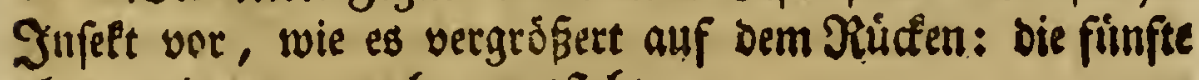
aber, wie es untenter ausfieft.

\section{8. \\ Bellbe Maide. \\ Tab. 3. Fig. 6. 7.}

Tipula flava. T. flava ; capite, thoraceque nigris, alis fufcis incumbentibus.

An Tipula paluftris. Lin. fn. fu. n. 1775. \& S. N. Gen. 252. fp. 54 ?

beidtreibung. Sie if eleiner, als bie gemeine Gelffe;

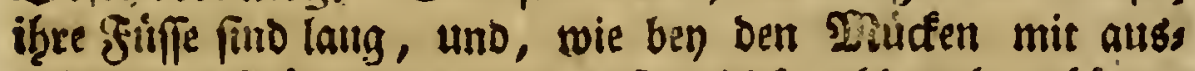

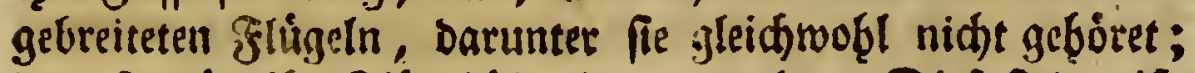

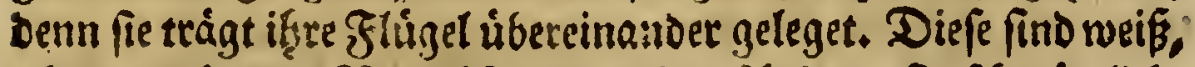

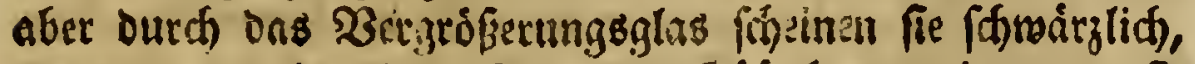

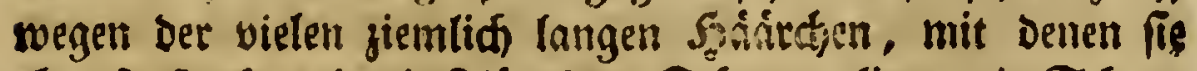
eben fo ftart, als Die Flliggel ber Sdfmetterlinge mit Sकup

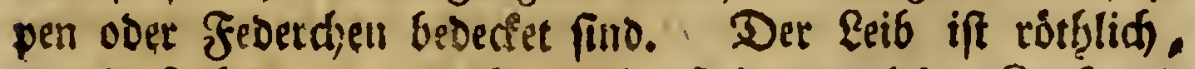
oranienfarben, oder gelb; Dod) ift jedesmal der Sispf uno

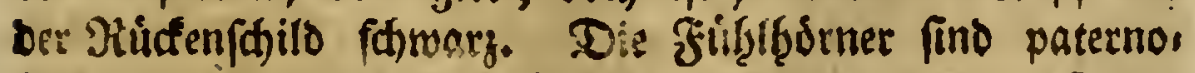

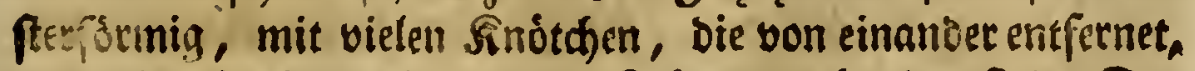

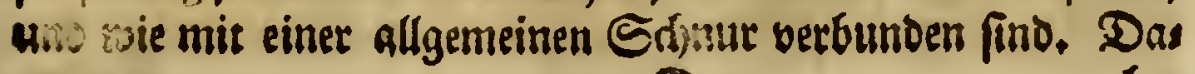


ber finto fie zicinlid) lange. Mitten an cinem jeben Sndts: c)

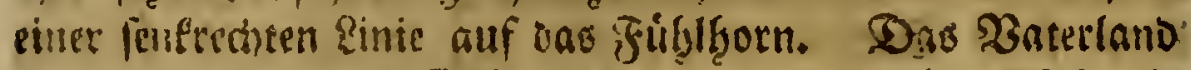

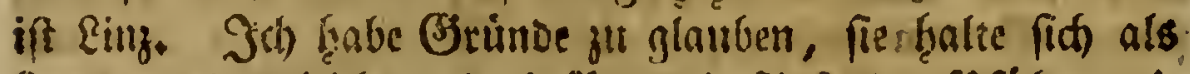

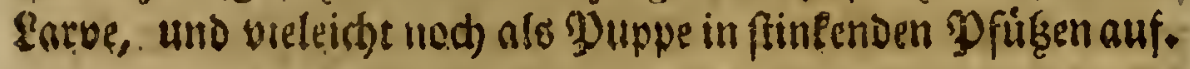

\section{S. 9.

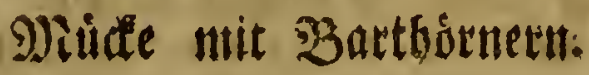

Tipula barbicornis. Lin. S. N. Gen. 253. fp. 25. Fig. 8. 9.

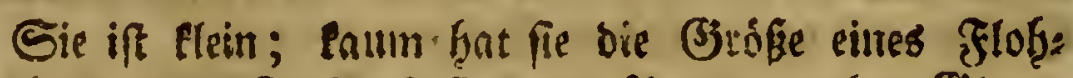

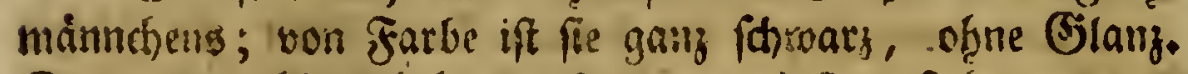
Gie mas wobl auth baarin fegn, wenigfteng fithen um Den

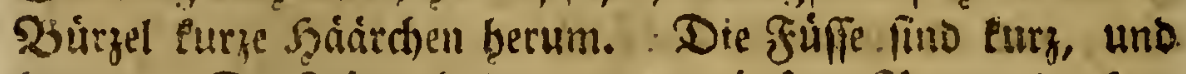

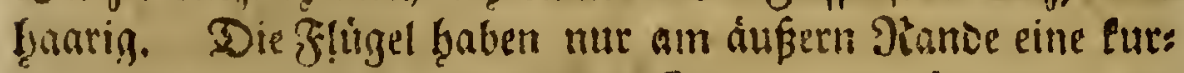

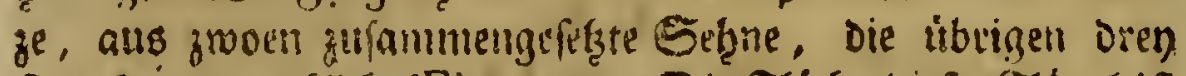

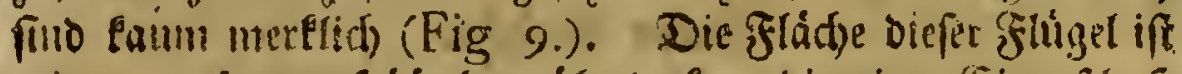

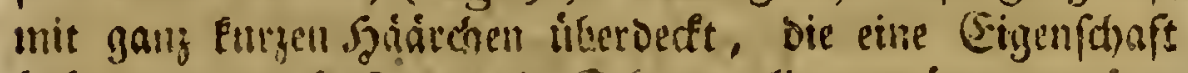

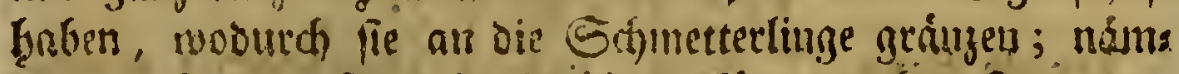

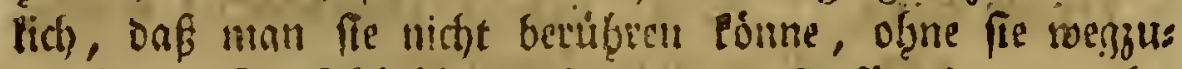

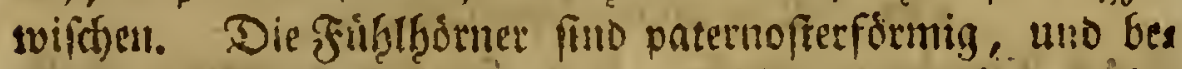

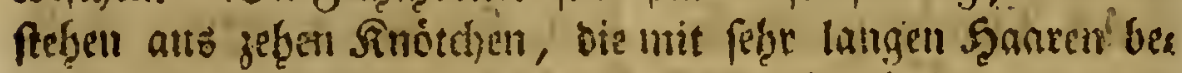
Feget find; die cberften oren woer viere aber baben nutr gany

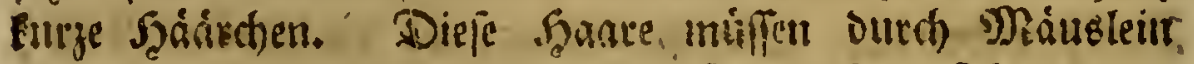

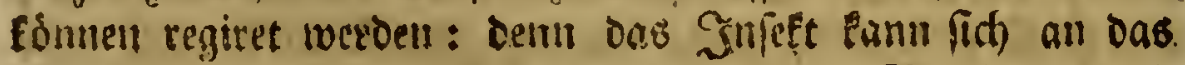
griţt(born antegen, uno fant fie in eimen $\mathfrak{B}$ uld ausbreis. ten, wie es if̧m Eefiebt.

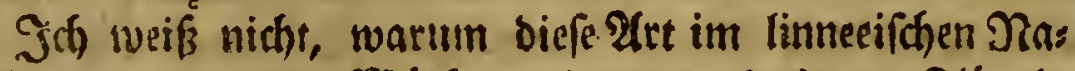
turfoffeine unter ben Mhicen mit ausgebreiteten Fluigeln.

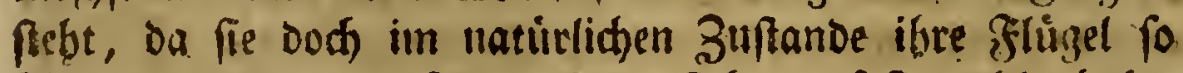
übereilnanderlegut, daş man faum frebt, daß fie weld)e thabe.

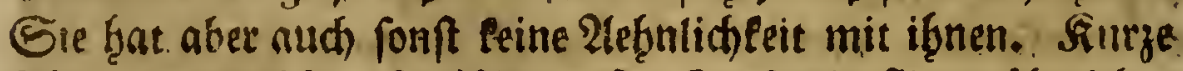

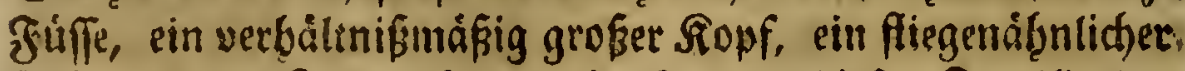
Qeiv: Inuter Fenuzeichen, die fie von biefer fanmilie dee Dhiffen abfontern follten. 


\section{Sedfte 2 bromblung.}

Finige baten gar Peine Inugen Şarare an ben Frutbls Gornern; fouft fint fie aber der befdriebenen 21 trt bollfoins

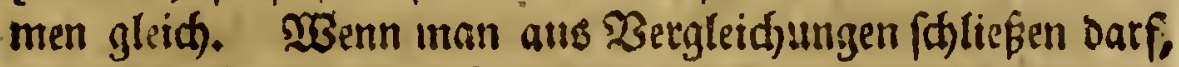
fo mögen fie bie. Xeibd)en feni.

- Diefe Mitce Esmmt bey teitern Frúflingoahenoen an unfere Fenfter, wo fie baun au Stafe bimaufertectset, abee inumer roieder zurúctfállt.

\section{§. 10.}

Ein Eleinet Raubfafer in bem Mtoofe.

\section{Tab. 3. Fig. To. I I. it}

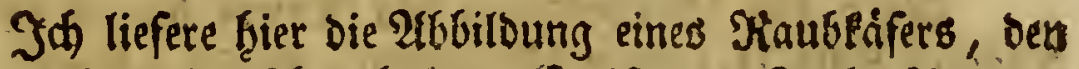

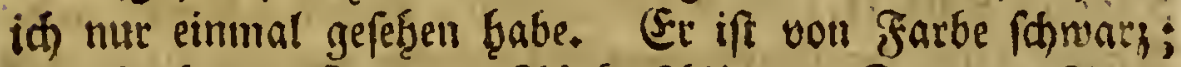

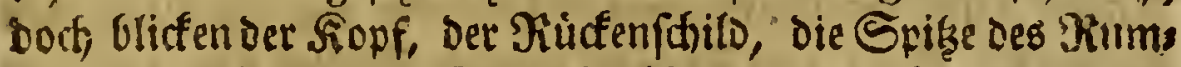

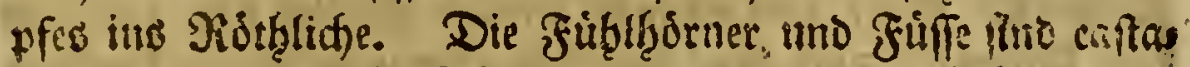

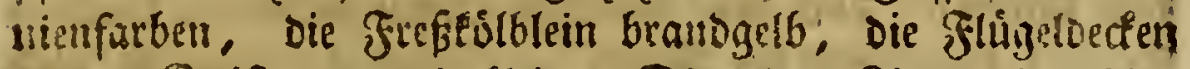
Fur.j. Er ift ungemsin flein. Die gelynte Figur zerget peine

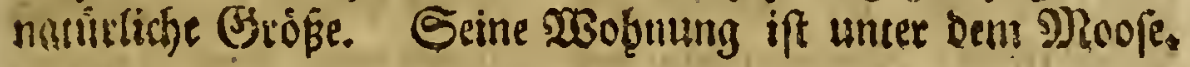

\section{II.}

Die Todenubr.

Tab. 3. Fig. Ip

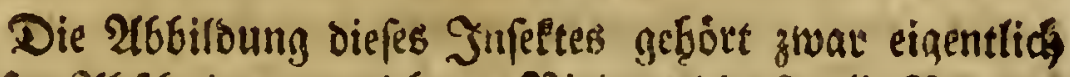

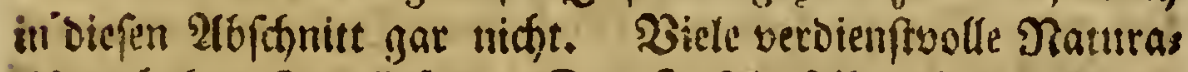
liften fraben fie geliefert. Das Surfeet felber ift fo belannt, Dá es eben nich)t nothrwatndig ift, forgfáltig barnady zu fus

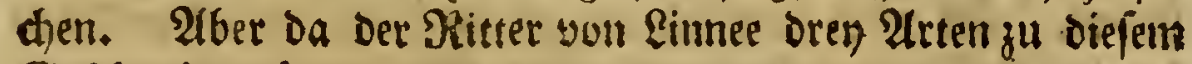

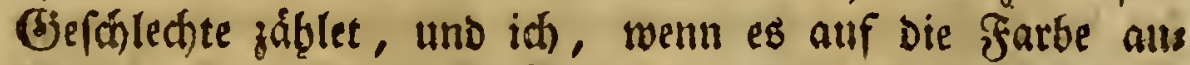

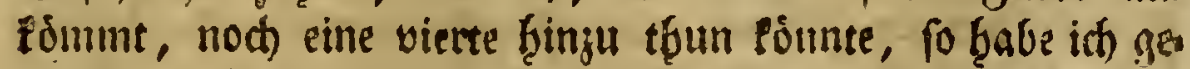
glaubt, idh fet) nid)t unred)t baran, wenn ich mesne $\mathcal{A}$ is mettungen berfege."

Dag Jinfelt, von bem die Rebe ift, und das man in Deutfhland mit einem ein Bifgen aberglăubifher Damen

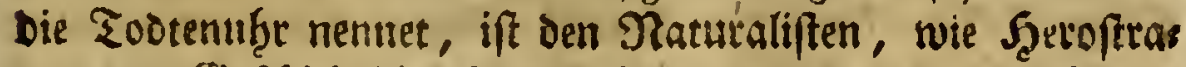
tus den (Befdhidtfd)reibetn, betannt getworden burd das 
Berberbuif́, bas es in ifreen fajonen Saunmlungen von. Sidgeln, SPflanzen, Jufetten, befonders aber von Edinets

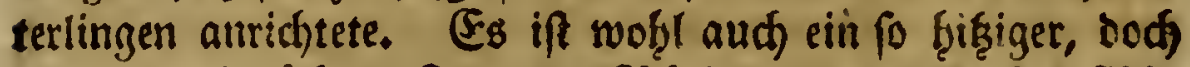

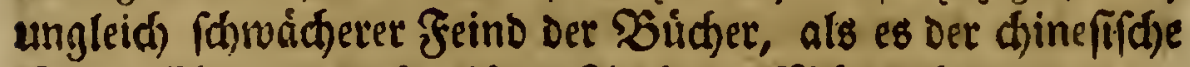

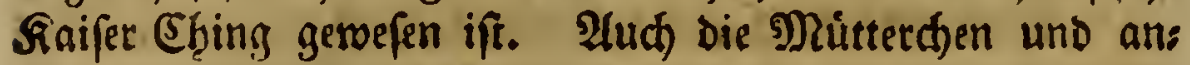
bere furchtfame Reute Pennen cs, zwar nid)t ber Sieftalt a fondern feiner 23 irfung nach. Denn es mad)t einen feghe. farfen Raut, indem es mit feinem Schmanze anf burre

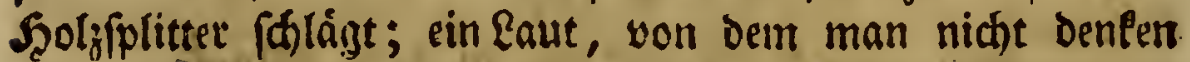
follte', Dás er yon einem fo ungemein eleinen 'Rórperchen

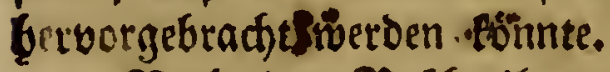

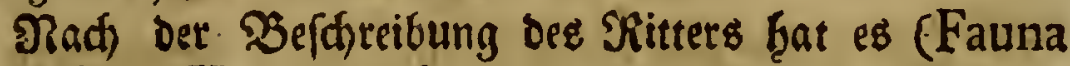
Suecica Edit. II.) einen lánglidhten, blaffen Fórper, gelbe 2ugen, und borftenformige futhfrbórner von Der Ránge Des

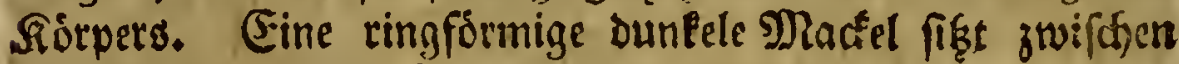
Dem Rumpfe, und hüber berferben fonmanzmárts ein Dunfeler Yountt; Die Seiten ber Ringe an ßumpfe baben fo viele

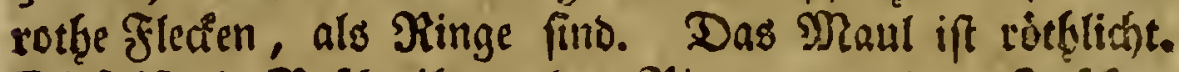
Diés ift bie Sefdreibung Des SRitters you bem Sinfepte,

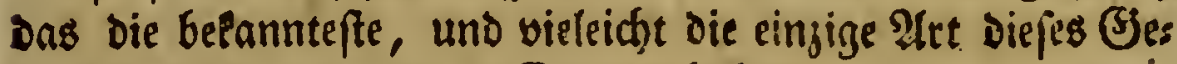
fiflectes ift, Die wir in Esuropa haber.

Эa) fage: Die Einzige; Denn es ift mir feftr betenes

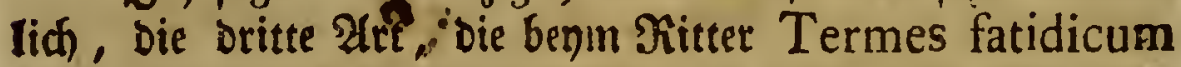
Geiffet, uno als Spanien gebưrtig fenn foll, fưr eine wirts

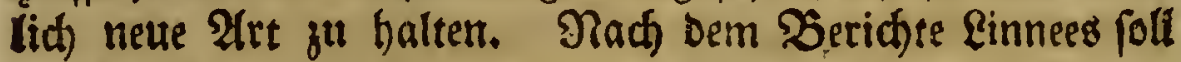
ps wie Die genteine Tobtenuhr ausfechen, utur noch eitumal fo grós fenn, und Dunlele 2lugen, und ein abfárbiges Maul Gaben. Es wiro jugleid Die geţnte Tafel bes eilfren Theis

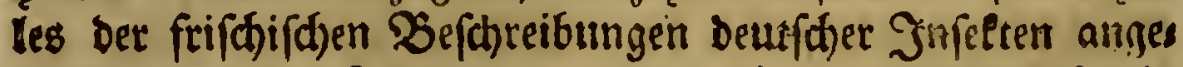

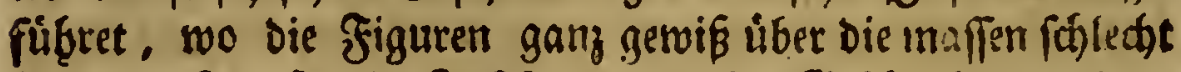

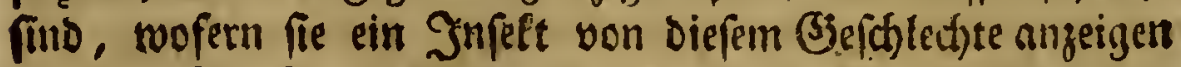
follen. Diz Beffereibung ift eben autd nithe dettlid gentug, uun beftimmen fu esonnen, ob es ein Termes fery, oder nidjt.

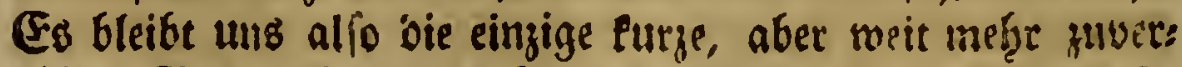

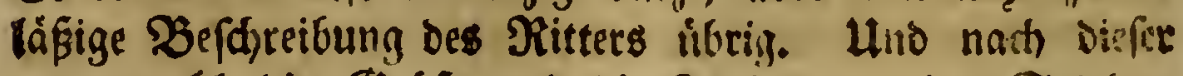

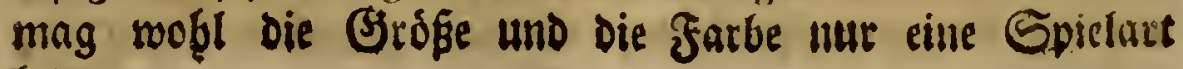
beventen. 


\section{Sicbente 266randututg.}

I. babe in meiner Sitauterfonmmlung welche anges troffen, die von Der Sróke einer mittelmákigen Laus wa: ren. Die Farbe war blaf́, wie an ben \&áufen, bas Maul

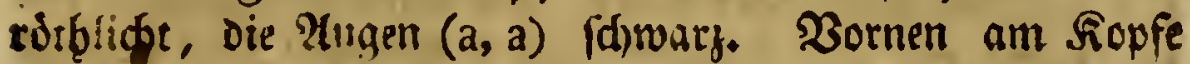

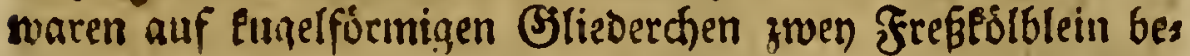
fortiget, und ginter Deufelben faffen Die febre langen borften.

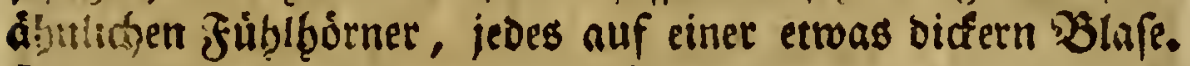
Die Juiffe beftanden auts bren Griedern, und Gatten an ber Epiz̧e zwo Silauen. Das oritte, das ift, Das leşie Yaar

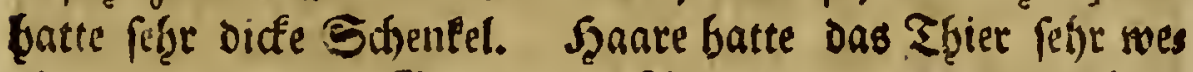
nig, nur um bie Jegend des affers war es etwas baas rigter.

Man fief̧t aus biefer Befffreibung, baß bas gegens wärtige Infelt gerabe Das Mittel zrwißhen Rinnee's zwenter und oritter $\mathfrak{A}$ (rt fen; Das beist, es if eine Schattirung,

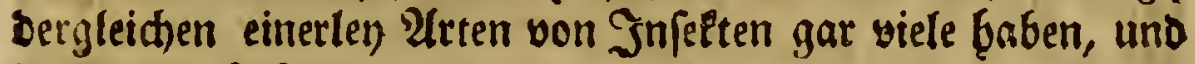
becte zwo áußerften, wenn man dic mittlern nicht zu Şilfe nimunt, gar leidst autd ben gefhidefeften Naturforidher bers fübren, fie für zroo Arten zu balten. 2Gber foldye Sdjats

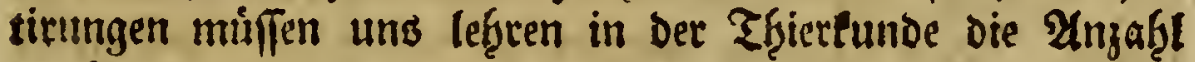
Der Ârten vermindern, wie fie es die Botaniften geleffret baben.

\section{SIblandlumg.}

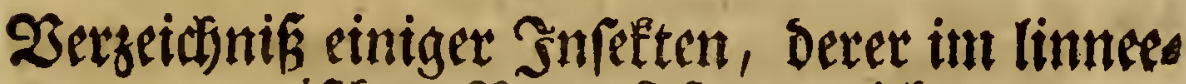
anifoben Paturititeme nidst gedact)t wird.

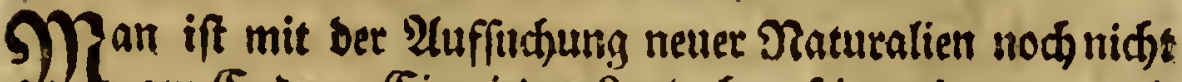
J) am Enbe. Ein jeder \&and bat feine eigenen, uno

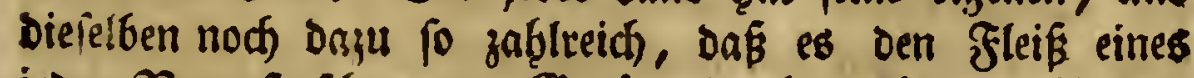
jeden Naturforfhers zur 'Senúge begablen lóme. Und in Diefer $\mathfrak{H} b$ fidft ésnnen Die fogenannten FIlacen uno Jaunen immer nod feg̨r núf̧lid feñn. 
Dan getátf in eine Art von Erftaunutg, wenn man in Den linnecanifiten Naturfifteme gegen brentaufend $\mathcal{Q}(x+e n$ von Jufeeten angerenget finbet; uno Dennod), wie viele frat

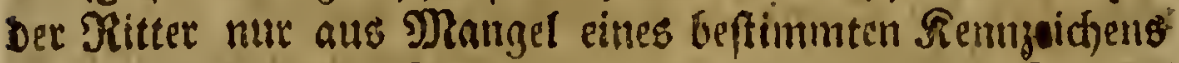
nifft ausgelafien! Omittere coactus plurimas fpecies paganarum (phalaenarum), fagt $\mathfrak{e r}$, nec non minutiflimarum, facie, etiantauctorunj picturis notas, fed mihi aptis verbis non diftinguendas. Wie viele .

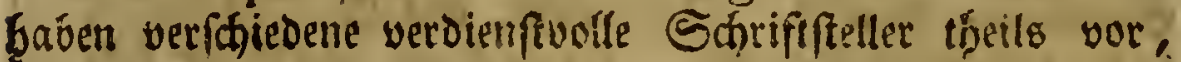

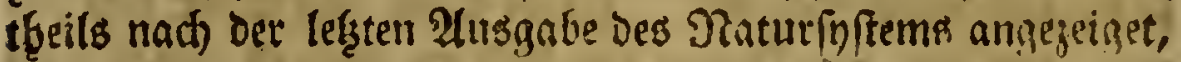

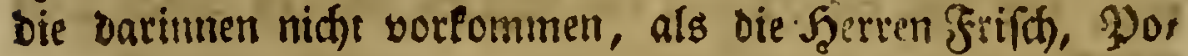

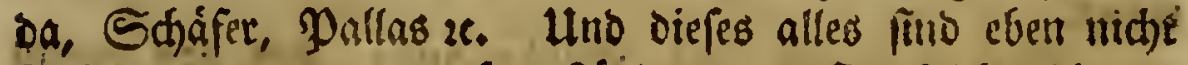
Snfetten aus neuentbecten \&ándern; es fino folthe, bie vor

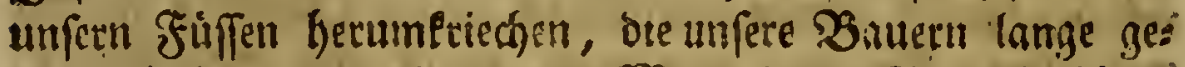
fannt baben, und Die nu: aus Mangel eittes Naturforffaers bis auf je unbelannt brieben.

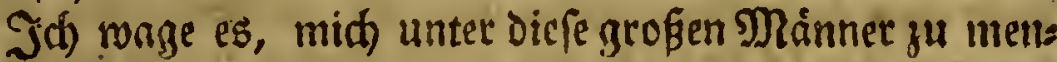

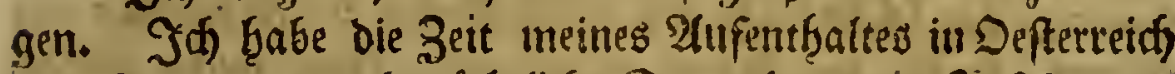

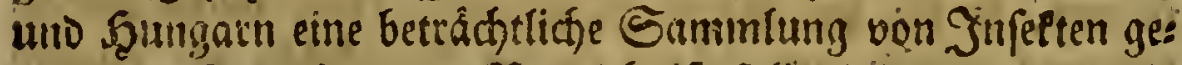
macht. Das folgende $\mathfrak{3 e r z e i c h m i}$ foll einize Davon, die

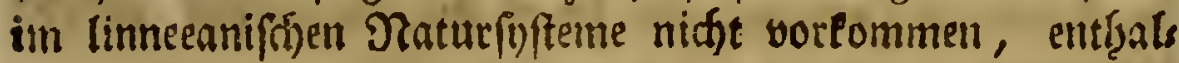

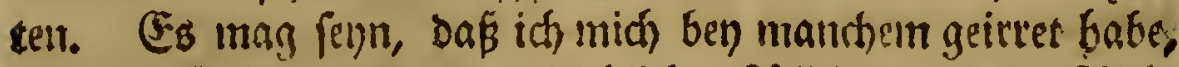
aber ber Fagler Des umbergleid, fichen \&offlings, an Der SRid,

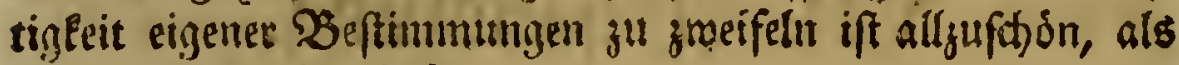

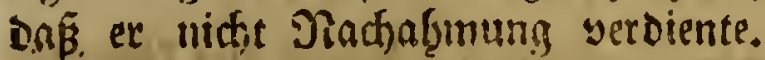

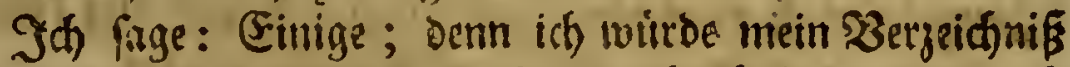
soentigftens nech eimmal fo frare genache Gaben, wenn ids alle Die, Die meines Erachtens noch nidht fino angefuffret

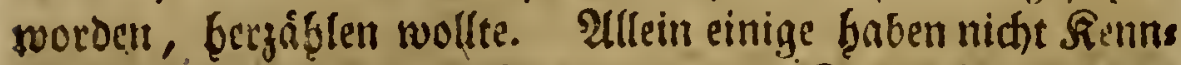

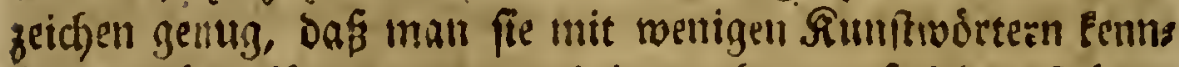
bac nraden esomte; yon einigeir aber miß id sepeben;

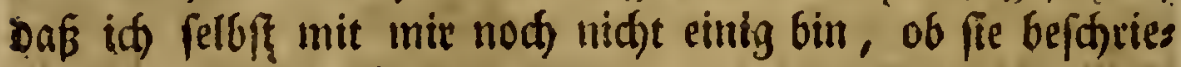
ben feyn, oder nid)t.

Son ber Staffe ber Sthmetterlinge thabe ich eine eingige Urt angefiniset; nimt, als wenn es in Defterreich nidit

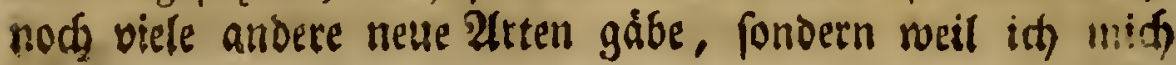


nidft unterffeben wollte, Dem vortreffididen 2 Berpe jweenet

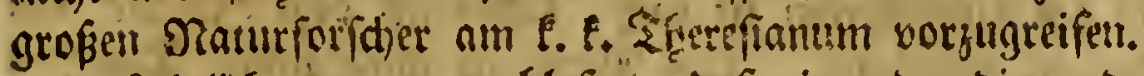

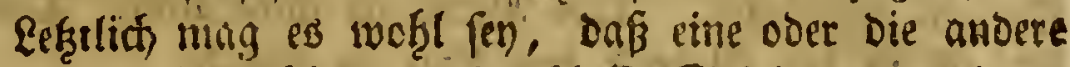

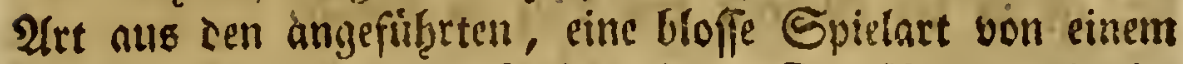

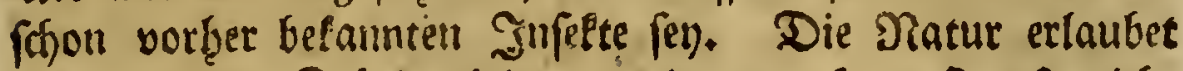
fid) in biefens Etridte vieles, und mant fann fie oft nicht

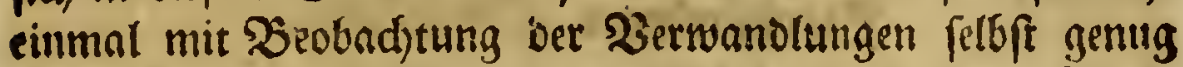
beloufchen. - Ja) babe zmenerlen Fictenfpinner (Phal. Bomb. Pini Lin.) getrabt, bende waren Eicen, uno wié fie eitrander unterfdhieben waren, fo waren es aud ifhre ßiaupen, unib gleidgwofgl warem fie gang zuberfidstlid eine und ebendiejelbe $\mathfrak{A}$ rt.

S. $x$.

\section{Fettfâfer nit zweencn Branopunften.}

Dermeftes bipunitatus. D. oblongus niger; thorat cis apicibus ferrugineis.

Befurretbung. Er iff to grof, als ber blame greets enfer (Derm. violaceus Lin.), fhwarzbraun von Jarbe,

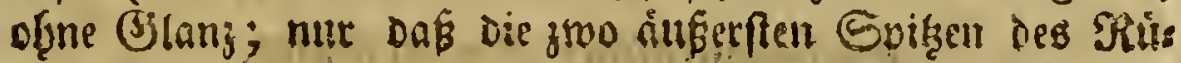
denjidildes gegen ben Krumpf einen brandgelben flecten bas ben. Das Gutter if mir unbelannt. : Er ift in ber. J̈ts geno von $\operatorname{sinz}_{\text {ju }}$ Jgaufe.

\section{S. 2.}

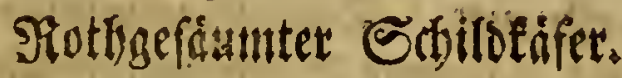

Caffida Janguinolenta. C. nigra; thorace elytrisque margine fanguineis.

Befidreibung. Dis Snfert ift fo großs, als Der

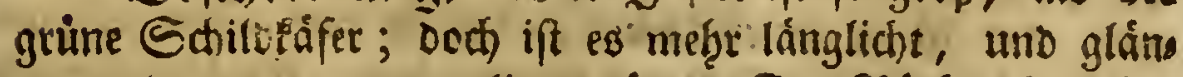
get, als ment es anspoliret máre. Der Rúdfenfátilo bat

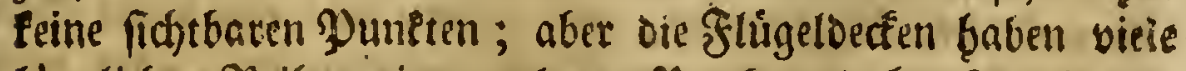
İ̀nglichte Peig̨en eingegrabener Puutte, dab̧er fie wie ges

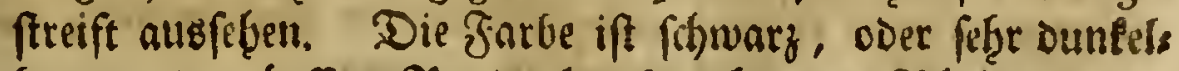

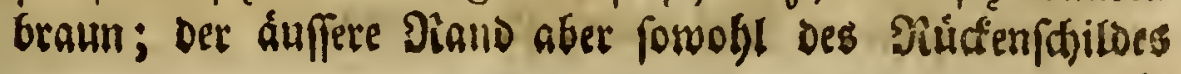


als ber frügelbecten ift roth, Daf̧er id bein Snfelte ben Diamen geidjipfet. Das Futter ift unbefannt. Das Sns

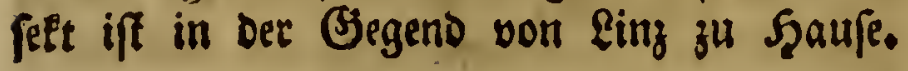

\section{S. 3. \\ Strobfatbenter Sdbilbéafet.}

Calfida fubferruginea. C. nigra, thorace, elytris, pedibusque fubferrugineis immaculatis.

Seichreibung. 'Das Snfelt ift um bie Şdffte tleis ner als Das vorige. Sopf, J゙úblfsorner, uno Reib fino

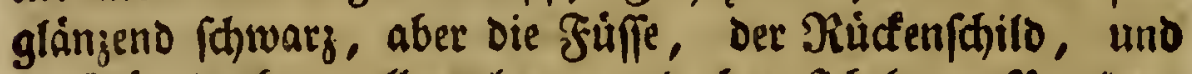

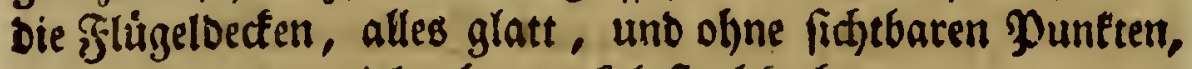
fino gelb, oder vielmege ounfel frobfarben.

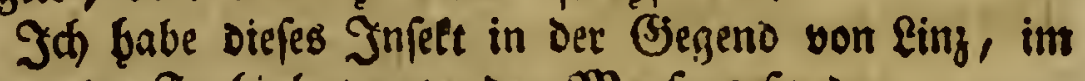
Anfange des Fruf̨ją̧rs unter dem Moofe gefunden.

\section{4. \\ Defterteidifder Sonnentáfet.}

Coccinella auftriaca. C. nigra, elytris fafcia rofea abrupta. Coccinella cacti. Ling. S. N. Gen. 198. fp. 41.?

Befchreibung. Diefer Sonnenéfer bat oie Erróke,

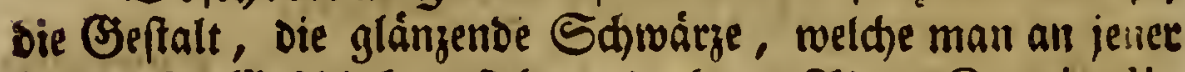
Int biefes (Sefhlechtes fief̧, die benm Pitter Coccinella opultulata (Sys. Nat. gen. 198. fp. 44. Faun. fuec. n. 500. Podimus. gr. pag. 25. n. 9.) Geiffet. Durims nen aber ift er unteríficeden, baß́ er nur einen eimzgigen rotben, bod) rofenfárbigten Glecten b̧at. Er ift unten am Srunde Der Slügeldecfen, und gebet, wie eine breite Sins

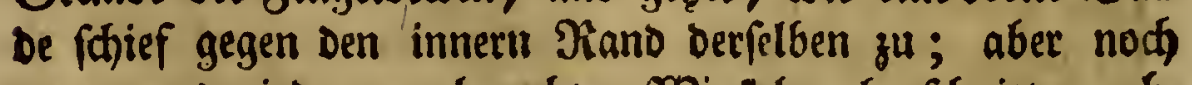
unterwegs wird er nad) recbten 2 Bineeln abgefdgnitten, obs ne Darnad feinen \&auf reeiter zu neģmen. 


\section{Eiebente 2rbbandlung.}

SBenn man bie ztoo $\mathfrak{Y}$ rten, von benen iá unter dies fem Biffer getcoet babe, wob̧l gegeneinauder beâlt, fo wirb man lvie tiberzeuget, fie verbalten. fid jll eimander, wie Gloffe Spielarten. Die Rarve mag Den Snoten auflófen. Sob babe fie in ber Bregeno von liny nut eimmal gefunden.

\section{S. 5 . \\ Wonferinuinbblattę $\mathfrak{f}$ et.}

Chryfomela menthae. C. ovata, nigroaenea, nitida: .

Beicbreibung. Suf ber $\mathfrak{W}$ afferminge findet tman eine Earbe, Die runglidt, Dabey aber obne 23 argen uno stauce

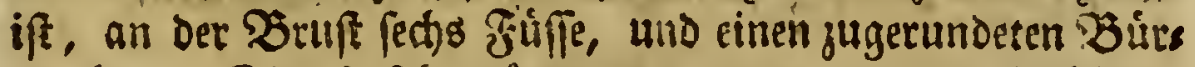
zel bat. Sie iff feget trâge, und wenn man fie beribret,

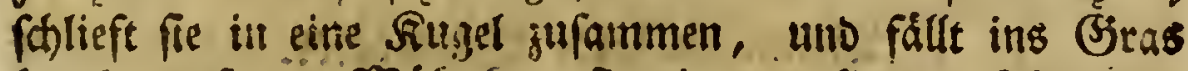

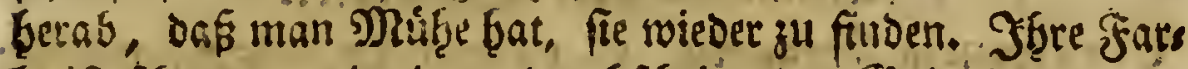

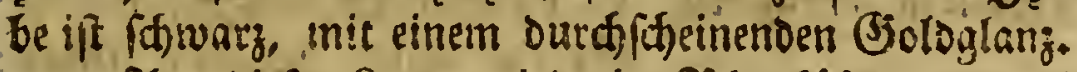

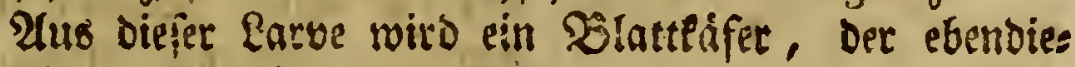

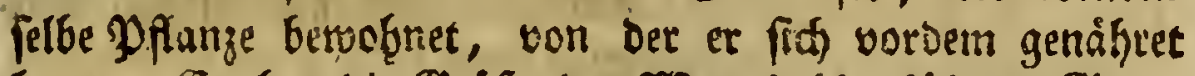

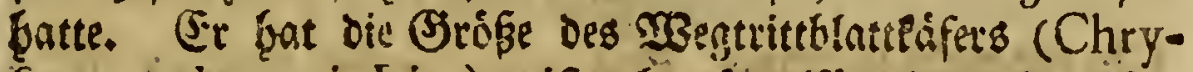
fom. polygoni Lin.), ift aber eugelfórmiger als oiefer.

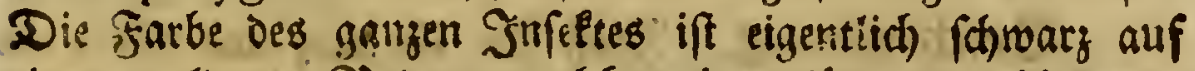
einem goldener S3oden, weldhes eine glåmzende, 佸ielente

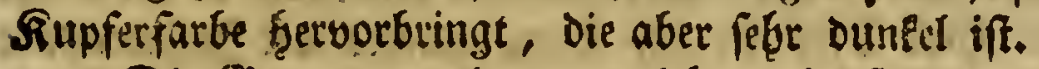

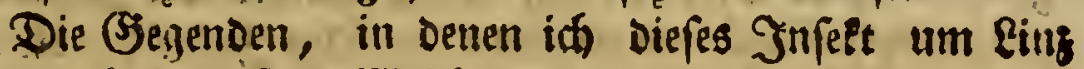
gefunden babe, find willtheringen und Rirdfficlag, an

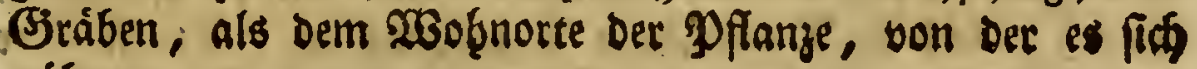
nábret.

\section{\$. 6. \\ Eletenblattiafet.}

Chryfomela Pruni. C. ovata, nigra; capite, thorace, elytrorumque opicibus rufis.

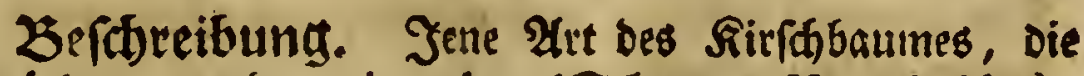

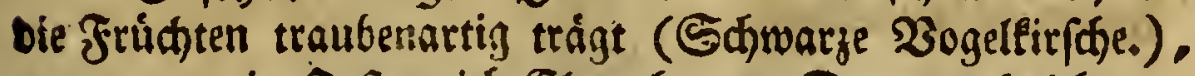
nenut man in Defterteid (Elerenbaum. Davon gebe id bem 
gegenwartigen Simfette, Das barauf, uno auf bem Yuftaus menfaume robsut, Den Namen, uno, bebalke mir Dell aridern Namen biefes \$atuns für eill anocres Jufept, Das mit Dem

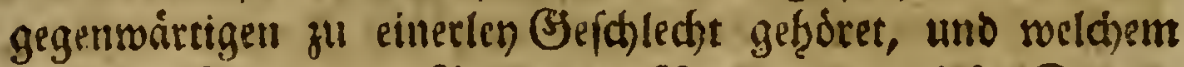

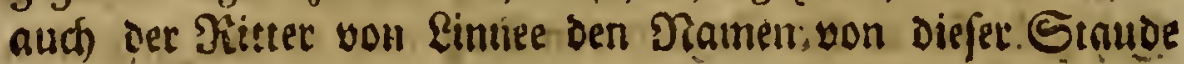
gef́chópfet bat.

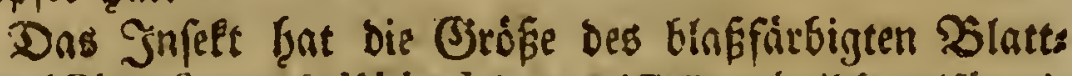
Eáfers (Chryfom. pallida Lin.), iff von balbêgelfớrmis ger Eieftalt, unb van Farbe glànzeno fanwarg.: Doch fino

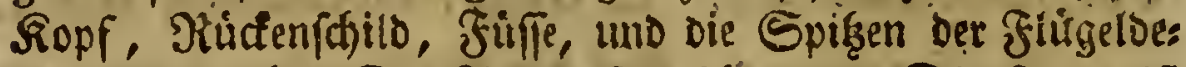
dent ziegetrotţ. Die Mugen fimb frfivarz. Die Earte ift

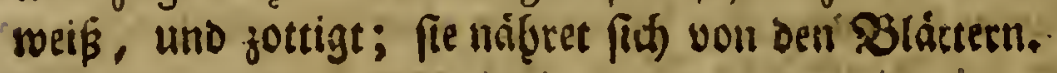

\section{S. 7.}

\section{Brnoflediluter $\mathfrak{B}$ latteafer.}

Chryfomela ferrugata. C. cylindrica, nigra, nitida ; elytris apice macula lutea; antennis thorace duplo longioribus.

Chryfomela moraeis. Pod. mus. graec. pag. 38. fp. 9.

bef́cbreibuna. Diefe $\mathfrak{A r t}$ ift găng uno fidger uns teríthieden von Rimne's Chryfomela Móraei, zu der fie der

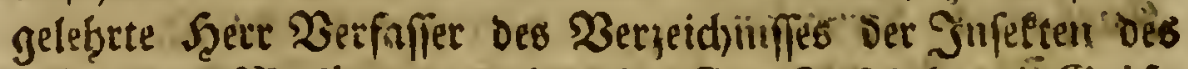

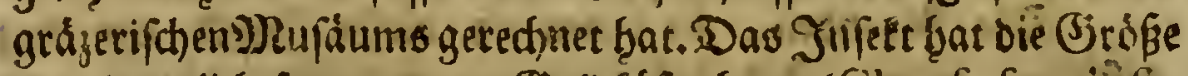
Des eigentlich) fogenannten Ooldeśferchens (Chryf. fpeciôfa, Lin.); das in Deutidalano fo befannt ift. Es ift abeet

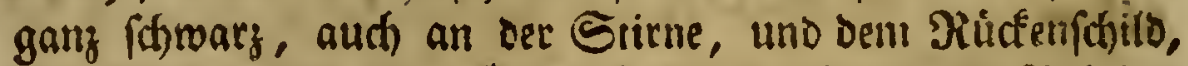

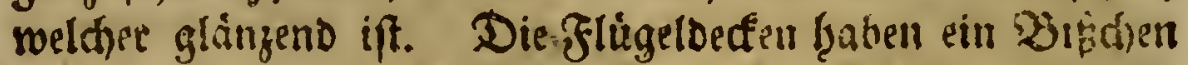
weniget Silnur; bas fómmt Daber, weil Eleine lánglidfte

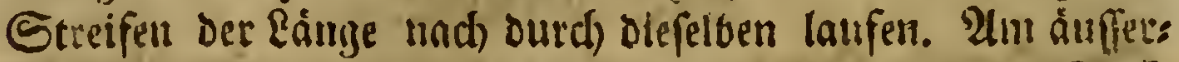
ften Ende ift allf ieglid)er betfelten ein roftfarbenes fFled:

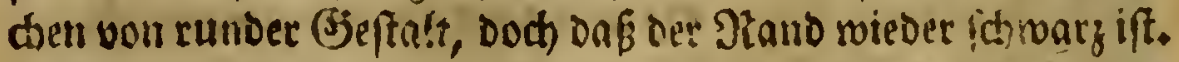
Die Szeimato ift \&inz, unb visteicht aud) Stenermarf; Das Gutter if unbelannt. 


\section{8.}

\section{Sotfleibiger Mlfterrifilléfit.}

Attelabus formicaroides. A. thorace elytrisque nigris; elytris fafcia rubra albaque.

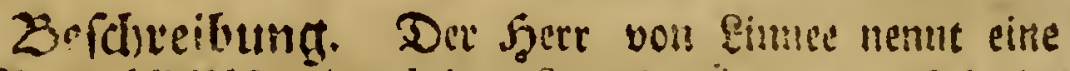

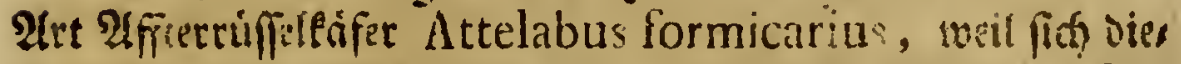

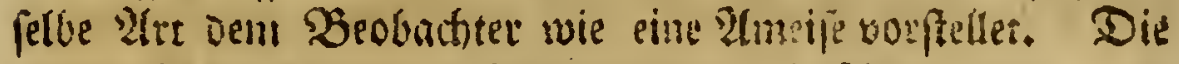

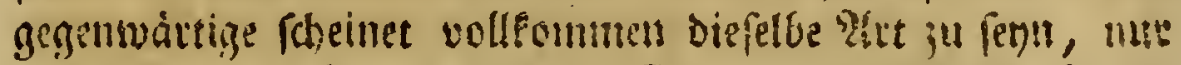

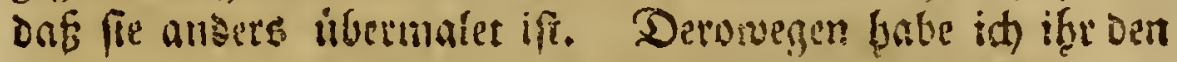

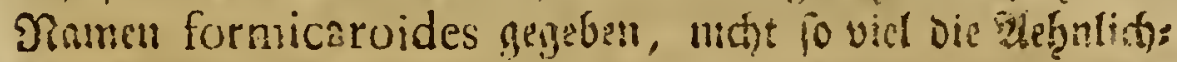
feit mit einkr sámeife, alo unit oer vorigen ấrt anzuzeigen. Der beufche Stumen wit' aus ver bejhreibung erfláret.

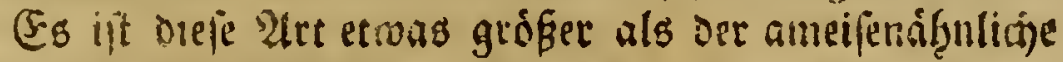

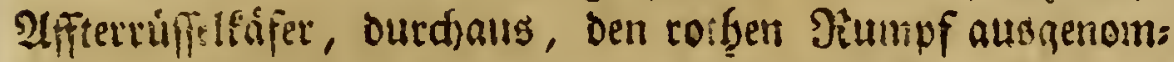

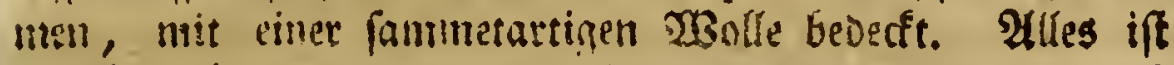

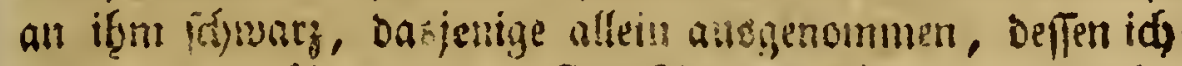

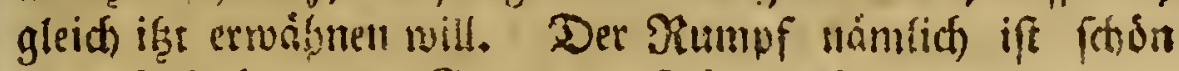

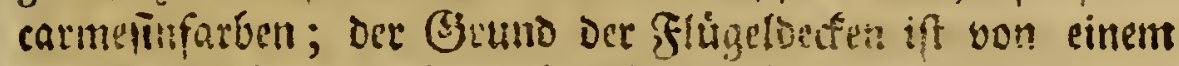

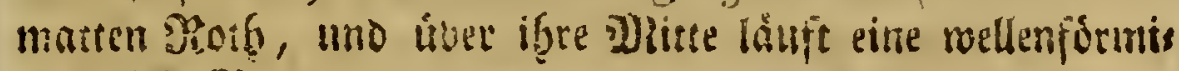
ge weiffe 3 inde.

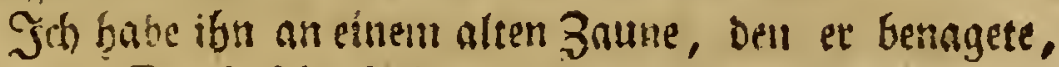
gefmoer. (5) iff fabr biffig, und wenn er gefangen ift, beifst er und) allerr Seiten your find.

$$
\text { 5. } 9 .
$$

Soljoros mit adst \$untent.

Cerambyx octopunctatus. C. viridis, thorace tereti mutico, elytris punctis octo nigris.

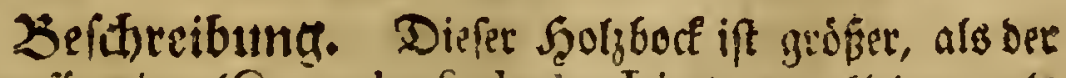
treppenformige (Ceramb. fcalaris. Lin.) uno fleiner, als Der, Den Der Pituter Den Gecḩund (Cer. Carcharias Lir.)

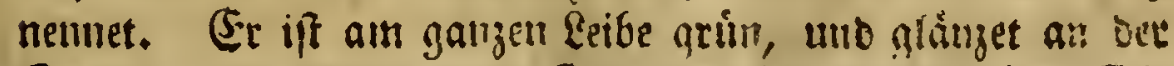
Soune, als wenn et mit ङ̧olofano befarenget wáte. Die 
Fủhthidtner, die fo lang als ber $\Re$ drper find, fhaben an ben

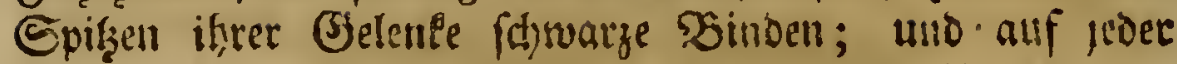

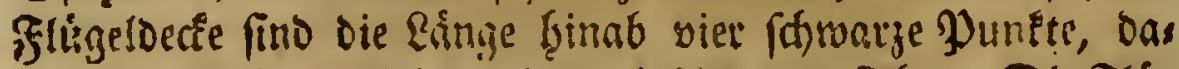

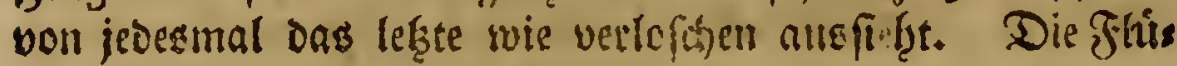
get ferbft firto rufigig; Der Shictenfsgilo ift walgenformiz uno oḅne Ertgoftumget?

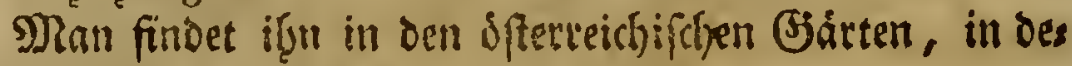
nen findenalleen angebracht, fino, fparjant.

\section{S. 10.

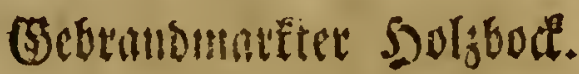

Ceranbyx pufulatus. C. niger; thorace inermi cylindrico, medio macula ferruginea.

Befflyeibuna. Er ift gerade fo grop, sls der

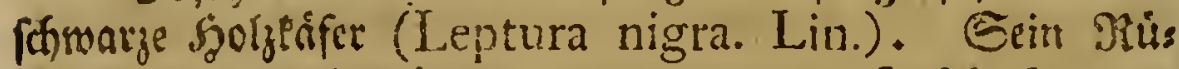
denforito ift walzenformin, tmo das ganze Jnfelt fo ziems

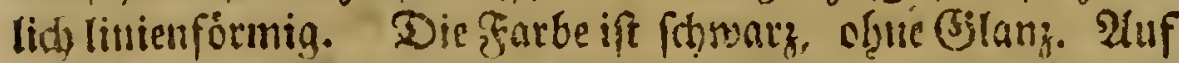

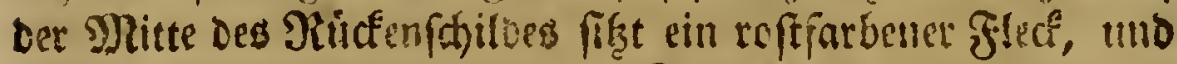

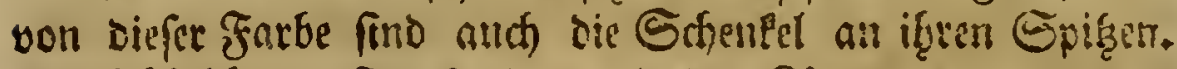
Die Griftethórner find fo laurg als der Sidrper.

Seine Szeimatb ift Defterteid).

§. II.

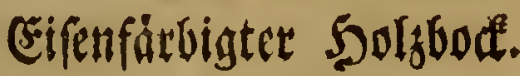

Cerambyx ferreus. C. thorace tereti muticó; plumbeo niger immaculatus.

Befdreibung. Das Infett ift linienformig, yon

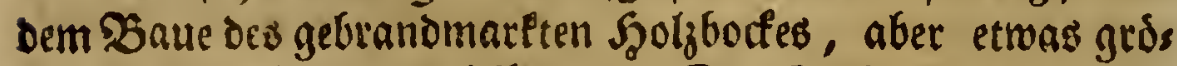
Ger uno ourdaaus gleidffárbigt. Die Farbe ift mie altes Eifen, bas eine Șdtwárze an fid genomment Gat. Die

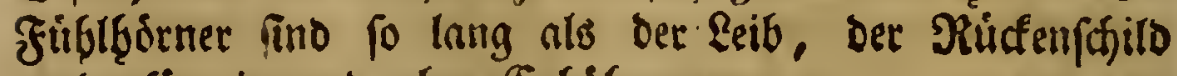
walzenformig und of̧ne Erthodgungen.

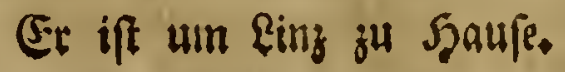




\section{\$. 12 .}

Fotheiptinter 50 labod.

Cerambyx erythrocephalus. C. thorace inermi cylindrico, niger; capite, thorace, pedibus, abdomineque poftice teftaceis.

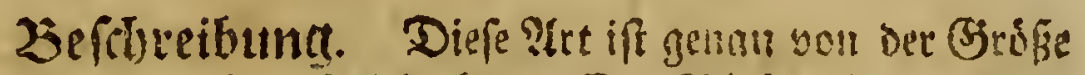

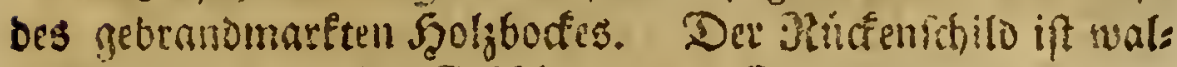

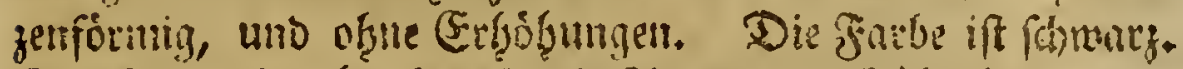

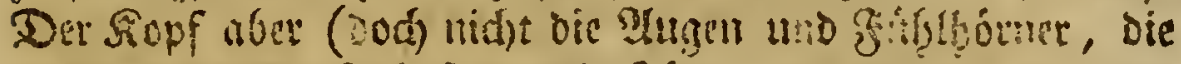

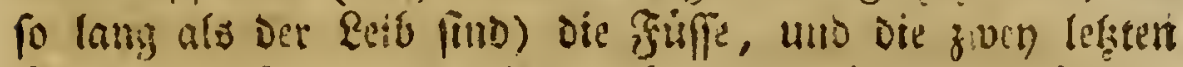

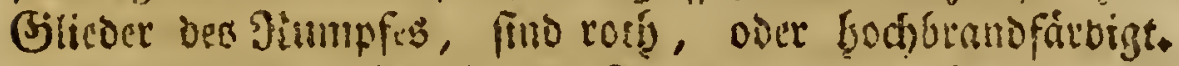

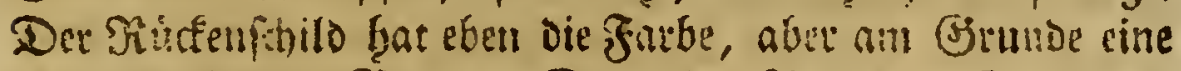
formale (d)norze Binde. Der oritte Jing voun Steiffe aur, ift mit an Den Seiten rotb.

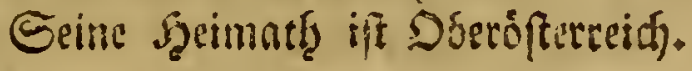

\section{\$. 13.}

\section{Rombotodghtifet.}

Leptura Lainda. L. nigra, elytris albo trifafciatis. Tab. 3. Fig. 13.

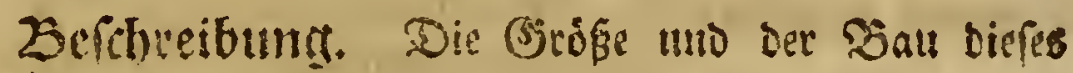
Syolintifers ift wie bin bem, Den der Saetr yon Rinnee den 2000uerartigen (Lept. arietis) nentret. Er ift aber vit

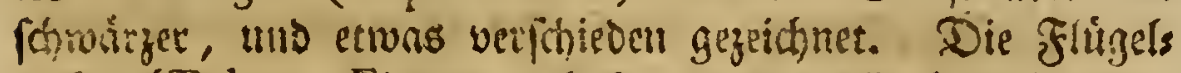
Decen (Tab. 3. Fig. 13.) haber oren weiffe Ditterbitloen,

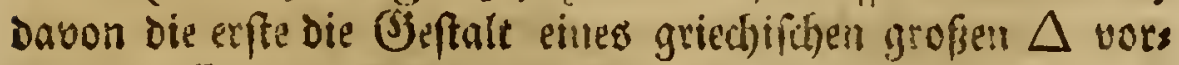

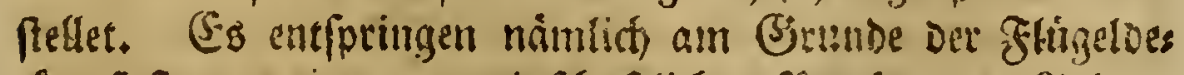

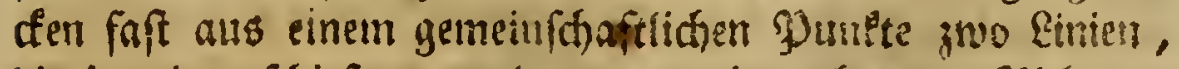

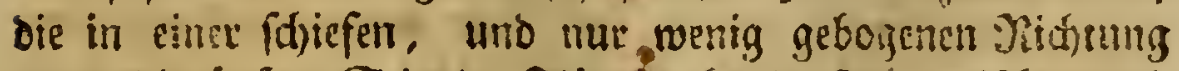

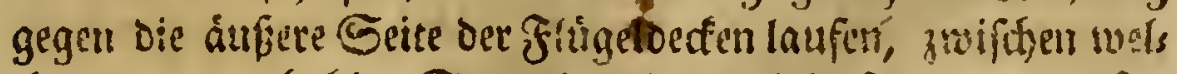

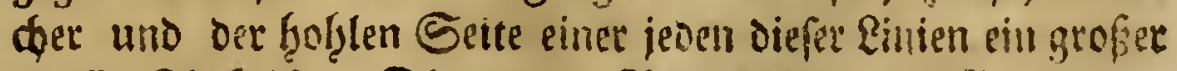
meiffer flect ift. Die zrence Binde ift in ber ghitte, und

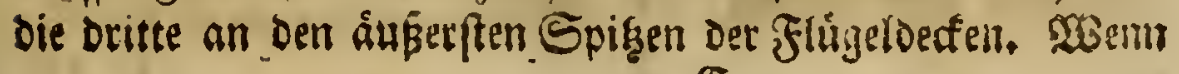




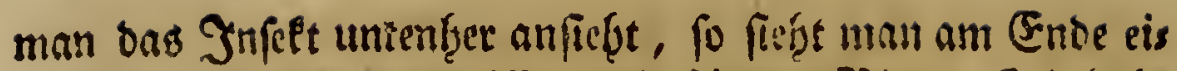

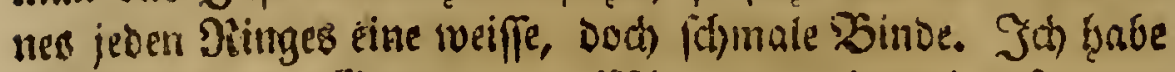

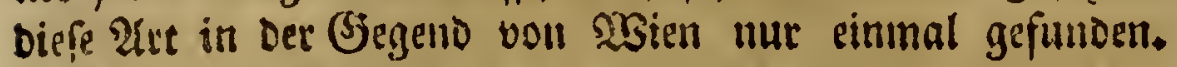
Das Futter ift mir unbelannt.

\section{S. 14.

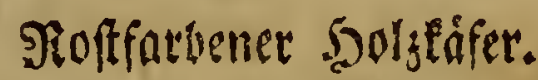

Leptura ferruginea. L. nigra; elytris ferrugineis, extrorfum late nigris.

$$
\text { Tab. 3. Fig. } 14 .
$$

Serchreibung. Die Gróßse und der Balt Des Tns

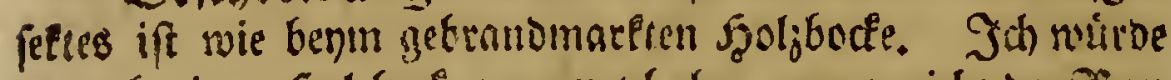

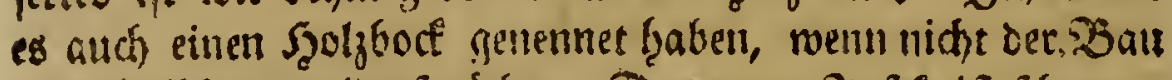

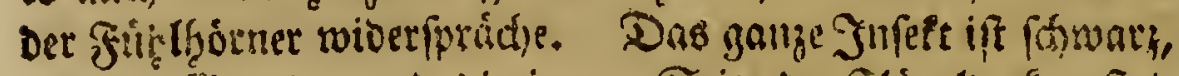

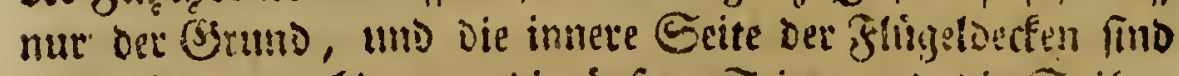

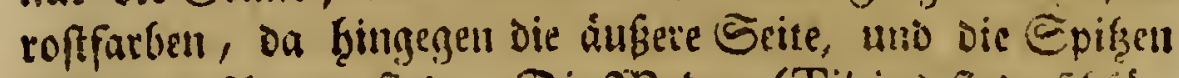

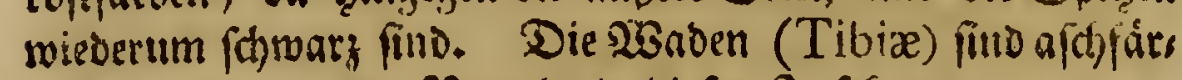

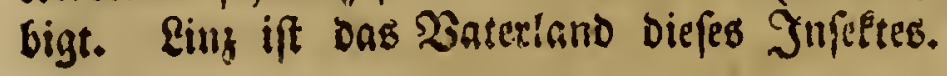

\section{S. 19.}

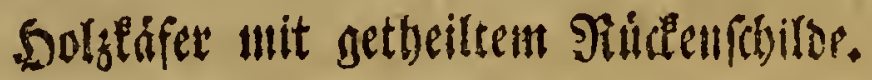

Leptura bipartita. L. nigra, thorace ferrugineo, linea nigra longitudinali; elytris macula communi ferruginea.

Befftreibung. Dirfe $\mathfrak{A r t}$ ift in allen Stiufen oer corigen gleid bis auf bie Farbe; zwar ift Die berrifismbe

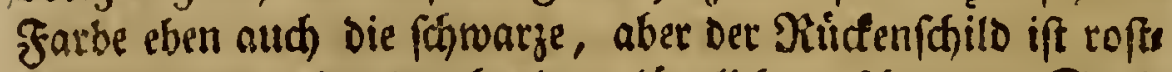
farven, unb wird Durdh einen lángliøten fohmarzen Streis

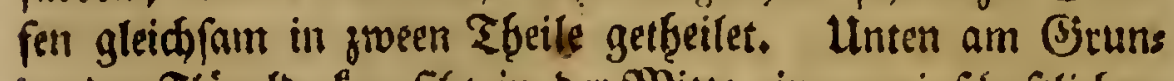
De ber Flingelbeden first in ber Mitte ein gemeinfistaftlid)er, roffarbener Eflef. Der Shumpf (Abdomen) ift ebenfalls

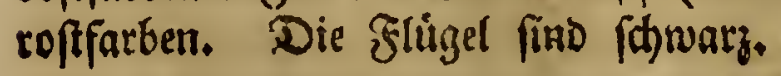

Die Szeimath ift \&ing. 


\section{Sicbente มמbbristung.}

๑. 15.

\section{Blutig cingefámmet Springldfer.}

Elater Janguinolentus. E.ater; elytris fanguineis, margine interiori macula ovata magna atra communi. Tab. 3. Fig. 15 .

Befchreibung. Er ift nut um etroas weniges Pleis ner, als er itt ver anjzefư⿱⺈,tell figur vorizeftellet woird. Der

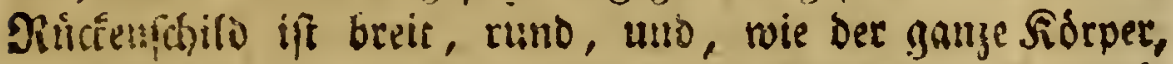

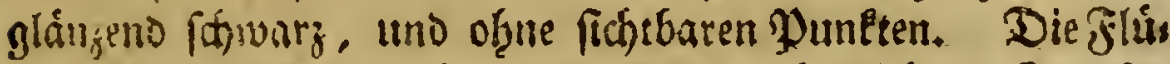

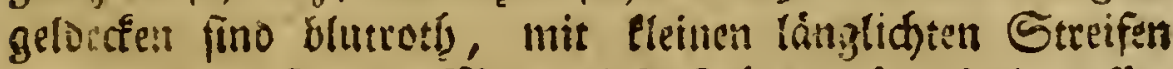

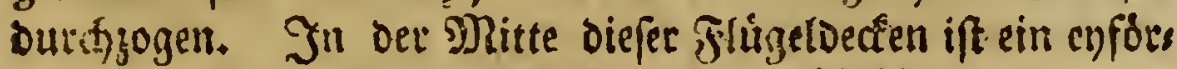

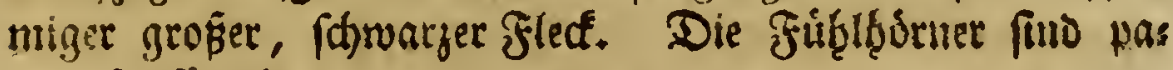
ternofterformig.

Man fann biefe 2ut leineswegs für eine Gpielart bes bfutizen Springeâfers (Elat. fanguin.) anfeb̧en. Der Uns terfísied if allzugrog, wenn man fie gegen einander b̨ălt.

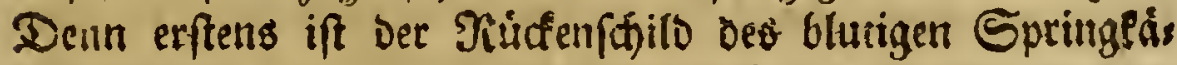

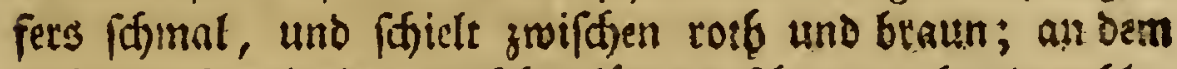

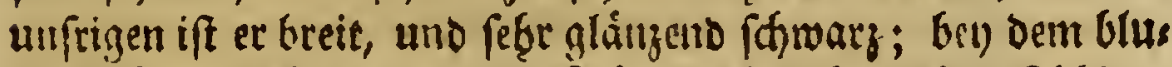

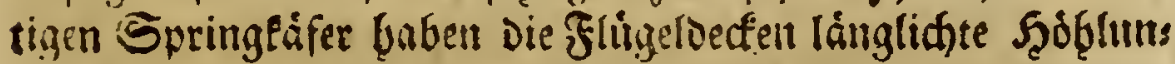
gen, Die fid auf Denten Des unferigen nidst finden; ben bern Glus tigen Springe fafer endfich find die Szodrner áftig; in unferet $\mathfrak{A} \mathfrak{x t}$ find fie paternofterformig.

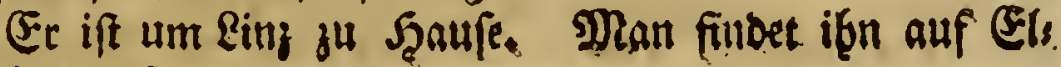
lerublàttern fikgento.

\section{9. $1 \%$}

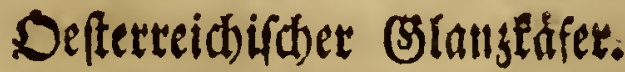

Cicindela aufriaca. C. viridis, pectore abdominisque bafi fubtus rubroæneis; elytris margine aureo tenuiffimo, punctis aliquot albis.

Befbreibung. Er iffeiten f̧alken Zoll lang, bren finien breit, wenn man bas Maaß quer über bie flügels

\& 3 Decen 


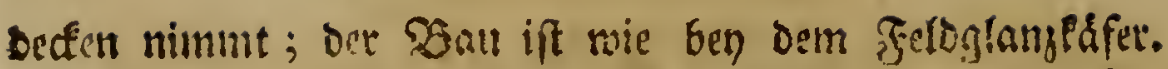
(Cicind. campeftris Lii.) (Er inag úbrigens Diefe ?trt

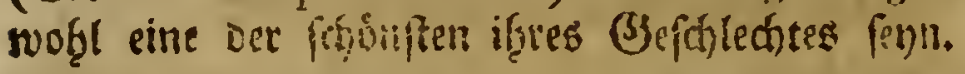

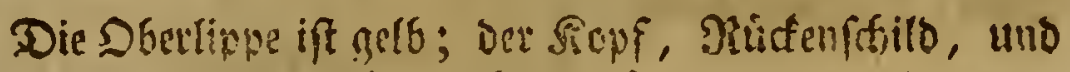

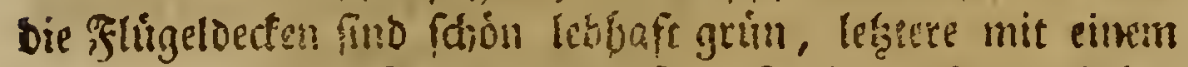

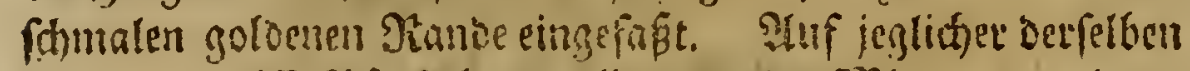

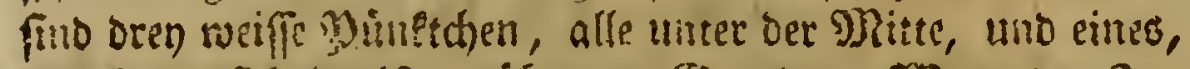

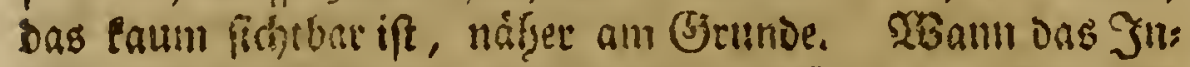
felt nodh im Reben ift, fiplen fie nie Silker. Nodh cin

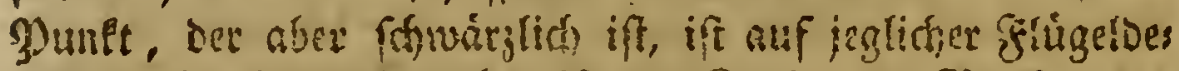

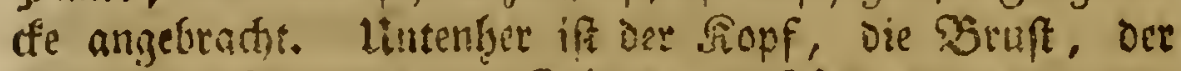

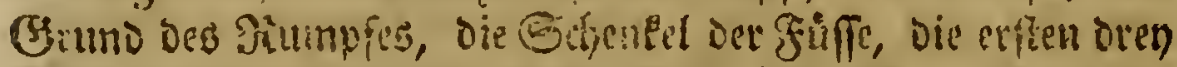

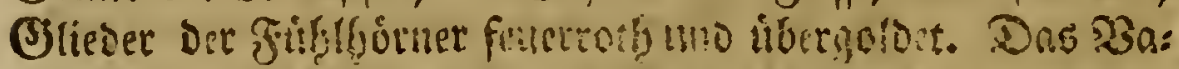

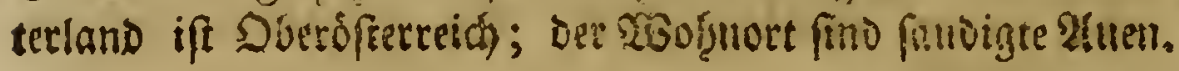

\section{S. 18 .}

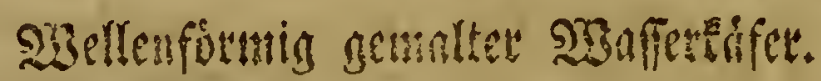

Dytifcus maldius. D. antennis fetaceis, niger; elytris ad bafin fafcia undulata ab. rupta leiruginea.

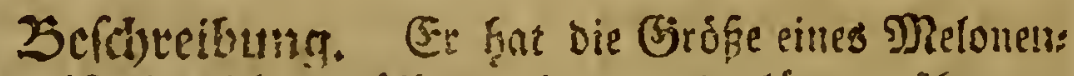

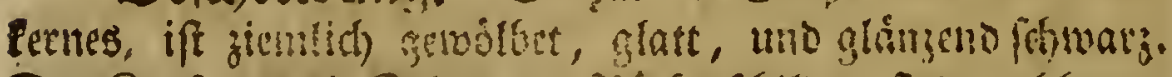

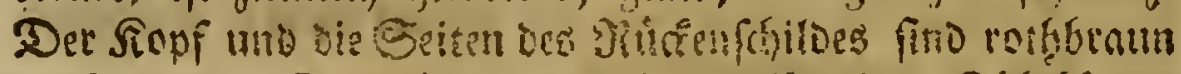

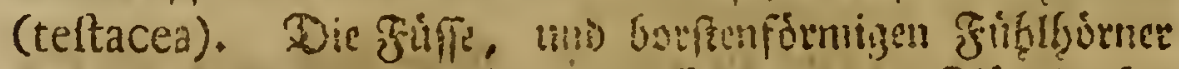

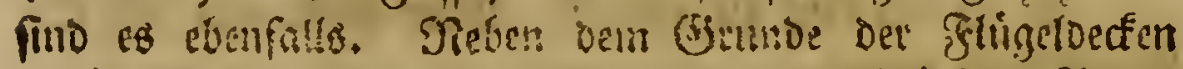

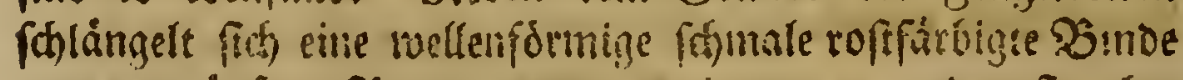

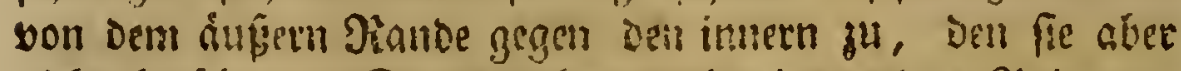
nid)t beriffret. Sonft geffet now eine antere sinie yon cben Der Frabe nebon ben kumern Rande, mit einer Ileinen

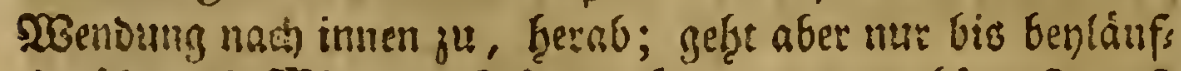

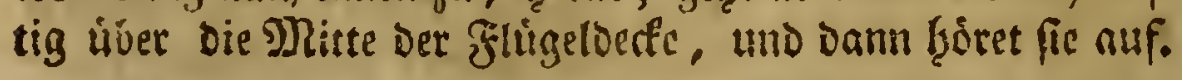

Es woţnet biefes Jnfelt um sing in einem ftebenden

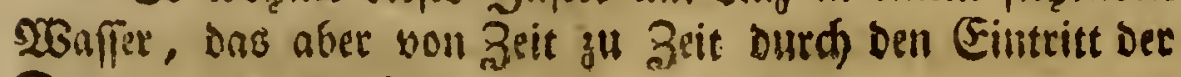
Donau ernetuet soird. 


\section{19. \\ Uligntifbce Mantumutm.}

Meloe hungarus. M. opterus, ater, lævis, thoracis bafi, elytrorumque margine interiori ferrugineis.

25cfdbreibunt. Er ift in allen Studen dem ges meincu Glaulicht fofwarzen Minynume (Meloe profcara-

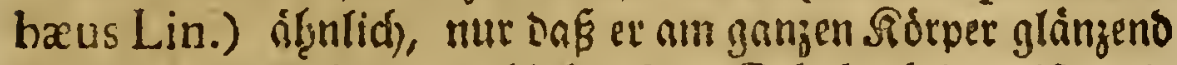

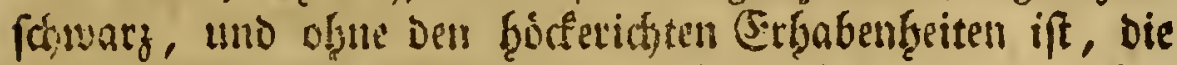

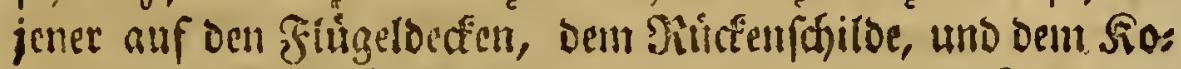

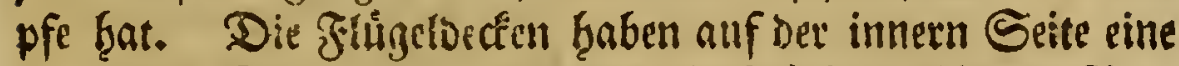

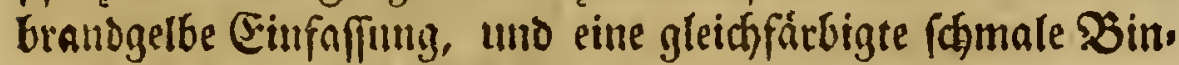
De láuft vorten am Bitudenfdjilde nad) Der Duere.

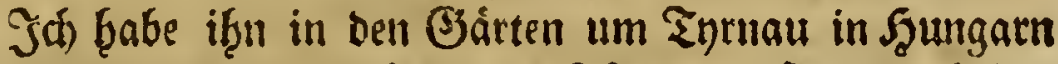
bairfig gefunden; und ich bin verfichert, Dapes eine befons

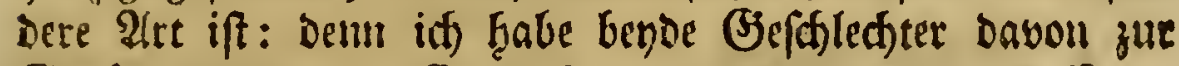

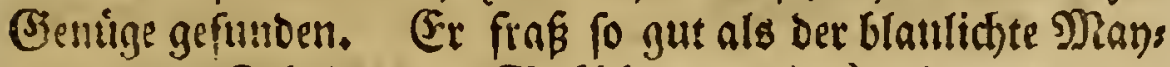
sutrm ins Sdyelferaut (Chelidon. majus) ab, mit Deffen

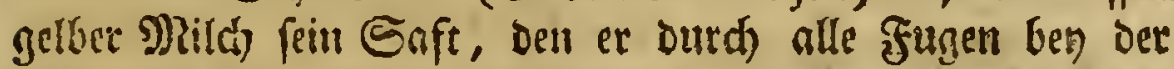

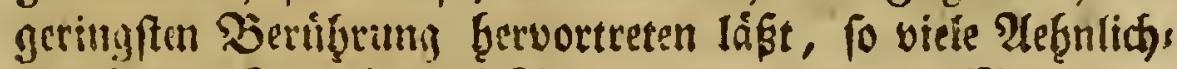
fcit that. Sowobr Diefe 2 rt, als Den gemeinen Maywurm

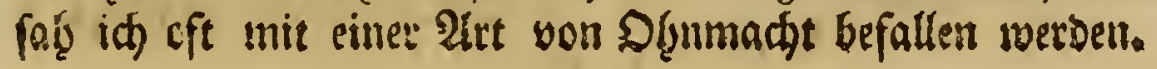

\section{S. 20 .

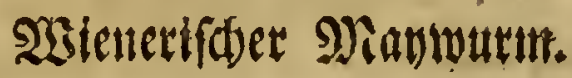

Meloe viennenfis. M. apterus, lavis, ater unicolor.

23efdreibung. Diefe $\mathfrak{A r t}$ ift meb̆e benm um bie

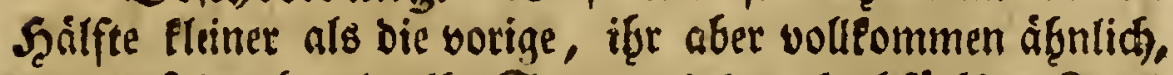
nur baß ber Grandgelbe Saum und der gleidförbigte S.uer,

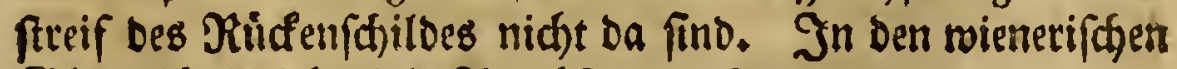
Biarten babe id biefe 2tat sfters gefunden.

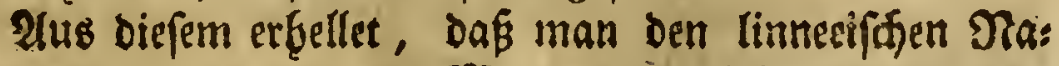

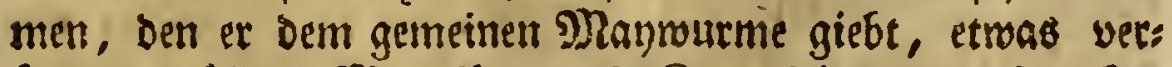

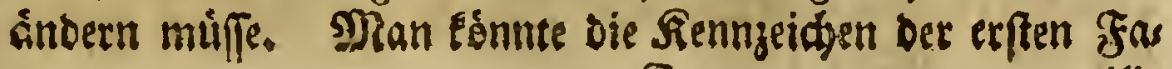

$$
\text { (E) } 4 \text { milie }
$$




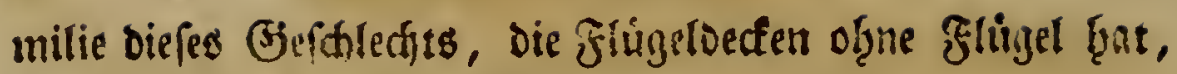
wieleidft fo mify?t:

1. Meloe profcarabaus. $M$. apterus niger (S. violaceus), elytris, thorace, capiteque nunctis elevatis. anmet:. Diefe Zirt teicet vies

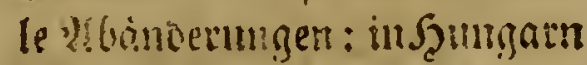
babe ids fo grepe gefumber, als ein Sonrootter jent mag. Sie marell tur twetiig Giàulidit, no and) biefers yeigitma nad) Dem Sose. Tabbe tum Ring ift

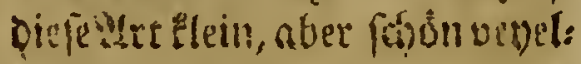
bjou; in watter citilegenen (j)es genoen ift fie mieser greks.

2. Meloe viennen/is. Mi. apterus, lævis, ater unicolor.

3. Meloe hungarus. M. apterus, lævis, thoracis bafi, elytrarumque margine interiori ferrugineis.

4. Meloe majalis. M.apterus, fegmentis dorfalibus abdominis rubris. Lin. S. N. Gen. 2 Is. fp. 2.

S. $2 \mathrm{I}$.

Brofingigter Moubläer.

Staphylinus buphthalmos. S. niger, inmaculatus, oculis magnis exfertis.

2Be(d)reibung. Er unter (fheibet fich yon Dem zmens flectigten Durch nidhts anders, als Den 26 gang ber Flecteu. Fann Der Hiteridied zwifhen oraniengelb und roffarben

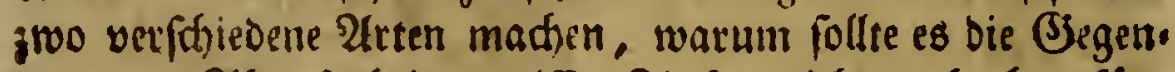

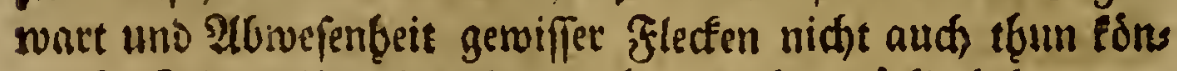

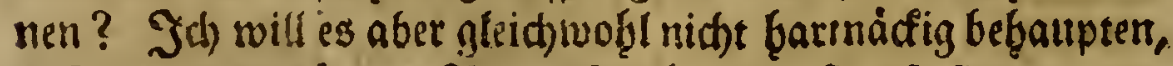
Dás die gegenwortige $\mathcal{A}$ tr, ofrwobl man fie oft findet, youts

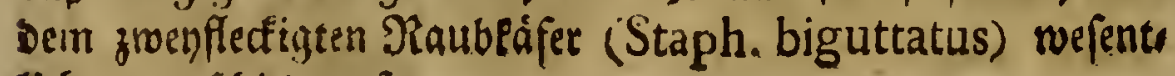
lidg unterifieden jey. 


\section{Eidbente 2lohnolndutg.}

\section{\$. 22.}

\section{Inbedidte Fulbitiabe.}

Blatta anelytra. B. elytris alæformibus venoforeticulatis.

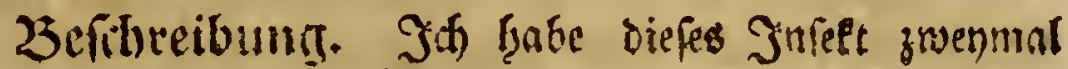

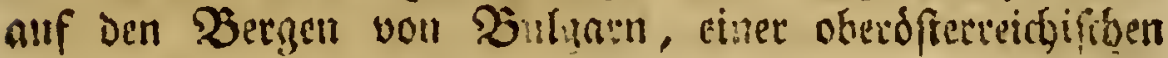

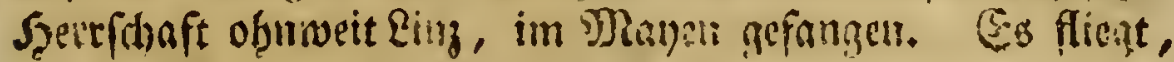

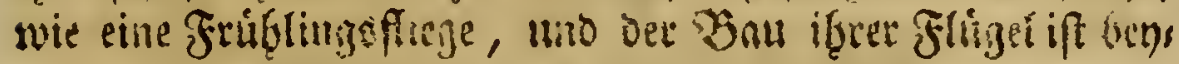
nutge éven derfilkighe.

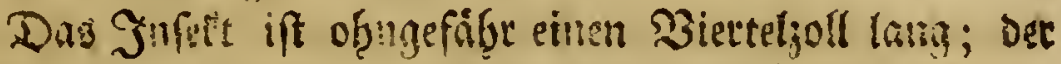

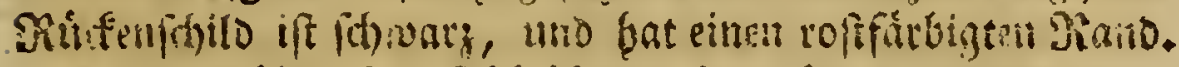

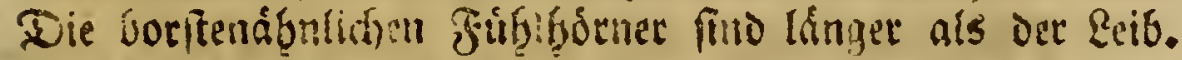

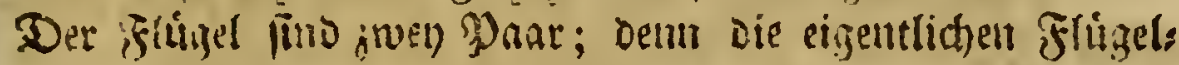

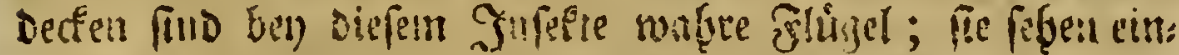

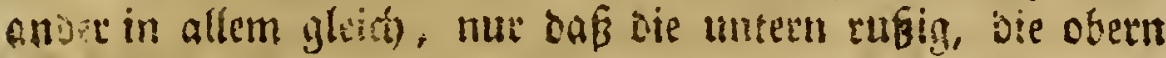

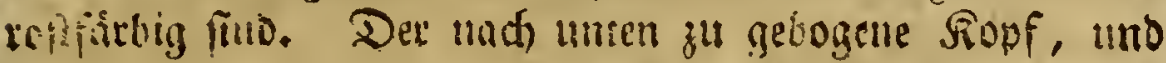

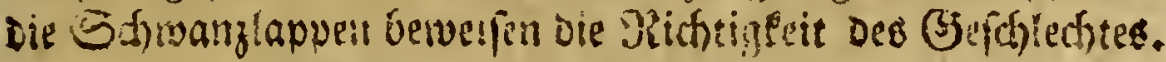

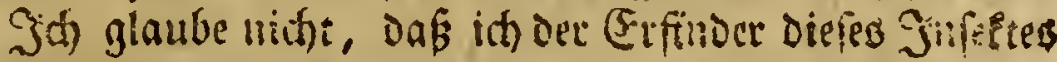

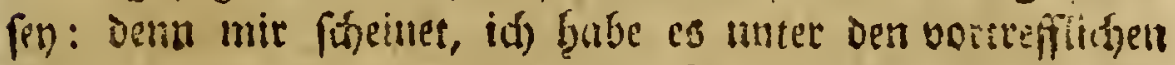

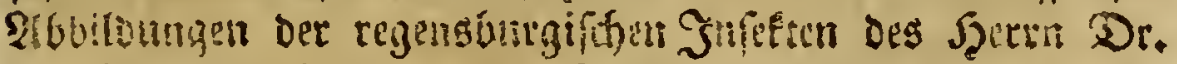

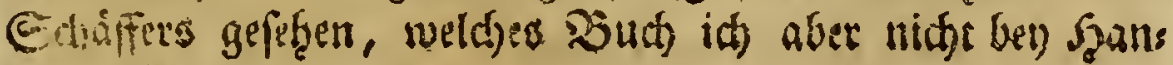
ien Gabe.

$$
\text { S. } 23 .
$$

Doppeltgirtelige Feldfeime.

Cicada bifafciata. C. nigra; pedibus pallidis; oculorum bafi alba; alis hyalinis, fafciis fubtribus nigris.

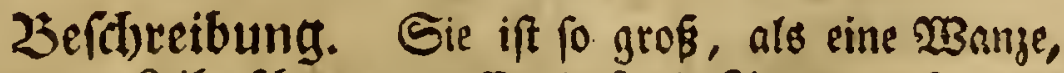
am ganzen Reibe fhroarz, auffer ons oie 2lugen auf einem neifen Grunde fteben, und die gruffe blaß̧ Gornfärbig find.

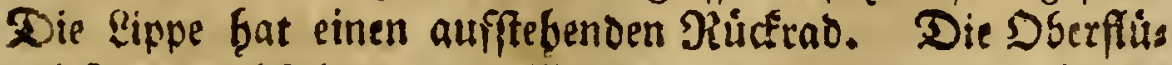
ge! fino burd,intig, wie 2 baffer, boch laufen bie Ditere burd) brey Binden, eine am Gsunde, bie nicht vollftándig if, eine in Der Mitte, und eine an Den Spizen, die volls 
ftánbiger frno. Sie geben ofle drey nidgt in einem Stüfe

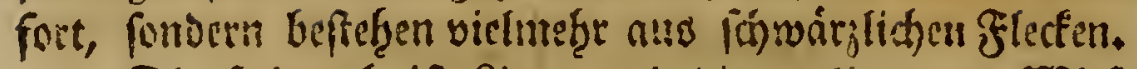
Die Steinnth ift Rim, nno die untiegenden swoiefen. Eie bitipft.

Эळ) nanne fie nut die Doppeltgurtlige, weil man bie

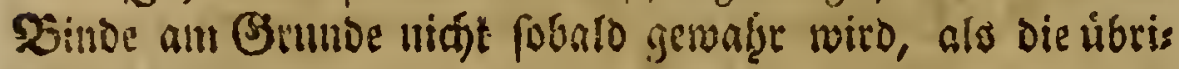
getl jwo.

\section{24. \\ Fenferfoteibenatige Felsheime.}

Cicada fereftrata. C. fufca, fubtus flava; alis hyalinis, apice nervis nigris feneftratis.

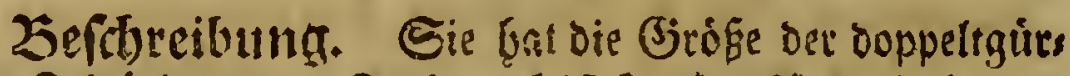

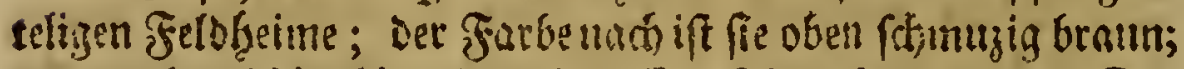

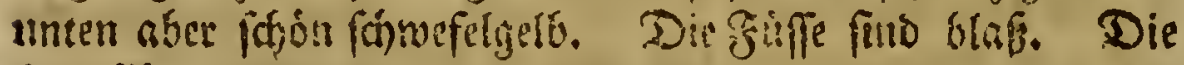
Doerfhigel fruo ourdafichtig wafferfarben, uno baben am

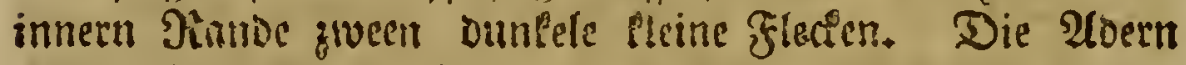

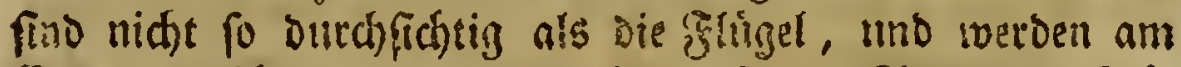

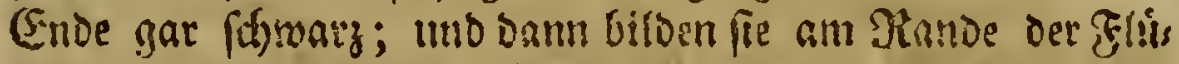
gel mittels varfajiebener Berbinoungen eine fenferentheibens

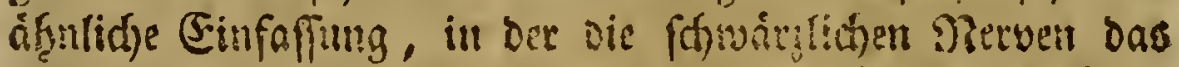

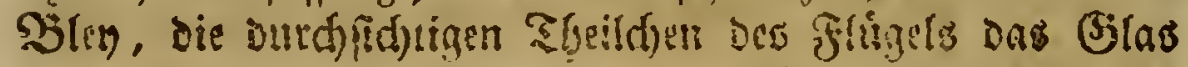

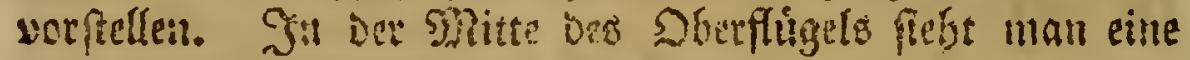

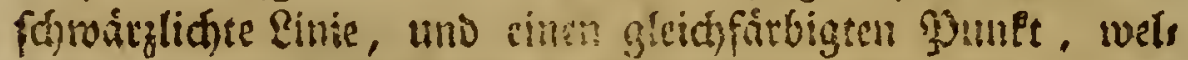

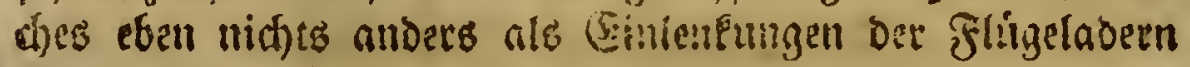
(Anaftomofes) fino, die dajerfoft etrons bumeter werden.

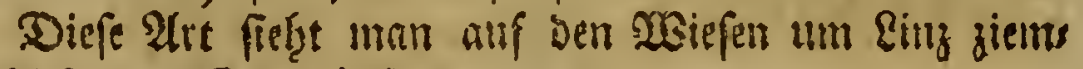
Iidh feltfant. Sie büpft.

$$
\text { S. } 25 \text {. }
$$

\section{Etinefiegendanlidye Ferblyime.}

Cicada hemerobioides. C. nigra; alis hyalinis fufco maculatis, nervis nigro diaphanoque alternatim maculatis. Cicada nervola. Lin. S. N. Gen. 223. \{p. 25 . 
23efdyreibung. Sie hat die Range einer groben Bettwanje, Dod ift fie fommỏter. Sie ift am gnnjen Reis

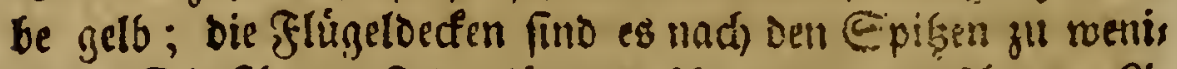

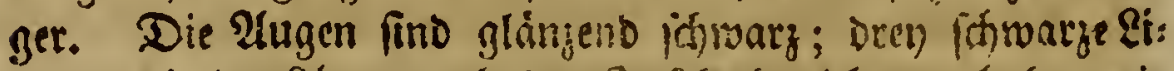

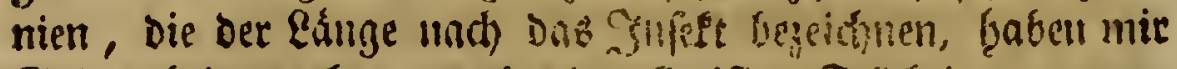

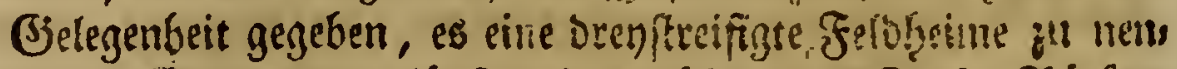

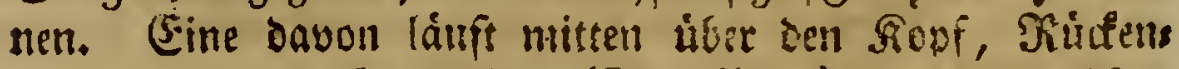
fajild, und bas Safildon (Scutellum), Damu zwicher Denl zween SberfígeIn fo fimab, Das er soul einem joben

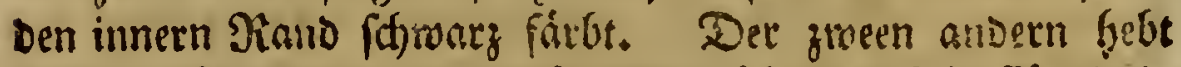
jeder am Uluge an, uno geţet mittent íber Dic DGerflinget bis

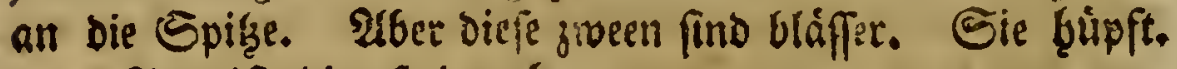
king ift bie Sgeimath.

\section{S. 28 . \\ Bierzelnte Feroheime.}

Cicada decimaquarta. C. pallida, elytris numero i4. nigro notatis.

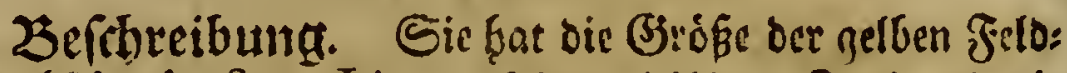

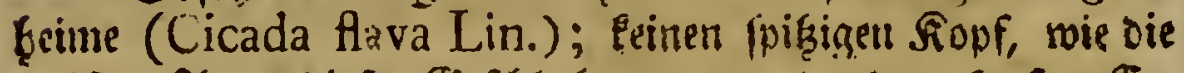

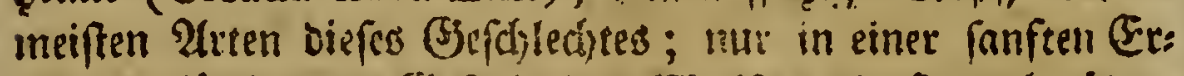

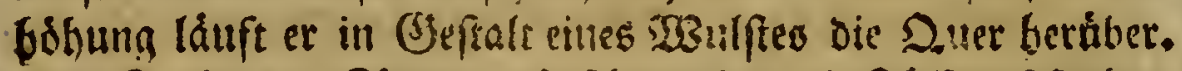

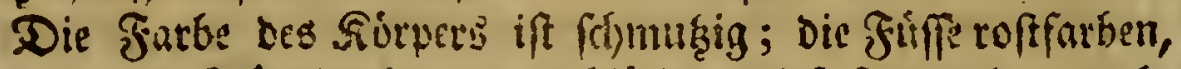

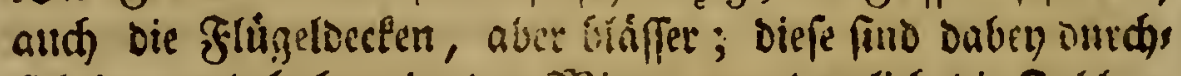

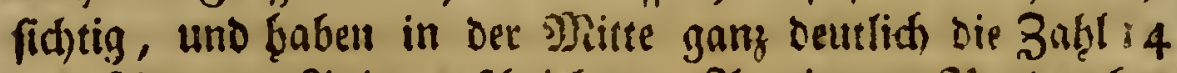

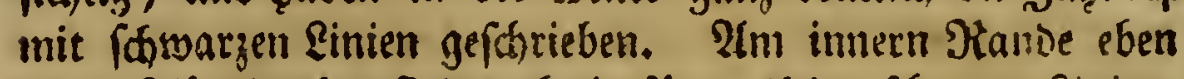

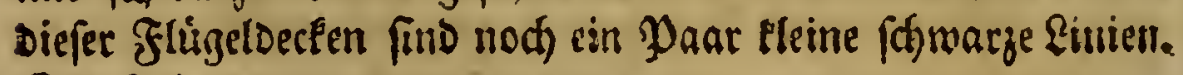
Sie fpringt.

Man findet fie um sing auf ben 2 siefen.

\section{S. 29. \\ Meiffledigte Feloricinte.}

Cicada albomaculata. C. nigra; oculis, maculisque elytrorum duabus albis.

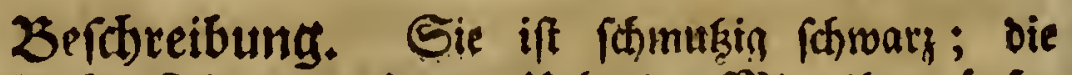

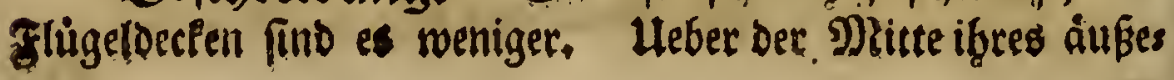


ren Standes, Der Spiģe zu, frazt auf jegliderer eill wriffer

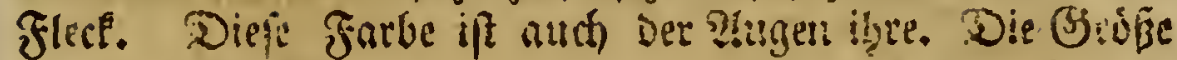
iff wie die ber গilidengartenwange (Cimex oleraceus Lin.). Sie pringt.

$\mathcal{E i n}_{\mathrm{f}}$ ift das Saterland.

\section{S. 30 . \\ Sierfledigte Fildhefme.}

Cicada quadrimaculata. C. ferruginea; elytris ad marginem exteriorem maculis duabus albis.

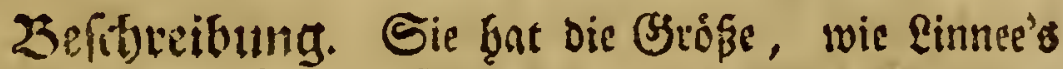

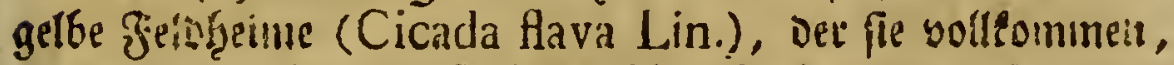

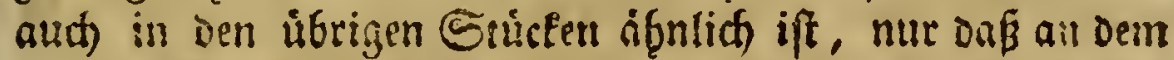

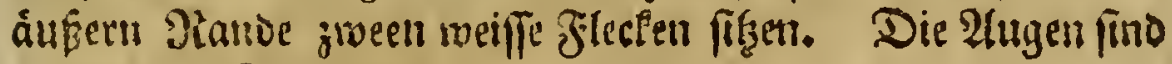
Fiswaiz. Sie fiptingt.

Sie wof̧nt in ben wienerifhen (S)äten.

$$
\text { S. } 3 \mathrm{I} \text {. }
$$

\section{Sotbaugine Feldgeime.}

Cicada erytrophthalma. C. flavefcens, oculis rubris, tibiis anticis nigro marginatis; alis hyalinis, lineolis obfcuriufculis.

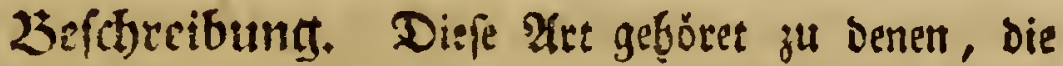

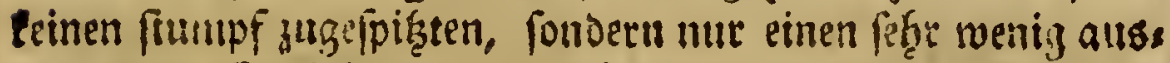

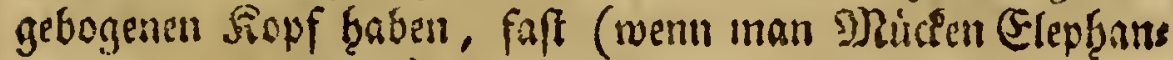
ten vergleithen Darf) wie ber Shammerfifal (Squaluts zygaena Lin.). Das ganze Jnjęt ift von Der (Jróbe oer von mir fogenannten viezzęnten Feld heime. Die 2 lugen fiñ rotf. Die 23urfúffe (Tibix) Des erfen Waares Gaben burd)

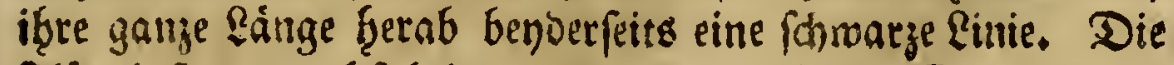
Fringer fino ourdfindstig, und waferfarben. Die Serven, Die hin und roieder etwas ounteler rerben, bilden barauf

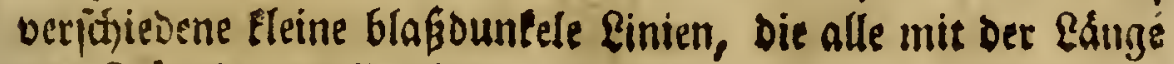
bes fríge!s parallel firod. 


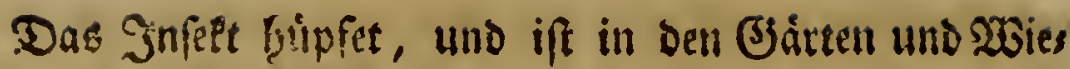

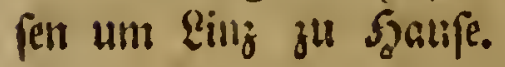

$$
\begin{aligned}
& \text { S. } 32 \text {. } \\
& \text { Sefterteidifale Samaze. }
\end{aligned}
$$

Cimex anftriacus. C. fcutellaris; corpore fubtus flavo, fupra obfcure ferrugineo, fcutello carinato, carina \& ad bafin utrinque macula flavis.

Befdyreibung. Syerr Frifh bat im brengebutent Theile feiner Be(d)reifung bentifher InfeEten eine WBange befdrieben (pag. 26.) unto abgebirdet (Tab. 24.), Die mit

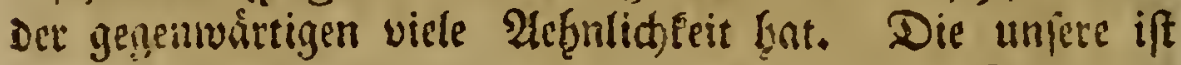
fo grof uno fo gezeidnet, wie oie friftififde. Der gange unterichied liegt in ber farbe. Sie iff unten gelb; ofien fo,

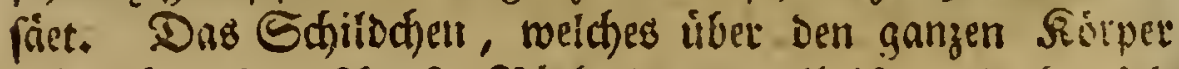

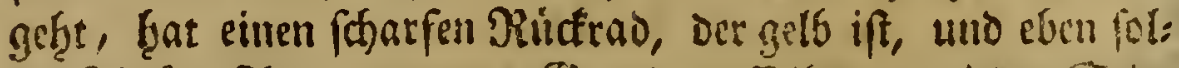

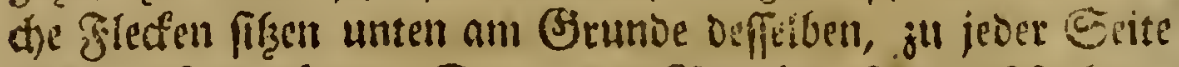
einer. Die duinnell Seitent des Bnudjes find roffarben, und fortippenartig Dumller fohattivt.

Sing ift Die Szeimath Diefes Snfettes.

\section{S. 33 .}

(3)ủttelige 2 sanje.

Cimex cinctus. C. ovatus, ferrugineus, thorace fpinofo; fcutello falcia nig!a a thorace feparato.

$$
\text { Tab. 3. Fig. } 16 .
$$

2Sefidreibung. Sie ift folang, als bie Gincter (Cimex nebulofus. Pod. græc. pag. 56. n. 8.) aber

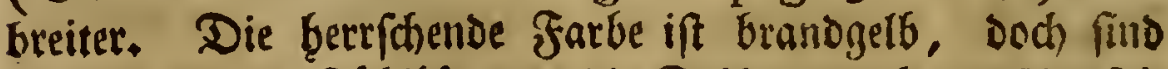

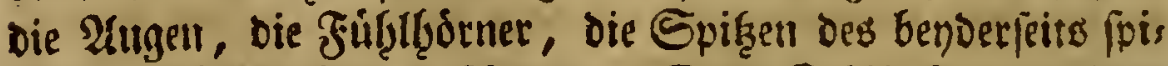

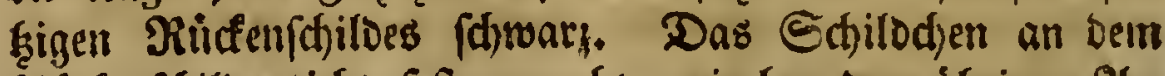
Riuden(d)ilde nidjt feft gemadt, wie bey ben übrigen $\mathfrak{A}$ rs 
tell, fondern fare davon abgefowtert, Daf man cill guttes

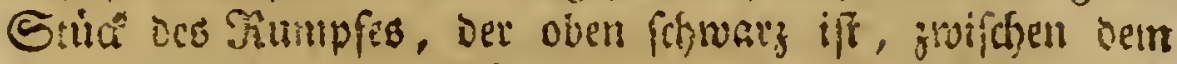

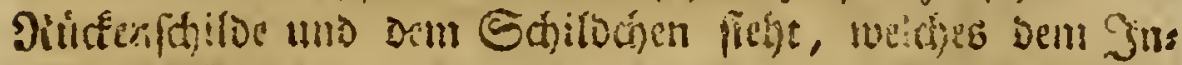

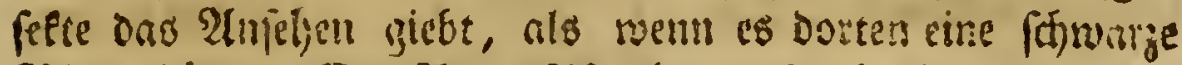

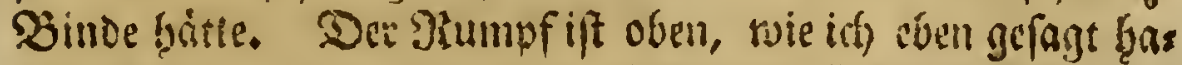

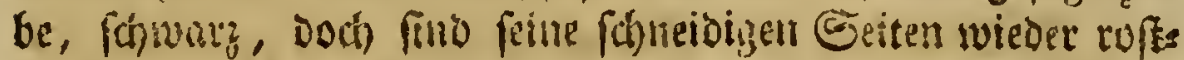
farben, weldyes wechfelsweife mit einer Dunzelern Btopffar:

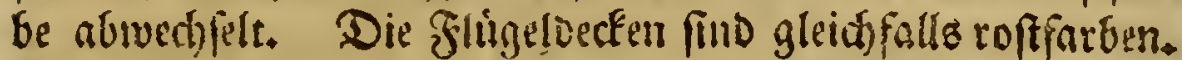

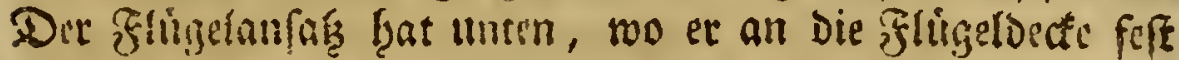

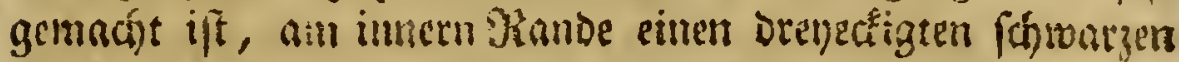

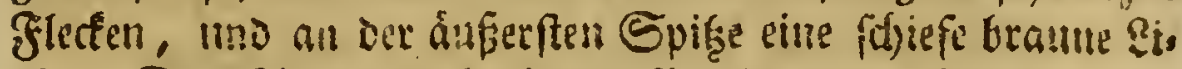
nie. Der Stintere ift falfmondoformig ausgeformeift.

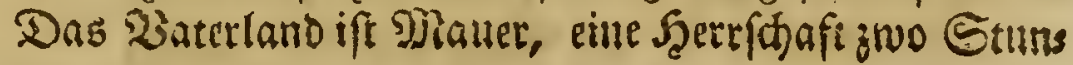
Den von WBien entlegen.

\section{S. 34 . \\ Belegegeidnete $\mathfrak{W a n t}$.}

Cinex flavatus. C. ovatus niger; fcutello elytrisque apice lateribusque flavis; thoracis margine, lineaque media flavis.

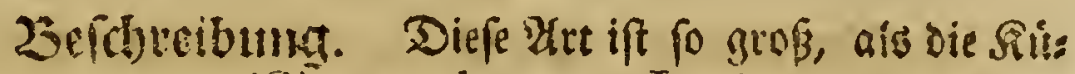
d)engartenmange (Cimex oleraceus Lin.) oper etwas bars

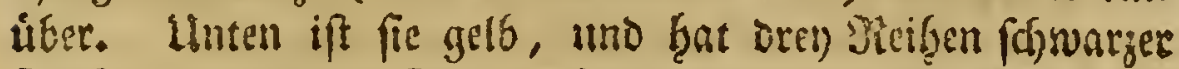
Flicten, Davon Die Seitenriţen aus runden gounlten beftes ben, vie aber anf Der $\mathfrak{B r u f f}$ gróser, unto in ifreer Mitte

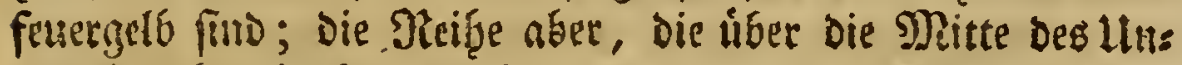

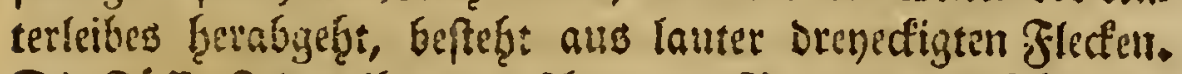

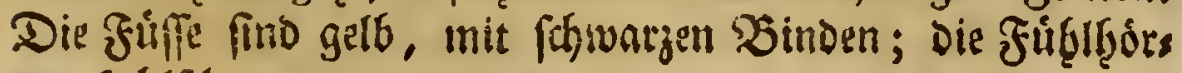
ner follifitimars.

SGen ift Das Jufeet grintid fdywarg. Der אopf uno

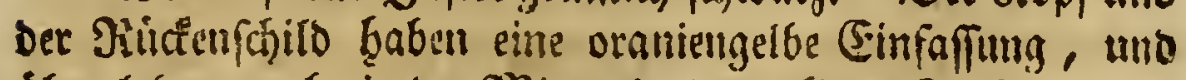

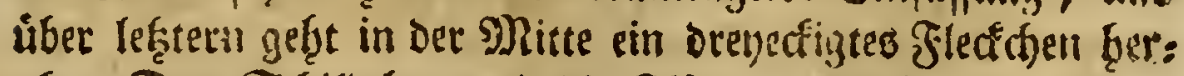
a6. Das Sdjildd)en und bie Flügeldecten find ann Sans be oraniengelf; und an ber Epige des Seffilbd)ens, vent

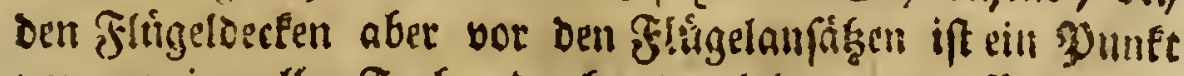
bon oraniengelter Farbe, Der ben Den lesten rautenfórmin iff.

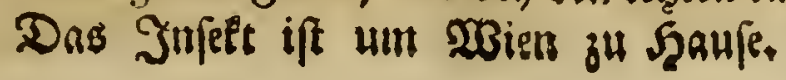




\section{35 .

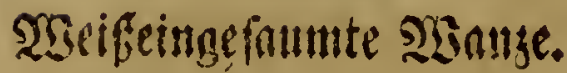

Cimex albomarginatus. C. ovatus, cœruleoæneus, elytris albomarginatis.

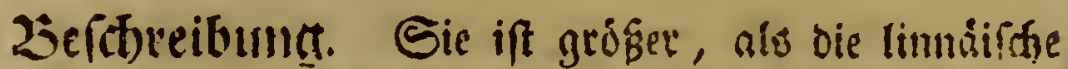
blaue Sranze (Cimex coeruleus), nn Finrbe und Biefralt aher berfelben gang glcin, bis anf oie eleinen 2(bweidsunts

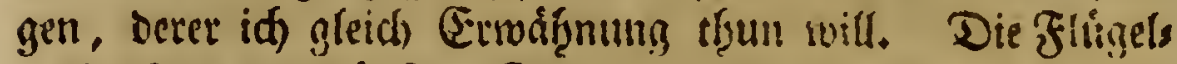

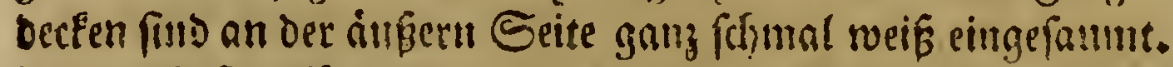

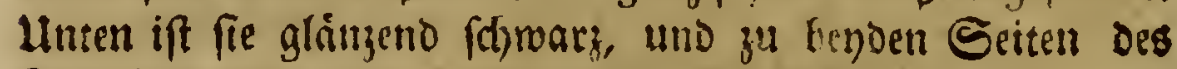
Satdjes fino ganz Eleine weiffe yumetrn.

Sie rookznet in ben Begenden yon 23 ien.

$$
\text { S. } 36 .
$$

$\therefore$ Sthonfte $\mathfrak{B a n j e .}$

Cimex vernififimus. C. ovatus argenteus, capite, thoracis fcutellique bafi violaceoæneis.

Lefebreibung. Es if biefes die artigfte wosing?,

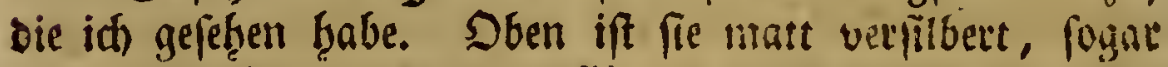
bis auf Die Sitiben Der Utnterfúget; Det Fopf aber, umb der

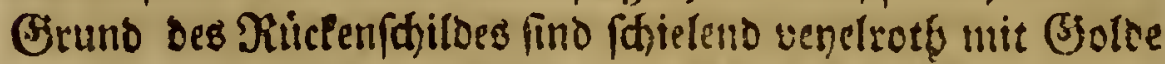

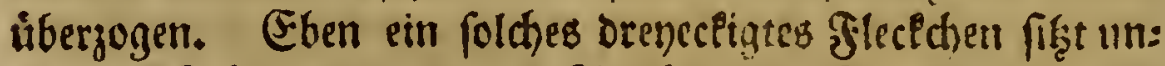

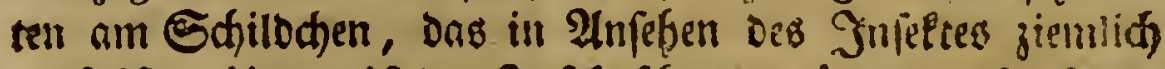

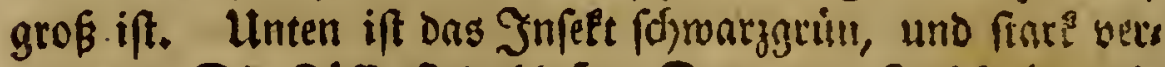

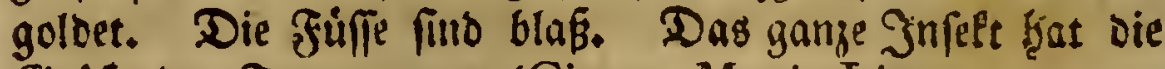
Gróşe der Trauerwange (Cimex Morio Lin.).

Tath babe fie nur einmal, aber bende (Jefichlecteer miteinander, in ber Jenend von ginz gefunden. Sie fint einander nichts verfáieden.

\section{37.}

BIutrotbe $\mathfrak{X a n j e . ~}$

Cimex 
Cimex fanguineus. C. roltro arcuato, corpore oblongo nigro; elytris rubris; abdoninis lateribus rubro nigroque variis.

Cimex (iracundus) oblongus niger, thorace fabro, poftice rubro, elytris rubris; abdominis lateribus nigro rubroque variis. Pod. mus. gr. pag. 18. 11.17.

Tab. 3. Fig. 17.

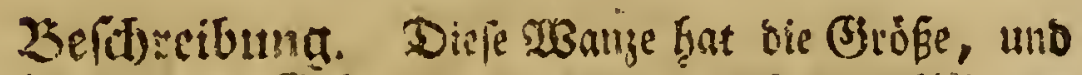

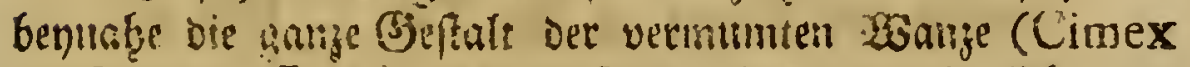
perfonatus Lin.). Der Siopf iff Elein, lánglidbt unto

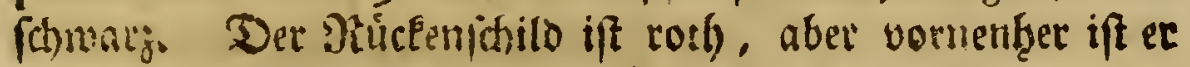

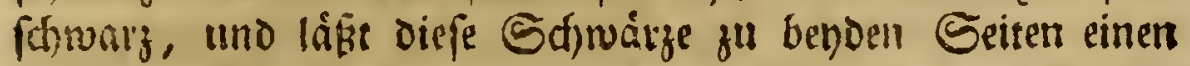

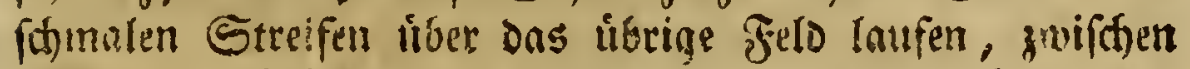

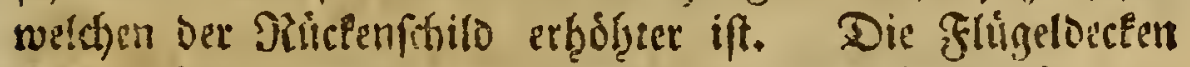

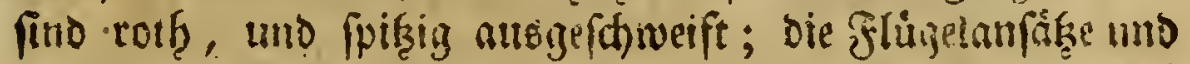

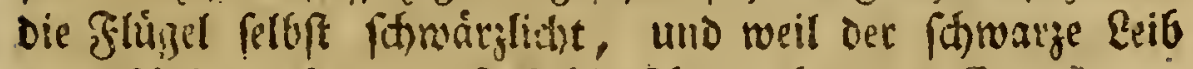

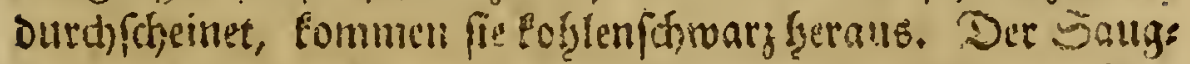

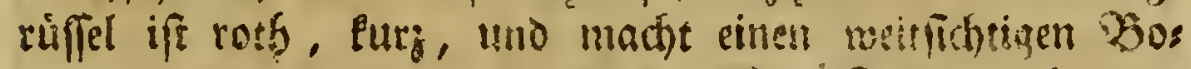

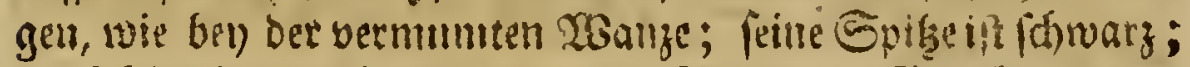
Die Fiffe fritb roth mit fommarzen Binden. Die Setent des Banders mergfelm mit rorb und forwary ab; aúer fie fino nidjt berworfttzeno, mie been vielen alldern Sitten.

Sie hât fid un wien auf. Bieteid)t if fie and

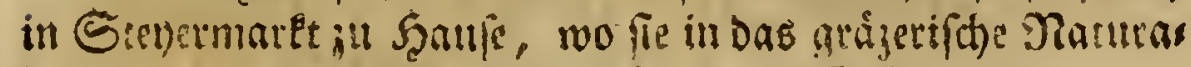
lievíabint getonnmen ift. Sandige Brande follen Der

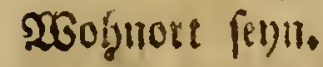

\section{S. 38 . \\ Sisinfelnotte.}

Tinea tefflla. $\mathrm{T}$. alis fuperioribus rubro luteoque teffellatis.

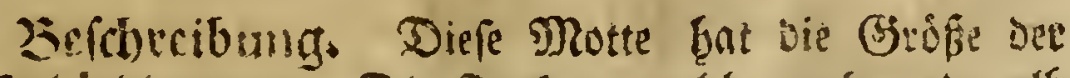

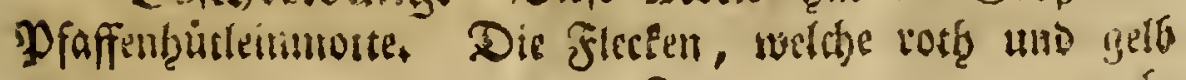


wedhferweife find, fteller einigermaffen ein Damenbrett yor, fie find aber nidjt regelmáfíg vierectigt, fondert b̧aben die Ectert mie abgeftumapet.

Das foutter ift mir unberannt. Die Şeimath ift die Eegend um Eimz; Der $\mathfrak{W}$ eg nad) Dem rogenannten Frens berge.

\section{39. \\ Eelber Souft.}

Ephemera flava. E. cauda bifeta; lutea; alis pofticis minimis.

5)anbb. Det Ratut. 4. B. Tab. 6. Fig. 2.

3eid)reibung. Sie if gelb, fogar bie Flligel, von benten bie untern gang Elein finto, fint es, aber ungleid) bläfer als ber Eeib. Die Sdiwanggabel befteget aus brenen Sorften, Die vont sumeeln ßingen fheceigt lint.

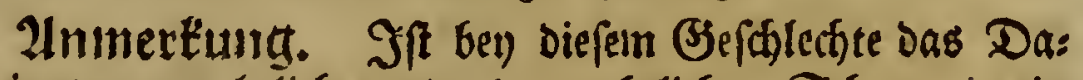
penn eintes znenzabelidften oder brengabelidfren Sd,manges ein

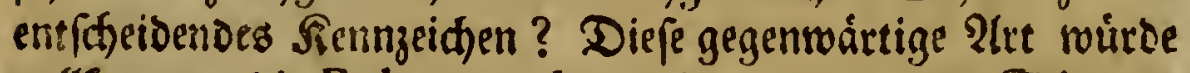
volffonmmen bie Ephemera lutea fenn, wenn Der Schmans

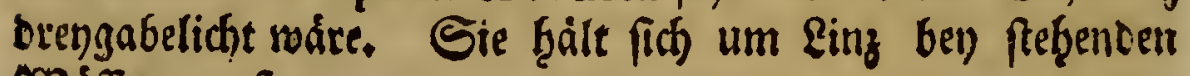
woâferm aur.

\section{\$. 40. \\ Maidenartige Slotpionfirge.}

Panorpa tipuloides. P. alis omnibus æqualibus ferrugineis immaculatis, pedibus longis.

Žefchreibung. Die Gróge bes Jufettes ift faft wie der Faffranfárbigren Mhidfe (Tipula crocata Lin.) ih̨re. Das galuze Infelt ift rofffárbigt, aud Die Fsliggel, bie eints ander vodlig gleith, lang, und obne Madel finto. Der Eoik ift walkenformig, wie ben ben saafernyınphen mit

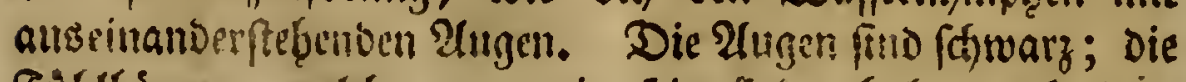

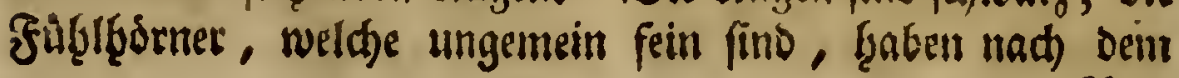




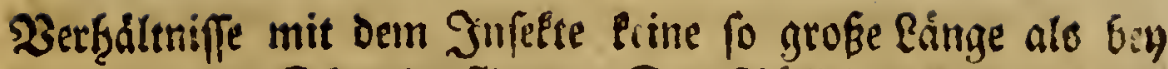
Der gemeinen Slorpionfliegr. Der Riuffer ift Eurg, oùn!ne,

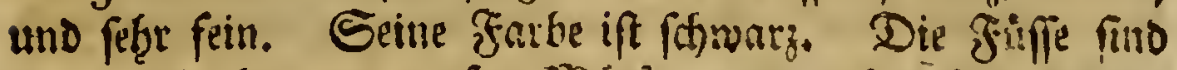

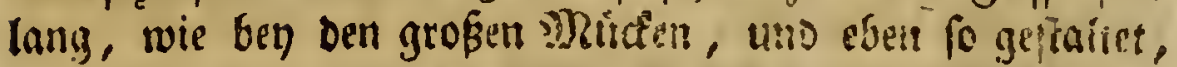

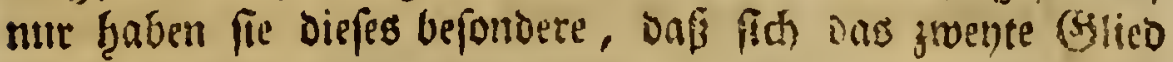

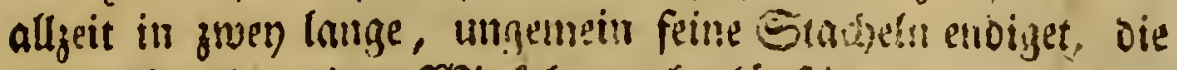
unter einander einen 20 intel von boy! inftig $40 \checkmark$, mit ber

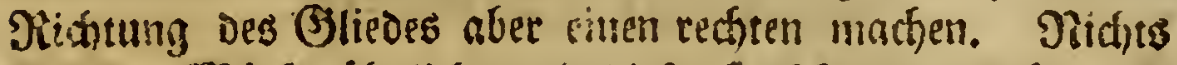

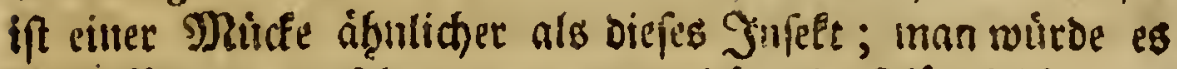

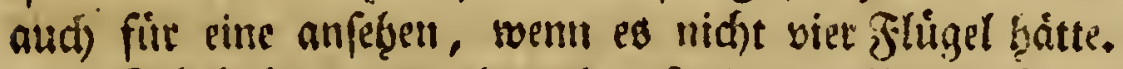
Jc) Gabe es nur einmal gefunden. Ëeine Şeimatg ift Riuly.

\section{S. 4I.}

\section{3ufanmengelwathicne Ethlupfuefpe.}

Tenthredo connata. T. antennis clavatis; nigra; abdomine fafciis Havis.

befichreibung. Sie ift fo grof, als eime Shounifi,

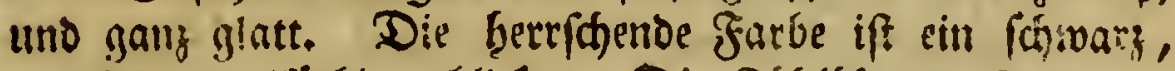

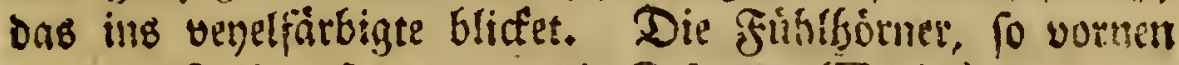
in einen Folben fidh endern, die Schenpel (Tibix), uno dia

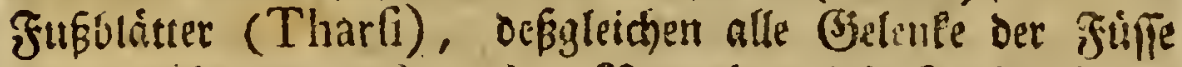
fino rothbraun (teltacea). Bon efen diefer Farbe ift oer

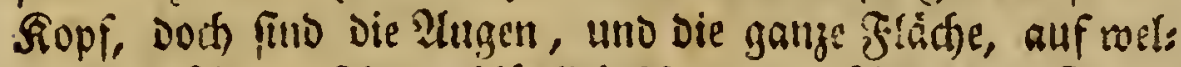

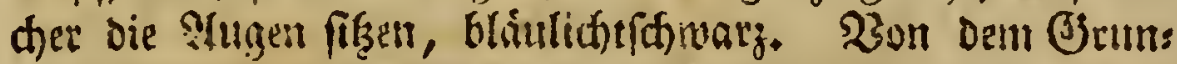

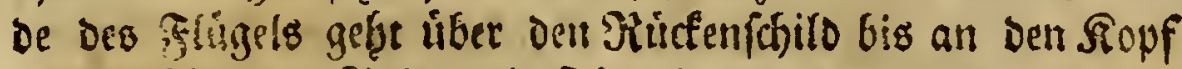
eitle retisbrame Rinie, Die fith mit Der vereiniget, Die von Dem Finget ber andern Seite berfommt. Der britte Yiung bes 3aunes ift an ben Seiten formefelyels; die nachfolnens Den Sititge baóen alle eine breite Binte von eben diefer Farbe.

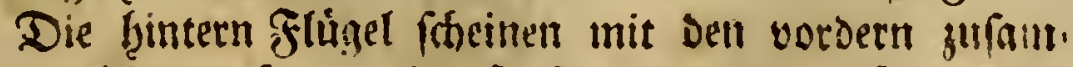
mengevatisfen zu feyn; aher fie fint es usicht. NRan faun fie auscinander lofen, obne fie ju jerreifferi, uno reem mant

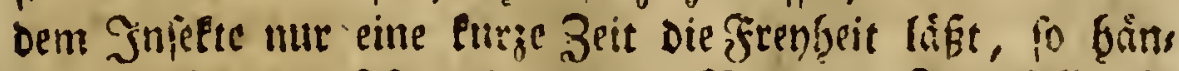
gen fie roicberum fep? aneinander. Nath den Zode fallels fie frenwillig auseinander. 
Gie mobnet anf Den Erren. Soll es eine biofe

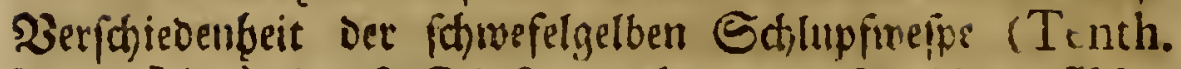
lutea Lin.) fenn? Die \&arye fonnte Den. Zroeijel auflófen, bie idf aber nidgt faht.

Defterreich ift Die Şeimatf.

$$
\text { S. } 42 \text {. }
$$

\section{Bmenfárubigte Edlupfwerpe.}

Tenthredo bicolor. T. antennis filitormibus, nigro cyanea, abdomine, alarumque bafi Havis; alis fafcia nigra.

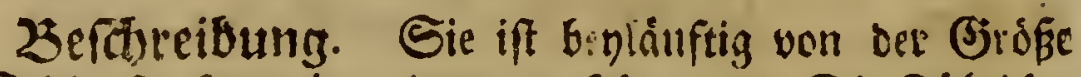

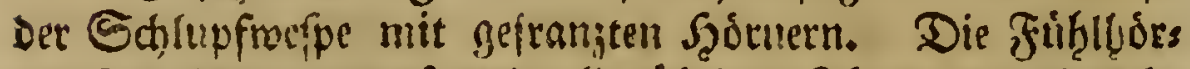

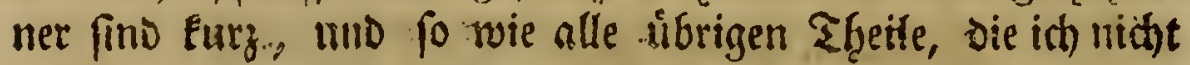
ausnefynen werbe, fahmarz mit eitrem venelfarbene: (J)ans

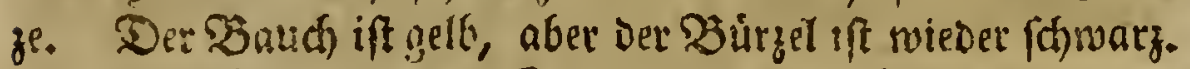
Die Dberfligel fruto voum (3)runde bis zur Seálfte gelb, Dann

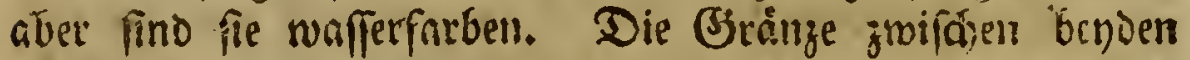

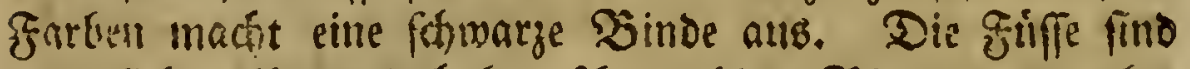
eigentlid) gelb, und habent fdymarglane Bindent, bie afer

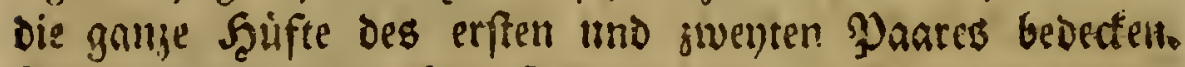

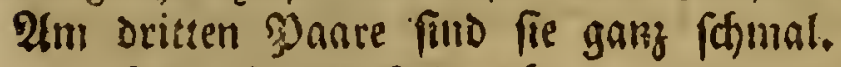

sing ift Die Şeimatb.

\section{S. 43. \\ Toftfárbigte Schlupfrerpe.}

Tenthredo ferruginea. T. antennis feptemnodiis nio gris, albo annulatis; corpore faturate ferrugineo; tho. race, pectore, verticeque nigris.

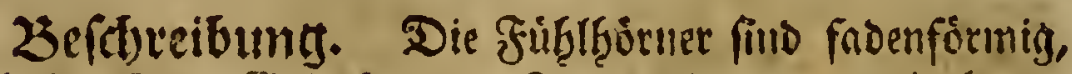

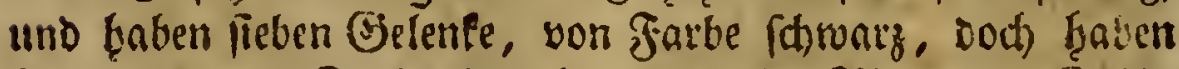

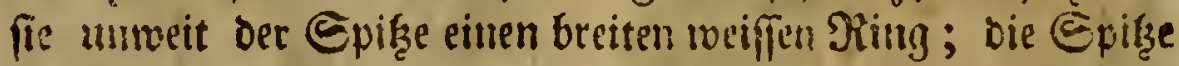

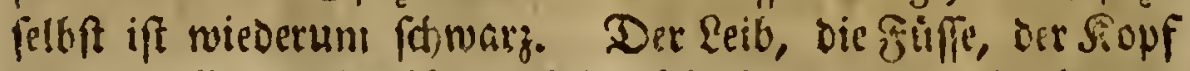
unten, alles biejes ift bunfel roftfarben, oder vielmelyr cas 
franicubraun. Der ORicienfifild, die Sruft, und der obere

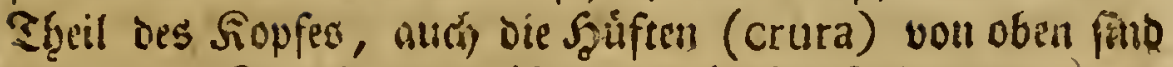

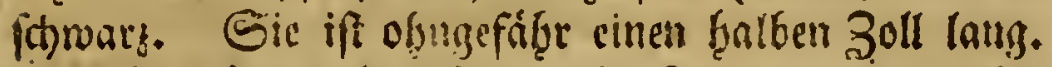

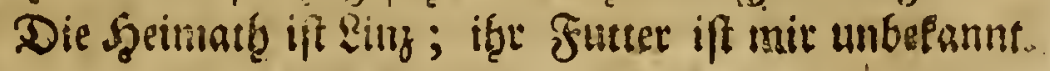

\$. 44 .

Beritigeite Shlupfiverpe.

Tenthredo annularis. $T$. antennis feptemnodiis, atra, nitens; antennis apice albis, tibiis omnibus ferrugineis.

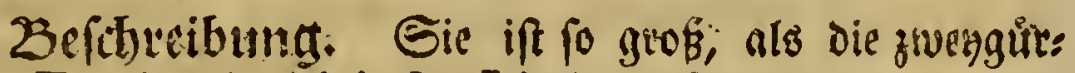
telige (Tenthredo bicincta Lin.), glämzenofdawarz, mit

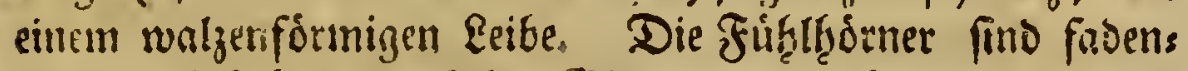
forminig, befteben ang fieben (Btievern, uno haben eine weiffe

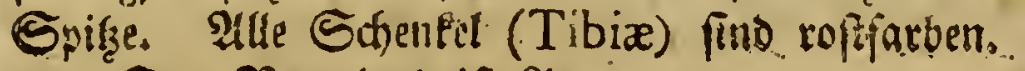

Das Bateriand ift Eimz.

\section{S. 45 .

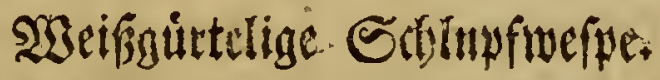

Tenthredo albicincta. T: antennis feptemnodiis, nigra, abdomine ad bafin cingulo, tibiisque omnibus annulo lacteo.

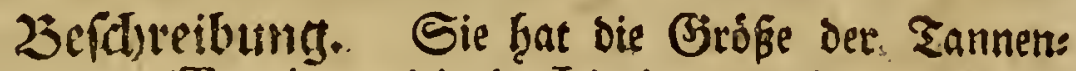
fiflupfroeipe (Tenthr. abietis Lin.), Der fie aud) fonft youfoummen ábnlid) iff. Die 2lumeristiungen bavon beftes

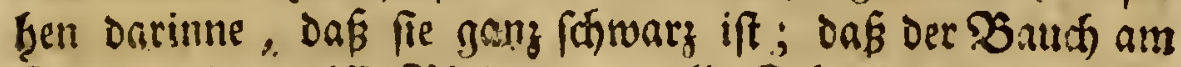
Ërunde eine reiffe Binde, uno alle Eddentel einen mildy; farbenen Ring baben.

Das Batetiand if Deftetreict).

S. 46.

Paillenfátbigte Edlupfwerpe.

Teuthredo framinea. T. antennis feptemnodiis, corpore flavo, abdomine fupra fufca. 
Befareibung. Sie ift gróser, als bie grine (Tenth. viridis Lin.), aber ebent ro gegetidnet, mit Dem

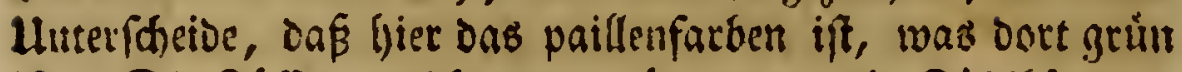

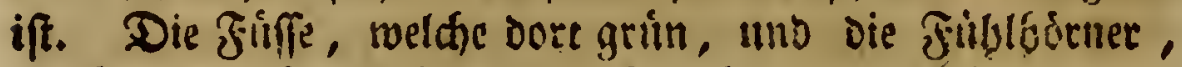
sveldbe dort fómarz fino, fino bier bell cafrautiensinan.

Das 23aterland if Deferectich. syan fángt lie an Dattern, wo es viele 2 Beiden uno Erten gुieb́t.

\section{ఠ. 47. \\ Siotbfüfige Sd)lupfwefpe.}

Tenthredo erythropus. T. antennis feptennodris, nigra; abdomine lateribus albo maculato; femoribus pofticis læte coccineis.

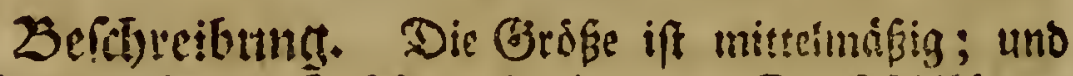

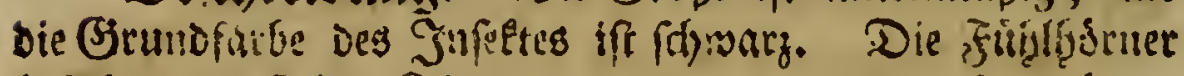
befteben nus fieben Bstievern, yon oenen bre erffen lánger

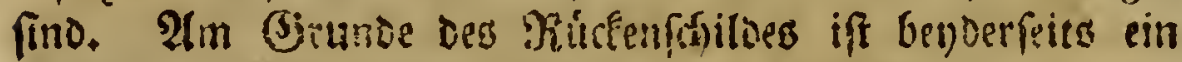

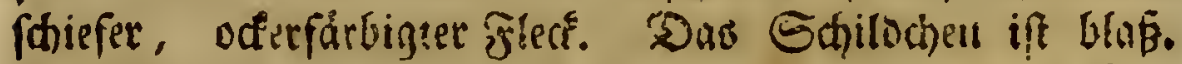

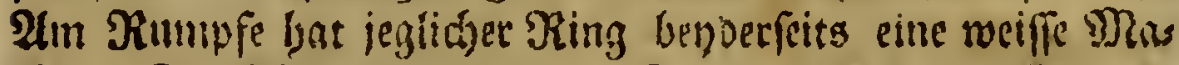
del. Die füffe hagen einige Eonderlidfetten. Das et:

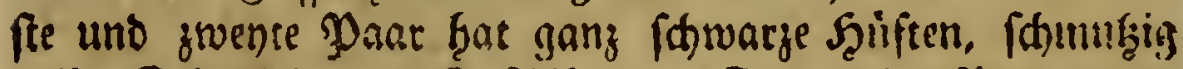

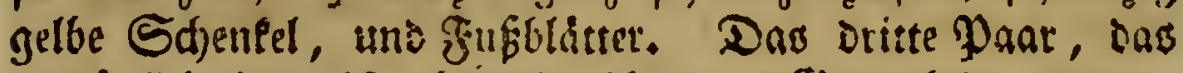

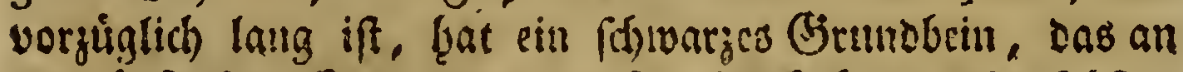

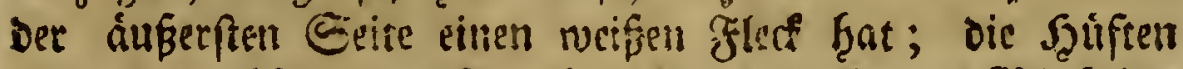

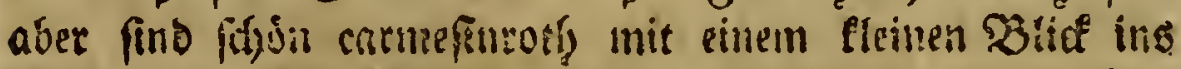

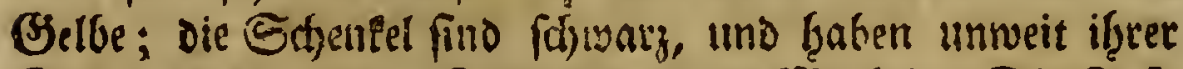

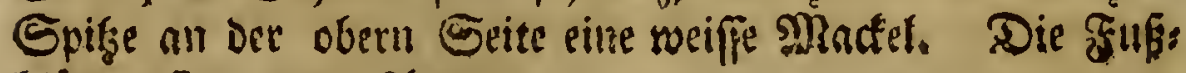

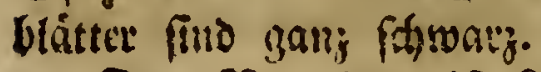

Das Baterland ift Ling.

$$
\text { S. } 48 \text {. }
$$

3menfeafigter Simusentobter.

Ichneumon binaculatus. 1. fcutello flavicante, antennis albo annulatis, niger: fegmentis duobus poftremis fupra macula gyplea. 
Beidoreibung. Fr Gat: bie Rånge eines balben

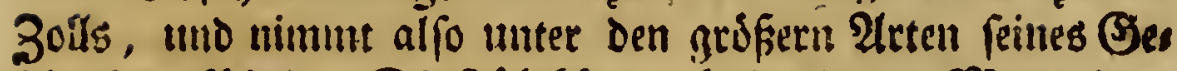

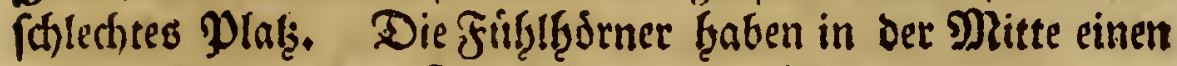
weiffen Shing; Das Ectilod)en ift frobfarben; die zween

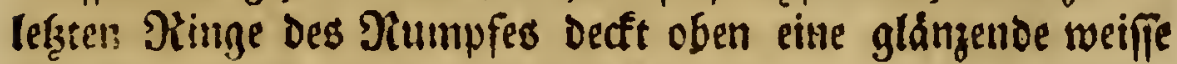

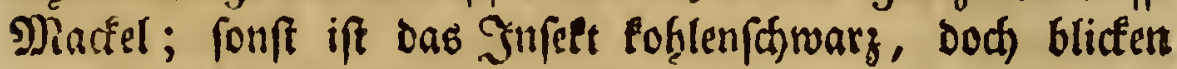

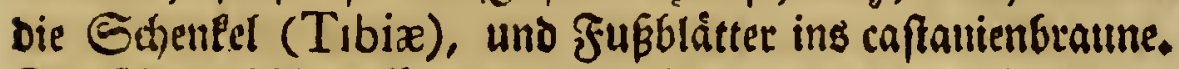
Der Rummf ift enfortmig, unb fiset alif einem feger eurzen Etengeldjen.

Siuz ift bie Şcimatb.

\section{S. 49.

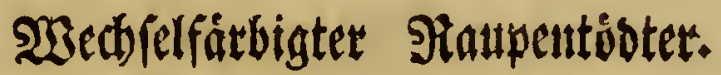

Ichneumon alternatus. I. fcutello flavicante; niger; tibiis, tharfisque albo nigroque variis.

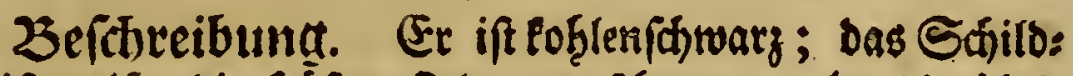

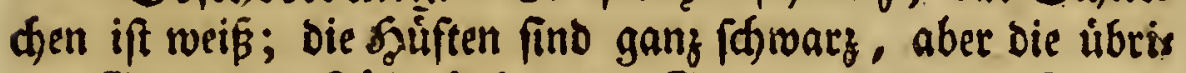

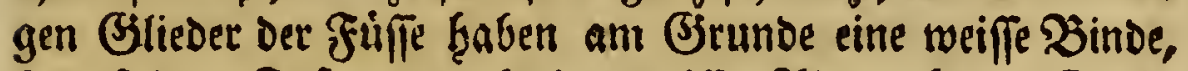

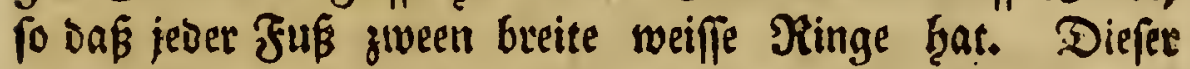
Raupentobter ift linienfórmig, und Der Rumpf fisct nuf eittem furzen Stielden. Er gef̧oret mit unter bie grofen Anten diefes (Gefd)ledtets.

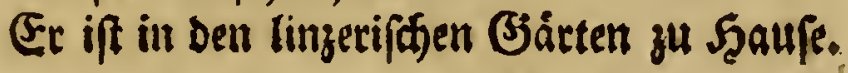

\section{S. 50. \\ Dreyfátbigter Raupentỏbtet.}

Ichneumon tricolor. I. fcutello flavicante, "niger, fubpetiolatus, femoribus rufis, pedibus albidis.

\section{Tab. 3. Fig. 18.}

Sefchreibung. Er ift von der Grópe der Gerfulis fhen $\mathfrak{A}$ meife (formica herculeana Lin.), ganz fifimal; Der Rumpf ift nur mit einem febre turzen Stieldgen an bie

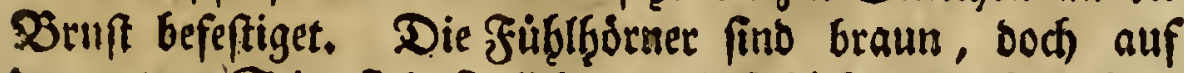
Der untern Estite find fie lidster uno faft brandgelb. Der

$$
\{4
$$


ganze Reib ift fithwarz. Dng gelbe Sdyith hen aubgenommen.

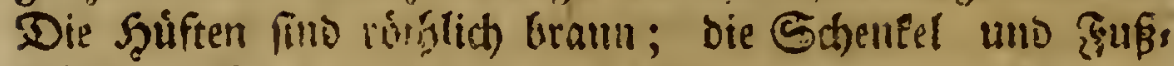

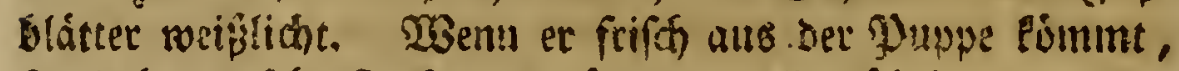

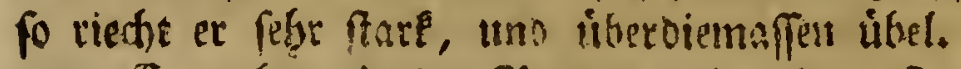

Er nolynet in ben Sianpen, in einer fino ifgrer oft guzall uno brey.

Das Gebanfe (Fig. I8.), in Dent er fich Zcit feines

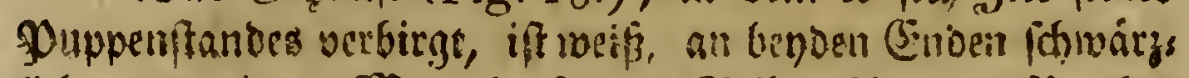

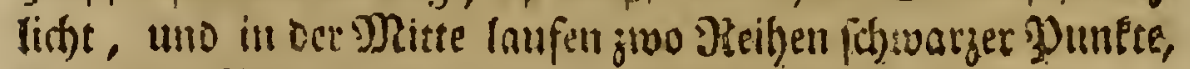
suie grwo Sinden Gertum.

\section{Q. 5 I \\ (sentalter Stanpentiostet.}

Ichneumon pitus. I. fcutello flavicante; antennis ferrugineis, medietate nigris.

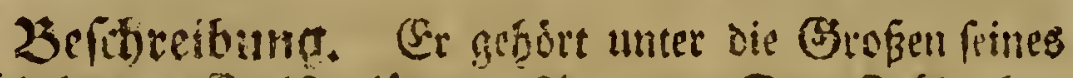

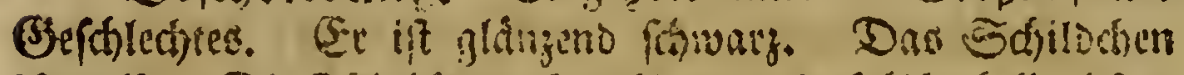

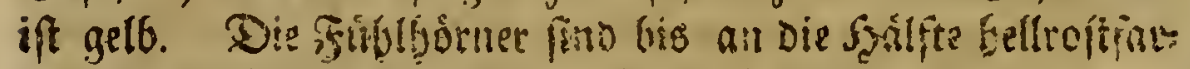

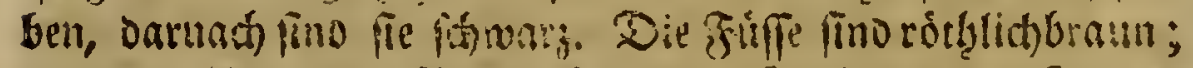

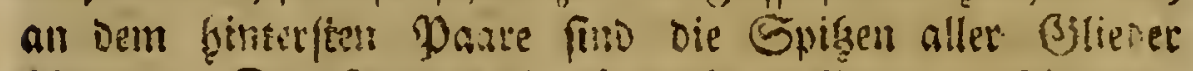

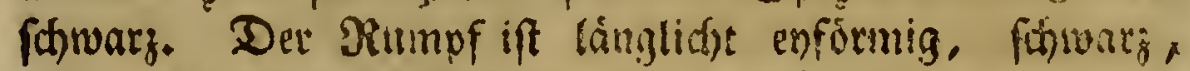

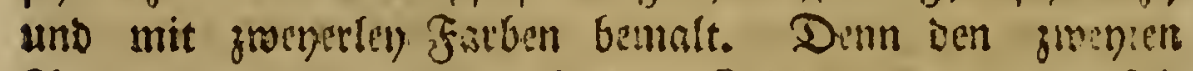
Bing, over verr erfen mans bem Stield)en, und Dan fots

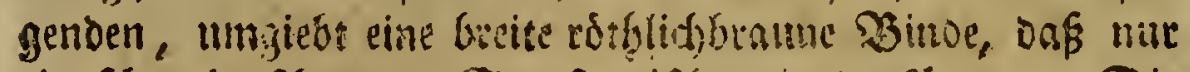

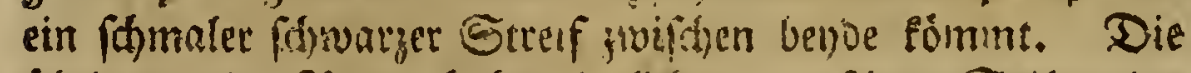

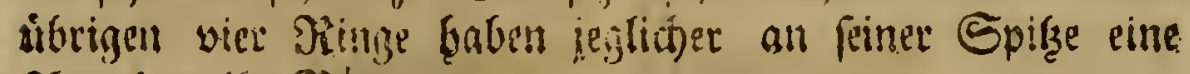
fohmarle gelbe SButros.

Err if: nifft gai feltfam, uno wotgnet in Defterreich.

$$
\text { S. } 52 \text {. }
$$

Ichneumon ferrugineus. I. ferrugineus, antennis nigris albo fafciatis; oculis abdominisque apice nigris.

3effbreibung. Er geţort ebenfalls unter bie Fros Bur. Der Fimpf ligt auf einem Eurzen Stichten, ift ey: formig, uno ţintent fiunpf. Der ganze Raupentóster ift 


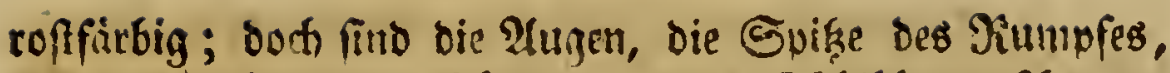

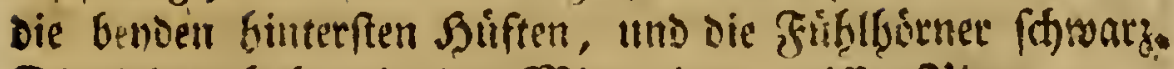
Die legenten baben in Der Mitte cinen weiffen Biing.

Ere ift in Deftetreich) ju Staulfe.

$$
\text { S. } 53 .
$$

Salbgittelinget Finuentooter.

Ichneumon Semiannulatus. I. niger; antennis nigris medio fafcia dimidiata alba; audominis petiolati fegmento fecundo, tertioque rufis.

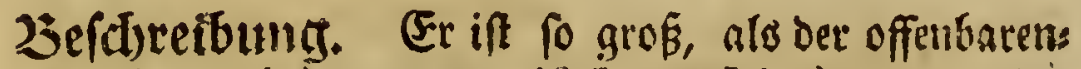
de Sampentóder (Ichneu. manifeftator Lin.), uno bat

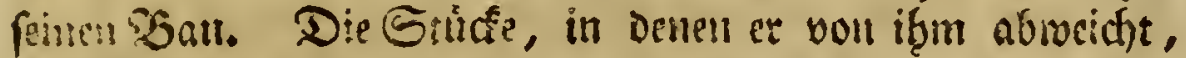

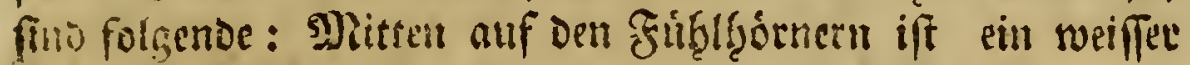

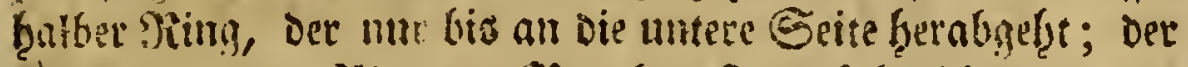

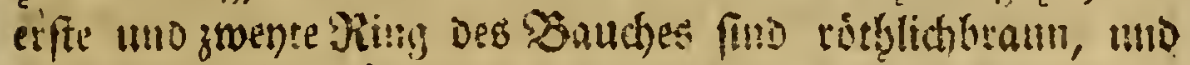

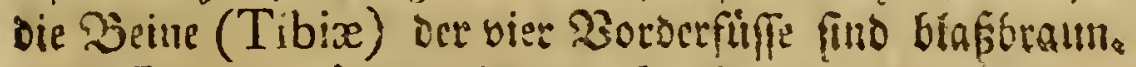

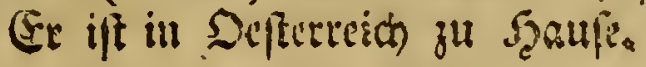

\section{54 .}

Firders Siaupentioter.

Ichneumon Fifcheri. 1. niger, antennarum baft, tibiis tarfisque, abdomineque, demto petiolo \& apice, rufis : femoribus omnibus clavatis.

Berstreibung. Er gef̧ס̊t mit unter die grofen

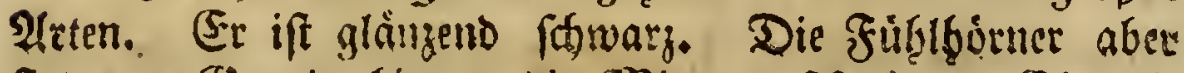
fino youn (S):unde bis an die Mitte roffarben. Even fo

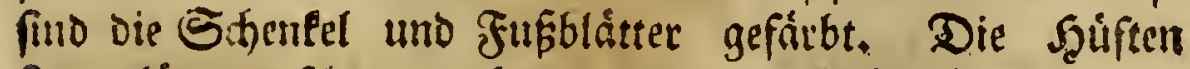

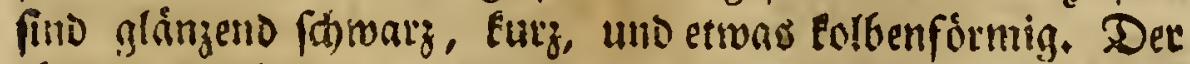
långlict)te, Gelleaftanienbraume glängende Siumpf fiket auf einem fdywargen Stielchen, uno ift an Der Spifze viederum fofroary.

Dberdfterreid ift bie Şeimath. 


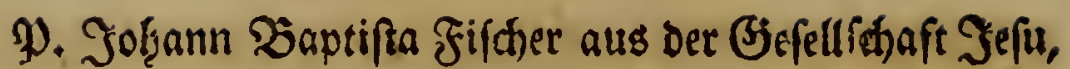

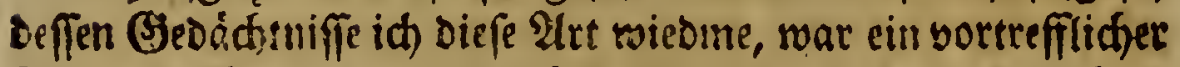
Naturfor

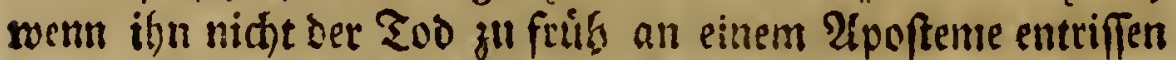

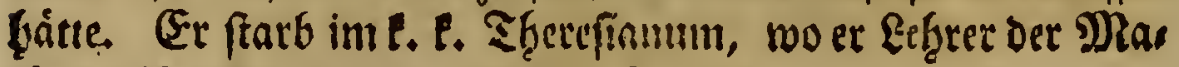
thematil war, 1762. Den 29. Sullus.

\section{S. 55 . \\ Rangfiffiger. Paupentobter.}

Ichneumon macropus. I. niger; antennis apice, abdoninis medio, pedibusque ferrugineis, pofticis nigro ferrugineoque variis.

2Beffireibuna. Er madts benláftỉ cinen balben

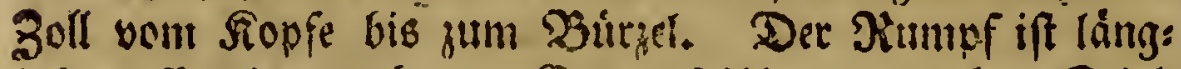

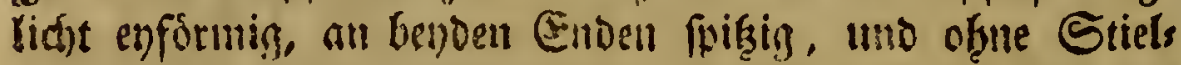

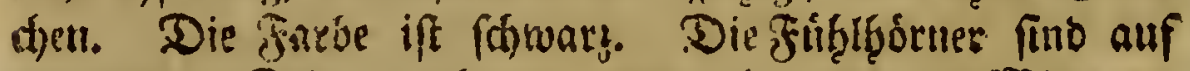
Der untern Ecite burchaus, oben aber von ber Mitte an

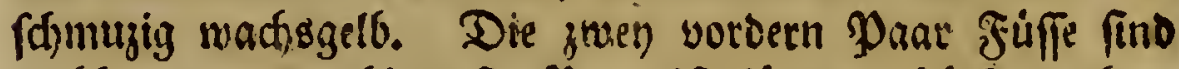
rotófreaun; Das biuterfte $\mathfrak{P} a$ ar ift limner, ftärfer, ebens

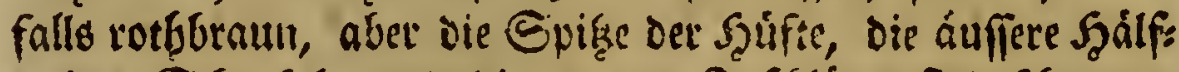

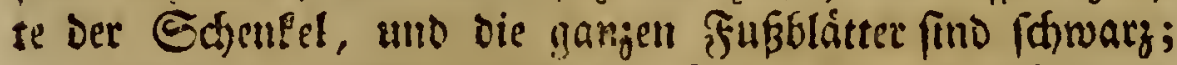

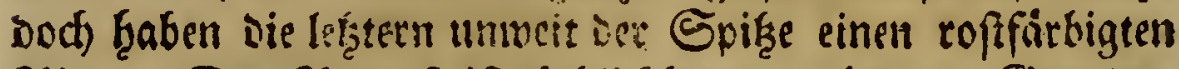

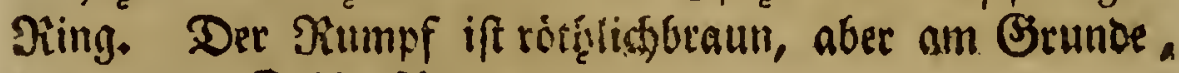
uno an ber Spizze fahwar

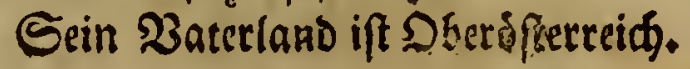

$$
\text { Mo. } \$ 6 .
$$

Ichneumon occifor. I. nigger; abdomine falcato, fafcia ferruginea.

Befdurcibung, Der gegenwartige Paupentobter ift in allen Stúcfen, wie ser jagende (Ichneum. vena-

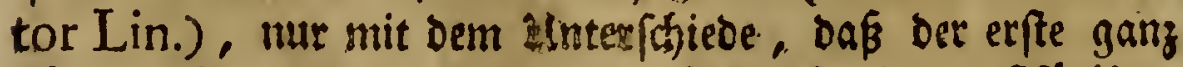
fdimarg ift, uno mitten um ben Rumpf eine rofffárbigte SSimpe gewulloen ift. 
febr fofwer, uno bennabe dirfte man fagen, unmỏglid.

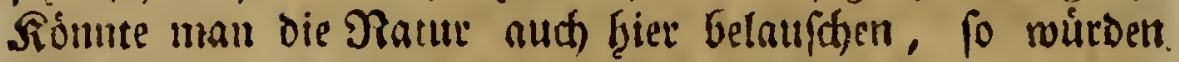
vieleicht viele angeblidgen 2 Irten zu blofen Spielarten wers Den, unl wer reis, ob Dann nicht mantbe angebliche Epielart den Ylaf einer ishten 2 irt einnef̧!nen wúrde.

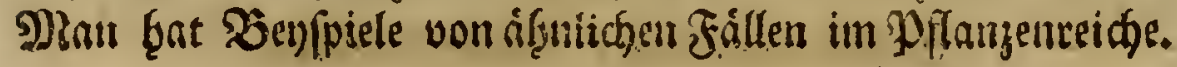

\section{S. 59. \\ Rieienmudie.}

Tipula gigantea. T. alis patentibus fufcis, medio undatim albis.

Tipula maxima. Pod. mus. gr. pag. 113. fp. 6?

25efibreibung. Eie ift Diegrof̧te aus ben befanns. ten Mnicfen. ßoom Butrgel bis an ben Sopf ift fie einet

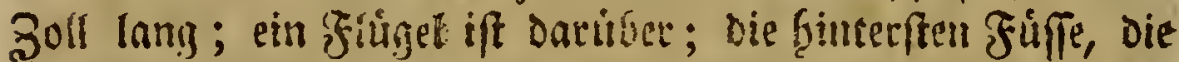
frenliah wogl ein wenig lainger, als Die tibrigen. fino, ina: hen $2 \frac{x}{4}$ Zoll aus. Die Farbe ift grau. Die Flúgel fint beaun, am imnern Rande fino fie co rentiger. MRitten Durd) fie geht Der Rátme nath ein wallenformiger, jitfact: laufender, breiter nuißer Streif. Llsterbaupt unterfaceidet

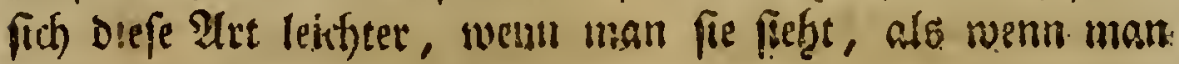
fie befitreibet.

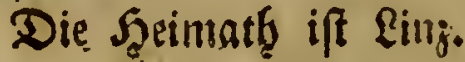

$$
\text { 5. } 60 \text {. }
$$

\section{Pieryigte siluet.}

Tipula venofa. T. alis hyalinis, venis fufcis fufco. que marginatis.

23eftyreibung. Sie gišt Der Riefenmude wenig nach. Das Siennjeichen liegt in.Den Flügetn. Sie fino.

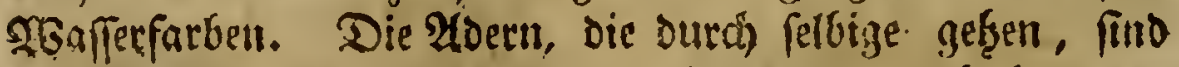
braun, uno neben ifgnen laufen begocreits nod Graunere:

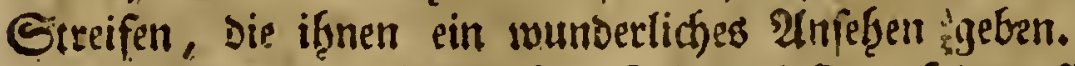

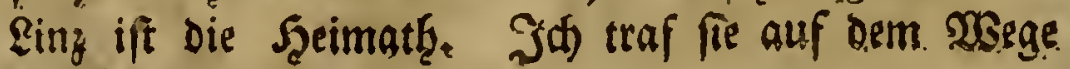
nad) 2 Billecringen an. 


\section{Siebente 2lbbandiung.}

\section{S. 61 .}

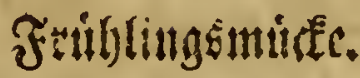

Tipula verna. T. cinerea, alis hyalinis, fafciis dua* bus punctoque fufco.

$$
\text { Táb. 3. Fig. ig. }
$$

Scflbreifung. Sie if afdenfarben, und etwas

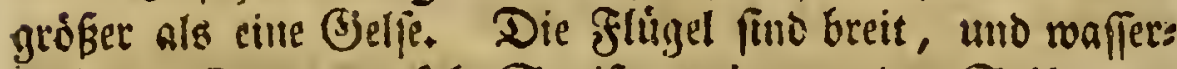
farben. Zneen Dunieie Etreifen, einer an ber Epiz̧e, Der

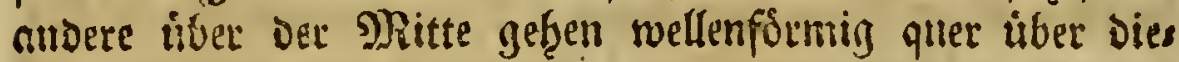
felben. Unrseit Dis Brunses ift ein Dunfeler Punft am áuß̉ern SRande.

Die 19. Figur Der Dritten Tafel fellet einen vergrós ferten fluigel vor.

$$
\text { 5. } 62 .
$$

\section{Blutende Miufe.}

Tipula homorrhoa. T. nigra, abdomine poftice fan. guineo, tibiis niveis.

Tipula paluftris. Lin. Syft. N. Getr. 2\{2. fp. $\{3$ ?

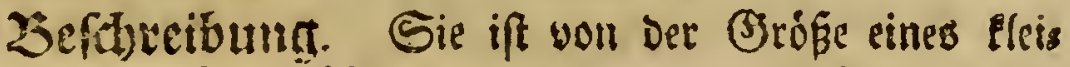

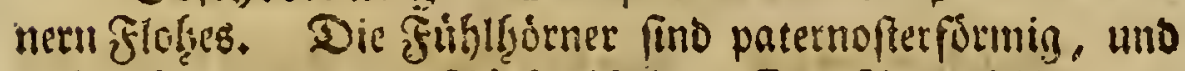

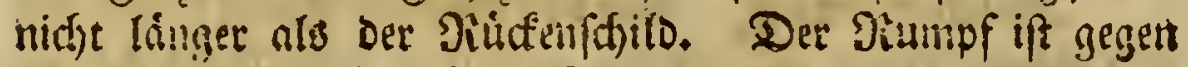

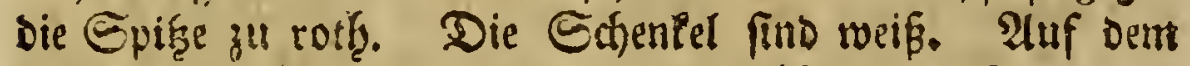

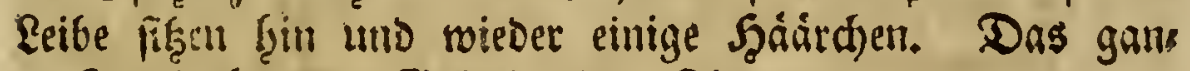

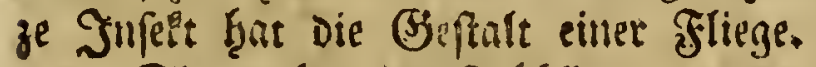

Sie wof̧nt in Früb̨linge. an Den Fenftern.

\section{\$. 63. \\ Sieue Fliege.}

Mufca nova. M. antennis filatis clavatis inedio fetigeris, fcutello bidentato; nigra; fulvo pubefcens.

2beid)reibung. Sie ift etroas gróṕer als die pơ belbafte frliege (Muf́ca plebeja Lin.), umb eben fo gefrat: 


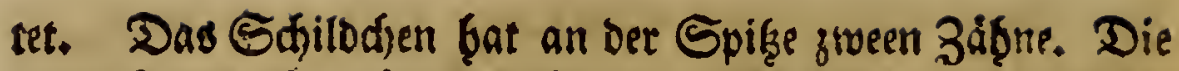

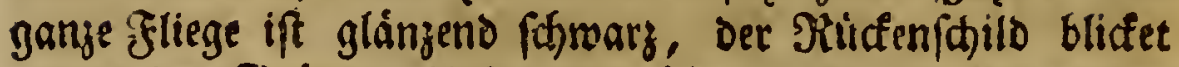
etrons ins Graine. Lleber und úber ift fie mit eurgen lins

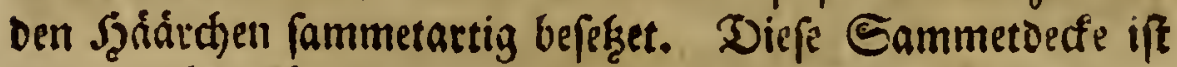

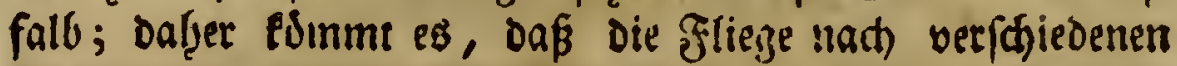
weendungen zwithen falb und Stbwary fpielet, wie es der Eidcenfalter, Den die Franzofen Darum le changeant nennen, jwifthen SBlau und Sdtwarz thut.

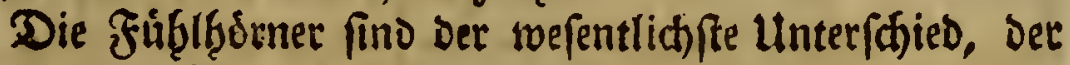
zwifden diefer fFliege und Sinnee's Mufca mutäbilis (Faun. fuec. n. 1807.) herriftet. Denn bey Der unjrigen fino fie lang, nach vornen ausgefirefet, und haben an Der Spi.

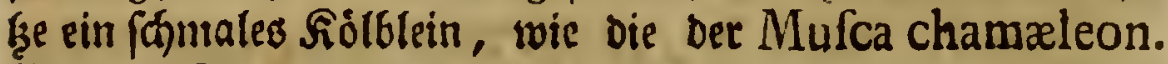
$\mathfrak{2 n}$ Der Seite firt eine elurze Borfte.

Defterteid) ift das Baterland.

\section{64 . \\ Tootentopfaffiege.}

Mufca Atropos. M. antennis fetariis, fubtomentola; thorace albido, maculis tribus nigris; abdomine nigro, fafciis interruptis margineque fegmentorum flavis.

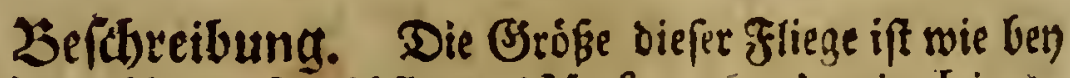
Der fowargblauen fleifthflege (Mufca vonitoria Lin.). Sie ift aber gróftentyeils gelb, und gar nidbt taarig, aber

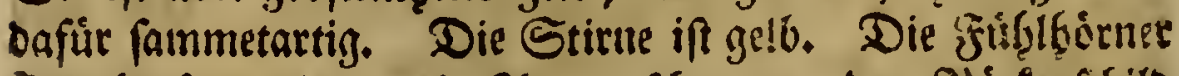
fino borftenartig; sie Atugen fawwar ; Der Silufenfahito blafinelb, mit oren fohmargen flecten, dabon zween naje

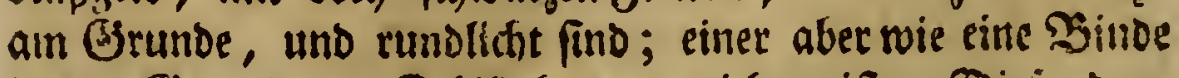
in Der Segend Des Sdjildodens gegeiduntet ift. Dieje bren Sflecen fietlen Der Einbiloung einigermafen eillen Fedtens topf vor. Der ßumpf ift fhwarz, und gelbe Binden ge: ben uber benfelben nad Der Sure, bie aber allemal in ber 3) Ritte voin Sdywarzen unterbrodjen werben. $\mathscr{A}(4)$ bie Diaunber eines jegliden Ringes fino getb eingefaffet. Die Frifie fino gello. 


\section{Siebente 2lbbandlung.}

Sie Exflieget die Blumen. Th babe fie forrogl um Sing als un Woien angetroffen.

$$
\text { S. } 69 \text {. }
$$

\section{9) (ausfärbigte Fliege.}

Mufca murina. M. antennis fetariis tomentofa grifea: thorace lineis tribus nigris; alis fufco maculatis.

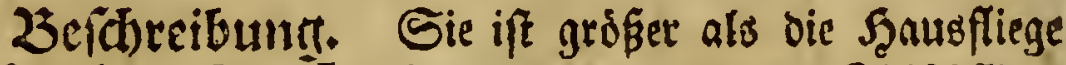
(Mufca domeftica Lin.), uno fleiner als Die Fleifofliege (Mufca carnatia Lin.), Durchaus mausfarbati, die Saas Iancicrestled)en felbft nidjt ausgenommen; aber iffre Stiels

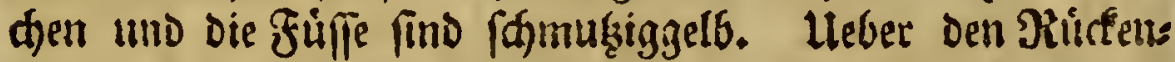

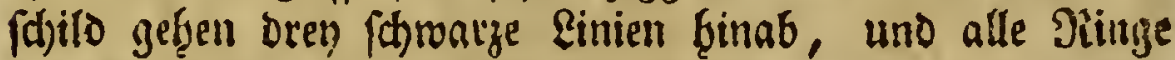

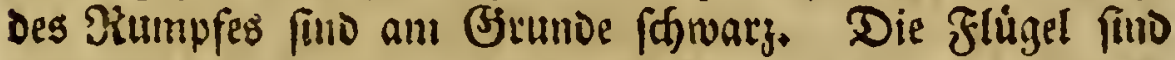
rafferfarben, tuno mit vielen Dunteln, in einander fliefens Den Miadeln bejäst. Die Fúb̧lg̨orner fino Gorftenformig. Eiliz ift Das \$ateriamb.

\section{\$. 66.}

\section{3iwengirtelige Fliege.}

Mufca bifafciatr. M. antennis fetariis, lævis, nigra; abdomine cingulis duobus, pedibusque anticis quatuor flavis.

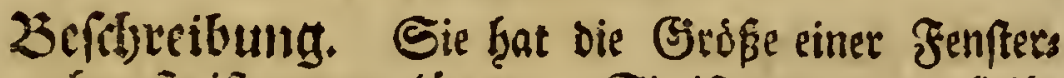
fliege, aber fie ift etrvas länger. Sie ift am ganzen \&eibe

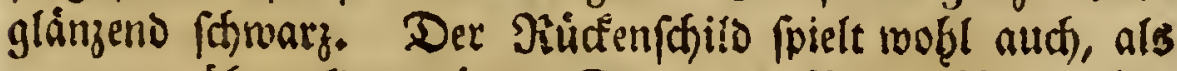
wemu ex úbergoldet wáre. Die zmen Paare Berderfáffe fino gelb; und úber den enfórmigen Şaudh gef̧en zwo gets be Bindent. Bon eben Diefer Sarbe find Die Śelenle der

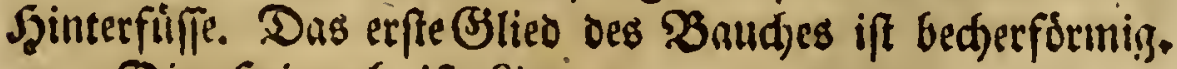
Die Şcimath ift Einz.

Die 2 I, Figut bet 3. Tafel bilbet ben Rumpf vers gró́ert ab.

$$
\text { 5. } 67 .
$$

Rinzerifde Fliegse. 
Mufca lincen/is. M. antennis fetariis, nigra; fronte rubra, alis hyalinis; marginis maclilis, anaftonofibusque duabus fulcis.

\section{Tab. 3. Fig. 20.}

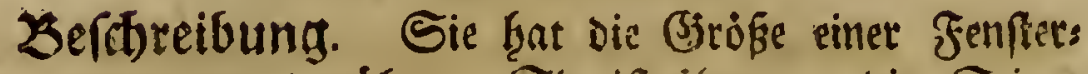

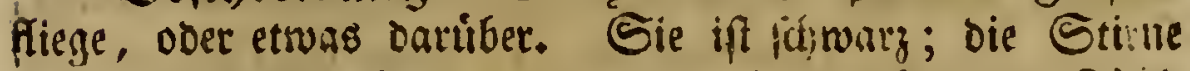

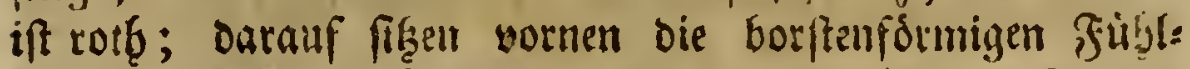

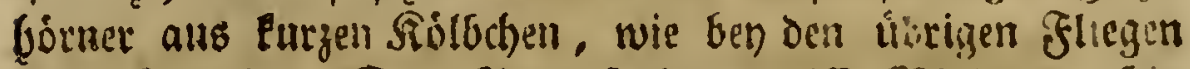
Diefer Familie. Der Rumpf hat meiffe Bindent. Sgit und wieder figen ant Reibe borftenformige Jaanre. Das

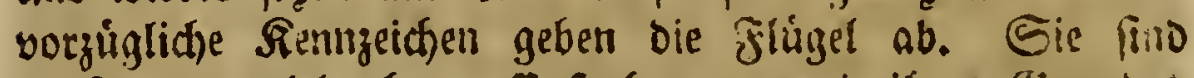
weif, oder vielmebr wafferfarben; ; !mweit iheres (H)rmbes

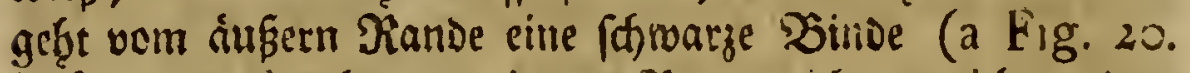
Tab. 3.), Die aber den innern Biand nidist erreider; Dats

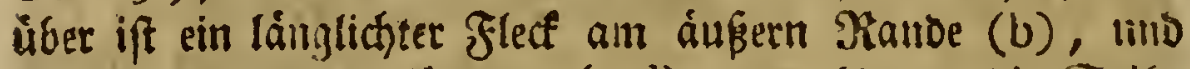
endlid) ein anderer lángerer ( $c$ d), Der bis an Die Exif̧e

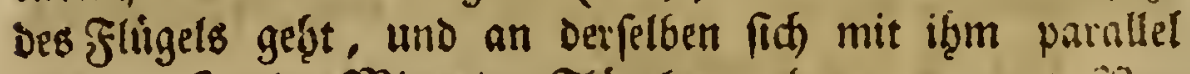

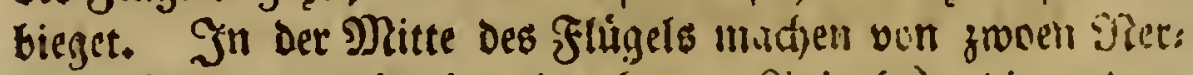
venturtinoungen die eine eine braune Rinic (e), Die allbite einen $\mathfrak{p u n f t .}$

Das Baterlanio ift sing.

\section{68.

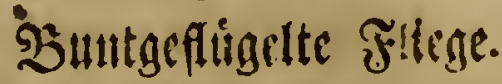

Mufca pceciloptera. M. antennis fetariis; capite rufo; alis rufofuficis, albo variegatis. Tab. 3. Fig. 22.

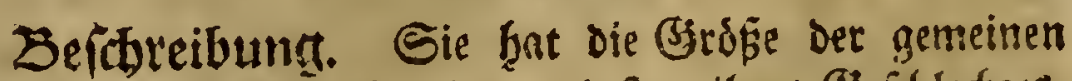

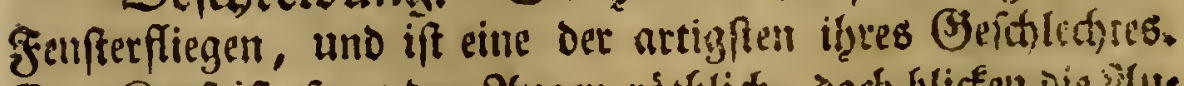

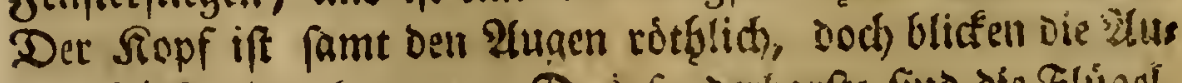
genl fiárfer ins braune. Das fonderbarfte fimo de Flúgel. Sie fino rothbraun, vom immern 3anse gefer oren laizets formige und ein wentig gebonente meifie Errcifen fouti bis an

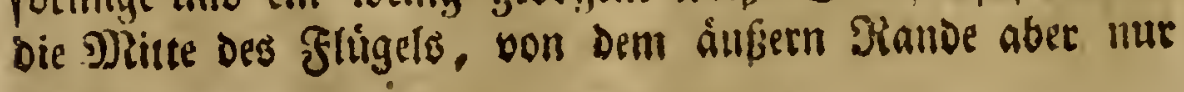
zmeen. 


\title{
Siebente :Hbranding.
}

Ring ift bas 2 aterfand. Die 22. Figur fellet einen fligel vergrofert vor.

\author{
\$. 69. \\ Riingelgelfe.
}

Culex annulatus. C. niger, abdomine cingulis quinque albis, pedibus albo annulatis. Culex xgypti. Halfelqu. itin. pag. 470. 12. 121 .?

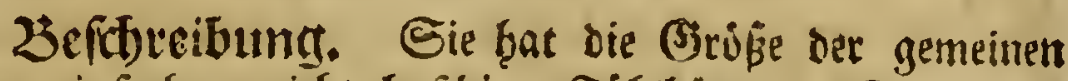

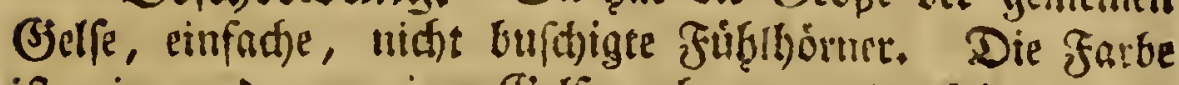
ift wir an Der gemeineni (Berle, aber etwas buneder. Heber Den Simm gregen fumf meise Binden. Die Fuife, berons

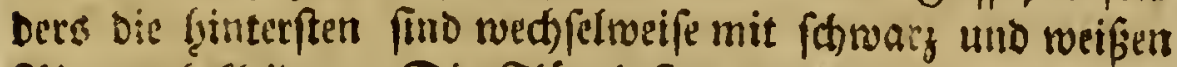
Singen befleibet. Die flúgel find buteleter, als ben bes

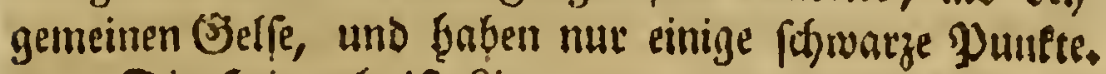

Die Şeimath ift \&ing.

$$
\text { S. } 70 .
$$

Epinnenuttiger Sielfuß

Julus araneoides. J. pedibus longillimis, utrinque XIV. Julus araneoides. Pallas fpic. fas. IX. p. 8i.

$$
\text { Tab. 4. Fig. I } 6 \text {. }
$$

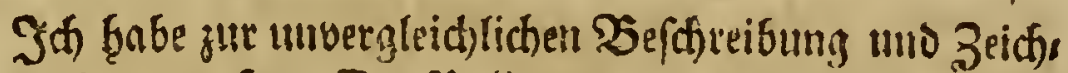
numg, Die uns Sharr Dr. Pallas davon geliefert bar, nichts

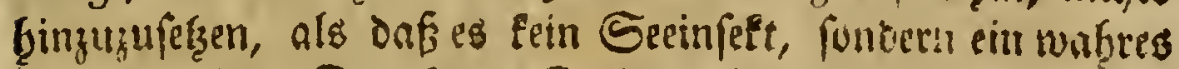

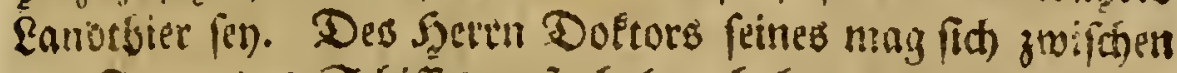

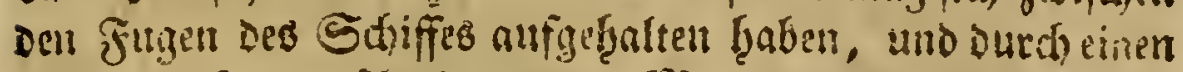

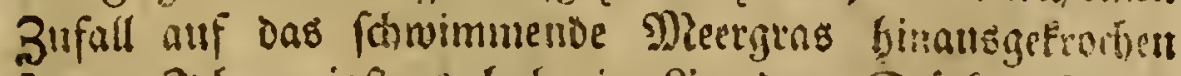

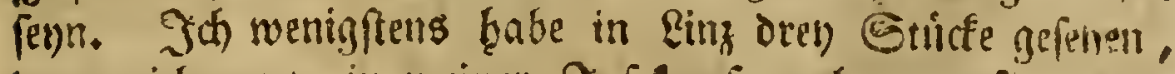

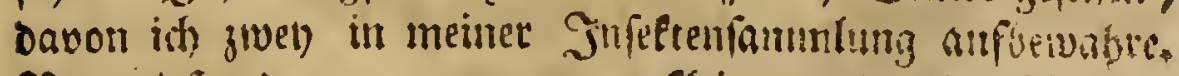

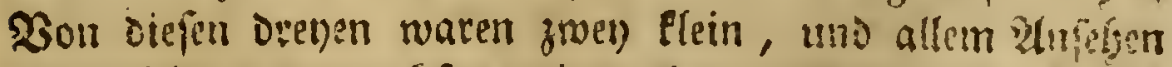
nad) nidhe ausgemadifen; eines aber volltomunen fo, wie es

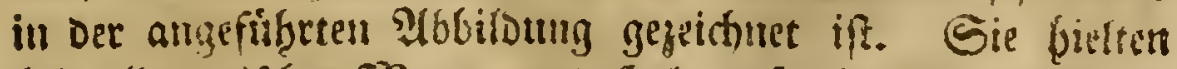

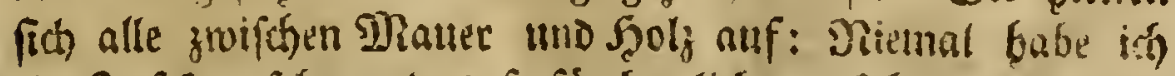

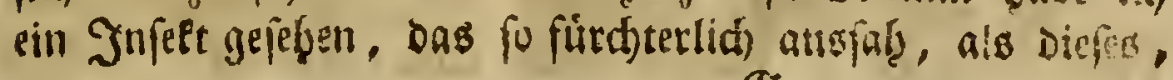


da es nod lebete. Mit der Stectnadel gefrochen bís es

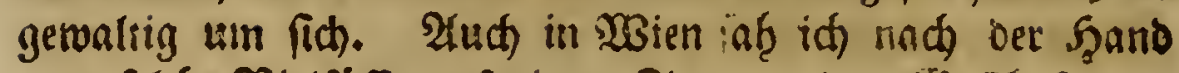

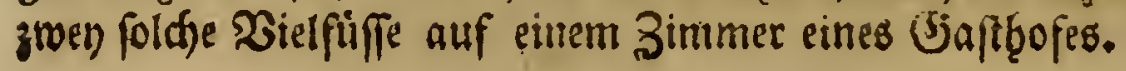

\section{VIII. அGbandlung.}

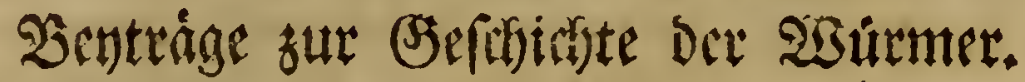

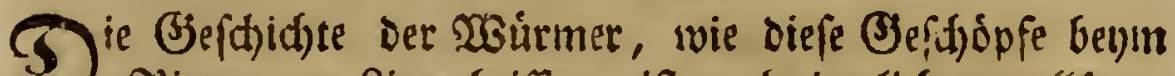
Psitter yon Rinee bृaiffert, ift nod ziemlid unvoullom: men. Lund diefes if wabr, fowohl, menn mait es von der

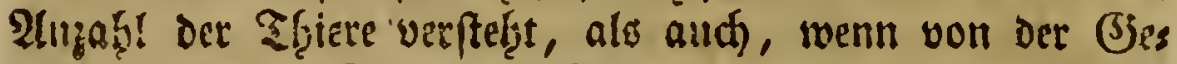

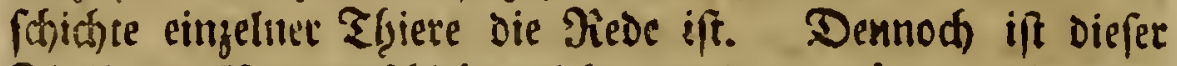
Flyeil Der Naturgefdidide uidft metriger ergázent, als je ein andecer. Utub wie fount ers meniger reun? Şat nict)t eben

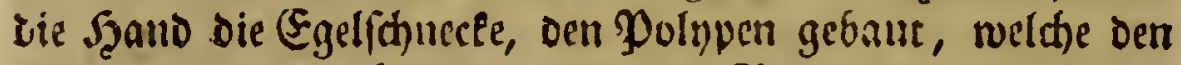
\&swen, Den wir fürdten, unlo Den Biber, Derr wir berwuns

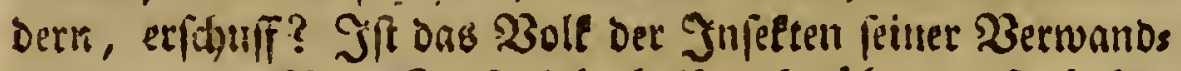

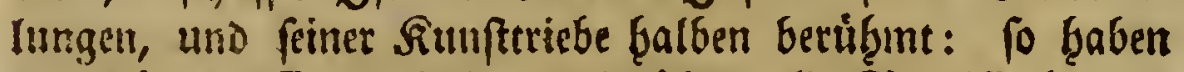

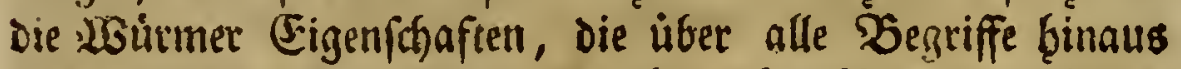
fino, welthe wir uns von der ţ̧ietifchen Natur macheten.

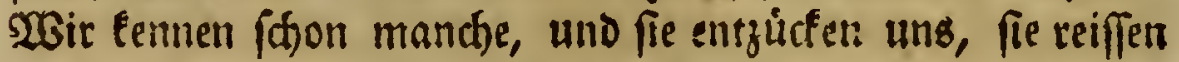
utrs in bie gewaltigfte Erftaunung oahin; wie viele aher wiffeit wir nicht, Die alles úbrige úbertteffen dưlften, roenn eimmal Rienumure Diefes Felo bearbeiten wollten!

Biegennoårtige $26 b$ bendlung foll eines ober bas andere

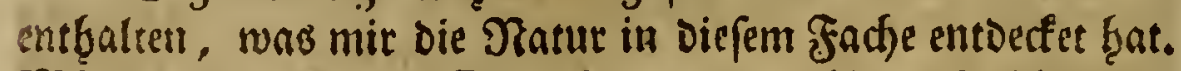

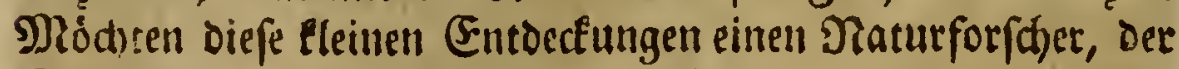
Marfie genug bat, aufforbern, fid Der Llnterfuchung Diejer Thiere zu weihen! Id bill verfichert, die Natur fer nod nirgends weniger, als hier erjidspfet suorden.

\section{S. 1 .}

Gordius infectorum. G. pallidus totus, in aëre obrigefcens.

Finige Raupen, befoncers jene, woraus bér bunte Nefferfalter (Pap. Polychloros Lin.) fobmmt, weroen 
von Diefen Tfiere geplaget. (Es findet fid) in iffnem meis

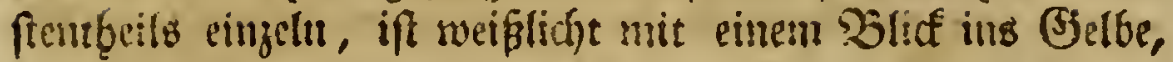

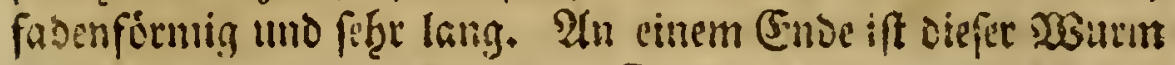
foifig, an alldern frumpr. (5re friecht Dem Sulfette ben

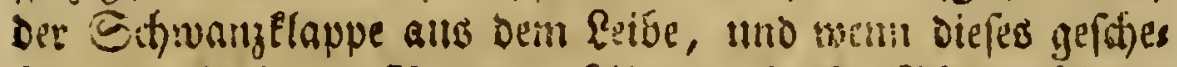

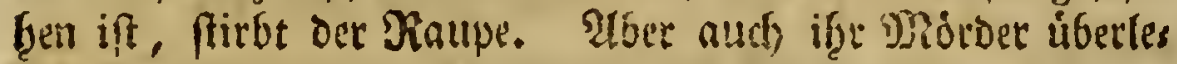

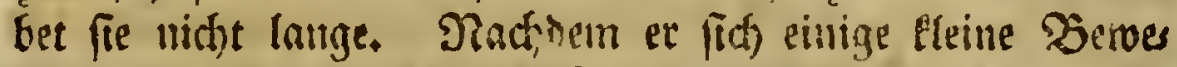

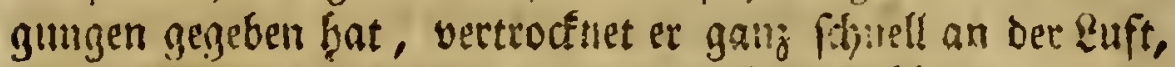

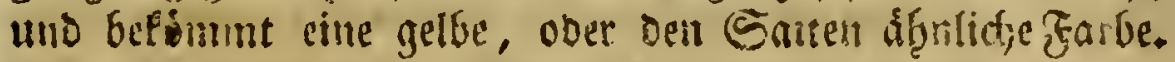

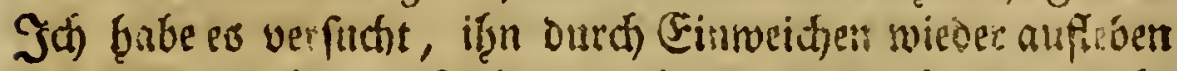
zu mad)en; aber umpouff; tr wiro zwar meid), uno madt einige bervegungen, die abat von benen einer eingerweid)ten Saite nidte unterfósieden find.

Dis erfte Figur der vierten Fafel ftellet einen folden

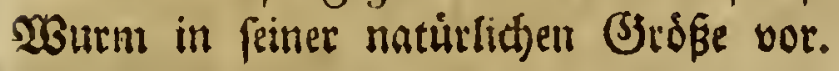

\section{S. 2.}

Afcaris vermicularis. $\operatorname{Lin}$

Es befdurdigt Det Sherr Dr. Mallas Den exfrabenen Berfaffer Des Daturigftems eitrer LInrid)tightit, Daß̧ er eitre

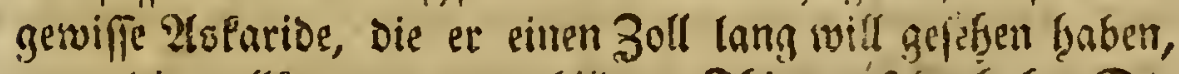

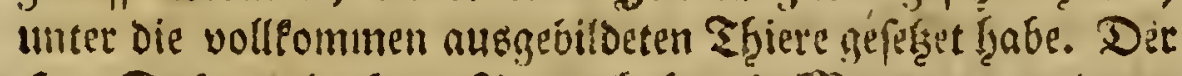
Sherr Doftor glaubet, Eimnee fabe die Dadaen, ans bentell

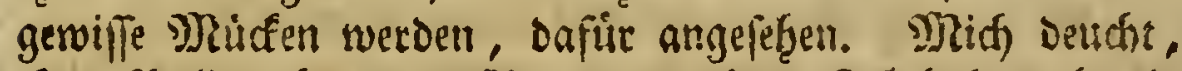

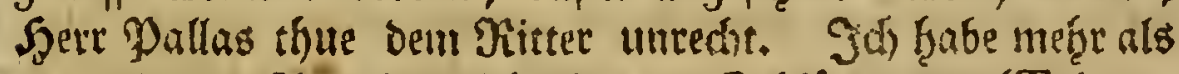

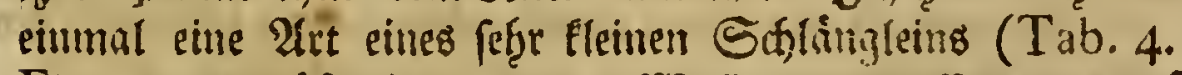
Fig. 2. verneóbert) in reinem $\mathfrak{B a}$ (f)er angetroffen, oas aulf einer tiefen Woiefe von einer Ergieflunin der Donau unweit Sinz, zuritubtieb. (5s waren peine Benegungen aufferors

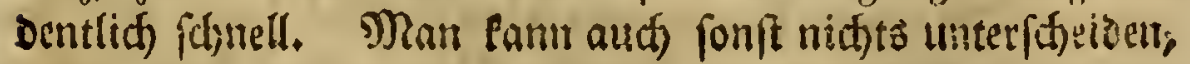

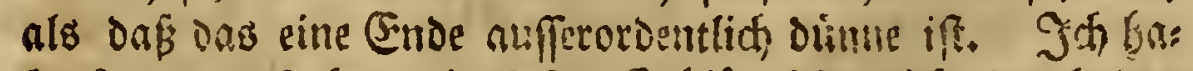
be fogat verfucht, of diefes Sdyläng!ein nicht durnt bas

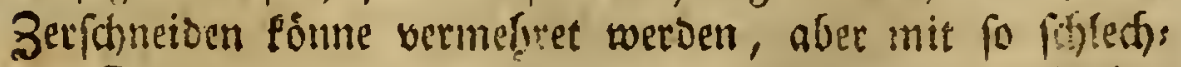
tem Erfolge, Dás bende F̧̧eile in weniger als einer batben Siertelfumbe toot waren, nadjoem id fie netremet knte.

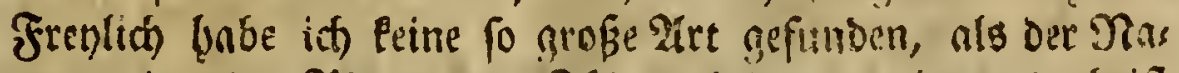
men, Den der Pitter Den Fęiere giebet, angeiget, Doch ift 


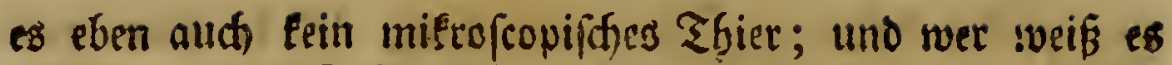

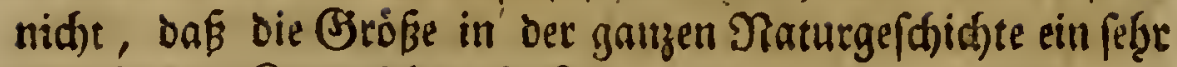
unridbtiges Sennjeichen fen?

$$
\text { \$. } 3 .
$$

Fafciola fulca. Pall. fpicil. fas. 10.

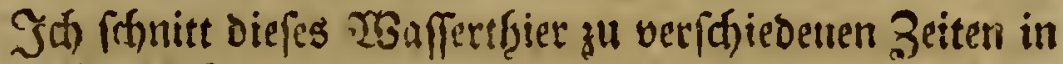
Stivefe. Bende Theile fdymanmen und Proden nody eimen ober

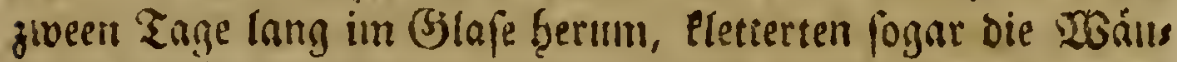
De Des éslapes herauf; aber enolict, vergiengen fie, Daß̃ nichts als eime leere Şaut jurúcte blieb, Die fint) aud bald in wonfer aufdete.

\section{S. 4 .}

Fafciola minima. F. oblonga, antice rhombea.

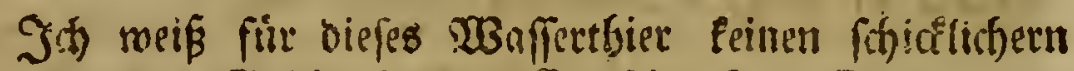
Ort, als bas Giefchlecht ber Eigelffuneffe. Es ift grwar

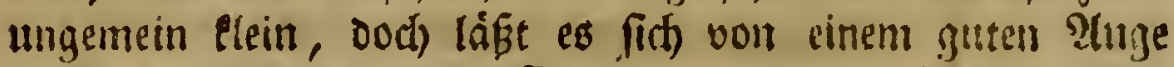

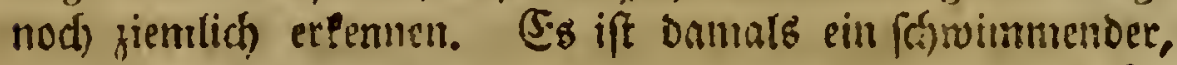

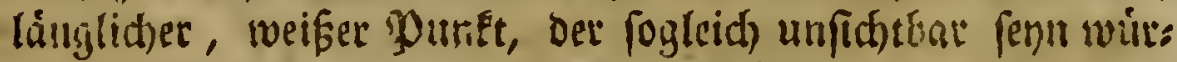
De, wein et mur ein wenig fleiner máte. Die britte mo

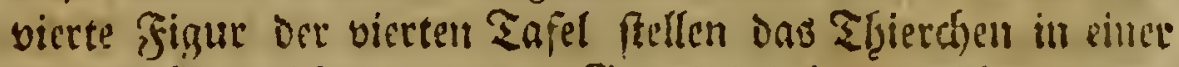

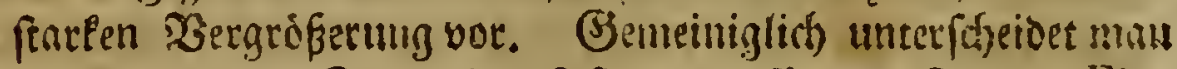
an Der vorvern Seite eine faft rautenfionnmige Sigur (Fig. 3.), bie in gern einen Sopf nemuren wollte, weun fie fonft eine (5igenfihaft won einem Siopfe badtte, ats Das fie fich an

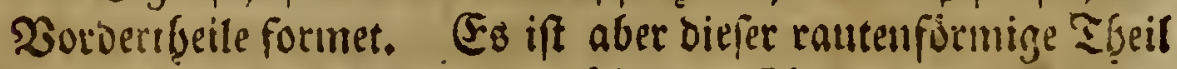
Dutrch lein ऊjelent mit Dem úbrigen Sidiper verbunden; er

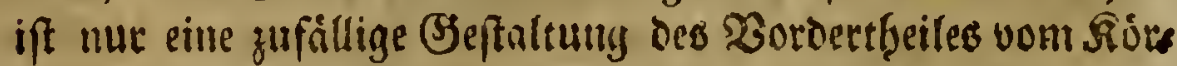
per. Die vierte frigur ftellet eben daffeltbe ThGier vor, Das

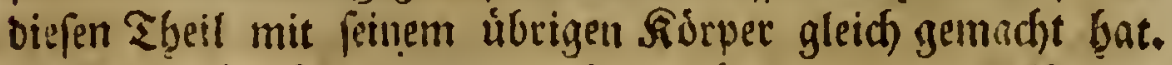

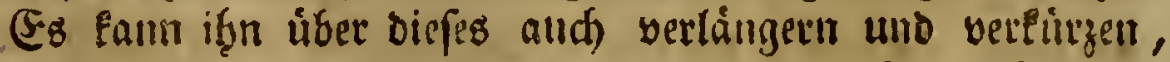

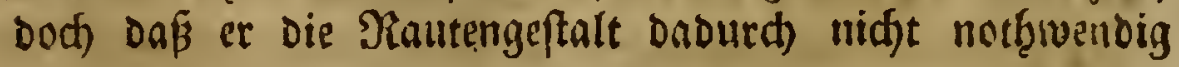
verlie:e.

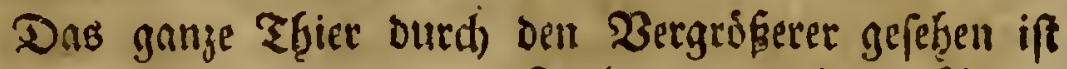

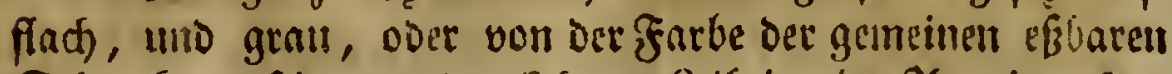

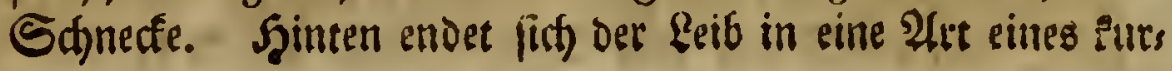




\section{Ilte Ibhandrung.}

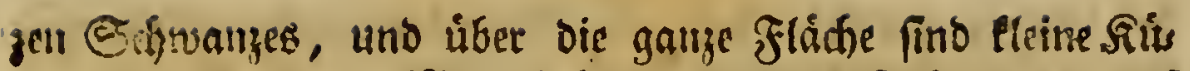
geldien zerftreut. Man fieḩt es elar, bá̉ fie nicht allf ber Dberfáche haften, fondern Durd) Die Şaut Durchícheis nen. Dafir fat biefe Ire Eeine $\mathscr{A}$ dern, wie fie Die Rebers

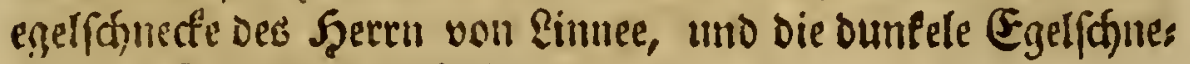
cfe Des Dr. Pallas baben.

Sie fpielt am Sirumbe des Gefáfers, obet an feinem Siande, wie das Mcidertbier; Conft aber lann es febre bef̧ento

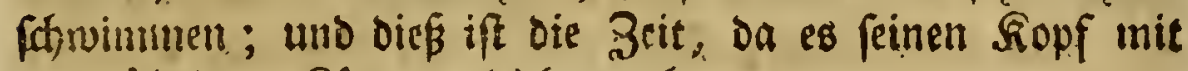
Dem librigen Rorper gleid) macht.

Эक) fand es in einem ftef̧enden 2 Baffer, Das ganz mit Şornblatt (Ceratophyllum), uno $\mathfrak{W B}_{\text {afferlinfen angefüts }}$ fet war.

$$
\text { S. } 5 .
$$

Fafciola compofita. F. corpore bilobo; lobo antico cordato, poftico rotundato.

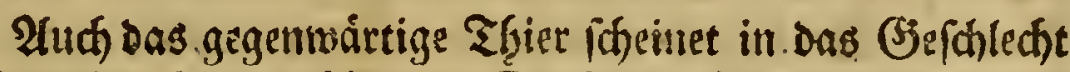

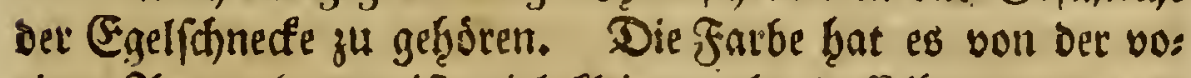
rigen $\mathfrak{A}$ trt; aber es iff viel lleiner als baffelbe, und Dem

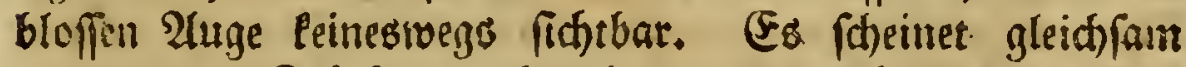
aus zweyen Stricén zu beftef̧en, Die benläuftig yon gleis

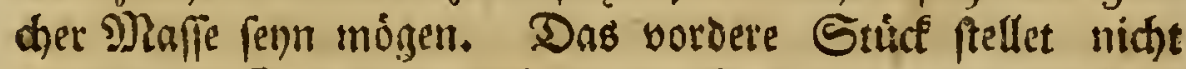
uneben Die Bieftalt eines fummpfen f̧erzzens vor, Deflen Bers

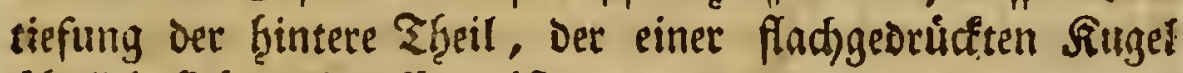
ábnlid) frebt, eingefinget ift.

Das FGier fowwimmt nidft fifnell, und wenn es auf

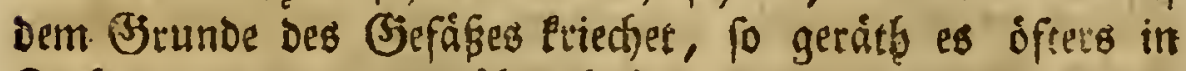
Zưfungen, Die benen ábnlid) find, die man bey Den affiers polypen und Jinfufionstḩierchen getwaf̧ wirt.

Thd habe es ben Żizelau, einem nidit weit von Ring entlegentent Dorfe, in einem langfam fliefsuden $23 a$ afor ges funden, Das aus lauter lleinels aufgebenden Dotedren ents foringet, und in melthem Tamnenmedel (Hippuris), Stern: traut (Callitriche), Sameultraut (Potamogeton), fF: ofds

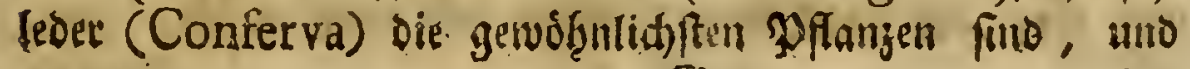


Der Boben fiemlis, ftare mit Fiuşftrammen (Spongia fluviatilis Pall) íberdect ift.

Die finfte Fignur der vienten Tafel fetlet ein Thier

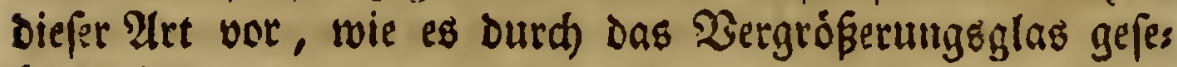
Gen witd.

$$
\text { 5. } 6 .
$$

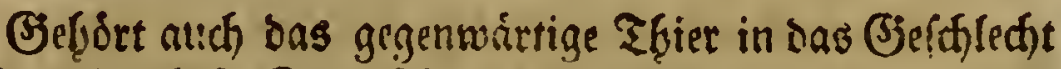

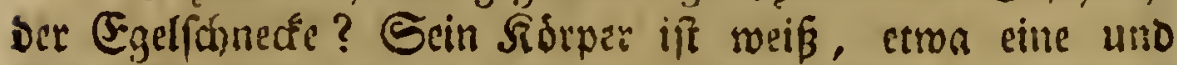

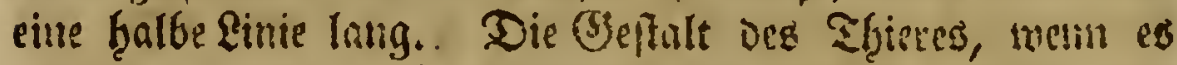

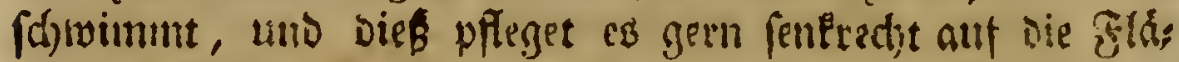

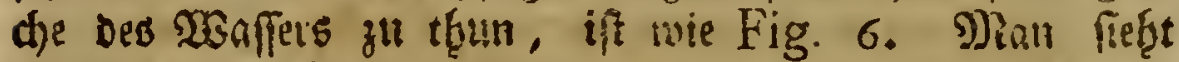

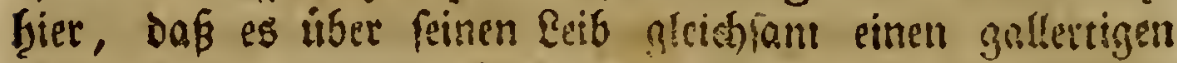

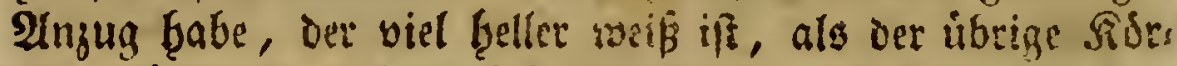
per. Ooer mant Eanm fiffs vorfetlen, als wenn ein fici.

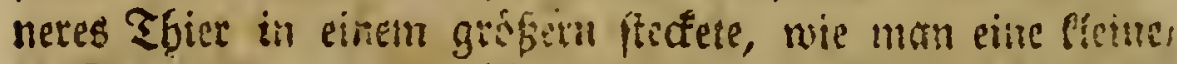

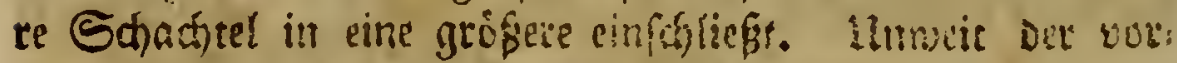

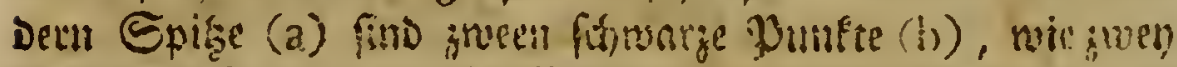

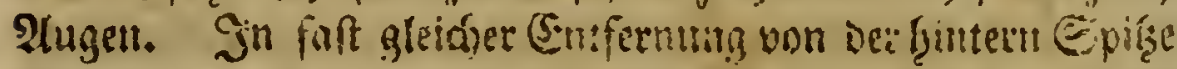

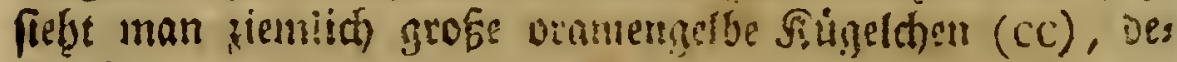

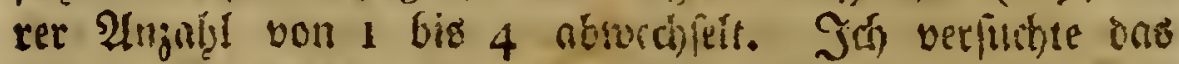

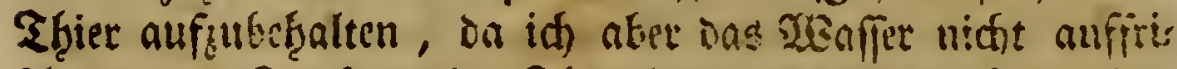

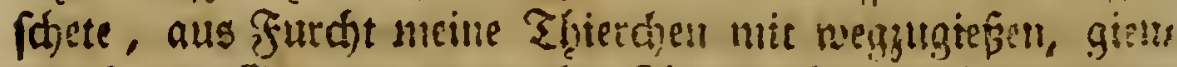

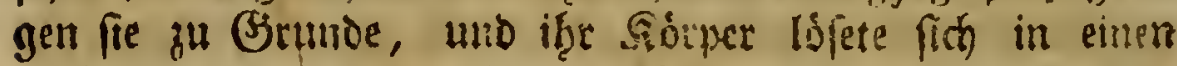

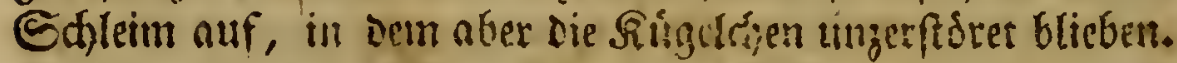

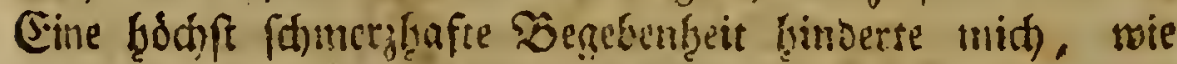

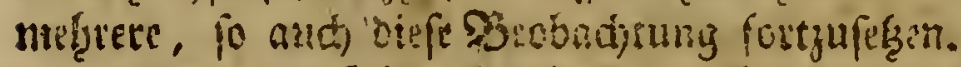

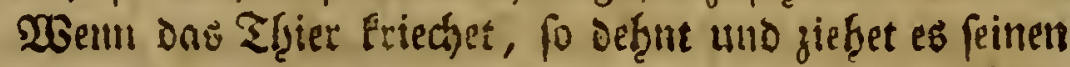

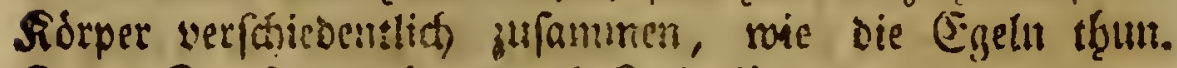
Seine Epeife Deudten mid) Giefenfurfe zu penn.

\section{\$. 7 . \\ Brachionus Proteus? Pall. elench.}

Szerr Sacter hat einen Proteus befátrieben. STh

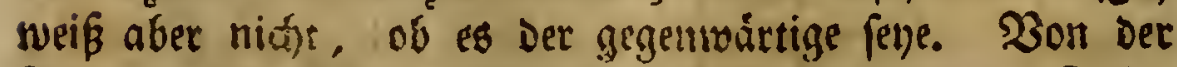
गtichrigfeit meither Zeichmungen bin in) überzenget. Sollte

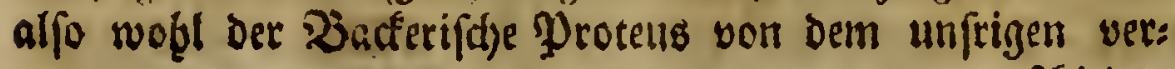


foriesn foyn? Wenigftens wenn man figur an Figur, (Ses

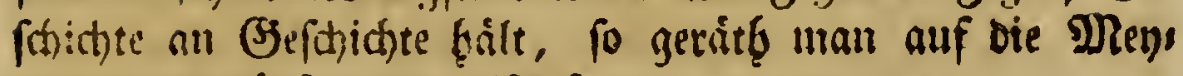
nunis, eq Dinfle bem aijo fenu.

Man fundet ibu in Den maiften ftelgenden 2 Báfern in ber Oegens von Ring, vorneţintid in jentent, in neíchem

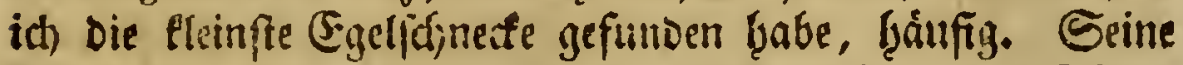

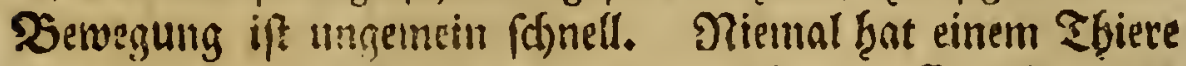

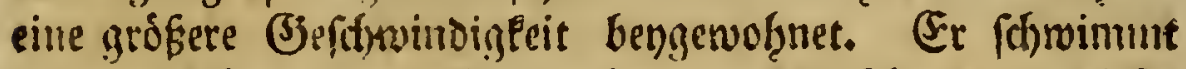
gemeiniglid auf Dem $\mathfrak{x a f f e r}$ becum; unr felten, und diejes

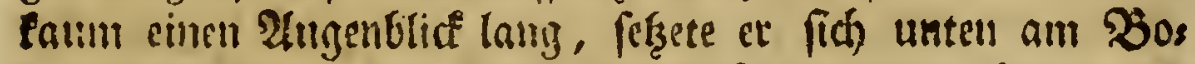

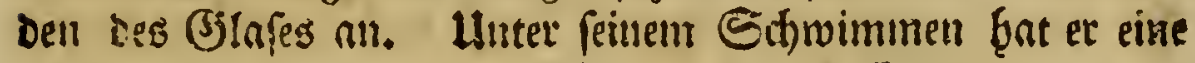
fierzforminge Beftalt, uno b̧ált cin langes (33tied, wie einen Sd)reif, gefđlámgelt úber fị) (Fig. 8.); weil er fich aber

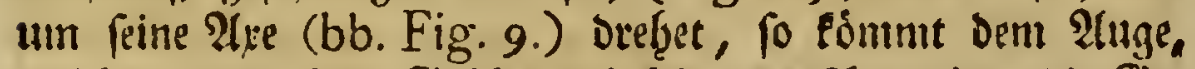

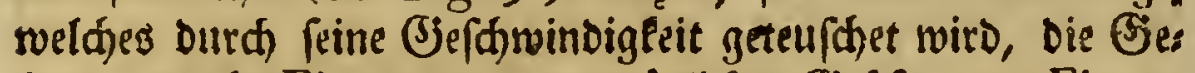
falt, welde Fig. 7. in Der naturliden (Sroße, uno Fig. 9.

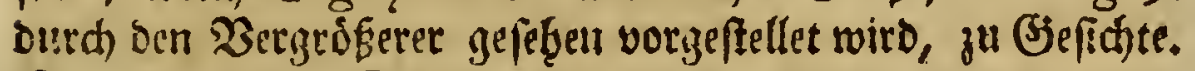
Man fann feine Bjeftalt leineswegs ausnebmen, wenm man iffin nicht afles groffer bis nuf einen einginen Tropfen, Det aber fefor flein fenn muB, entziebet. Sonft wird man ilnn allental in Bewegung, uno niemal anders, als, wie er Fig. 7. abgebiloet ift, fefren.

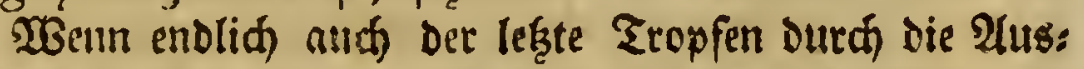

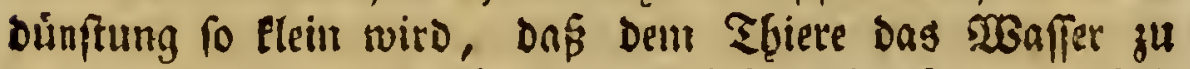
wenig svird, Damals fángt es an fid) zu ftrecten, und ftels let anfangs die Beftalt vor, welde id Fig. 10. abgezeids) net brabe; bie voul Det vorigen nod) nidht viel unterfajiedent ift. Enolia) faltet es feitren \&eib, Der vorber nur in eine Falte jufaumen gelegt gemejen zu fenu fafeinet, aus einams ber, noie die 11. Jigur ausweifet. Eef̧etlia erfápeintet es in Der Gieftalt Der 1 2. Figur, weld)es ein langer báutiger Sact ift, ans welchem einte lange Shnauze (ein langer Sd)weif wotirbe id fagen, wenn es nidjt gerade der vordere Theil brs Reibes wáre) berworraget. Sn Dein Sacfe, nidte weit von Der Spig̨e fieh̨t mant zroeen Dunfele Sistper (Fig. II. uno 12, a, a.), oie inan nicht eber rahrnimmt, als bas F̧iet feinell Reib allbeinander geleget hat.

(S) 4 Finfatt 
צnptatt das Tanfer alrodunfen zu faffen, babe ida

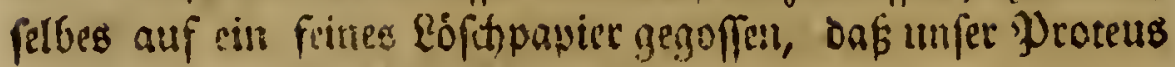

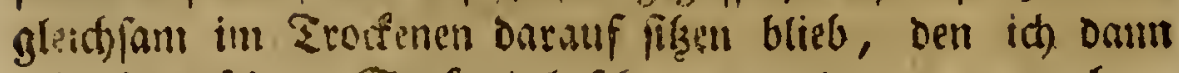
mit einer feirien Stectnadel feţe genall bavour wegnuthm,

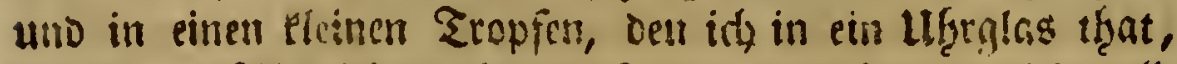

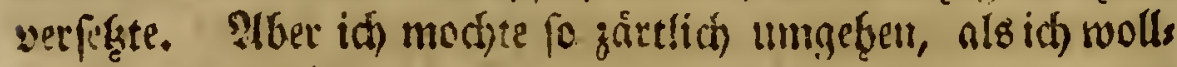
te, fo war und) Diejer Sannolung mein proteus todt, unb

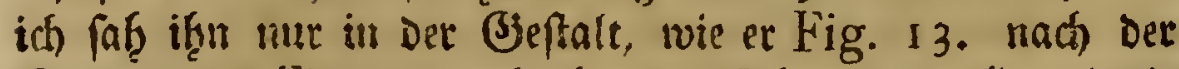
Seite, uno Fig. 14. obeither ausfieft, wo allemal bic

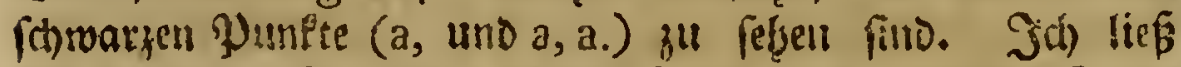
ihn nid)t nur Stunden, fondern Tagn lang in oiefem Stan:

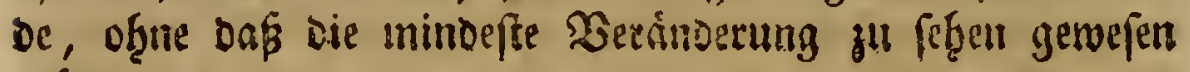
wâre.

\section{§. 8.}

Tubularia vaga. $\mathrm{T}$. vaga; bidigitata.

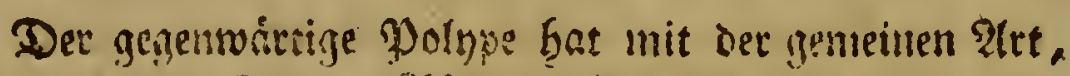

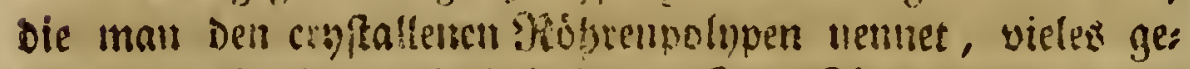
mein; er ift aber viel cinfadies. Erin Róper if̂ rme un.

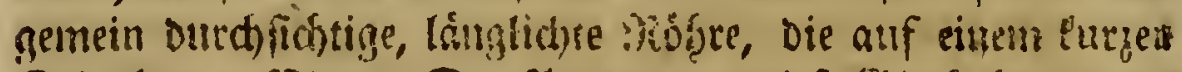
Stietchen auffiget. Der polnpe, aer Diefe (Stocte biwobne:, Gat einen faoenformigen Reib, ber in einer ouneelen \&inie

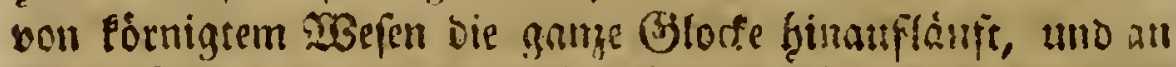
feiner Spike cin etruas dicfes Folblein hat, alif weld)em Die WBirbelwe:Egcuge befeftiget fino.

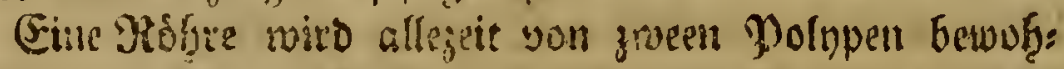
net, Davou bet cint Rleiner iff, oder menigftens zut fenn

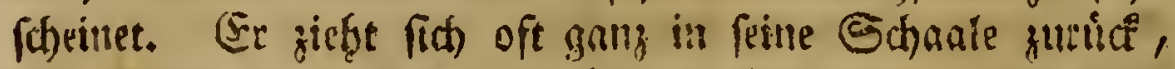

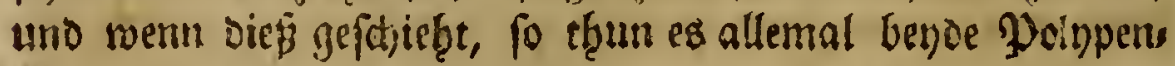
forper zuglert.

Die gnilje SMaffe ift viel lleiner, als das gemeine Näberthier. Fer forwimmt aber eben, rate daffelbe, roch ben reitem nidft fo viel, nod fo fdyull berum. Sein

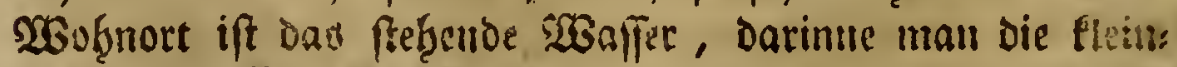

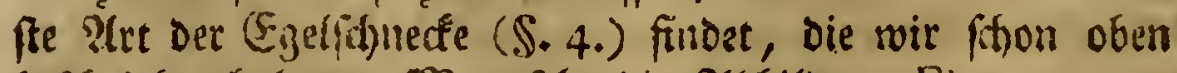

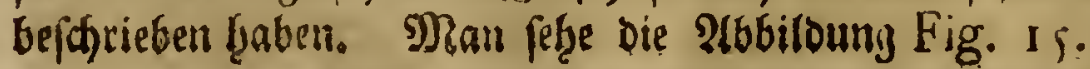




\section{9.}

Brachionus cylindricus. B, fimplex, vagus, cylindricus, cauda unileta, flexili.

Fig. 16 .

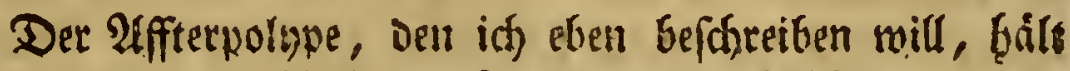
(iid) in eben bem SBaffir auf, alts dem id fojon lo mans

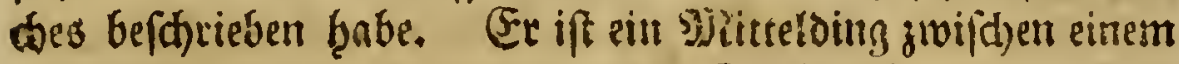

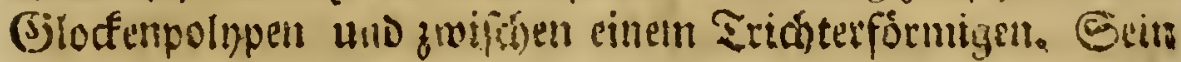
Eeió ift lang, faft maljenformin, ben verfohiesenen son vers

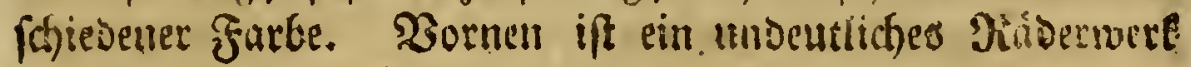
angebrad)t, uno binten endiget er fid in einen faynalen, fpifzigen, borftenfórmigen, nach allen Seiten beweylichen

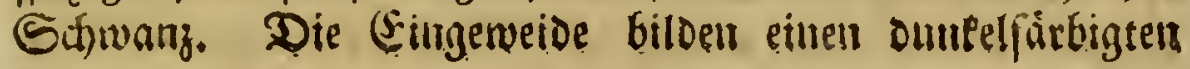
\$Bulit.

\section{10.}

Brachionus bicaudatus. B. fimplex, vagus, gibbus, cauda bifurca.

Die 2 Bunber biefes Stmpfes find nod nidft alle; wno.

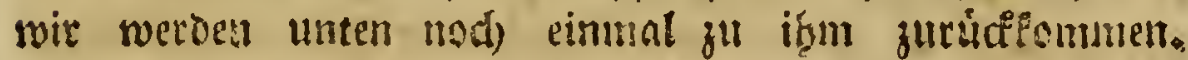

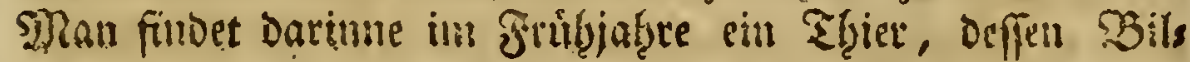

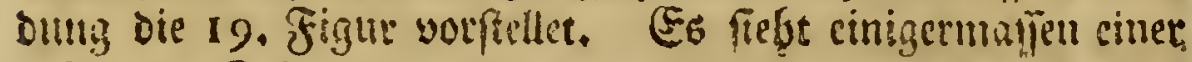
geiffurten Sthotre, noer bem altwgroretteten Schiffichen einis

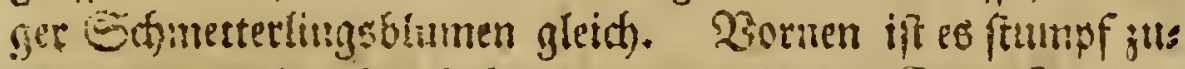
gerundet, uno mird fadfte immer tweiter, Eine Epalse,

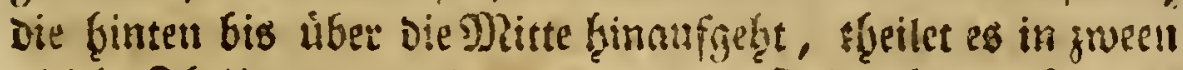

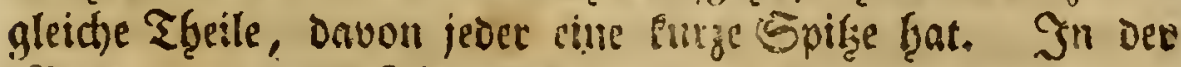
Ditte eines jeden Tfeiles freljt man nebfi ben undentlidten Eingeweiden, eine Sienhe Destlidyerer plunte (Fig. 19.).

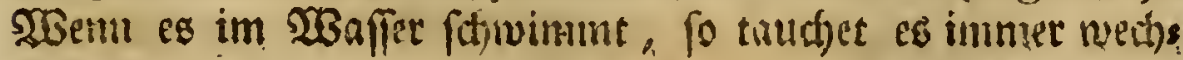
felweife eine Seite um die andere tiefer, fo dás es in cinee

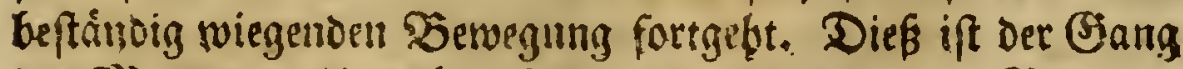

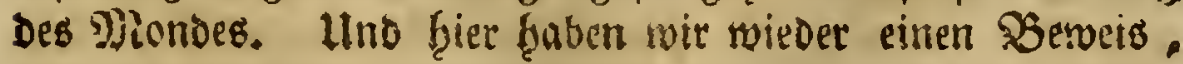

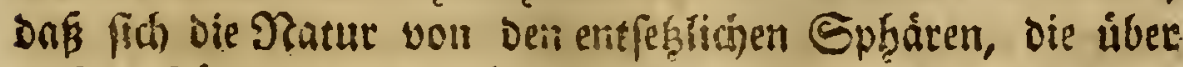

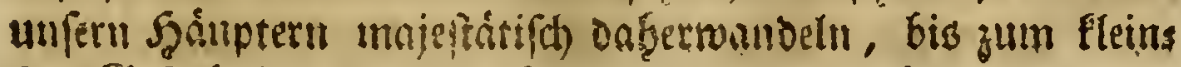

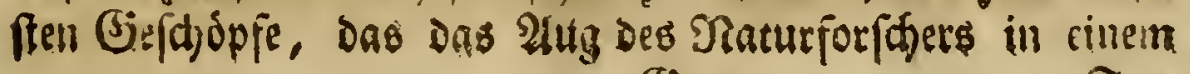


Fropfen faulen 2 gaffers entoecfet, immer gleidg fer, ims mer eben Diefertben Regeln beforge.

Whem ner Eommer fómmit, vermindern fíd biefe

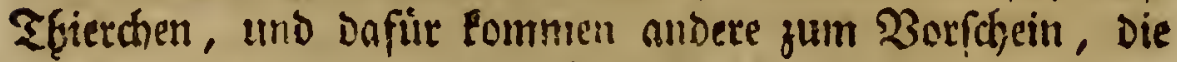
id) eben befdreiben will. Sitid fie eben bieftbers mit ben vorigen, tuto nut durch das allter verfajieben? Sind fie eire nelle भat?

Thtre Eeib if Fig. I7. vorgefteflet; tub fo fieffet man ignn, wenn man ifgn nadh der Geite betrahtert; er ift nies renformig, unb eben darun fucfeligt, went Der Yolupe in fetner naturtichetr Gtelltung (Fig. 18.) ift. Die Eins

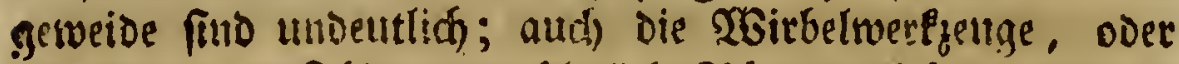

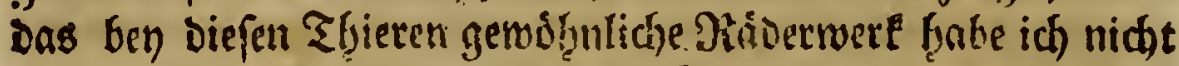

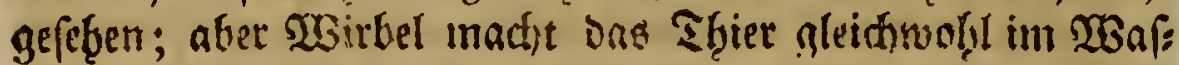
fer. Syinten flat es einen boppelten, faft Dem Siorper feloft gleid) langen Sdinomz, ben es moiftens in einer paralleten Bichsung bुált, oft aber ausbreitst, tint Damit einen farars fen Winfel gefaltet (Fig. I 8.). Sent Futter ift mit Dem Sutter Des Eapfelfótminem 2iffterpolnpelis genein, mit dem is alld fouft gemeinfchaftlid wohnet. Ein gleicher Trieb Gat fo viele an Sitten uno (Sebráud)en verfd)iedene Mens

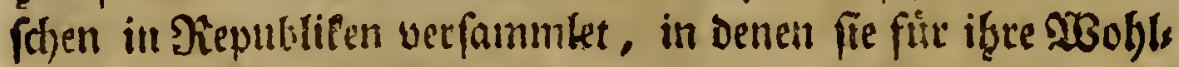
fab̧rt gemeinfódafulich forgens.

\section{S. II.}

Brachionus campanulatus. Pall. elench.

STEenn man Egein in einem Brafe aufbewabret, uno

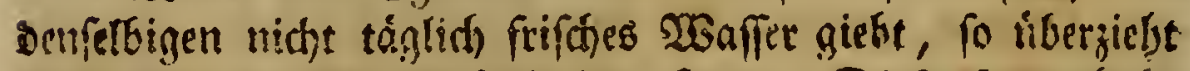

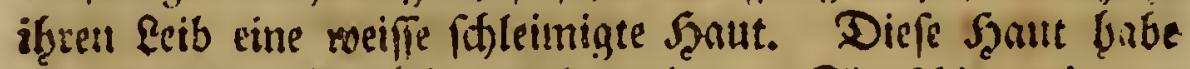
id Dured Den Sergrofferer betrachtet. Sie fhien mir aus lauter ourdscinanoer geflod)tenien Bilofenpolnper (Brach. campanulatus Pall.) zu beftȩ̣en, in Deren Zzwifhentáus

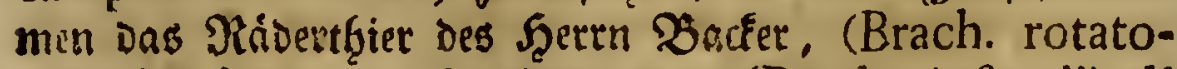
rius Pall.) uno Der Tridfeterpolnpe (Brach. infundibuli formis Pall.), uno Die Ynfurionstbiere gleidffum niftels.

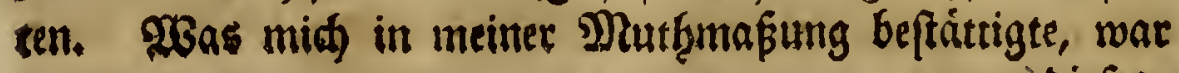
biefes, 


\section{2idte abbanding.}

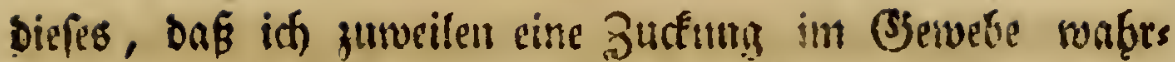

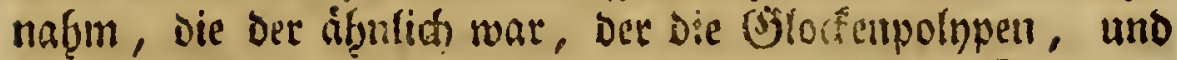
Die aftigen Afferpolypen (Brach. ramolifimus Patl.) un: terworfen fino.

\section{12.}

Volvox complanatur V. planus, tetraëdrus, globulis 16 compofitus.

Sn einem Sumpfe Der Biegeno um $2 \mathrm{in} z$, Der faft be:

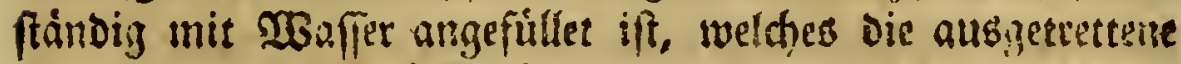

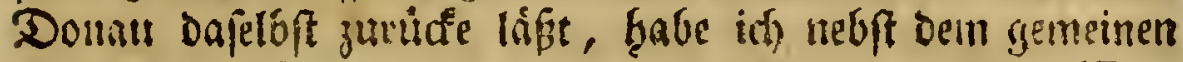
Sugeltbitere (Fig. 21. 22.), uno nod eitrm andern (Fig.

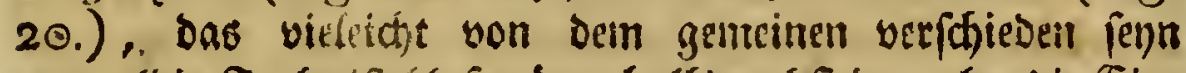
mag (bie Farbe ift flasgrin, halbourd)fitig, aber Die (5ins geneibe, ober bie Jumgen blicfen nifht Durah. Die Be. weghung bepteffet barinne, oas es fith frentwillig naty vers

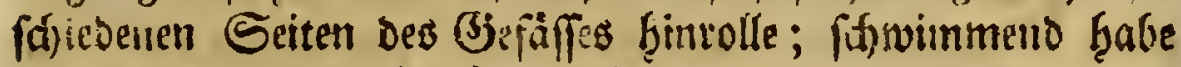
ich es niemals gefeben.), noch ein oristes gefunden, das

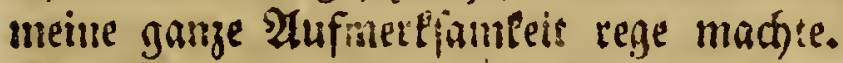

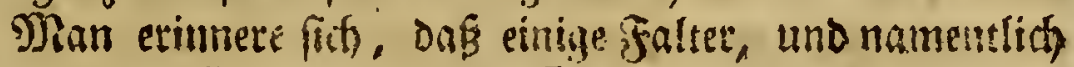
Dar Sioflfalter (Pap. Braliicæ Lin.) uno der Rúbenjalter (Pap. Rapæ Lin.) igre Coner auf eine mefgr oder weniger freistunde Flád)e eines biattes Dichte neben einander ferzen.

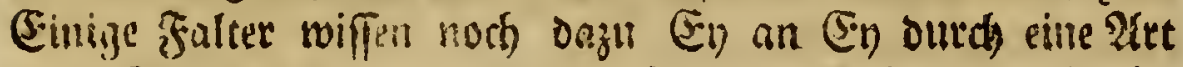
eimes Eemens aneinanoer jul bafeftigen, baß man fie bes

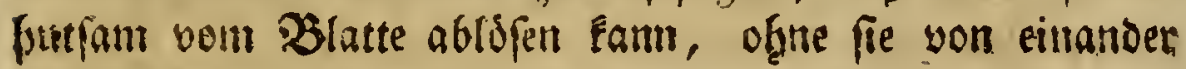
za tremett.

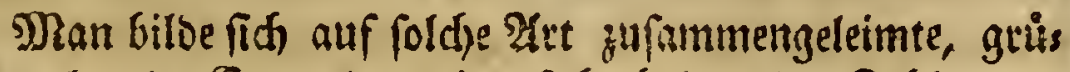
ne, Engelcunbe Siner ein, die, fechetin an Der Zahl, yon einem Falter ober einer (Fule in Der Dronung find Ginges

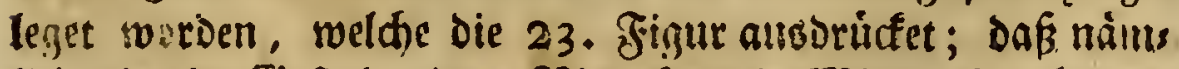

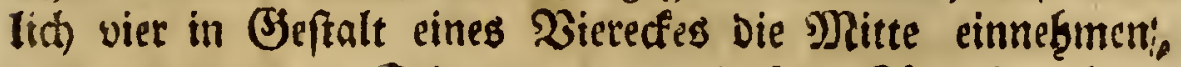
und jede Der bier Seiten bren Derglei(han Righelden bedes

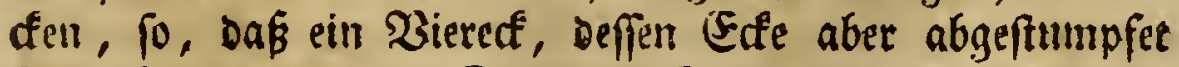
find, beraukeonme. Die ganze Sammlung von biefen an: faheinenoen (Enern ift mit einer 2 rt gallertiger aber bodbyft Durạ, 


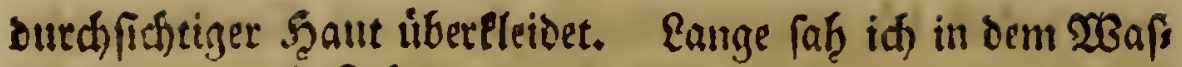

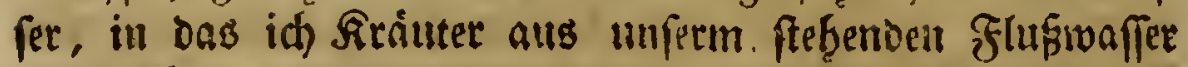
geleget batte, einen, und Den andern biejer. anfifeinendent

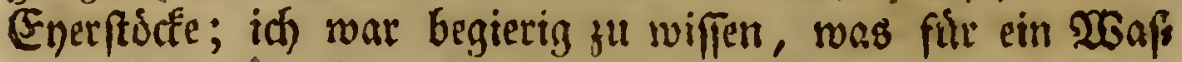
ferinfept daraus hetyorfomment follte. Tflein, ta id oas

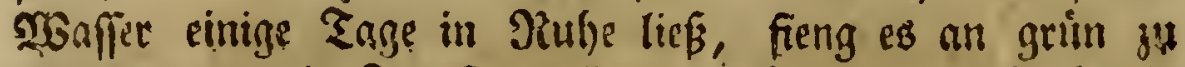

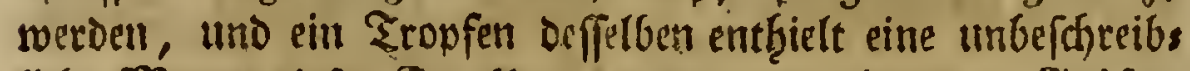

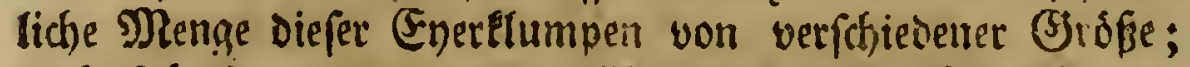

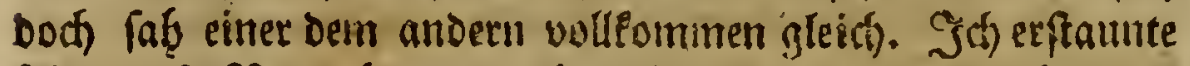

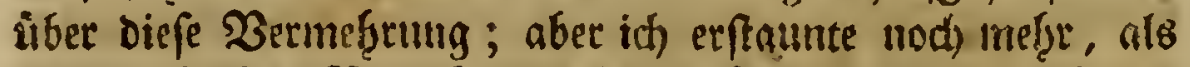
fich ein folders $\mathfrak{B i e r e d}$ yon feiner Stelle erhutú, fid auf eime finer Seiten frellte, uno nack allen Seiten, wie es

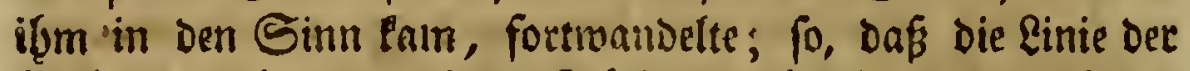
Richtumg, bald mit feiner fláche gleidflizf, bald auf Dies felbe fentredst aliffiel.

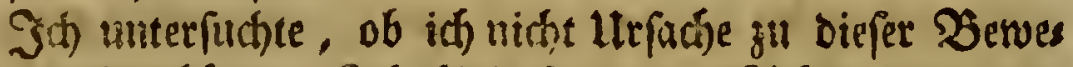

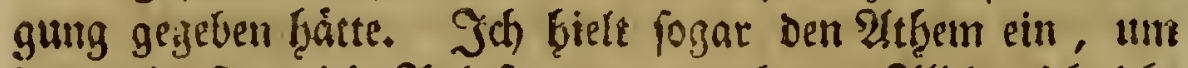

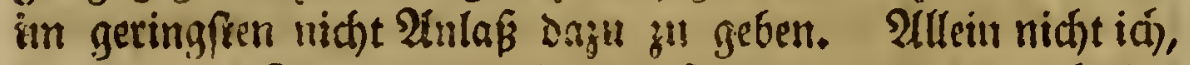
fondern Die Sonte vettrieb dicfe Thiere; denn es erfuben

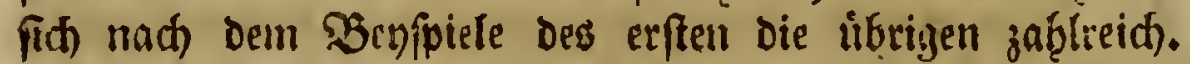
Sie ftanden zu ferye im Richte, und fuchten Sinatten. Eie waren aber ald im Sdatten nidist mit jectem Drte jufries Dent; fie ruffeten mansfimal nur, unb Dann fudoten fie fich einen bequemenn sit.

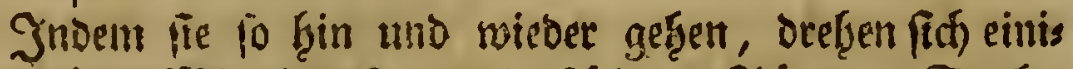

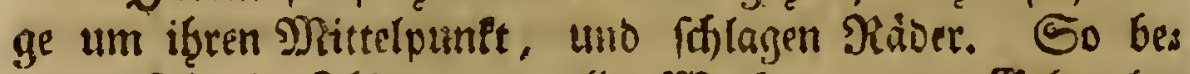

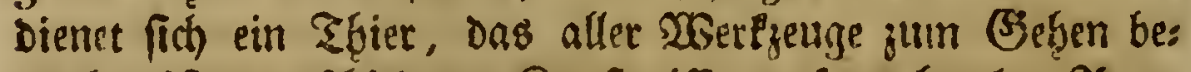

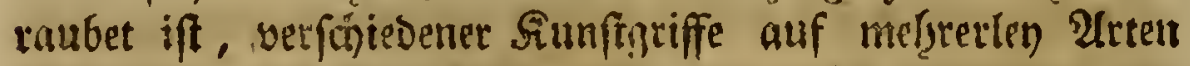

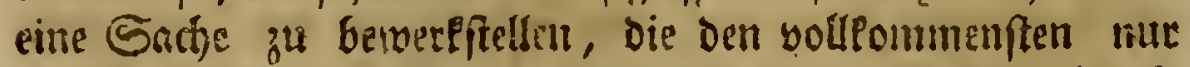
auf eine glicket. Es bat alfo das Fingetthiet eine ebent fo

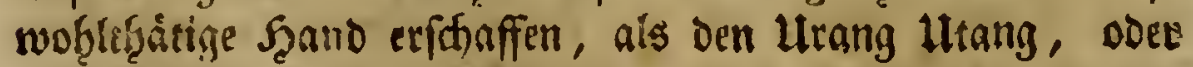
ben sinenfhen yon ఇilobar.

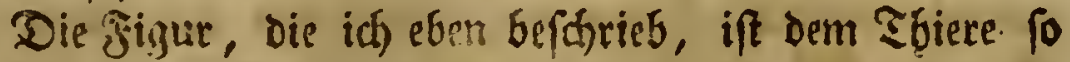

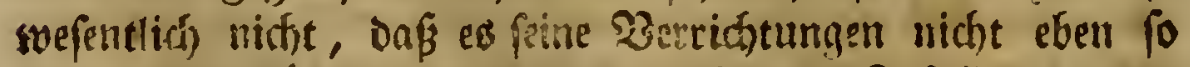

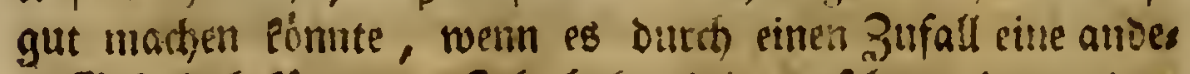

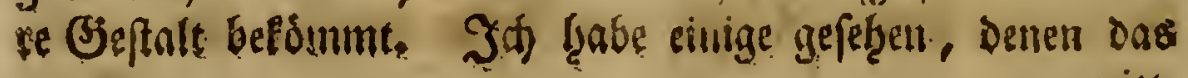


mittlete S3itref abgieng (Fig. 24.); andere, bie wie gerrifs

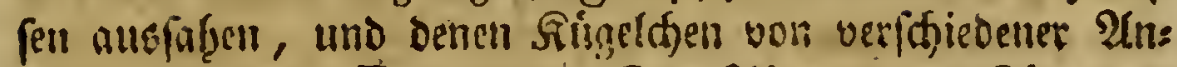

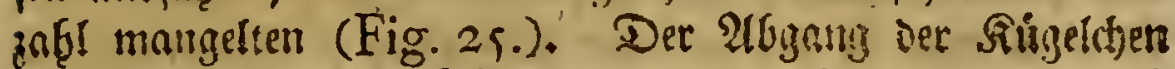
bey biefen zerftorten Sfeieren ift von I. bis 15: benn id

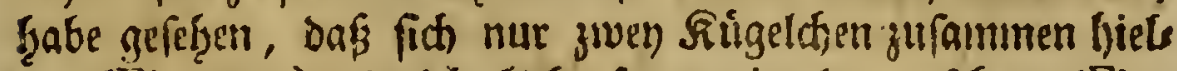
ten (Fig. 26.); ja id) biabe jogar einjelne gejefent (Fig.

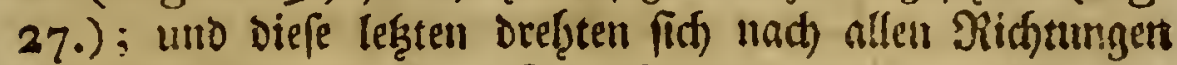

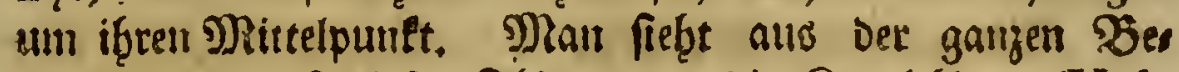
fareibung, Dafi diefes Thier unter die Sugethiere (Volvoces Lin.) gefioten múfie. Aber bas wüpte id nidgt, Dás jemans biefe Fit befurieben Gaátte.

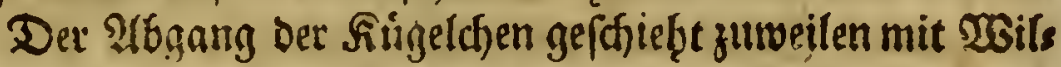
len Des Thieres: Denn ith habe es felber gefehen, dafi fín bas mittlere Biered abgelojet, und nach einem alsbern Drt weghbegeben Gat. Er geft)ieht aber offers roider bes Tbies

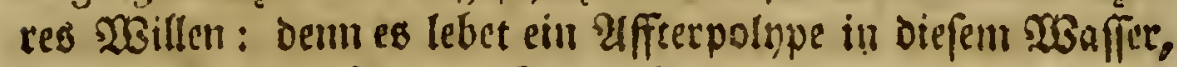
Der fich Davon nåbret. Diefer Mffterpolype ift ber capfers formige des Dr. spallar (Brach. capluli florus). Er ift ein Tyger biefer Sitgeltbiere.

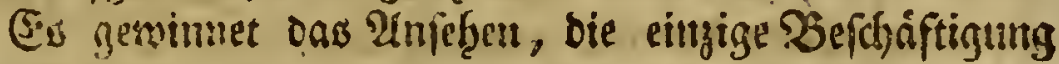

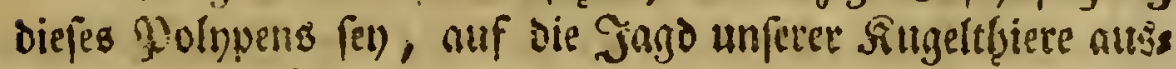

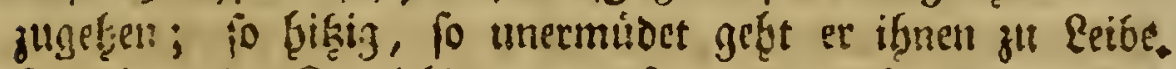
Sft ifm ein Rugelthier ju groß, uno Das find die meiften, fo greift er felbes furctifam an, und reiffet fich nur ein Siúct Davon weg; ift aber bas Sugetthiet flein, ober nue

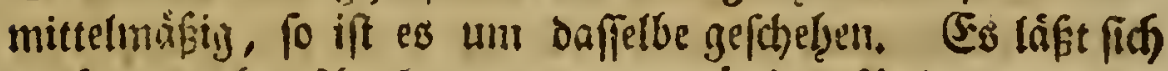
Denlen, es ferridge bey dem genentwartigen polypen eben die Mechanil, Daßs er bie verichlucten Siorper nur ausfauge, ullo nicht veronue; denu wolyer folleu fonft die vielen Slés lete biefer Sugeltfiere, Die, oben auf Dem IBaffer fanwims men, bertommen.

\section{\$. 13.}

Chaos redivivum. Lin.

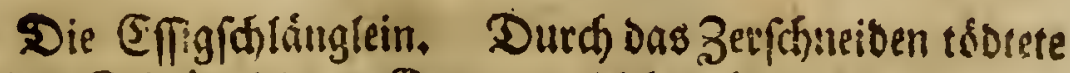
id Diefe Edblángleiu. Es mag gleidgroogl. fenn, Daf fie 
einen Edhnitt ansbalten Eonnten, ber fein genug wåte; eis nen reinen Sanitt, wic fich Dr. Skjaffer ausorudet. Uber fo was ju bewere"ftellen duirfte bey fo lleinen Beidios pfen wobl. fajwer fallen.

\section{14. \\ Chaos infuforium. Lin.}

Der gemeinen 2 rt diefer fo berifhmten F̧iere, ober vielmef̧r if̧rer verfdiedenen Äten habe id) fabon oben ers

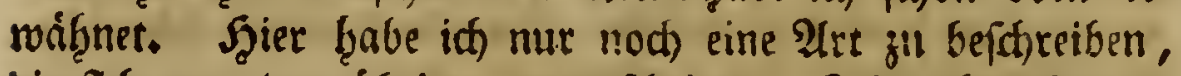

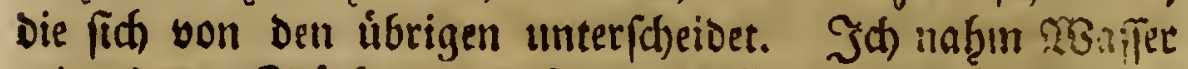

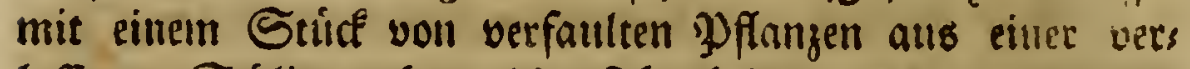
laffenen Sdfliergrube, bie fith theils aus unterirdipásen Duellen, tbeils von Dem Regen gefillet bat, uno fidon pebr viele Jafire mit 2 affermegerid bewastfan ift. Jit

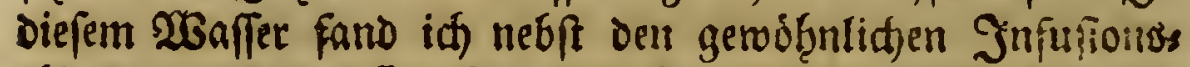
tf̣icren, und den (Slecfen : uno Trid)terpolypen nod) wirdere รffierhen, bie in Die \&\&nge gezogenen Kauten (Fig. 2\%.)

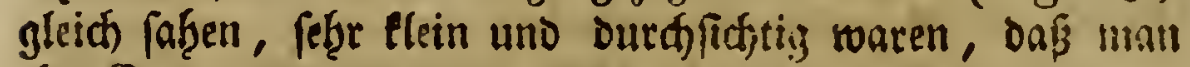
iff. (Eingeneide beutlid) unterfaciden Eonnte.

Sa beabe verfucht, ob fie nidyt ein (Embrno eilles Afferpolypen wácen; allein iá mod)te das Waffer aufbe: bealten, fo lange id) rollte, fo rafimen fie in if̧rec (S) nicht au.

Sie Pleben fid) getn an einanoer; und baraus ents ftefien veriáiedene Figuren, Die ieh unter ben Fignuren 29 , 30, 31, vorgeftellet 6abe. (58 mus nicht in ibrer gRacht fenn, fich twieder zu trennen: denn man freftes ibnen an,

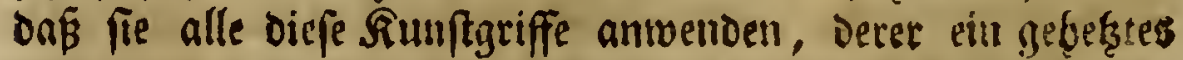

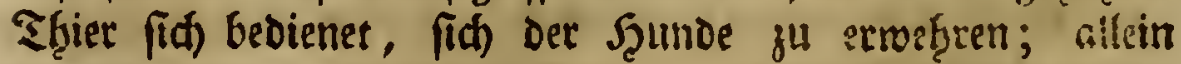
maiftens mit faled)tecen (5.rolg; benn fie ftreifen if̧ren Feinto febr Gart an Dem auf Dem 20 offer fthrimmenden Huratbe $a b$, weil er ju fein ift, 2Biderftand zu thun.

\section{ZInfang.}

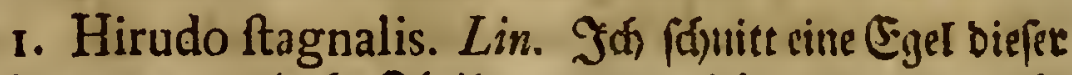
Att in zween ungleide Sfeile; Davon lebte ber eitte actit 


\section{Reunte $\mathfrak{A b h a n d l u n g . ~}$}

Tage, ber anbere ůber cinen ganjen Monate. Endia fdjnitt id) and) Diefen in groeen Theile; aber Dann waren fie bes folyettoen Tayes bende tobt.

(5ime andere (5igal biefer 2 trt iannitt id) in zween faft

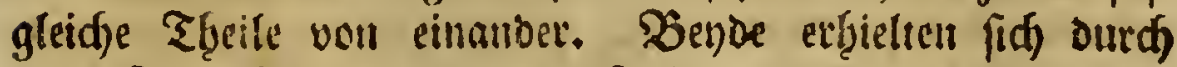
viele SJonatíse, nur wuroen fit innmer nagerer, weil fie

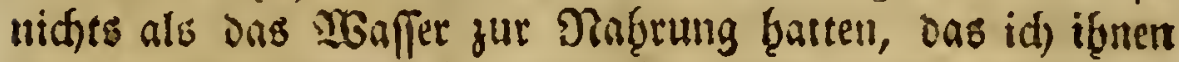
diters anfiriftete. Dod) wudjs ib̨nen Dar abyefdniteme Theil nirbe mad.

Der yordere TGeil befan einmal úber bein Drte bes Gdanittes eime blutroibe vierlappigte Drufe, die aber wies Der verfafwand, wie fie entfanden mar.

2. Brachionus? pilolus, In Dem Sonffer, deffen

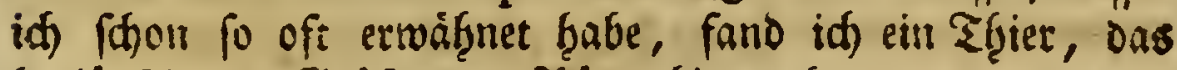

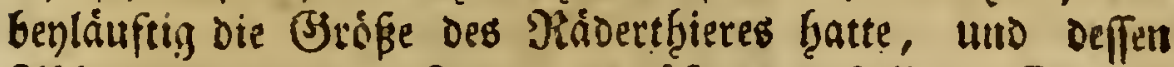
Abbildung Die 32. Figut vergrofert vorftellet. Fs bat einigemsaffen die Sieftalt einer Sauerbrum Ģabe. Do: lange Jaalo ( b b ) bat an feiner Spike eine Ereisformige Deffnung (a), bie aber nicht befandig offen ftef̧et. Der Reib ( c c) ift etrwas Dicfer als Der fgals, uno flat mitten eille Dunlele Siactel ( $\mathrm{de}$ ), Die mit Der Deffrung

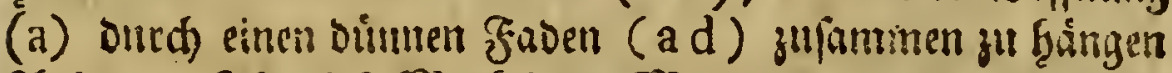

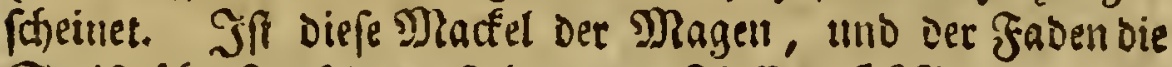
Eveiferobre? Şinten ftebelt zmo Floffen $(\mathrm{ff})$, Die die (Seftalt oer Sd)wanjfhuppen Gaben, weldje man ben ben Raublifern, und Rúd)enidjaben (Blatta lucifuga Pod.) ebendafeloft fiebt. Die Seiten fino mit Franjen aus Purs

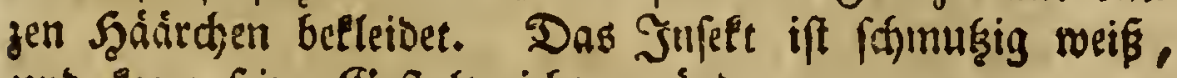
und Eann feitre Beftalt nicht verándern.

\section{IAbbandlintg.}

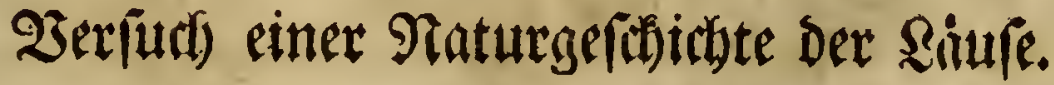

Co verdidytich die Infelten fino, die id in Siegentwart bef(f)ieibe, ro weif id Dennod nid)t, ob nicht eben

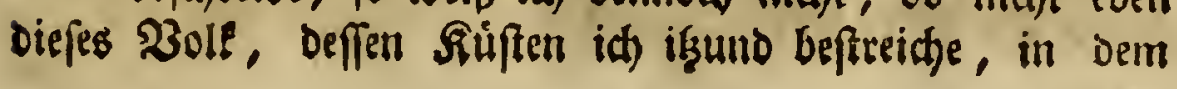


ganzent Jnfeltenfitaate das zafilreidgefte, und vieleid)t eben Darum Das erbeblecifte fer). Die Mlúfe, die es loftet, fie

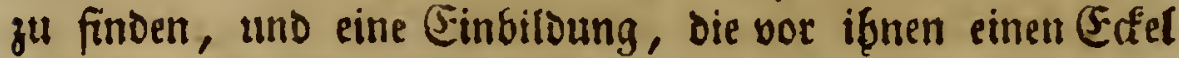

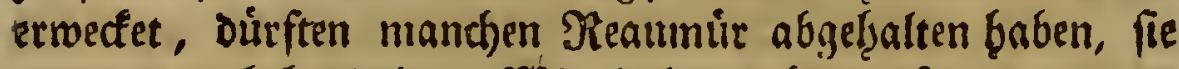
genauer zu behandern. Woir baben dafier anker bem, was

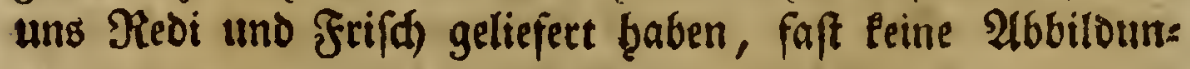
gell Davon.

Der PYan, ben id verfolge, ift lein anberer, als fie in ber Dromung zu liefern, in ber fie mir verfoummen.

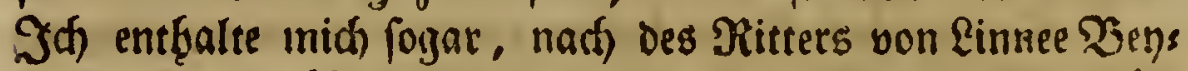

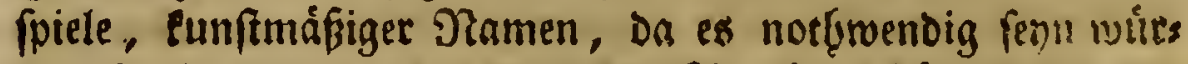
De, fie bey immer anmadbjender alnzabl beftindig jli vers ándern. Die einzige Benennung, der ich mid bebiene, neģme in yon Dem Fţiere ber, Darallf ınall fie findet.

\section{(E) $\mathfrak{i} \mathfrak{e} \mathfrak{A} \mathfrak{i t}$.}

Menfichlaur. Pediculus humanus.

Pediculus humanus. Lin. S. N. Gen. 264. Ip. T.

Es ift unnotgwendig yon biefer alt eine 26 bitum

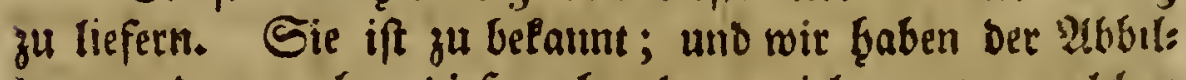
bungen Davon oṣne bief́ metegr als ztl viel, unter welchen frenlid wobl manche giemlidh faflectst geratisen haben; wothin aud jene Zeidfnung gebsiet, Die unz der berebte Berjaljer

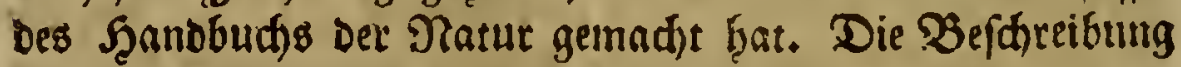
liefere in, um Das allerbetauntefte Jnfelt nicht gar úbergeben.

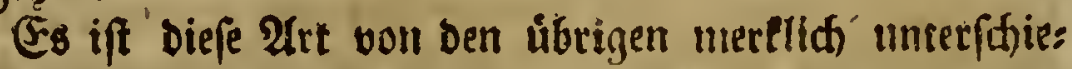
ben, und nur allf biefe fifeinet ber Ritter von Simte fein

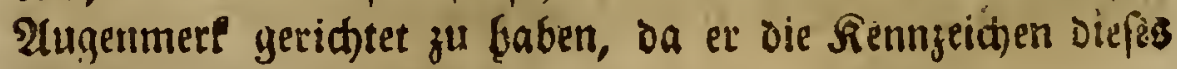
(B) (d) lect)tes nieber fatrieb.

Der אopf geḩt fpiz̧ig fu, und die untere Sippe fdieis net fidh fogar in einen Babn zu entigen. Die furzen frodens

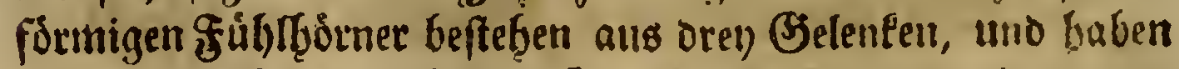

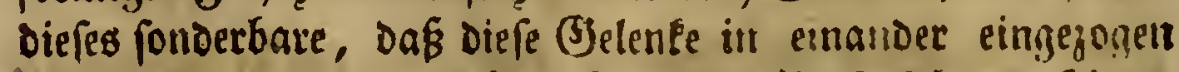

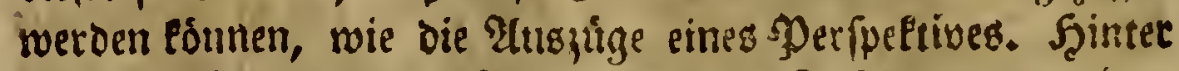

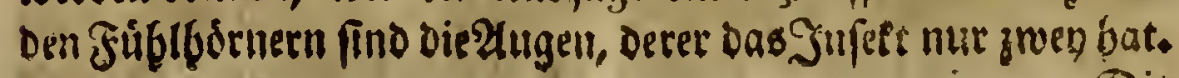




\section{Sectute stognondiuls.}

Die fedo Flipe fine an Den Seiten ber SBrnft befeftis get, uno beftebet eill jeder von if̧nen aus vier Gelenten, Davon bas auferfe fich in zwo robarfe Slauen endiget, von welchen die cine weiter zurudfftebt, uno mit ber bohlen

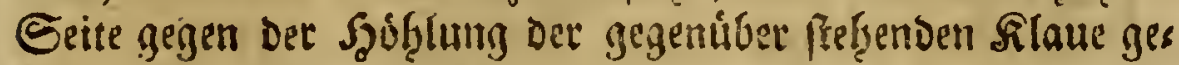

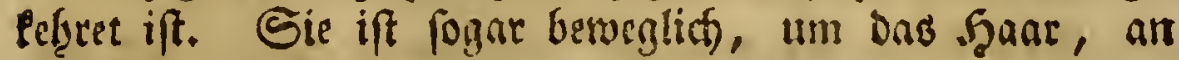
weid)em ons Tfier finllaufen twill, befto fefter zu greifun.

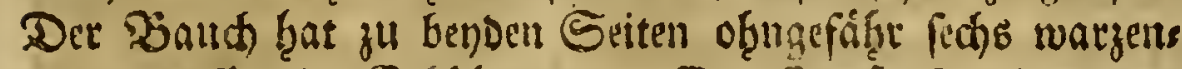

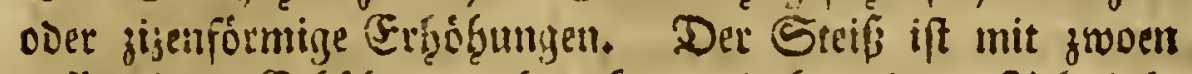

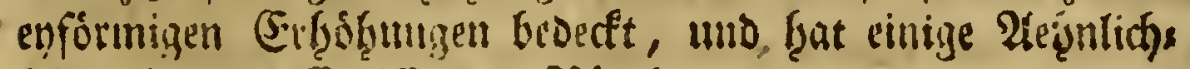
leit mit bum Striffe Der Siugel.

Diejes Snfert ift jiemlich nace; mux die Füfe, ber Sopf, dic Jublborner, und die Gigend des Steiffes if mit eurjen Sgăniechen befeget.

\section{Swe $\mathfrak{y} \mathfrak{t} \mathfrak{A} \mathfrak{A} \mathfrak{t}$.}

\section{(staginnitientlats. Pediculus Curuccx.}

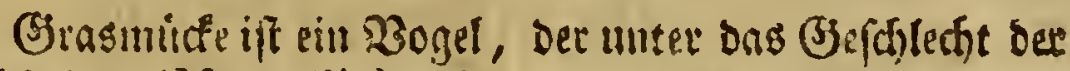
Bachfte!gen (Notacilla) gefióret, uno vin Eimmee Motacilla Curucca genemet wirb, Diefer 30 gel befónint die $\mathfrak{A}$ täufe, bie wir in Der erften fijur ber funften Tafel abbilden.

Der Ropf, ober vielmehr der Sicpfifito ift vornent.

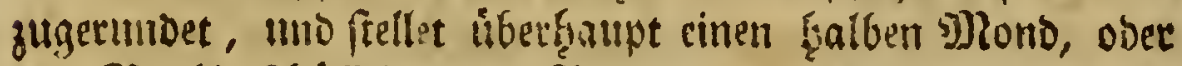

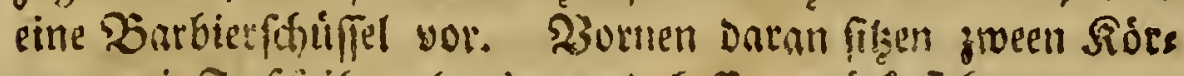

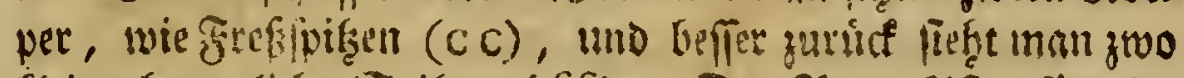

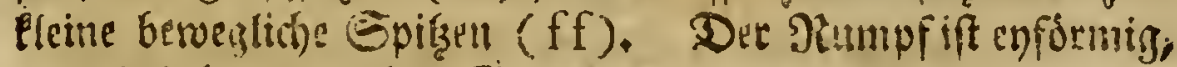
uno beferst alts beben Grkentu, Den rantenformigen Rus cfeliffito (g) niche mitgegriflet. Die Filfie Des Sinfeftes

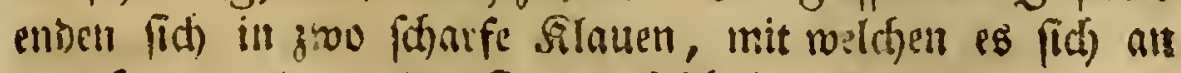
Det Samut und an Den Froern feftralten Eaum.

Die Farbe iff frymltzig. Der ganze Reib ift rebere

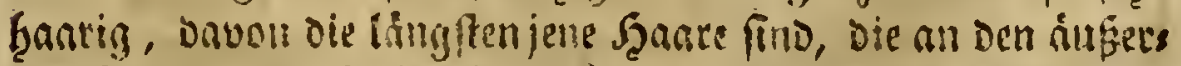
ften Theiler Des Reibra filzan (e e e e ee e \&c.). B̧efonders

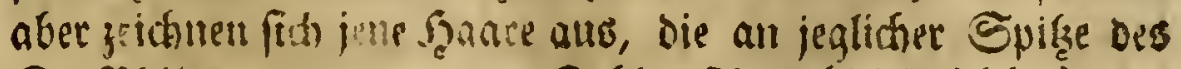
Sicpffildes, oren an Der Znfl, figen (bbb, bbb.).

$$
\mathfrak{S} \quad \text { Sotte }
$$




\section{Dritte $\mathfrak{A} \mathfrak{r}$.}

Sentnenlaus. Pediculus Gallina.

Pediculus gallinæ. Lin. S. N. Gen. 264. fp. 52\%

Pediculus gallinæ. Lin. faun. fuec. n. 1999.

Diefe Raus, Die man auf ben Shennen findet, bat bies:

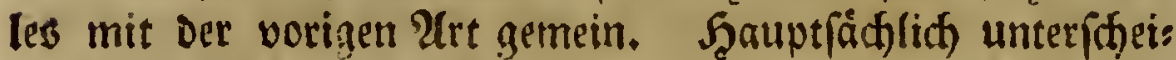

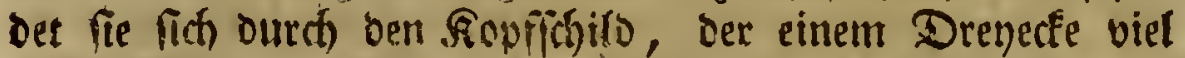

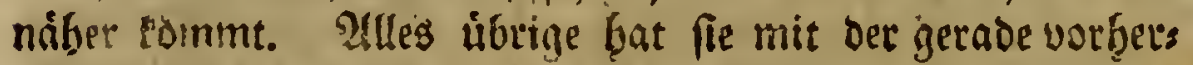

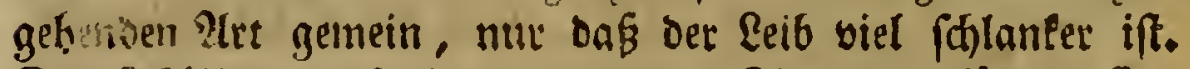
Die Mrbilloung ift in ber zroenten Figur Der funften $\mathfrak{Z} a s$ fel gemadht.

\section{Zierte Art.}

Taubenlatis. Pediculus Columbx.

Pediculus columbæ. Lin. S. N. Gen.264. fp. 36. Tab. 5. Fig. 3.

Sintree weifet an Dem angezeigten Orte auf bie 295 : bildung Des Sherrn Redi. Da id Die 2 Beté diefes Nas

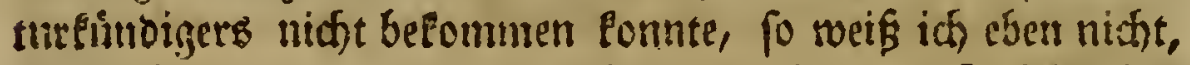

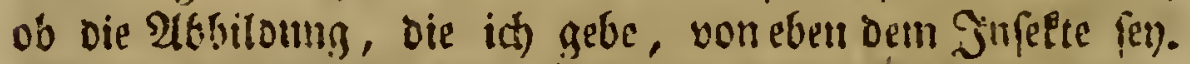
(S)entig! id habe bie oritte Sigur von einer \&kus genommen, Dic fậ báufig auf Den Sauben befindet. Die Jeffalt ift

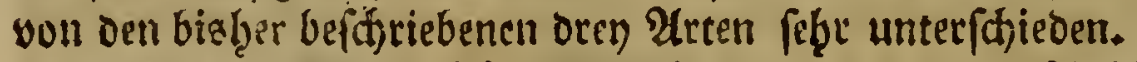

Der Fopfidsito (a) ift Gerzforming; und Die Fjúblhörs ner (bb) find an feinen Seiten befeptiget. Sie befteben atrs mibreen Belenten. Sie werden aud niemals nach Zorne 3 il beivenget.

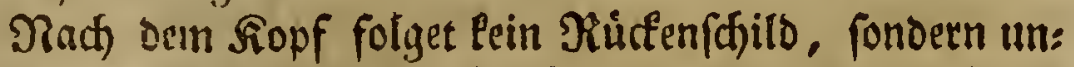
mittelbar oer Bumpf ( $d \mathrm{~d} d \mathrm{~d} d$ ), Doch if bet erfte Oiing

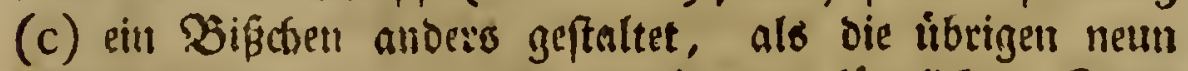
Simne ( e e e e \&c.), Die butrh eituen låmgliđtten Streis fen in ber Witte getheilet werden, ju beffen Genden Seiten

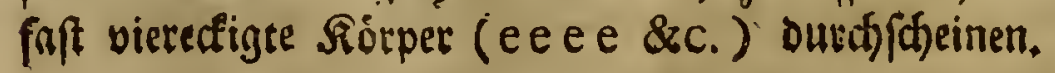




\section{SReunte Sc6randung.}

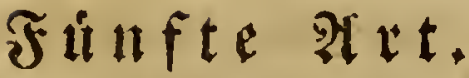

Sathefeldaculaus. Pediculus Rubeculæ.

Tab. 5. Fig. 4.

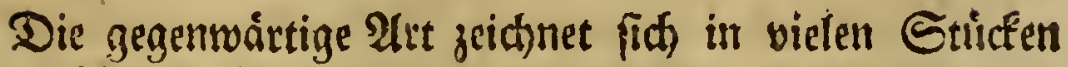

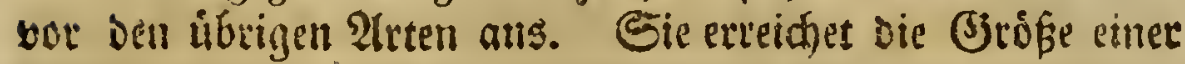

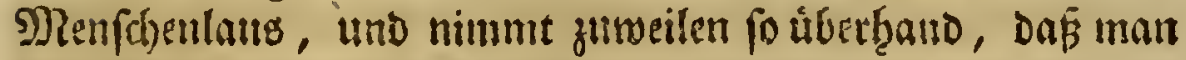

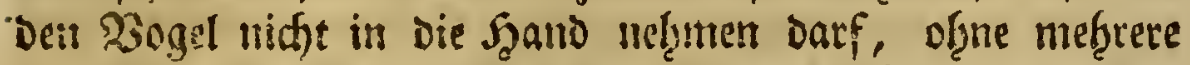

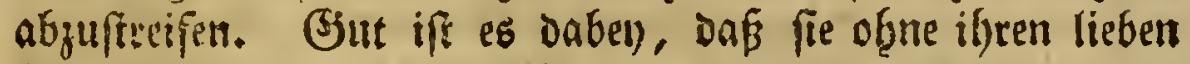

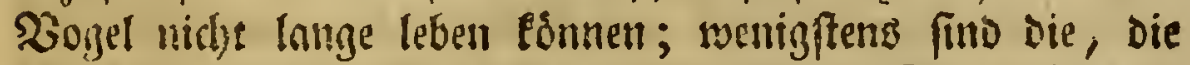
id) in cin Ufinglas fammette, unn fie mad) Bjelegenteit zu

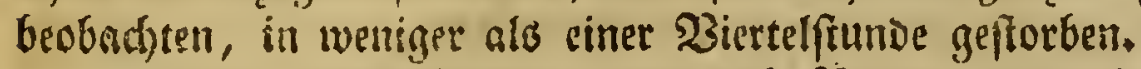

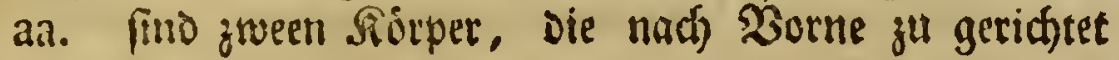
find.

bbbbb. if der Sopfficild, Der fich gegen den Siumpf in

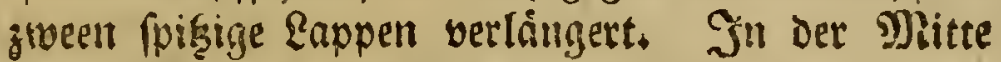
ift er erbaben; uns Giter nimmt man einen lebgaf:

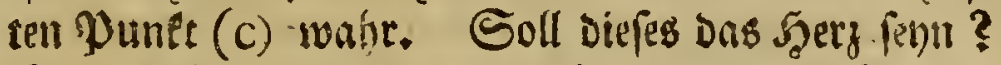

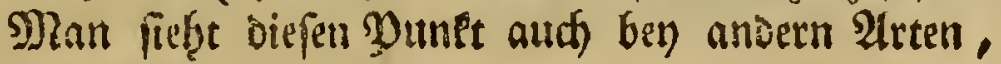
aber weniger deutlich.

d. ift Der अilifenffito, Der auf benden Seiten juges

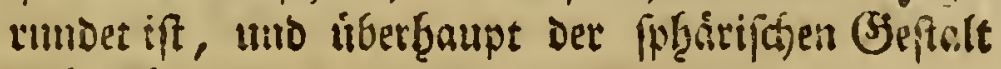
nafe poimunt.

Der Reif ift beunafe walgenformig; nut die erfen Plins ge fino ein Sigcten finmáler.

Das ganze Jnfept ift måkig baarig, mo fefte dutchs

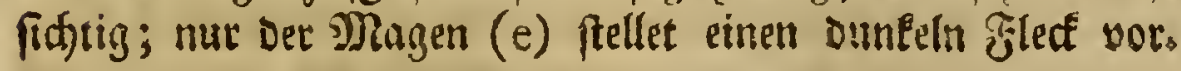

\section{Sed fite $\mathfrak{A} \mathfrak{x}$.}

Setchenlaub. Pediculus Alaudæ:

$$
\text { Tab. 5. Fig. r.\& } 6 .
$$

Die Rans, von ber fier bie Rede iff, findet mant auf ben Felolerchen.

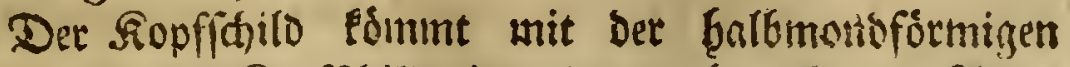

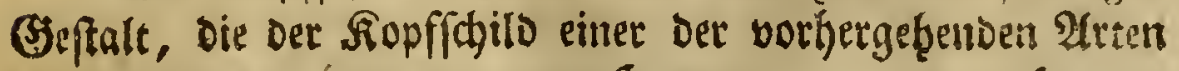




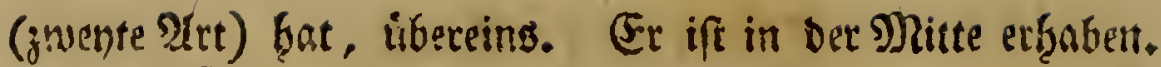

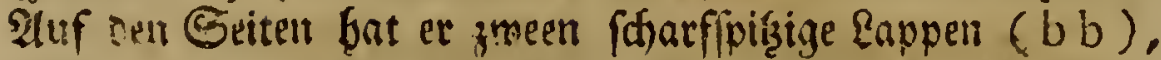

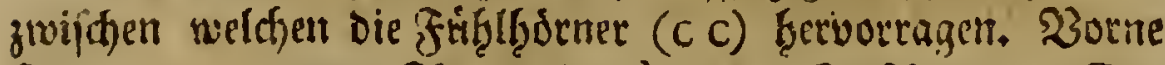
fino zuveen andere Fiorper (a a), wie Freffipigent. Der Retickenthits ift rautenforming. Der Riumpf beftefet auts

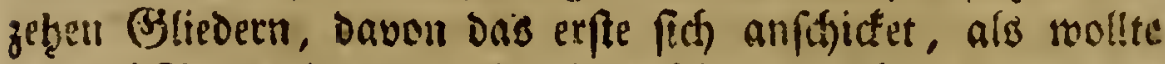

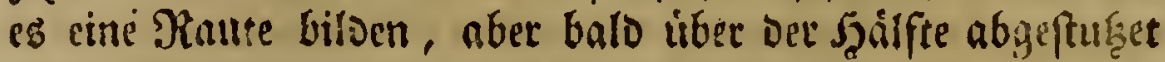

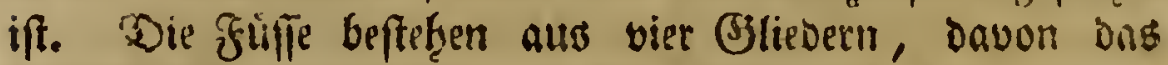

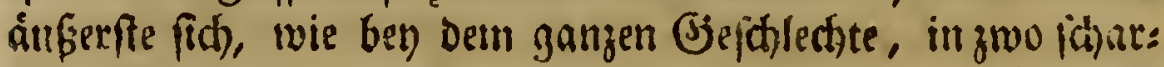

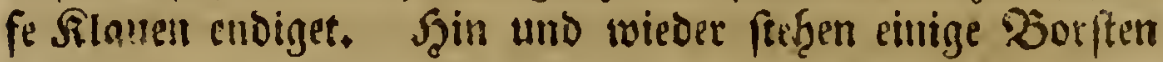

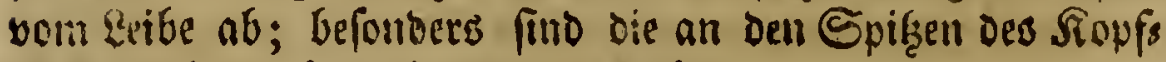
fä)lbes iffrer Långe ḩalben metervitroig.

Die 5. Figur frellet eine Rertemlitals yor, wie fie auf Dem Baud;e lieget.

Die 6. Fighur aber, wie fie auf Dem Mluffell lieget.

\section{Giebente $\mathfrak{A} \mathfrak{i t}$.}

2ummerlinis. Pediculus Citrinellæ.

$$
\text { Tab. 5. Fig. } 7 .
$$

Shmmer, Foldoammer, Aimerling, ift ein $\mathfrak{B}$ ogel, ber

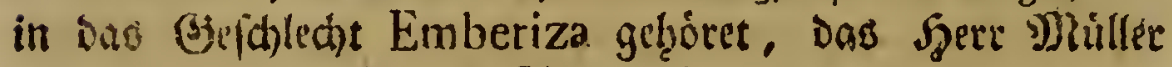

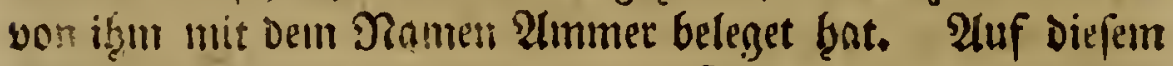
23ogel finver fich eilie Raus, Derer Beffalt wir in Der 7 ten Sigut entwerfen.

Sie ift von ber (Brö́pe einer mittelımáfigen Menfhnent laue. Der Gopfidgild ift beunate berzformig, aber rid: woirts nid)t vertiefet, foubern zugeruindet mit einem Eleinert

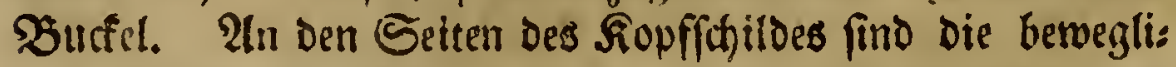
đen fpifigigen Rippehen, uno Ginter diefen die vielglieberigen

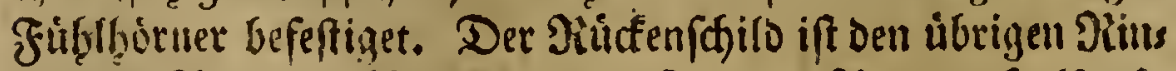

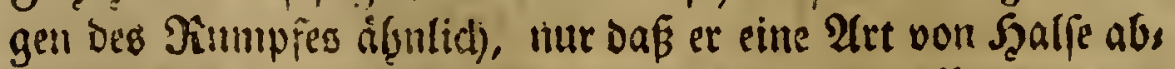
giebt, nad weldsent Der Siuntup vollfommen enformig auss

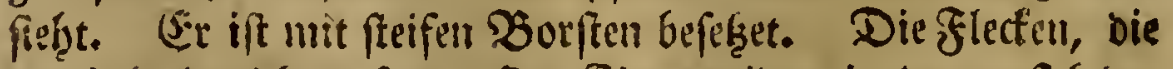

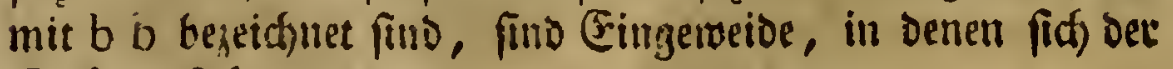
Sioth alfitialt.

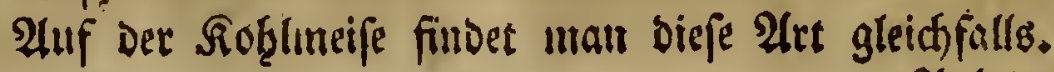




\section{Slettite ULbfandfung.}

\section{$\mathfrak{A}$ d) $\mathbf{t} \mathfrak{e} \mathfrak{A} \mathfrak{x}$.}

Snummriduntellaus. Pediculus Curviroftra.

Tab. 5. Fig. 8.

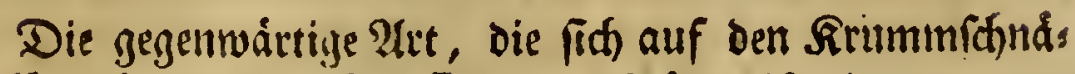
betı (Loxia curviroltra Lin.) auffiált, if eine vou den fa)onften 2lrten. Die Sirumbarbe ift blaffer, als an Den íbrigen Mirten.

Der Fopffatilo if berzformig; auf jeglicher Seite

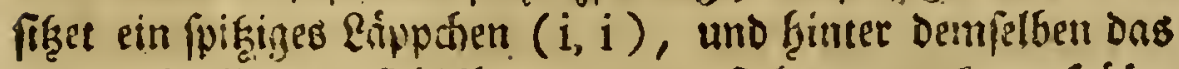

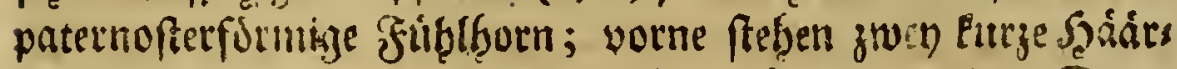
d)en ( $h, h$, ) bervor; von Denfertben gef̧t ein ounfeteo Diens eff $(h \times h)$ in Den Fupfichild ţineill. Die Seiten bes

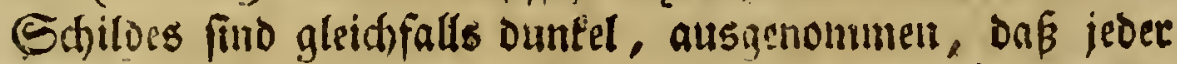

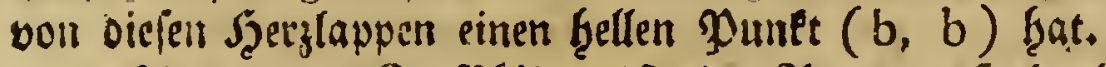

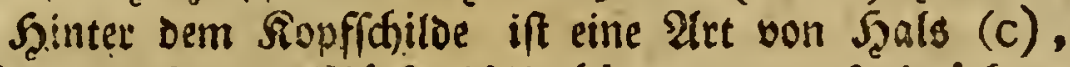

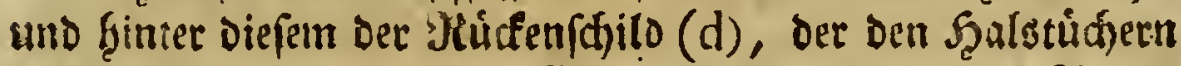

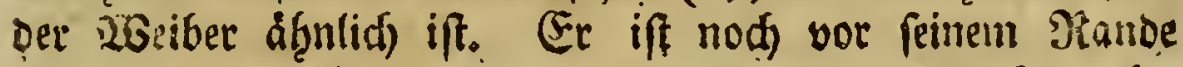
init einer bem Rande gleid, laufenden Dunleln ginie bes zeid)net.

Dor Rumpf ift enforming, uno jeglidfer Ring hat alı benden Seiten ein Dunfeles Drenect. So rmo aud die

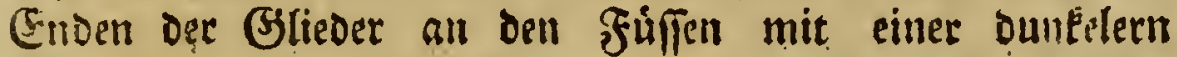
Binde bezeidutet. Der Nountt e, unso dis Figure f, fdeinen

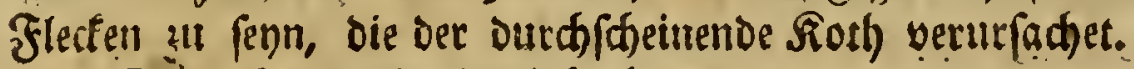

Diele Raus ift ziemlid baarig.

Dieß ift die gemeine $\mathfrak{2}$ trt. Sah) babe aber auf ebant biefem $\mathfrak{B o g e l}$ eine andere Laus angetrọfen, bie Der befthries benen ganz gleid war, nur dap tie gar leine Flecten baatte.

\section{Ne unt $\mathfrak{A} \mathfrak{x}$.}

Błlutfinflăs. Pediculus Pyrrhulæ.

$$
\text { Tab. 5. Fig. } 9 .
$$

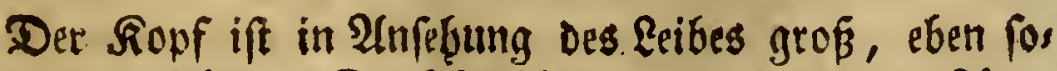

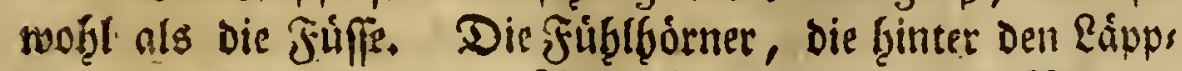
hen, wie in ber yorigen Art fethen, fheinen am $3 o r d e r:$

$$
\mathfrak{S} 3
$$


theile D:G Sonfighildes inmendig gleidffam mit einanber verbumber zu prn (a a a a).

Der Filper iff ourdffidstig und Gaarig, und fapt mit:

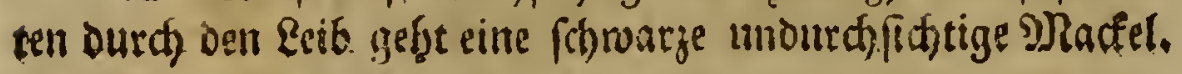

\section{Behnte $\mathfrak{A} \mathfrak{r}$.}

Strinfinflaus. Pediculus Chloridis.

Tab. \{. Fig. 10.

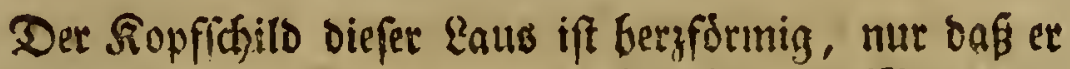

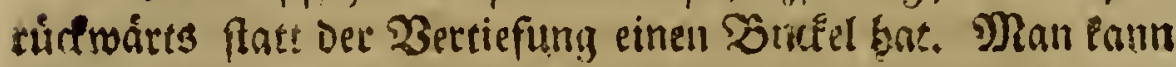

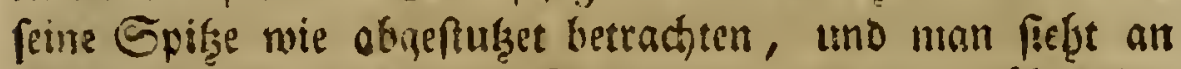

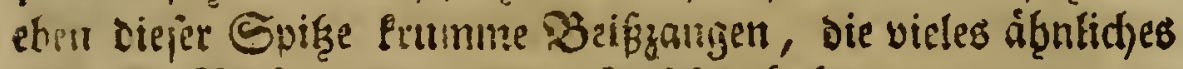
mit Den 3 aifígangen anderer Jarsete haben (e e).

Der eigentliche Dituffenigtilo manyelt. Statt peiner ift nut etu etwas fotmálerer Fing oa.

Der Runtw ift eyfótmig, in Der Mitte erfraben, tuid

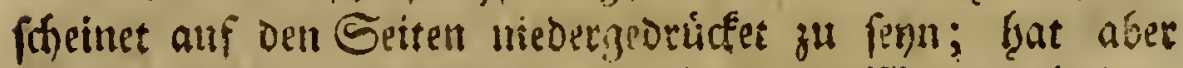

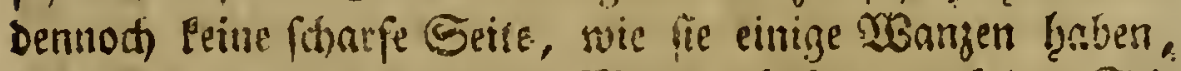
Derer Reib gleidffails in der Mitte erbaben, als Dear Seis

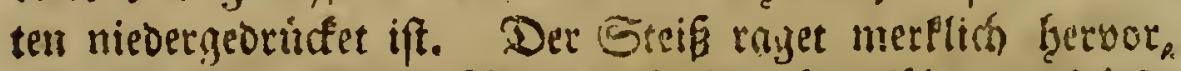

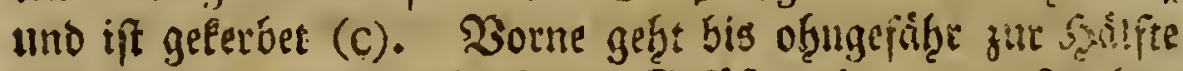

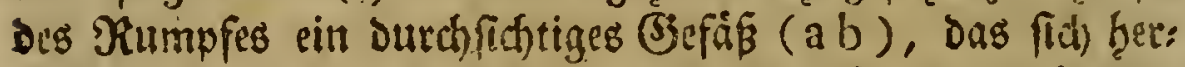

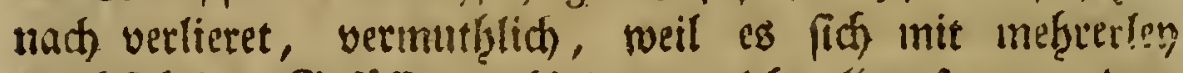

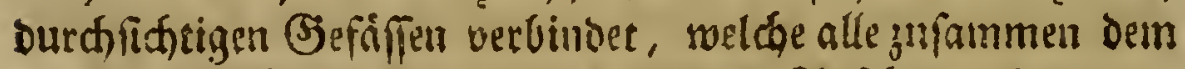

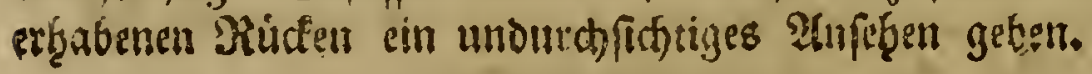

\section{Eiffte $\mathfrak{A} \mathfrak{t}$.}

Stanthur. Pediculus Sturni.

Tab. 5. Fig. 1 I, U. D. folg.

Die Grópese des Infeltes ift wie eines fleinen frobes.

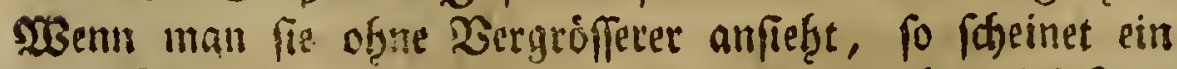
guter FGgeil bes Siopfes brandgetb zus fenn; aber diefe Jars

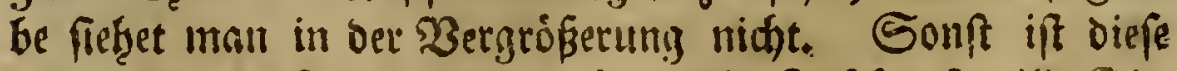
Eals yon Der Jarbe, wic es bey diejer Snfeltenfamilie te ift; fie ift anch fo gebaut, wie die meiften bisber bes

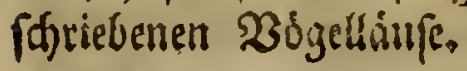


Der Sopfidilo ift Gerjformig, "W', bat sornen eine

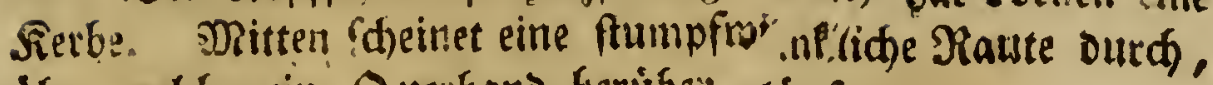
iber weldae ein Suetbano heraber láaft.

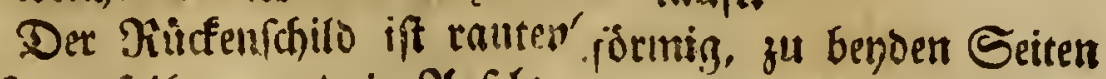

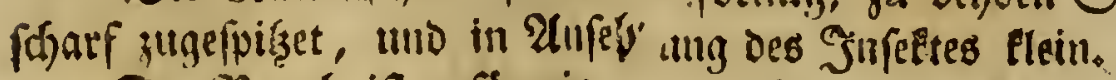

Der Sulud if enformig, und bat an jedem Sticoe

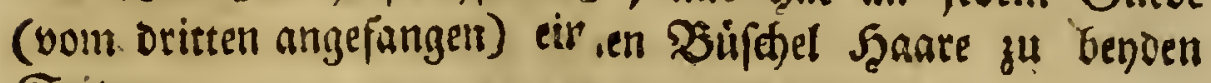
Seiten.

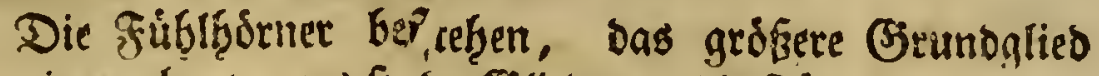

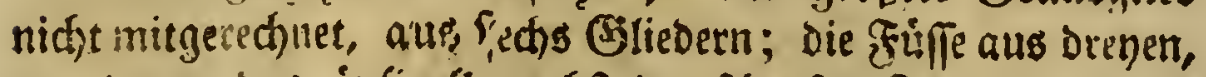

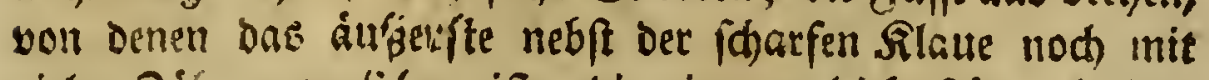
yielen 3 áfmen ver/jeben ift, bie eitre ungleiche \&änge baben, und dam Infette ftatl: ber fFinger bienen.

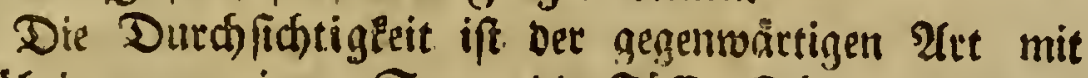
Den úbrigen gemein. Sogar die Fuffer fiegt man ourd

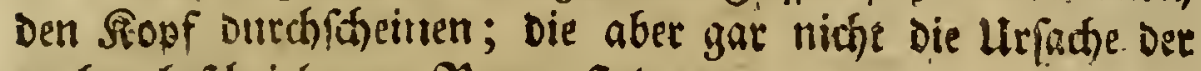
vorf̧er befhriebenent Raute find.

Die 12. Finut ftellet eine etwas verifhiedene Ríne Spielart biefes Juffeltes yor. Der Reib ift furger, uno beuget fid nefor in Die Runbung. 2loer Der wejentliden

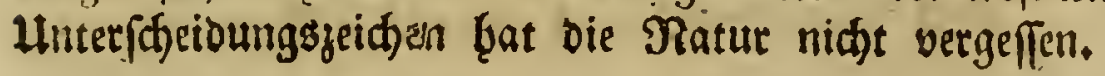

\section{Ertflitung bet Figuren.}

Fig. I1. Cine gemeine Staarlaus nach einet farten Bergróperung.

a. Det Sopf.

b. Die rautenformige Durd)(क)einende (Seftalt init ber Suevbinde.

c c. Die Fúblfírner.

g. Der Múctenfchilo.

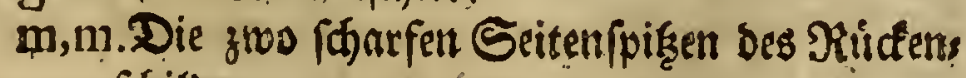
idfildes.

eeee. Die Fúffe. Man Gat Gier nut oren, uno eimen fralb verftectetl ausgeorúcfet. Man fiebt bey bem ganzen. Sefoblechte fetsen alle fedfe auf cinmal.

$$
\text { મุ } 4 \text { bh.hh. }
$$


hh. hh. Die zuen erften Bauctringe, die dyne Share fino.

dddd \&c. Die tibrigen Baudringe mit įren Seitenbüichelli.

f. Der Steís.

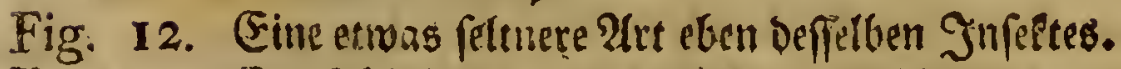

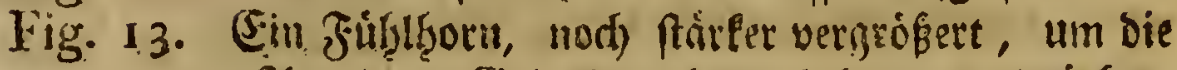

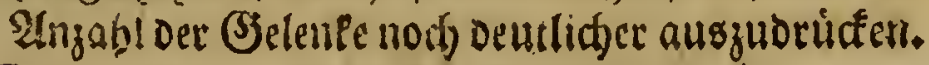

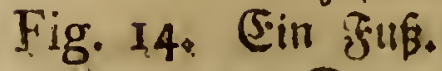

a. Das erfte Blited,

b. Dad zronte, unto

c. Das britte (Slied.

d. e. f.g. h. Sind verfthicbene Sfádflein yon uns

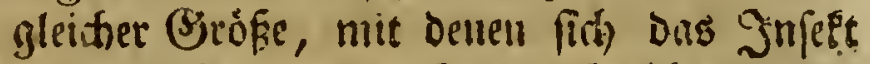

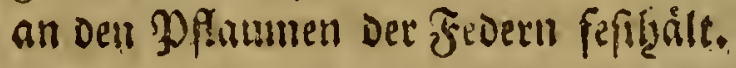

\section{$\mathrm{X}$. 9lbyomblung.}

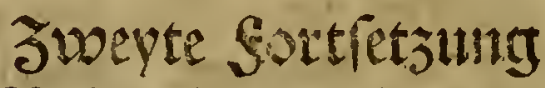

Der $\mathfrak{B} e$ foretbung Der Mitben.

\section{Cit $\mathfrak{i}$ แnd}

Acarus fetis quatuor pofticis, quatuor lateralibus.

Tab. 6. Fig. I. HII A.

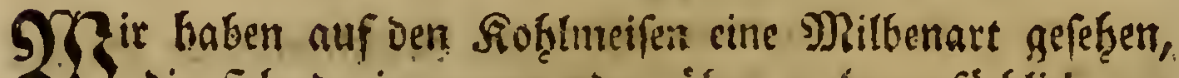

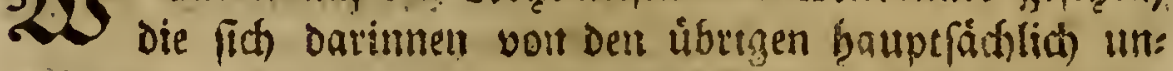

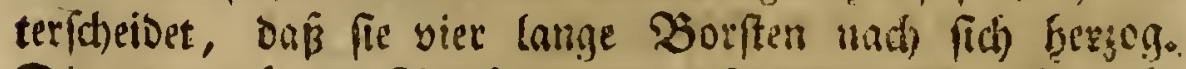

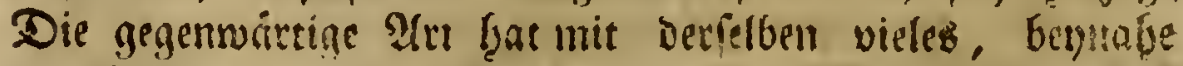
Den 230 brort ferbfit gemein. Man finbet fie auf. eituer Eleis

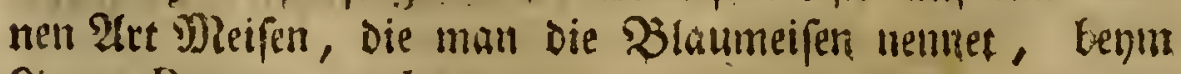
simnee Parus coeruleus.

Sie if unzemeits fleir, und man wưtde fie nidft fes

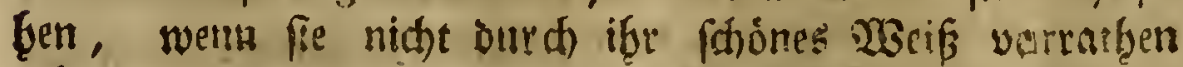
wurre. Denn Da Derjenige FGeil Der Federn, weldyer bes 


\section{3elnte abbandlung.}

Decfet ift, ben ben meiften súgeln, uno efen alld ben ben

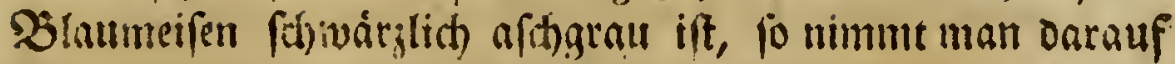

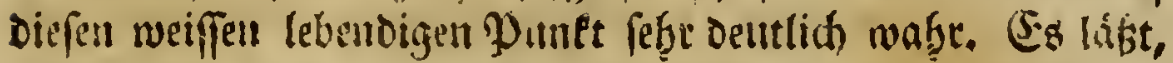

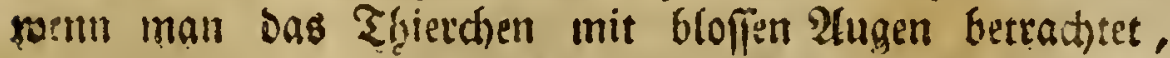
als waire ein guter Theil bes ßorberleibes offerfárbia, oder

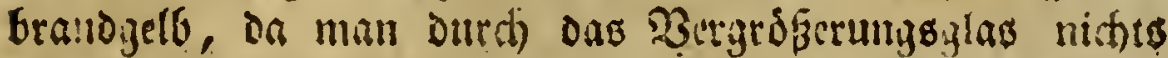
Davon gewafer wird. Durch diefes mun gejefent bat ev die (J)eftalt, in Der ich es in Der 1 , Figur Der 6 , Fajel abges zeichntet babe.

Dar Sidrper feat etwas rautenforminges, und if an

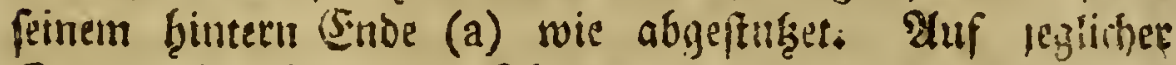
Seite diefes abgeftugten Theiles raigen zwo jienlich lange Sorften fervor (bb, bb.), welthe das Thier in (3):f̧en

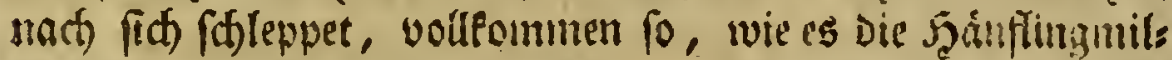

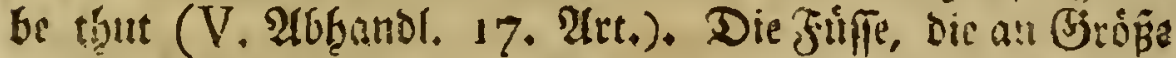

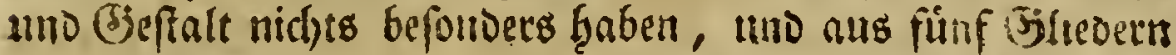

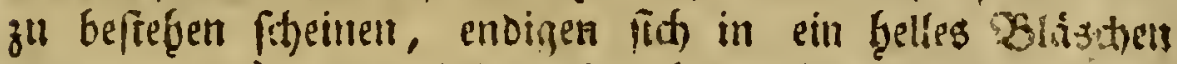
( $\operatorname{ccc} \operatorname{cccc}$ ), das fid flad) oritefen lábt, menn fị) Das. Sţier Danit anf̧ált.

Soir Gaben ben metarerley Milben futon Dergleichen

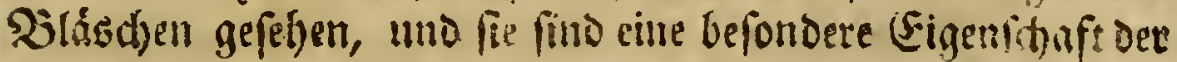

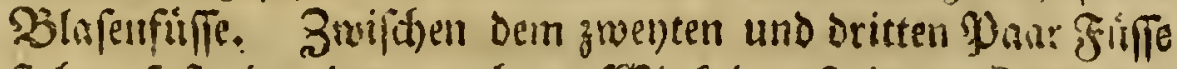
ftefen faft in sinem rechten Whinet anf jeoer Seite ein Daur Doorften fimans (d D, d D), bavon jenre, oie Dem Dritten Paare ráber iff (D), etwas flüger ift, als die alns Dere (d). Sontt ift Das Jnfeft fhi nact, mur bas man auf jeglidgem Frufe oren ftrife Sorjen unter einem mit:

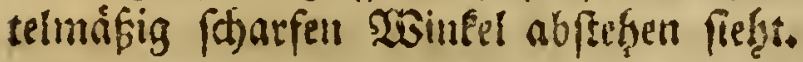

Der \$unft, iber dem Fig. A. ftehet, zelget die na:

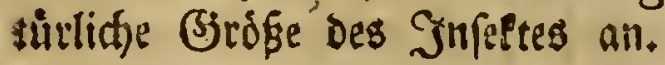

\section{Swev) Ind fwantigfte art.}

Acarus lateribus fublobatis; abdomine poftice bifeto, fetis corpore brevioribus; pedibus quatuor polticis gracilibus. 


\section{3ebute 266 and lung.}

Acarus Siro. Lin. Sys. Nat. Gen. 266. fp. I5. Acarus Siro. Lin. faun. fu. n. 1975:

$$
\text { Tab. 6. Fig. 2. unb B: }
$$

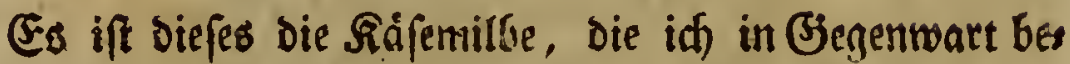
forreibe; eine Der befaunteften Itrten biefes (J)eidjechtes; Die aber nichts befto rentiger oem Stitter von Sintree außser

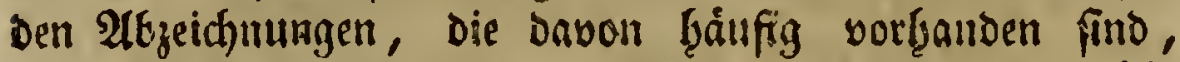
nid)t beeannt zu fenn fateinet. Denn nad) demajel(ben mils:

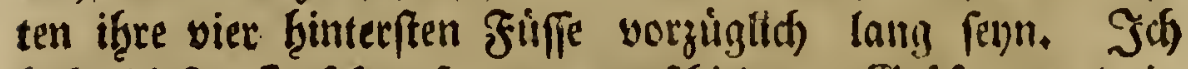

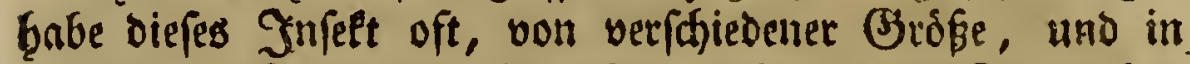
mandherley Stellumgen betrachtet, aber Diefes Rennzeichen habe id) niemal bemerten eónnen. Eber mollte ing bes

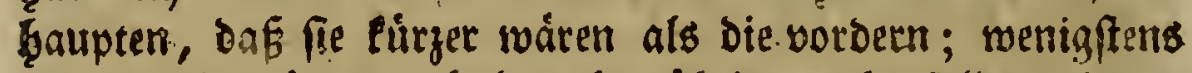
fino fie viel sưnner; haben aber úbrigens ebenfalls an jeoen Gelenle auf der vordern Seite ein Innges $\mathfrak{J g}_{2}$ ar, und endis gen fith. gletáffalls in eine ftumpfe Spifge. Der Stlieder Wqabe id tuberall fünfe bemerter.

Das erfte Paar Fuife hat erraas befonders, Das idh

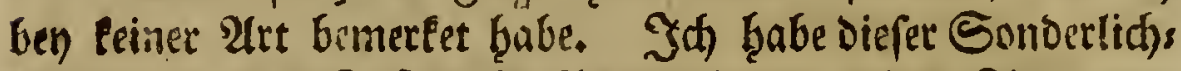
Peit wegen einen Ful diejes paares in ber britten fetgur ents

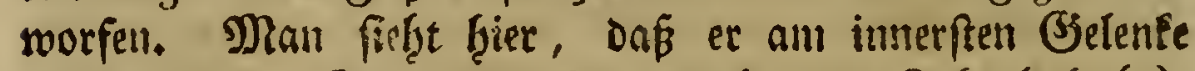
an ber untern Seite einen Erummgebogenen Zafin babe (a),

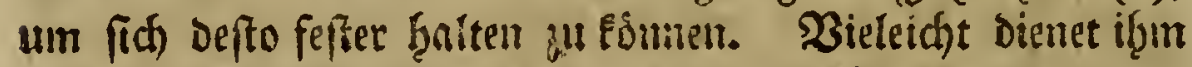
diefer Zaf̧n aut, bequent? graben zu tömen, indem ex

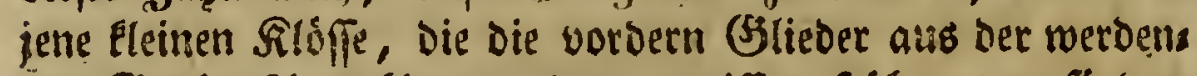
Den Brube ihon bis zul einer gemiffen, Szoḩe alsgefórdert traban, vorm Mitcéfaulle fidhert.

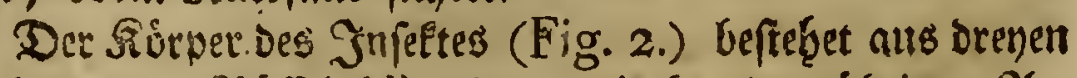

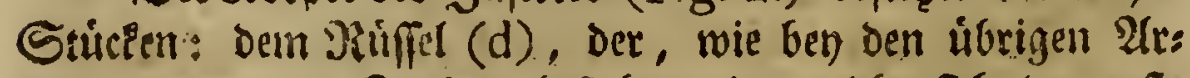

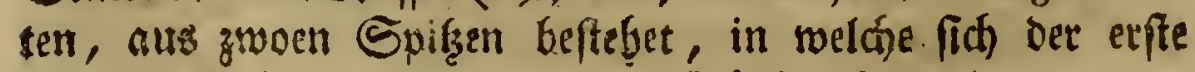

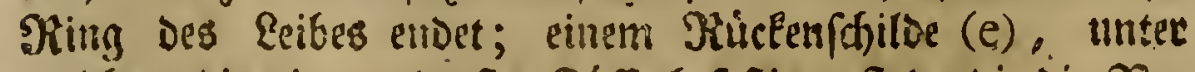
sveld)em bie vier vorderften f̧uiffe befeftiget find, die oie $\mathfrak{N a}$

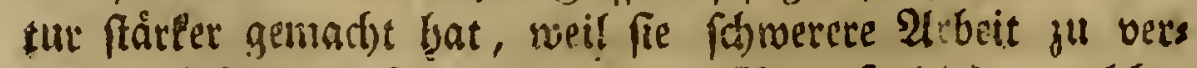

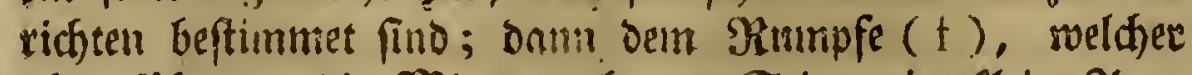

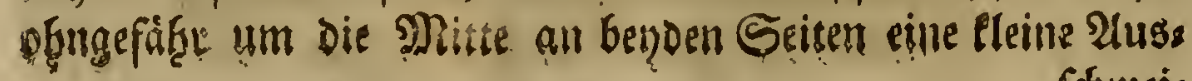

fofweis 


\section{Sefunte 2lobiandtumg.}

ridweifung bat. Unt diefe (Sigend formmt auth ein oder

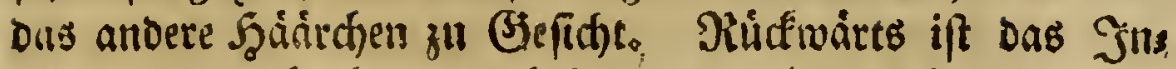

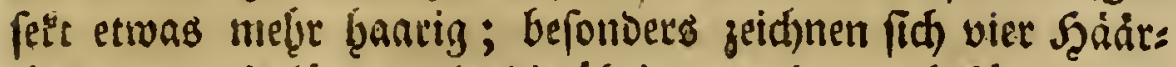
don aus, Die länger als die úbrigen, aber buch fưrger, als Die Şalfte des leibes find. Sie fteten auf Dem Rórper

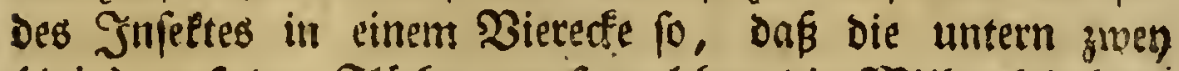

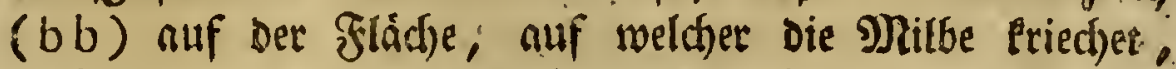
nachgezogen werden; Die obern zwel aber in einer paralles len Sichtung mit Derfelben Gleiben.

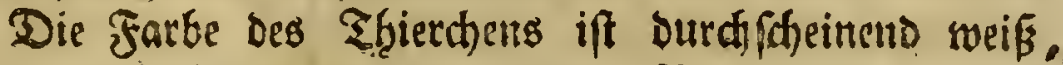

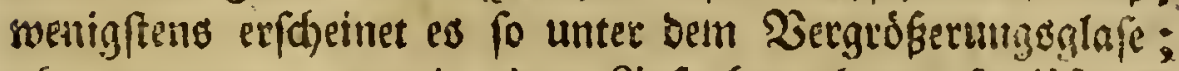
aber wenn man es mit einer ginfe betrad)tet, fo lifet fie am Sopfe, und Den Füfifen etrons brandgalbes blicfer.

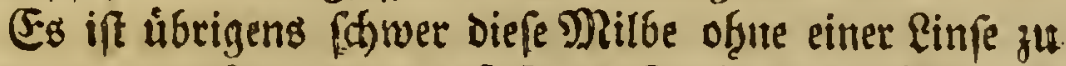

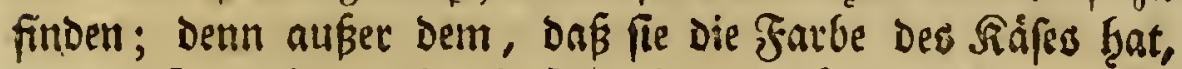
in Dem fie wolinet, fo ift fie babey vorginglich. Heitr.

D6 fie mit Der Mef̧: und Rrajenmilbe einerley fen,

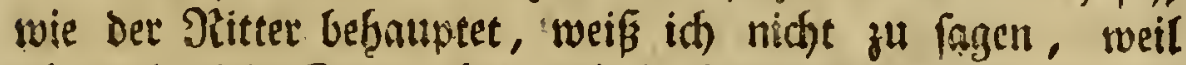

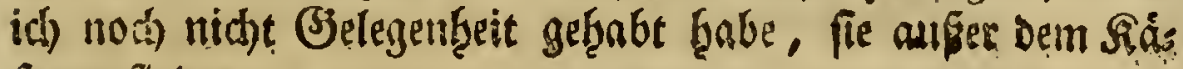
fe zul finden.

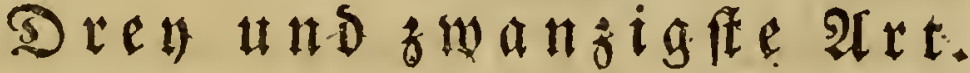

Acarus pedibus fecundis craffifimis; corpore toto teftaceo.

Acarus craflipes. Lin. S. N. Gen. 266. fp. 8. Acarus craffipes. Lin. faun. fu. n. 1269.

Tab. 6. Fig. 4.

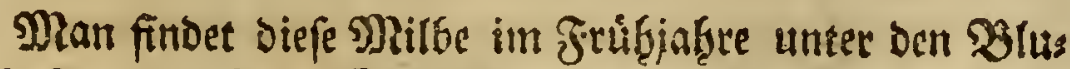

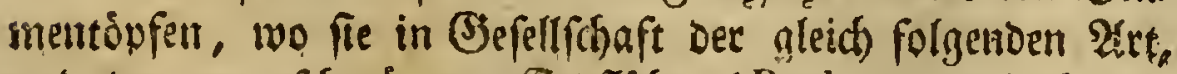
und ber ungefdiwánzten Erofloge (Podura ambulans) wofenet.

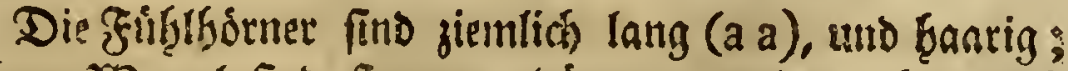

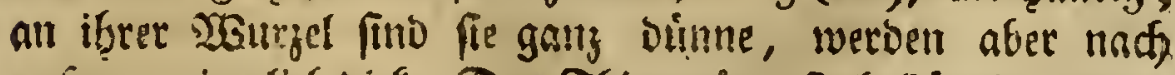

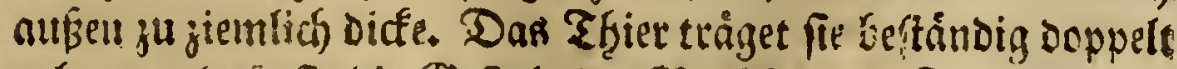

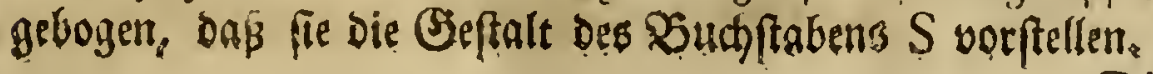


Die Sorderfúffe (bb) fitto famal, fabenformig, und, befonders an Der Epizee, baarig. Jal Bonnte an

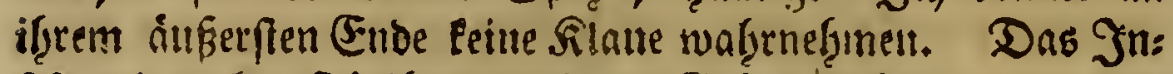

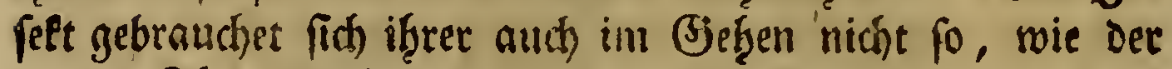

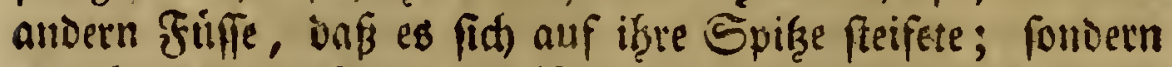

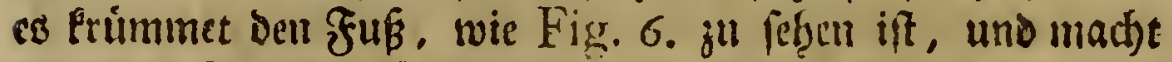

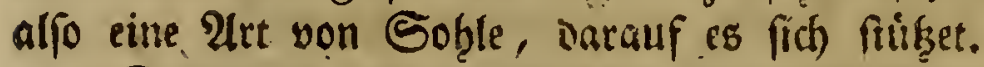

Das jwente Waar ift jenes, Das feiner vorzigliffen

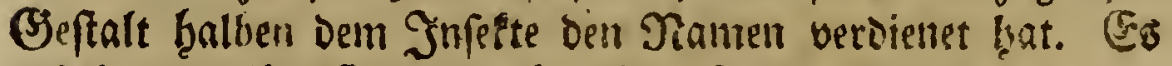
beftetht aurs finf Şliedern ( $c, d, e, f, g)$, Dauen die erften $(\mathrm{c}, \mathrm{d}, \mathrm{e}, \mathrm{f})$ rumbliats und dicte fins, das finfre $(\mathrm{g})$ aber

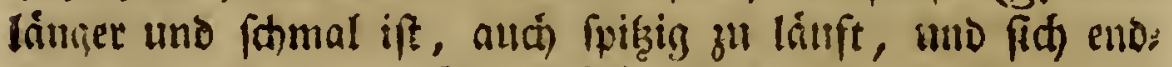
lid) in eitre boppelte $\mathfrak{R}$ lause $(h)$ enoiget.

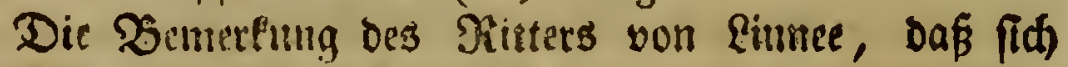

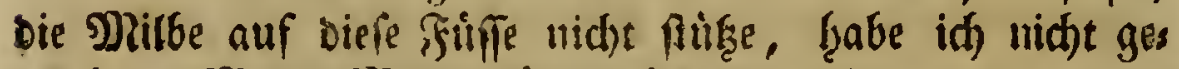
madt. Meene Milbe firsete fid Darauf.

Das dritte Puar (ii) Gat nid):s befonders, als das es bas fürzefte aus allen ift. Sin peiner Epifge hat es eine Doppelte Slaue (k k). Die Anzafl Der Śliever Ponn: te id) meter an biefem nod) cinem andern Paare, aufies Den zwentęn, genau betnetlert.

Das viette Paar (11) ift etwang lầnger als das drits

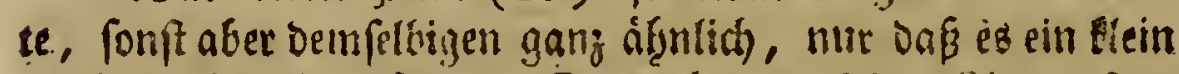
wentg Dider iff. In oer Spize hat es leine Silaue, forts

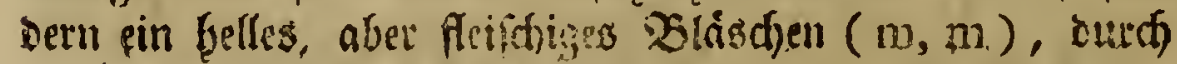

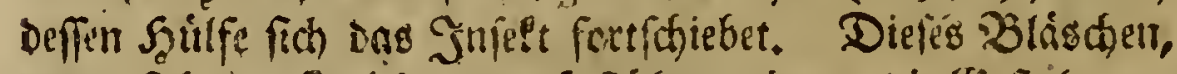

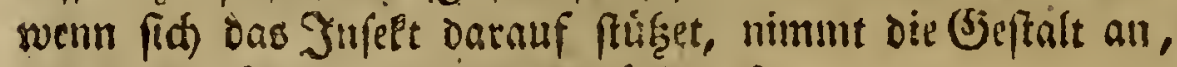

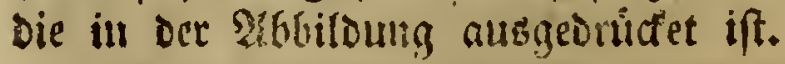

Der sistper ift enformin, uno cafanienfarben. Die

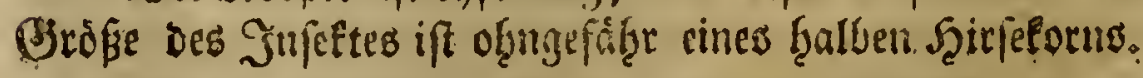

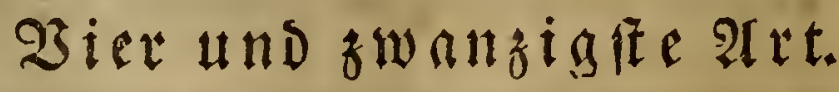

Acarus pedibus fecundis craffifinis; corpore teftaceo, ano pallidiore.

Tab. 6. Fig; 5, \& 7: 
Die 7. Figur fellet cime D?:!be wor, die fogrof, als die Săfermilbe (Acarus coleoptratorun Lin.), beell ca. ftanisubraun, und an fintern Tfeile bed Reige vou einet now blaffecn farbe iff. Sie ift fefor fanell, und bat an

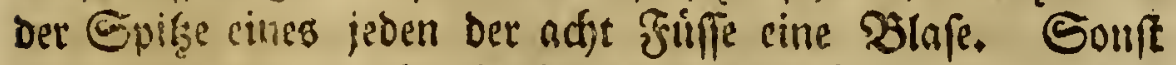

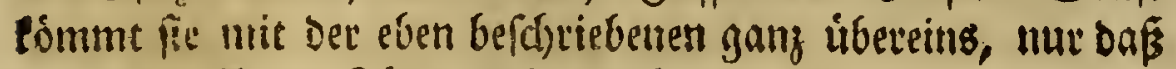
Das erfte Tlaar şiffe nistst fo bearig ift.

Sic frât fid bey faulenden

Eitre Evietnat finot man zahtreid, wenn man it fette Erroc grábt. Diefe nleidjet gang Det nur befdricbes nen; Diejer eingige lluterfatic fcheinet fie von ifge zu twens neit, des oas lginterfie paar friffe an ber Epige Eetine SEláddjev bat.

TSc:m oiefes gnfelt nod) jung ift, fo ift es ganz weifs; mo sann fiegt man feme Eleinen stugen, Die rothbraun fino, fege sectition.

Die 5. Figut feellet eine junge Evomitbe yor.

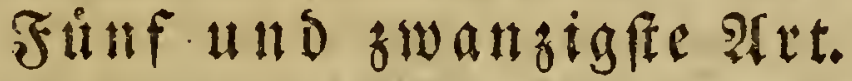

Acarus corpore antice dentibus quatuor,

$$
\text { Tab. 6. Fig. } 8 \text {. }
$$

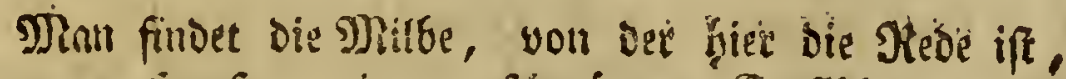

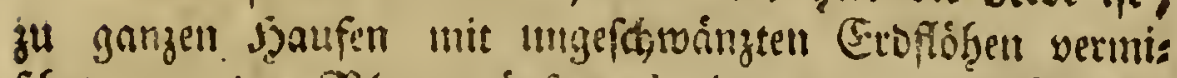

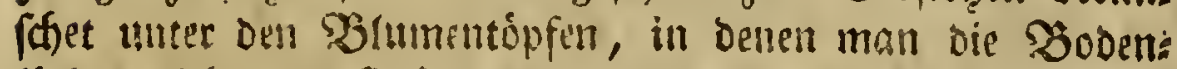
lód)er nidnt nit Trummern von zerbrodbenen Gjlápern, $\mathfrak{u}$. D. g. úberdectet bat.

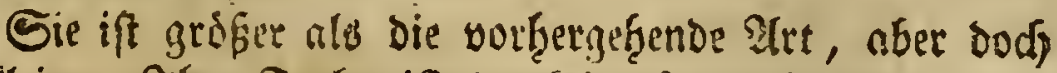
fefre elein. Glere Garbe ift onnell caftanienbraun; went aber bas Thier nod jegr jung ift, fo ift fie belfer.

Der Reib ift frowartig, uno enformig. Borme rager

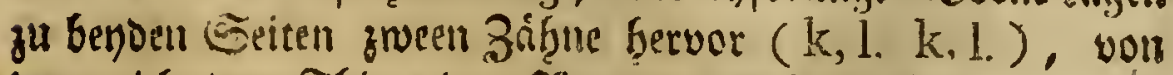
Denen id ocra Thiere den Diamen gefhopfet habe.

Die Fuffe fino ant Grobe falt eimander gleid). Die

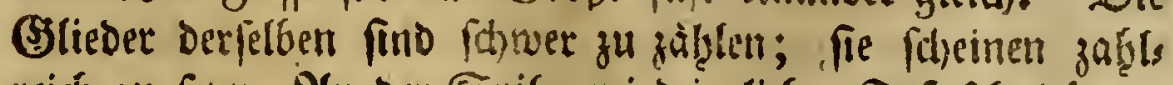

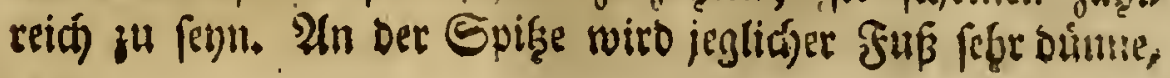




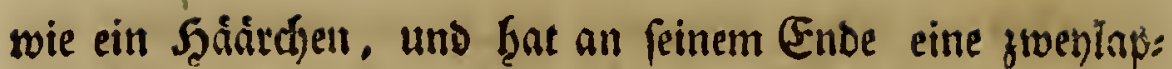
pige Sohte, znifhen wethther eine fefre feine Flaue hervors raget (b.e.g. i. b.e.g. i. ). Das erfte Waar Ffiffe (a a) ift baarin, und Gat befonders unneir Der Spize cin Paar

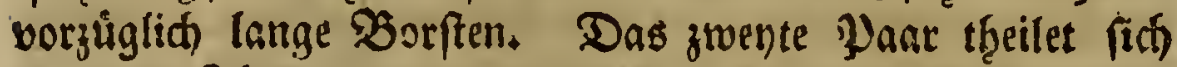
in zroeen Theile, Davon bet eine $(c, c)$ einest ziemlich breis ten Schentel, Der andere (d, d) Den Unterfús vorftellet.

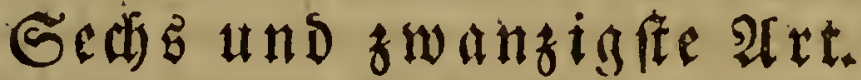

Acarus femoribus omnibus clavatis. Acarus geniculatus. Lin. S. N. Gen. 366. fp. 19. Acarus geniculatus. Lin. faun. fuec. n. 1977 .

Tab. 6. Fig. 9. \& 1o. unto C.

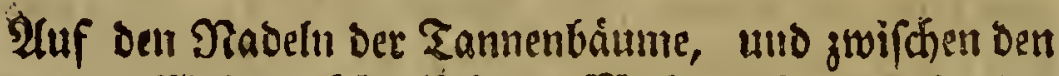

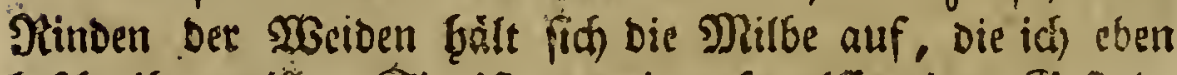
befdreiben moill. Sie ift voll einer fugerformigen (S) ftont, und fo elein, Daßs man fie ofgne $\mathfrak{B}$ enguilfe einer Rinfe Fatim

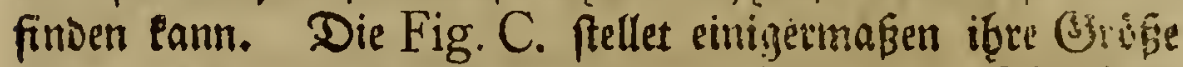

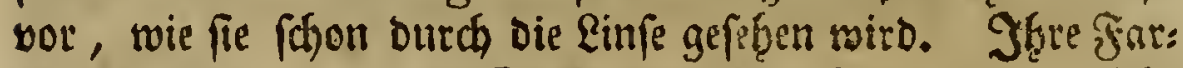

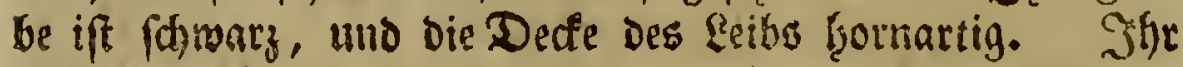

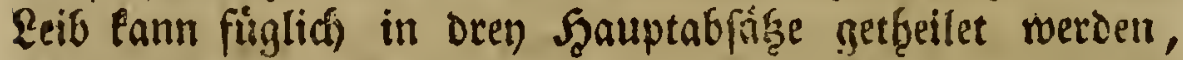
Davou ber erfte bie Sannauze, unt einen Theil bes כoorlei:

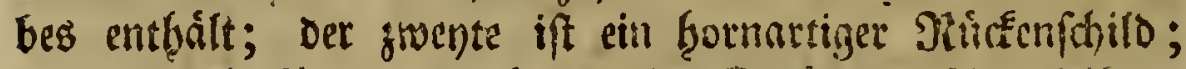
und endida fómmt die Gornartige Defe Des Shintevleibes,

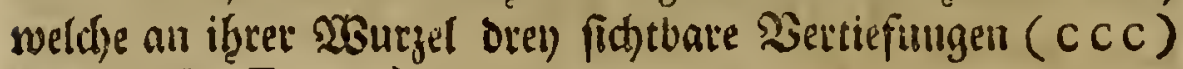
bुat. (5. Fig. 9.)

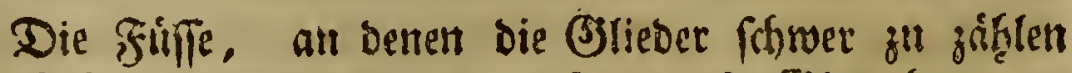

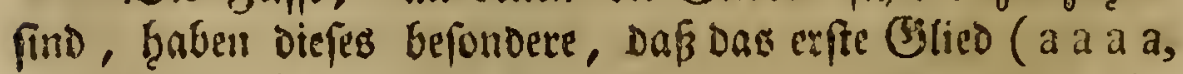
a a a a) vorzinglich biffe ift, uno biefes zwar an Dan vier

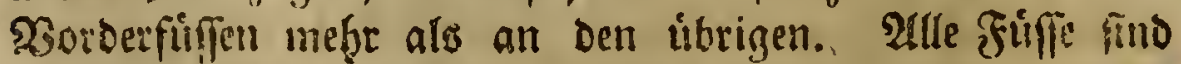

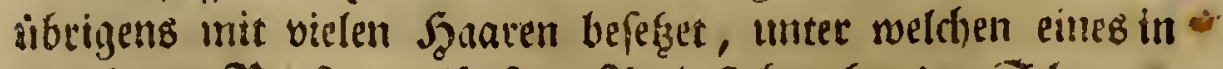

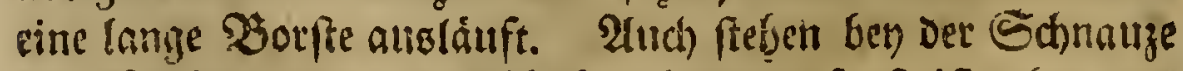
Der Milbe ein paak Şáárchen bervor, fonft ift aber Das Sunfelt gaing glatt. 


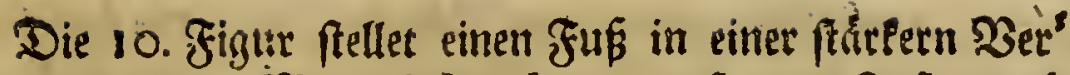

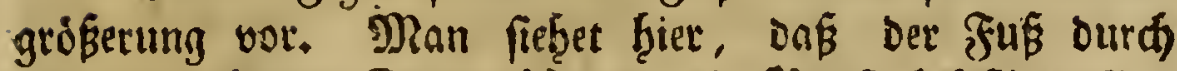
ein ganz suitimes Finde (d) al die Soruft befeftiget ferg; aber gleidh Darauf anferfnlich bicfe wiro, enolich fanell wie: set abnimmt, uno faft linienfórmig fortláuft. In feinem áuberften (5noe fiefzet man zwo Slauen (c). Sah ftelle Gier

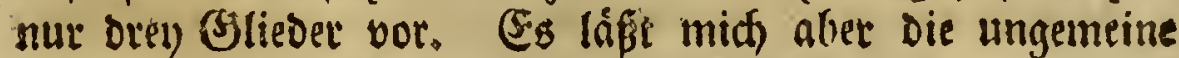
Sleinbeit dev Infeftes in einer volleommenen Lingenifbeit, ob nicht das erfte Glied (a) auts Drenen beftefte, Derer eines vor ber Solbe, und eiries nach Der Folke frid befónde, fo, baß̧ die Solbe fír fith allein ein (Jjlied ausmadje.

\section{Siefen und fiwanzigfte $\mathfrak{T} \mathfrak{x t}$.}

Acarus abdomine glabriufculo, fub inceffa globofo.

Acarus fungorum. Lin. S. N. Gen. 266. fp. 3 I. ? Acarus fungorum. Lin. faun. fuec. n. 1987.?

\section{Tab. 6. Fig. I1. \& I2.}

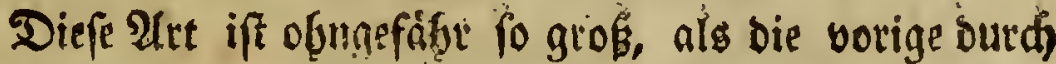
bie Rinfe gefthen war. Son Farbe ift fie fa)mukig toft farben.

So febr bie ztwo Zeidjungen, die idh Davon gemacht ţabe, von einamber unterfchieden find; fo ift es ood eben Daffelbe Infelt. Die 12. Figur ftellet es vor, wenn es Prie: det; uno Darın ift eg eir Sounentaferchen in Miniatur:

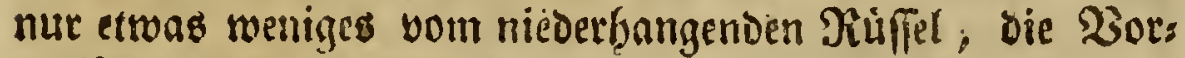
Derfiffe, uno zuweilin Die Spitzen ber librigen fíffe fommen

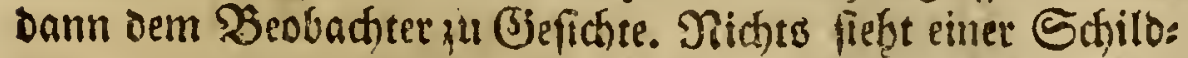

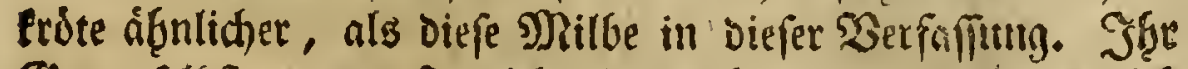
Bang feltoft, wenur fie nid)t beunuhbiget wiro, ift ziemlid langfam, uno fohilotedotenindfigig.

Wentu man fie aber um einer genautern Detrachtung willen zroifhen zroet Bjlifer bringt, und, Domit fie nicht alls bem Ditempunfte b̧inantsomme, ein wenig enge cin fdilieffet, fo nimmt fie die Beftalt an, bie Fig. 11. abge: bildet ift. Sie ftrectet námlidj Den Şals, an Dem Der Dops 
pelte Saugruifel, getade yor fidf ber, unb bie grinfe uad

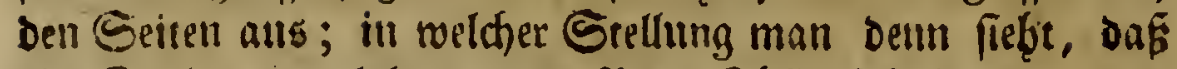

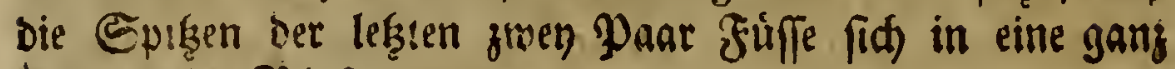
tleime belle Blaje endigen.

\section{I(}

Acarus corpore fubbilobo, poltice fetis quatuor corpore longioribus.

\section{Tab. 0. Fig. 13.}

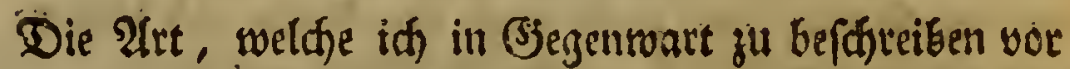

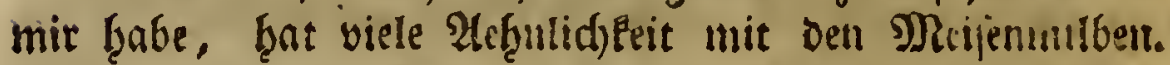
Sie if ungemein Elein, dás man fie laum mit bloffem

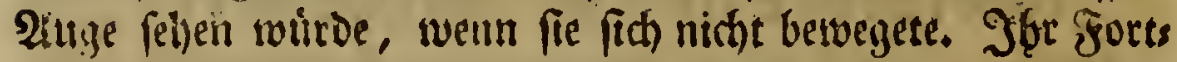

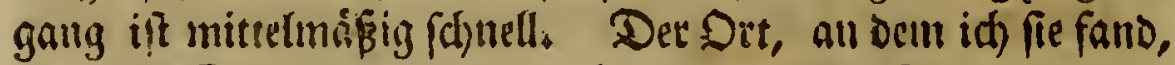
war eine Edjachtel, in Der id einige toote Rautpen lange aufberwaḩrte, von benten fie lebte. FGtee Geffalt ift laingl: d)t, zu benden Eeiten etwas ausgef(b)weift. Lleberall, unz nach ällen Seiten freţen lautge Szaare vom Korper ab; befonder's aber ziefge fie vier Borfen, bie lánger, als bie gange whits

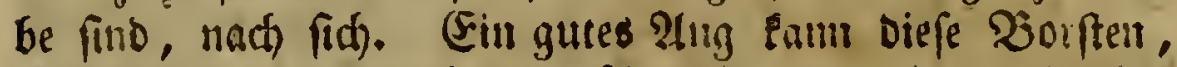

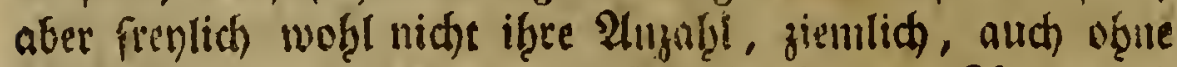
Zergróferer, unterfetseiden. Die Sortbe Des Fórpers ift weis, mit einem fotwadhan Blict ins rothe; Die früffe aber Gaben gar feine Farbe, und wirben yolitominen unfidet bar

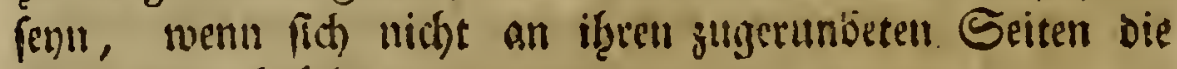
Ridatfralen beridgem.

\section{Peun แกb fwangigfe $9 x t$.}

Acarus ovatus, macula bafeos nigra triloba; utrinque fulcis tribus longitudnalibus.

Acarus elephantinus. Lin. S. N. Gen. 266. Ip. I.

$$
\text { Tab. 6. Fig. 14. \& } 15 .
$$

Die Siguren, bie id) von dirfer Mnitbe mittbeile, fino

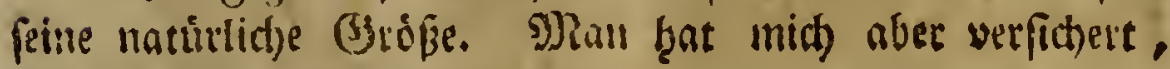

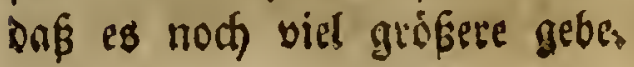


Man bringt fie aus Dalmatien mit bet gemeinen Gdirsfrote (Teltudo orbicularis Lin.), won beren $\mathfrak{B l u t}$ fie firt) nớçret.

Die Farbe ift robllid. Die Seiten Des Sepfes, die Finfe, ut: Der enformige flect noţe an Sepfe, fmo

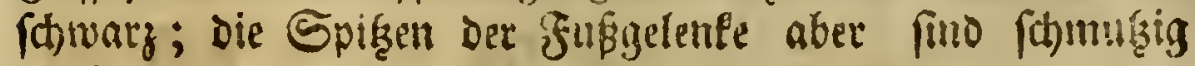
weis.

Die Seftslt Des \&eibes iff etwas länglicht, genen bett

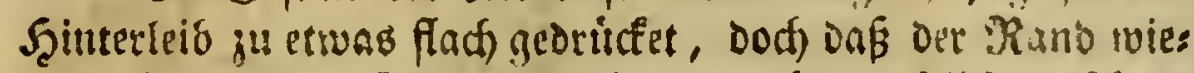

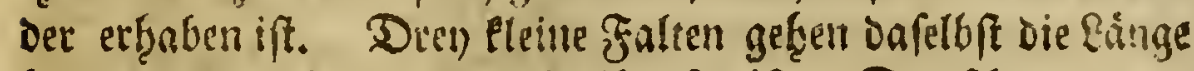
fin, wowon die intutlere die lángfte ift. Der fowwarze ens formige flect ift gleidsfaun in Drey \&appen gethetlet, Die aber fo verbunden fulo, Daßs der llintis gleid)wohl enfors mig ift. Llnten geben zwo fobiefe falten johier bie ganze Ránge des Reibes Gerab. Die Ufferoffnung ift ein wenig unter oer D) Mitte Des \&eibes, uno Ginter berfelben eine Falte bis an ien Rand.

Scere Dr. Yallas fat einte americanifabe Milfe (Acarus groffus Pall. Spicil.zool.) beficreben, die man auf

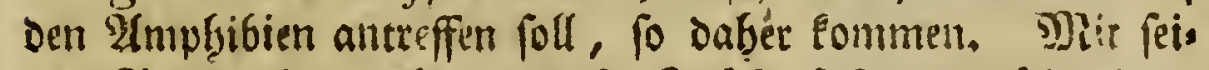

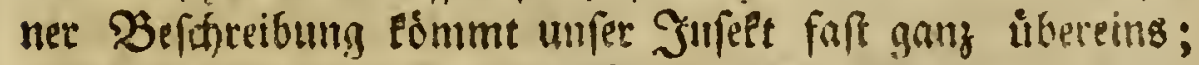
aber Die Figur ift fo ziemitid von ber unsern verithieden.

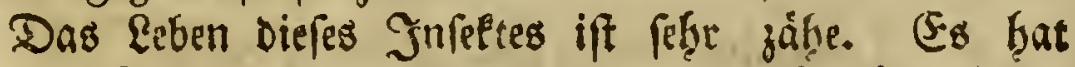
thir eittes ùber bie orey 5 wod)en an ber Stefnadel ges lebet.

\section{Aqbrandlintig.}

\section{Sonaucre Lnterifudung einiger fit)

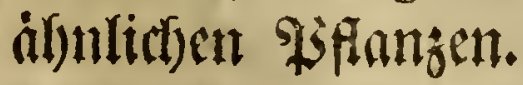

\section{Meit Sett!}

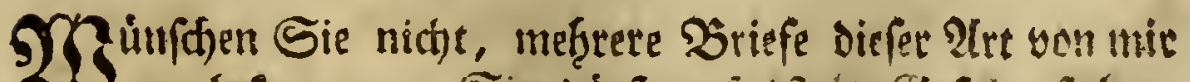

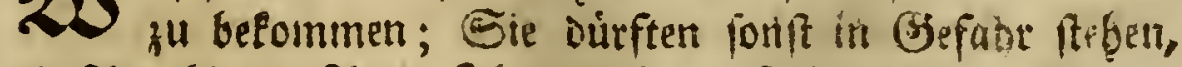

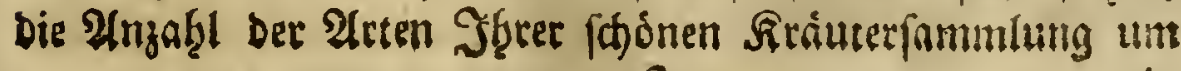
$\Im$ 


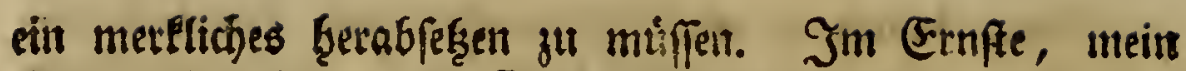

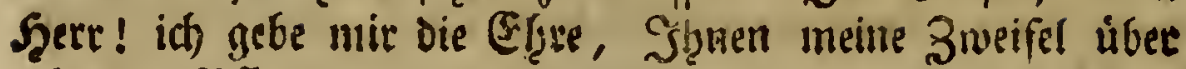

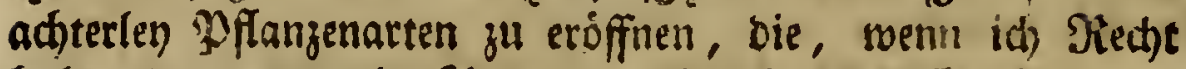
Gabe, Datin mur vier $\mathscr{2}$ tten von eben fo vielen (\$efdlect)tern fern werben. Es fint diefes

I. Verbafcum Thapfus. Lin. fpec. pl. Edit. IIr. Tom. 1. pag. 2\{2. Lin. S. N. Edit. XIII. Tom.2. p. 169. Reyger die um Danz. wild wachs. Pflanz. pag. 83. gen. 62. fp. I. Scopol. H. carn. p. 284. fpec. I.

II. Verbafcum thapfi. Lin. fpec. pl. Edit. IIr. Tom. 2. app. pag. 1669. V. thapfoides. Lin. S. N. Edit. XII1. T. 2. p. I69.

III. Leucojum vernum. Lin. fpec. pl. Edit. IIr. Tom. 1. p. 414. Lin. S. N. Edit. XIII. T.2. pag. 234. Scopoli carn.p.230.

IV. Leucojum æltivum. Lin. fpec. pl. Edit. III. T. 1. p.4I4. Lin.S. N. Edit. XIII. T. 2. p. 234. Scopoli flor. carn. p.23I.

V. Prunella vulgaris. Lin. fpec. pl. Edit. III. T. 2. p. 837. Lin. S. N. Edit.xIIr. part. 2. p.404. Scopoli flor. carn. p.461. Reyger. die um Danz. wildwachs. Pflanz. p. 215 . gen. 190. fp. I.

VI. Prunella laciniata. Lin. S.N. Edit. XIII. T. 2. p. 404. Lin. fp. plant. part. 2. pag. 837 .

VII. 
VII. Gentiana verna. Lin. fpec. pl. Edit. II. part. I. pag. 33 I. Ip. 10 : Lin. S.N. Edit.XIII. part. 2. pag. 199.

VIII. Gentiana bavarica. Lim fpec. pl. Edit. mr. part. 2. p. 331 . fpec. I1. Lin. S. N. Edit. XIII. part. 2. p. 200. Scopoli flor. carn. p. 299. fp. 8.

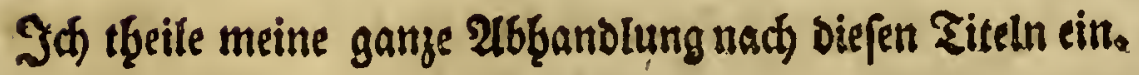

\section{1. \\ Verbafcum.}

Der Nitter von Eimnee bat, wie Thren belunnt ift,

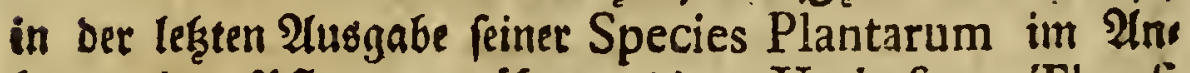
hange eitrer $\mathfrak{Y}$ flange errodiontet, bie er Verbafcum 'Thapli

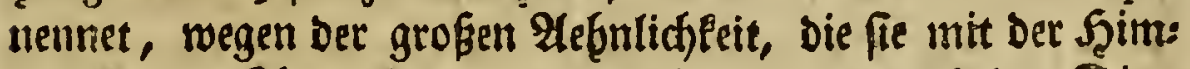

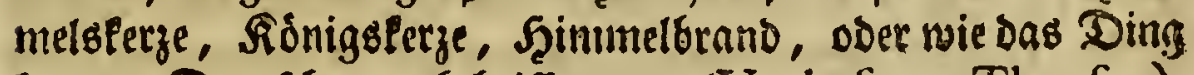
ben uns Deutifhen noch beiffen mag. (Verbafcum Thapfus), bat. Er beḩauptet, zufolge einer von feinen Rieblingsment: numgen, fie fen aus einer Bermifdung Des Blumenftaubs

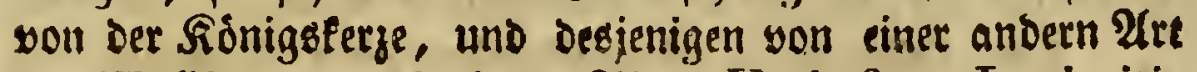

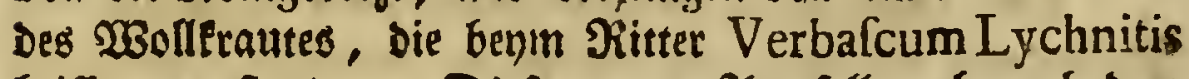
beiffet, entfrandert. Diefe zwente 2 trt forf aud nad dem Borgeben Des Pitters bie Stelle ber Mutter verttetten haben. Diefe Mennung erbáartete fíd Daburd, weil man unfere

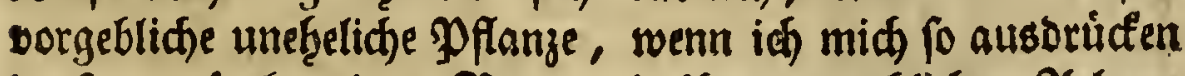
Darf, auf eben Dem Beete mit ib̆ren angeblichen Reltern

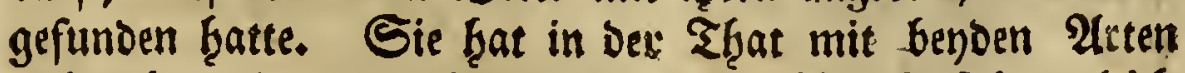

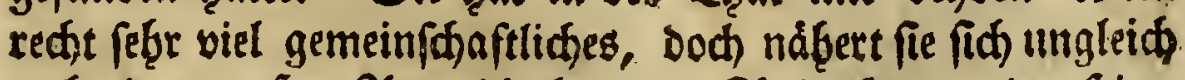

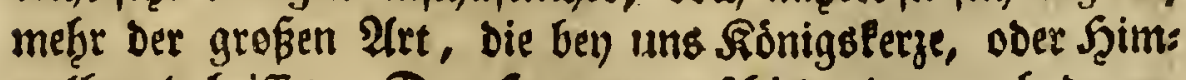
melbrand heiffet. Der Şauptunterffdied, Den aud ber es'

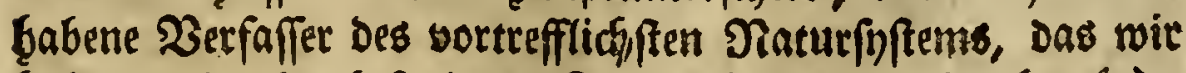
haben, als ein befonderes Sentumgeident angegeben f̧at $(a)$, berubet Darauf, Dáp Die gemeine Sidnigsterge eitten ganz

$$
\Im_{i} 2 \text { eimfas }
$$

(a) Syft. Nat. Edit. XIII. Tiom. II. pag. 169. 


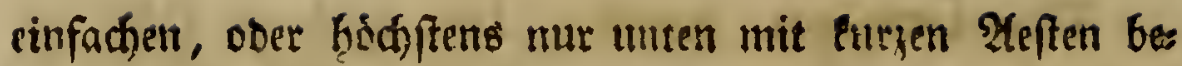
refien Stengel fart, Da berentgengen bie Pflange, won Der sie $\Re$ ede ift, viele, lange, uno allf allen Seiten bervors Fommende $\mathfrak{A}$ fefte treibet.

Die Pflamze ift in Der (Segento von Ring nidht feltfam, und id) Gatte gegenmártigen Sommer (S)elegenb̨eit genutg Ineis ne Seobathtungen daruber anjuftellen. Soh mache mir das 3ergnigen, Sie mit bem, was ids glaube gefunden zu Gaben, zu unterbalten.

Die 1 flanze ift Peine unebelidye Dflanze. Sie vess langen Berotife. Sie eann ev nicht fenn; romigftens die, Die id) beuer fo zalilreich un \&iuz antraf, connten es nicht

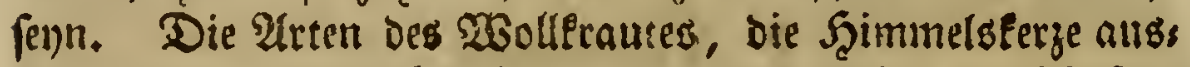
genommen, waren úberbaupt bet) uns nidjt gar háufig, uno allemal von der Stelle, wo ein Verbafcum thaploides fallo, enteglidf weit entfernet. Diemal ftand unter Den $\mathfrak{P}$ flanzen Des Verbafcum Lychnitis, oder einer antern

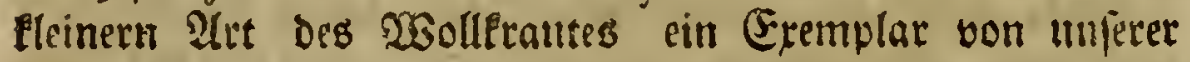
Pflanze; aber faft allemal traf id weldhe unter einer zab̨l: reichen Menge von Verbafcum Thapfus an. (Es batte ood Das roiverfpiel geffjetien múfen, wenn bas Ampels soolleraut (V. Lychnitis) bie Mutter màre.

Die Pflange ift eine Epielart ser Kóniggterze. Nichts von Det 2 Belt ift leidgter zll berweifen, als Diefs. Job bin felber im Stantoe, und jedermann ift es Desglets (h) n, nach meinem Belieben cin Verbafcum thapfoides alts einem Verbafcum thapfus. gu biloen. Eo braucht weiter mef: nicht, als bie Gpirze einer heranwad,fenden

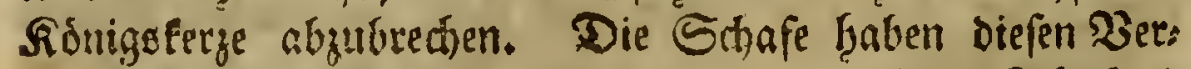
fuch, ofue es zu wiffen, vorlingft gemad)t. Эch fand

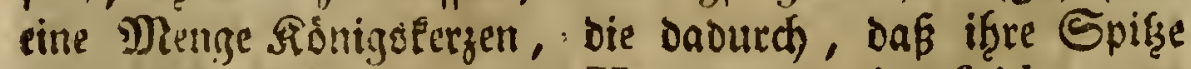
abnepflicfet war, zu einen Verbafcum thapfoides aus: muthlen. Fin beftiget Froft in Frubiab̨re, der bie now zarte Spike verierbet, bringt gleidje Wirfung hervor. Ia fand zrone auśs andere, wo die Sarbe nicht fo llar war. Jih umterfinctite bie Spizze, uno fand fie allemal bejhoidis 


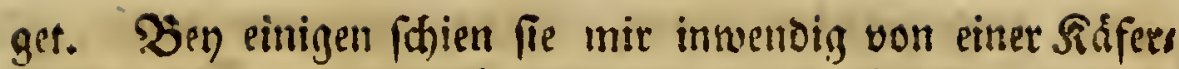
made, oder vour eitter Jlottenraupe aufigejegrer ju werden: Denn fie batte alle Mertmale, die andere ppfanzen von die:

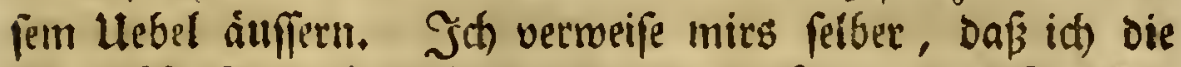

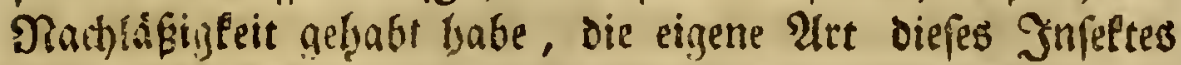

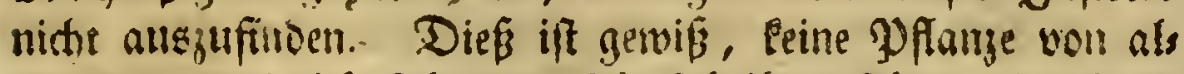

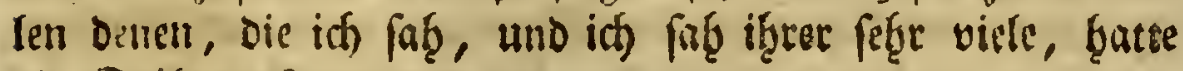
Die Spifge gejund.

II.

Gentiana.

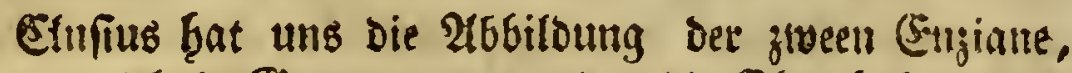

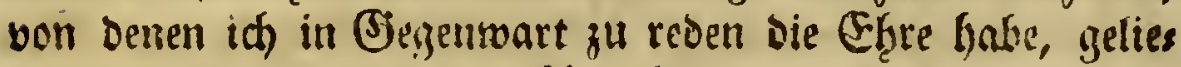
fert; fie find einander fo âfenlich, als wenn fie eine eins

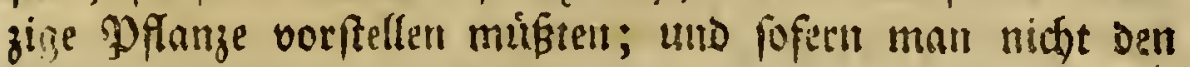
Takt Des gelebrten Berfaffers Dazu lieft, zuglein aud mit

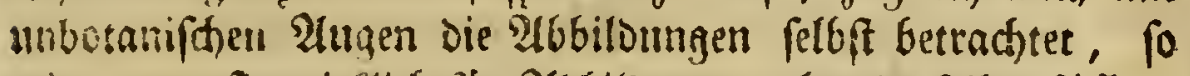
miro man fic wirtlich für 2Lbildungen ebent Derferben $\mathfrak{p}$ fans

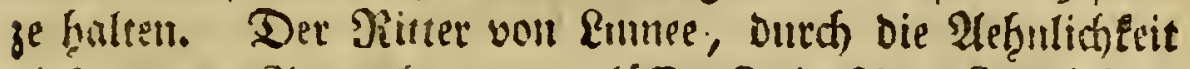
Diejer zwoen $\mathfrak{A r t t a n}$ berwogen, láffet fie in feinen Speciebus Plantarum unmittelbar auf einander folgen, ob er fie ichon in Der beenzeḅnten Aturgabe Des פraturfintems Durd Das zwoifcherifuting der G. pyrenaica, uno G. pumila ges tremet hat.

3(6) Gabe bie Gentiana bavarica zueerft suf den bos ben Sernen unweit dem Benedictinerftifte Steyergarken, ante beionders auf dem fogenannten Sabmiroleutnerbarge,

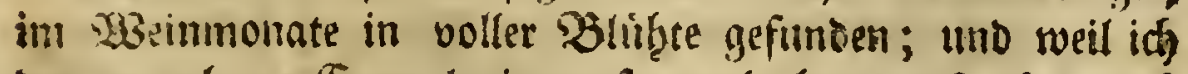
Davon methrete Exemplarien gefanmnelt batte, fo theilte ifs Davon einine unter meine Frentude, Die mir die Frautcers

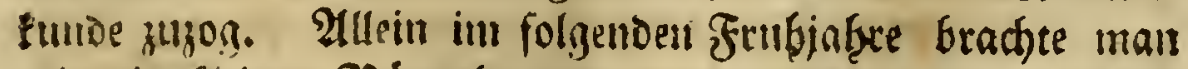

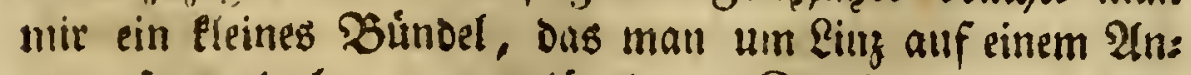
ger gejammelt batte, und fúr lauter Gentiana verna autss

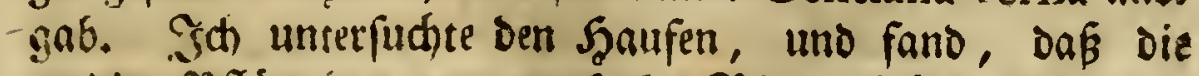

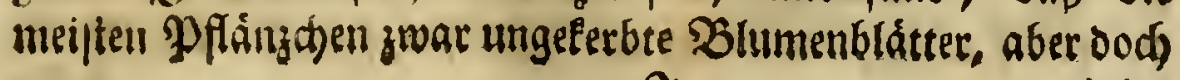

$$
\text { I } 3
$$

einige 
einige aud gelerbte badten. Man verficherte mich, fie ráren beyberlen unter einander gewadsfen. Da nun bie ganze úbrige Beffalt beyber 2 rnen cinander fo gleidy ift, Da bier Sthifezeit uno Standort eben Diefelben waren,

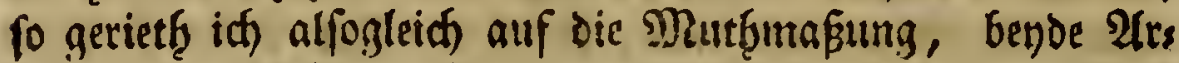

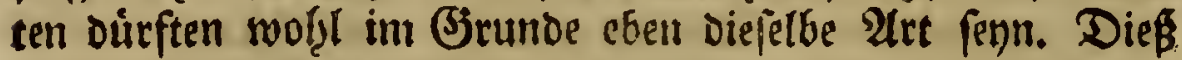

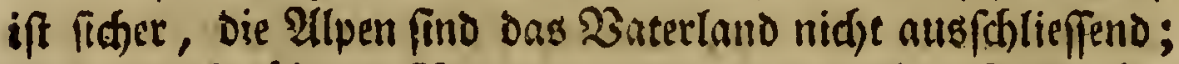

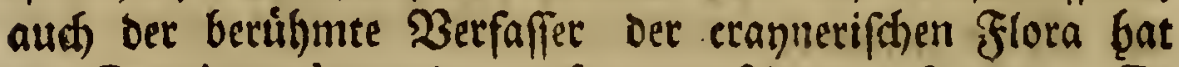
Die Gentiana bavarica aufer Den $\mathscr{A}$ ipen gefunden. Es

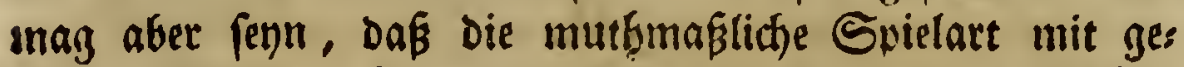
Perbten Blumenblättern auf alpenbergen Ģáafigiger entfteţet. Man weik es Doch, wie viel Der Drt fur Esinferbung der gemeinen Slátter bentrágt; follte at liber Die Şlumens blátter weniger vermégen, bie Dodh im Grounbe mit jenen

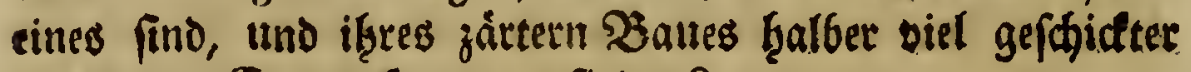
fiid jeoen Finsurut ju empfinden?

III.

Leucojum.

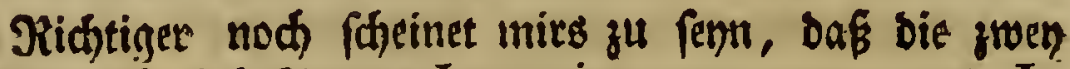
Revelojen, námliḉ Rinnees Leucojum vernum, uno L. xeftivale ebendiejelbe P flanze fenn. Der Bemeis ift eurz, uno, wie miá) Dencht, jienlida riattig. Sie belieben ib̆n zu vernebmen.

Das Leucojum vernum bat nad bem Ritter eine SItumenfdecide mit einer eingigen SBlume: Das reftivale

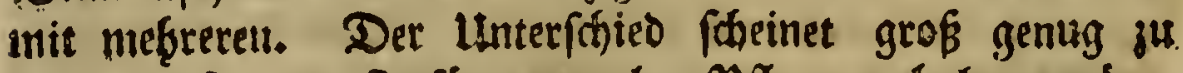

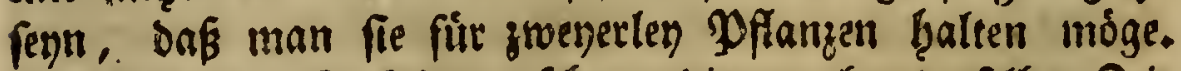

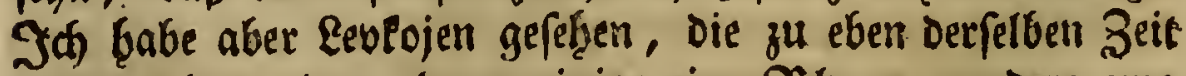
nefammelt worden, Derer einige eine Blume, andere zwo nus ebenderferben Slumenfdheioe berwoortagen hatten. Fines. roar Darsunter, bas unter Der Scheibe eimen 21/t trieb,

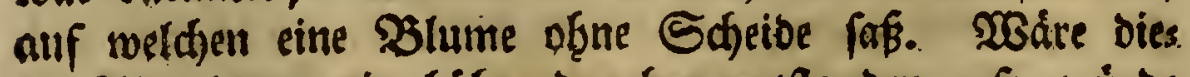
fer $\mathfrak{A}$ ft ein roenig bjober Daroben entfanden, fo múrde is ein Leụcojum aftivale gewefen [eqn; "ein meuig befier 
beffer barunten: båtten wir ein Leucojum vernum gebabt.

Td ţabe bie Muffe nidgt geţabt, Die Sadje genau gemug zul unterfutben. Ager bebentlid if fie, und vers Dienet Huterfuctung.

\section{IV.}

Prunella.

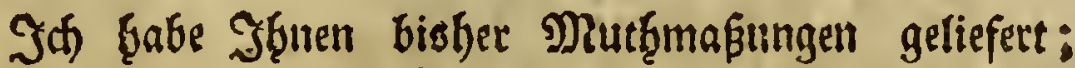

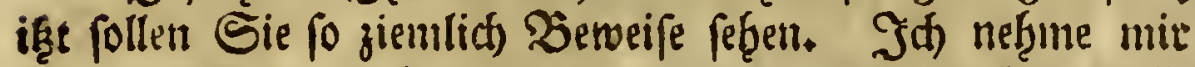
yor Darguthun, Daßj die gemeine und die lappigte Braunelle

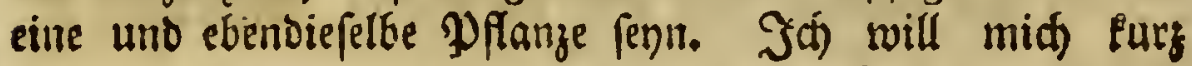
faffen. Sie, mein Szerr! belieben die 6. HGbildungen yon eben fo vielen כraunellen gu betradden; id merde nid)ts

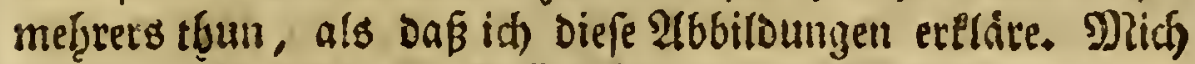

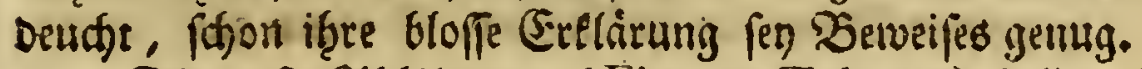

Die erfte Abbildung (Fig. 1. Tab. 7.) ffellet eine fajone, wohlgerwachjene Yuflanje vor. Es ifit etwas feltfas

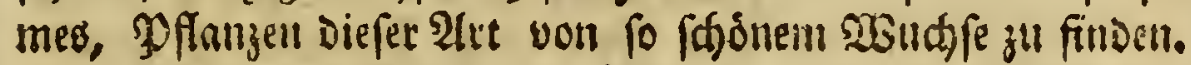

Die zroente 266 biloung (Fig. 2. Tab. 7.) fiellet eine andere sBratmelle sor, die in Den 2 tuen unt Ring ganz ges mein ift. Sie find Plein, und in \&ufebung Der vorigen

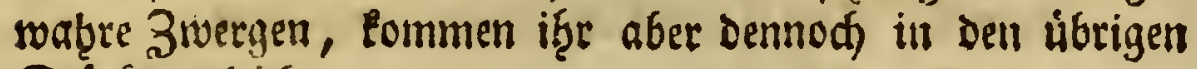
Stúden gleid.

\section{te Slátter.}

Die Dritte Braunelle (Fig.3. Tab. 7.) Gat gelerbi

Die Sraunelle Der 4. Figur (Tab. 7.) Ģat tiefes

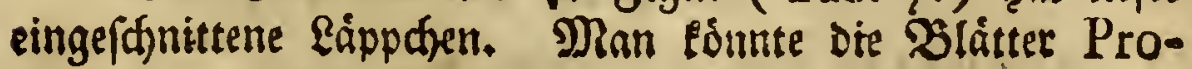
fundius dentata nennen.

In Der 5. Jigur (Tab.7.) esnumt eine Şraunelle

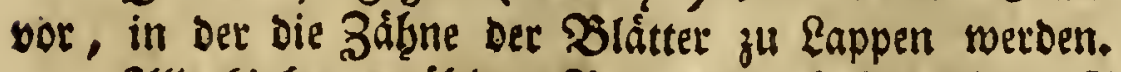

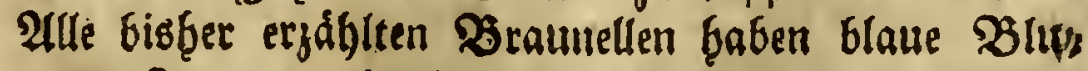
men, uno find ganz niedrig, Die erfte ausgenommen.

Die folgenoe Brannelle. (Fig. 6. Tab. 7.) ift wis,

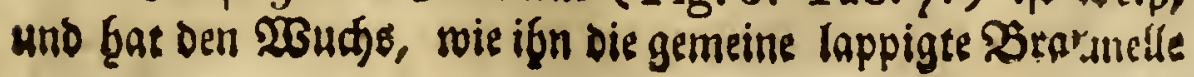
baben 


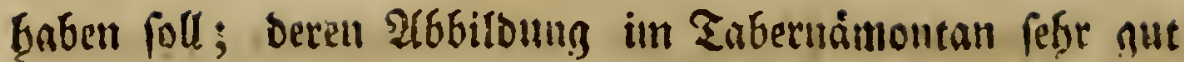
ift. WBir baben nad) unferm Exemplare die Der redfften Figur serfuctert.

Die frebente Bratmelle, die iff enne, ware eine viels

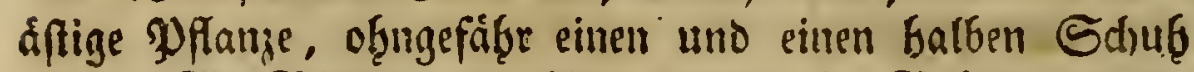
fod. Die Blume war blall, uno alle Slátter marent in Rappen getbeilet, wie es die oberften ben Der vorbetges bendert fint.

Diefes, mein Şerr! finto

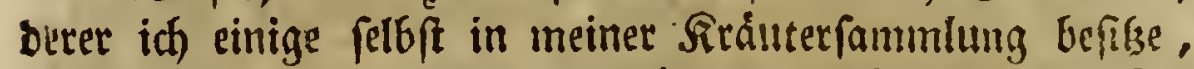
andere aber menigftens gut erb̧alten gefebeen thabe. Sie

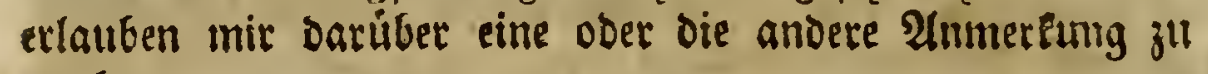
madjen.

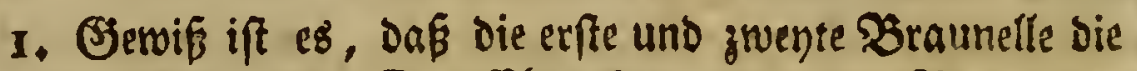
gemeine fen. Der Efyarafter, Den Der Ritter Des gemeiner Sraunetle zufdjreibet, ift ig̨nen ganz eigen:

Prunella foliis omnibus ovato oblongis petiolatis. Lin. fpec. pl. p. 837 . Lir. Sys. nat. Tom. 2. p. 404.

Prunella bracteis cordatis. Lin. flor. fuec.

2. Die fectjpe ift offenbar bie lappigte Braunelle bes Ritters. Der Éţaralter ift iţr ganz eigen:

Prunella foliis ovato oblongis petiolatis, fupremis (quatuor) lanceolatis dentatis. Lin. fp. pl. pag. 837. Lin. S. N. Tom. 2. p. 404 .

Seier ftef̧t in ben Speciebus plantarum eine $\mathfrak{2}$ (n)

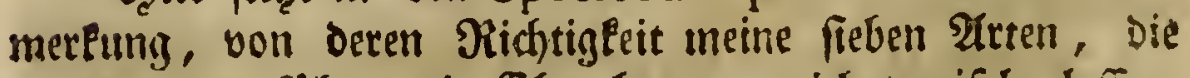

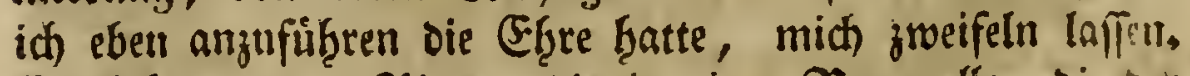

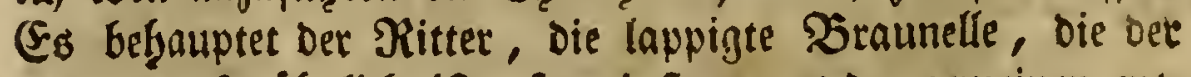
gemeinen fo áf̧ulid) ift, fen einffens aus Der gemeinen ents fanden, und plange fich ig̨t fortoaureno fort. 
3. Эळ frage enolid, unter welche $\mathfrak{A}$ rt gebsbren bie übris

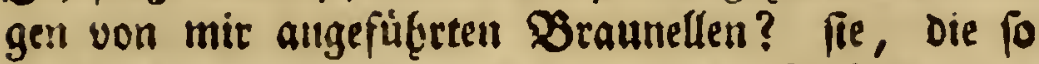
fiufenweife von ungetbeilten ganzen $B$ láttern zur

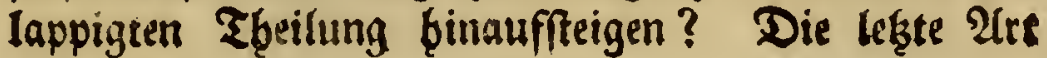
bat ourchaus lappigte Blátter, gar leines bavon ift unjerfhnitten. Jift nicht felloft bie, bie Der Rits ter unter bem Namen Der \&appiyten bejhreibet, eine Stufe, eine untere Spielart diefer lefgetern? Siben uns endiid fo viele Stufen nidts eben Das Rectit, bie Braunellen von 1. bis 7. für eine einzige $\Re_{\text {trt }}$ żu balten, als bie mittletn 2 atten Den Pitter verams: lieffen, Die Medciago polymorpha von a bis für einerley Pflaizg zu balten?

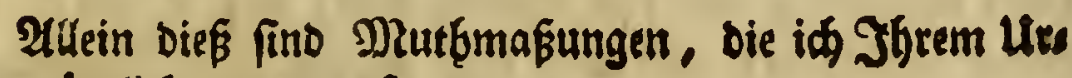
4qeile gänylich untertwerfer, 36,260

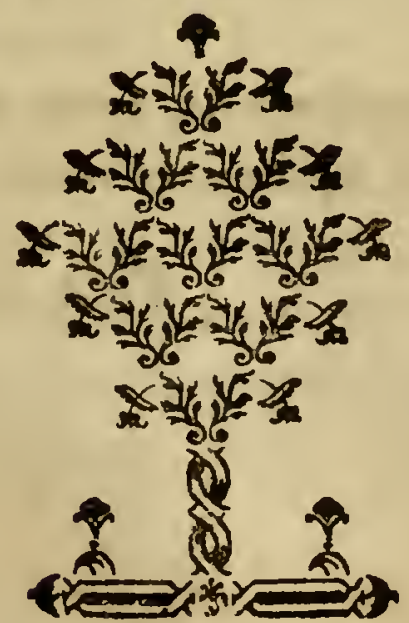


Det ernflitie शunf und Berlangen Des Berfaffers iff, Das jedermann foldes mit 2ugen feben, und barnat) sin uro theil abfaffen mód)te; nicht aber auts uebereilung bas als falfक verwerfen, was bier erjáblet wirb, wetil es ibnt fo wun Derbar vorfoimmt; noch auch blok auf jein wort ifm Blnuben beglegen; obne felbft Die כerjude bavon zu machen.

\section{Bacter Bantr. \}. S̈ebr. bes Dicrofs:}

Utinam complures in terris noftris rerum naturalium fcientiæ operam navarent.

\section{Poda Ins. Mus. Grose.}




\section{2oerzeidnin \\ Der}

\section{शbbandlungen.}

1. Befdreibung einer Dúdfe. - - - Befte t

II. \$efdreibung verfdiebener IIten aus bem Mils

bengefdlecte. - - - - - 3

III. Wabrnebmungen mit ben Jnfufionsithierden. - is

IV. Befireibung eineb $\mathfrak{B}$ lafenfuffez. - - - 3r

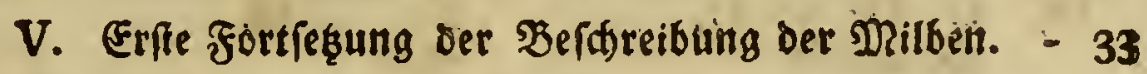

VI. Abbilouts einiget Infeften, von Denen meines

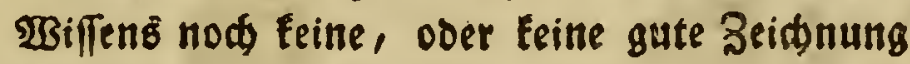

gemadt wordett ift. - - - - 42

VII. Berzeiđnißs eithiget InfeFten, Derer im lintreanis

fđeft Saturinfteme niçt geocicót swird. $\quad 59$

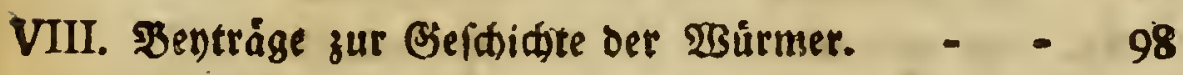

IX. Berfutg einer Raturgeitbidte ber \&äure. - - 1 -

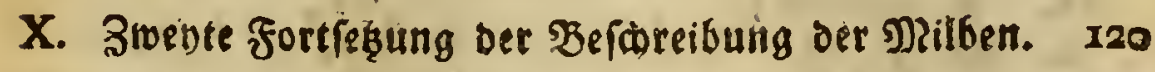

XI. Benauere lnterfudung einiger fiळ stgnliden

Pflangen. 
Seite כeile febler:

x. 3i. Diferem

2. 8. Bişน,

9. 21. 2lugen fevn.

12. 6 . Inp. 7. Inf.

13. 21. gefeben,

18. 3. Beziza

8. Eonferte

19. 31. Sputพน์ันกนเ

26. 23. श̊the

33. 25. ungef⿱idter

35. 11. Das recht

38. 30. phyfopodibus.

40. 26. Acarus primi

4I. 20. jtwoen

42. 28. verbecten

45. I. bertodinet,

48. 20. eirien \$unEt.

50. Ir. glinbe

57. I0. Fig. 10. II.

16. zebinte

20. Fig. 12.

59. 7. Solafe.

3I. Flaren

6o. 16. je

61. 3. fed,

62. 24. opuftulata

25. Podimus.

64. 19. moraeis.

67. $26 . \Delta$

7.. 3. opterus,

74. 34. fp. 25.

76. 9.

ro. ziveen

11. jeber

12. zrueent

78. 32. Dảs Sctiltoden an

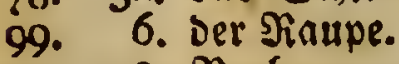

105. 23. Fienfe

106. 25. Pall. elench.

118. 23. Durdfintetigen
Derbefferung:

in Diefem

Sípđen

2ugen feyn?

Inf.

Sni.

feben,

Peziza

Conferbe

Than fetzesasu: (Afca-

Sotbe ris pollicaris. Lin.)

sef́chicter

Daß́

Phyfapodibus.

Acarus pedibus primi

zroey

berbidten

vertrocfnen,

eineti gelben \$unt?.

glänzende

Fig. II. 12.

eilfte

Fig. 10.

ริดศีi.

Floren

fie

fenn,

6. puftulata

Pod. mur.

Moraei. $\beta$.

$\Lambda$

apterus,

fp. $25^{2}$.

Dns lie

imo

jebe

zivo

ons Shilowen ift an

bie ßiaupe.

Jieibe

Pall. elench. 54.

unourdsfictstigen 


\section{INSERT FOLDOUT HERE}





\section{INSERT FOLDOUT HERE}



INSERT FOLDOUT HERE 



\section{INSERT FOLDOUT HERE}





\section{INSERT FOLDOUT HERE}





\section{INSERT FOLDOUT HERE}



INSERT FOLDOUT HERE 










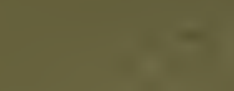

$-$

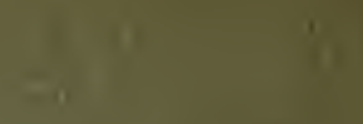

$-1$
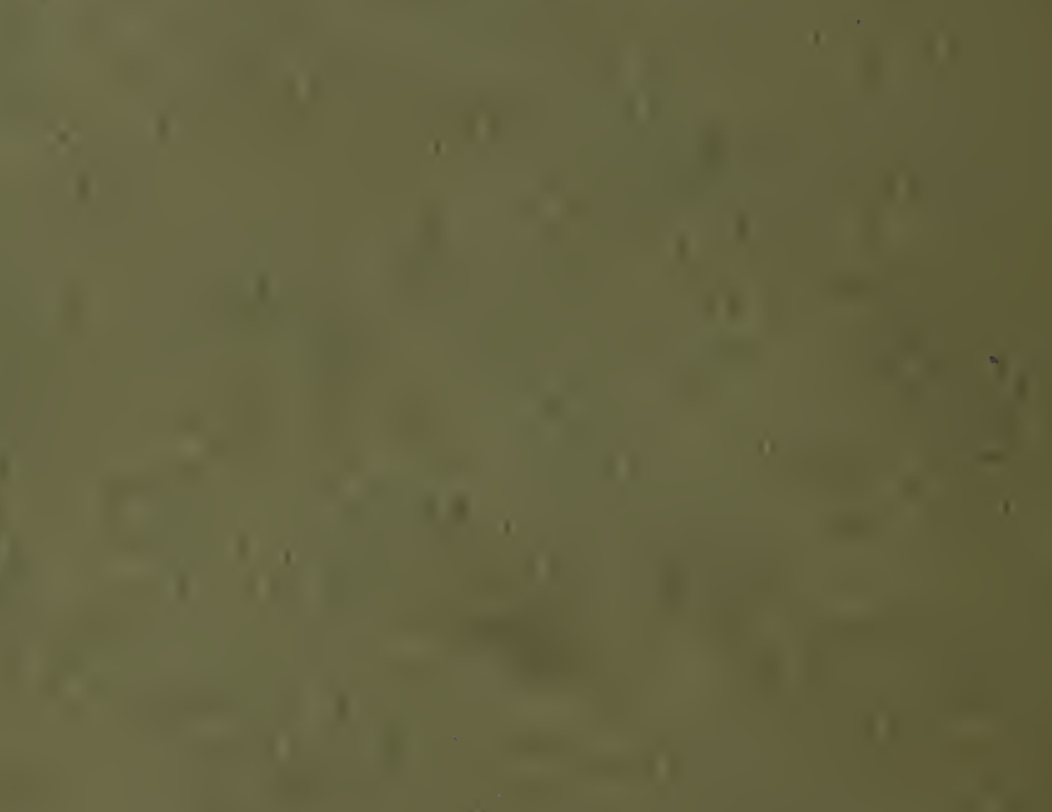

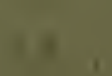

$x$

a.

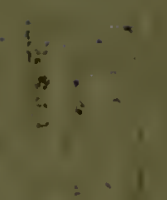

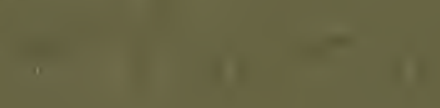

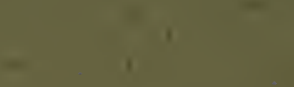

8

an:

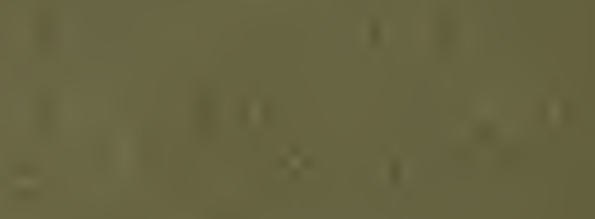

